\title{
INVESTIGAÇÃO TEÓRICO-NUMÉRICA DA AERAÇÃO EM ESTRUTURAS DE VERTEDOUROS EM DEGRAUS COM USO DE SOFTWARE LIVRE
}

\author{
Raquel Jahara Lobosco
}

Tese apresentada à Escola de Engenharia de São Carlos, Universidade de São Paulo, para obtenção do título de Doutor em Ciências: Engenharia Hidráulica e Saneamento.

\author{
(VERSÃO CORRIGIDA) \\ São Carlos \\ Agosto - 2013
}




\title{
INVESTIGAÇÃO TEÓRICO-NUMÉRICA DA AERAÇÃO EM ESTRUTURAS DE VERTEDOUROS EM DEGRAUS COM USO DE SOFTWARE LIVRE
}

\author{
Raquel Jahara Lobosco \\ Engenheira
}

Orientador: Prof. Dr. Harry Edmar Schulz

Tese apresentada à Escola de Engenharia de São Carlos, Universidade de São Paulo, para obtenção do título de Doutor em Ciências: Engenharia Hidráulica e Saneamento.

\author{
(VERSÃO CORRIGIDA) \\ São Carlos \\ Agosto - 2013
}


AUTORIZO A REPRODUÇÃO TOTAL OU PARCIAL DESTE TRABALHO, POR QUALQUER MEIO CONVENCIONAL OU ELETRÔNICO, PARA FINS DE ESTUDO E PESQUISA, DESDE QUE CITADA A FONTE.

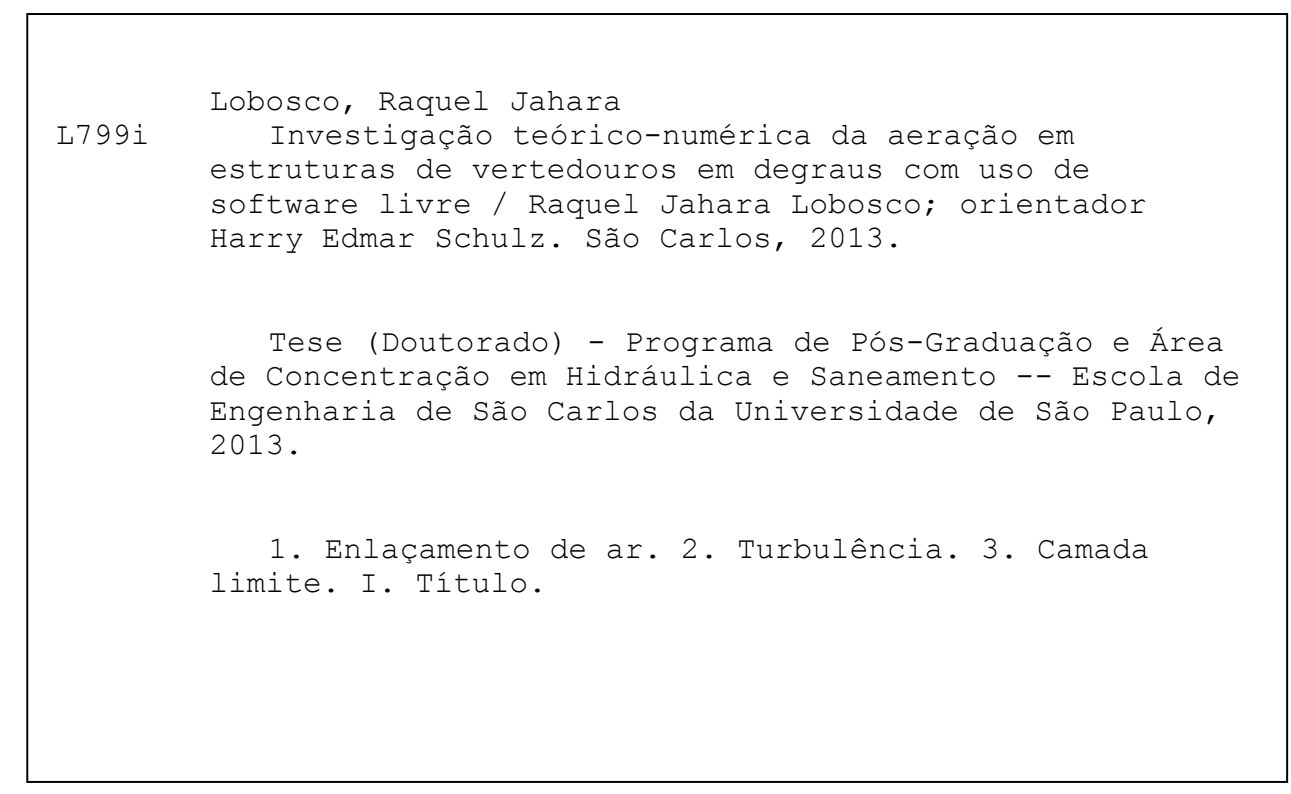




\section{FOLHA DE JULGAMENTO}

\section{Candidata: Engenheira RAQUEL JAHARA LOBOSCO.}

Título da tese: "Investigação teórico-numérica da aeração em estruturas de vertedouros em degraus com uso de software livre".

Data da defesa: 19/08/2013

\section{Comissão Julgadora:}

\section{Resultado:}

Prof. Titular Harry Edmar Schulz (Orientador)

(Escola de Engenharia de São Carlos/EESC)

Prof. Dr. Nivaldo Aparecido Correa

(Escola de Engenharia de São Carlos/EESC)

Prof. Dr. Alan Cavalcanti da Cunha

(Universidade Federal do Amapá/UNIFAP)

Prof. Dr. Carlos Eugênio Pereira

(Universidade Federal de Uberlãndia/UFU)

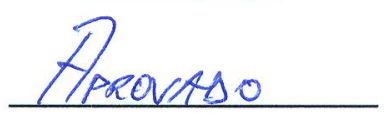

Prof. Dr. Fernando Augusto Alves Mendes

(Universidade Federal da Grande Dourados/UFGD)
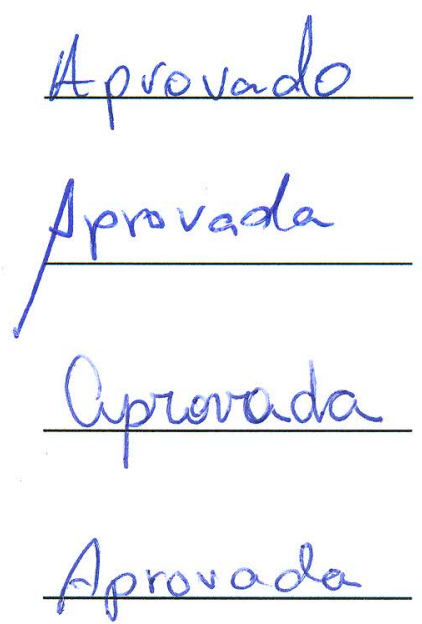

Coordenadora do Programa de Pós-Graduação em Engenharia Hidráulica e Saneamento:

Profa. Associada Maria Bernadete A. Varesche Silva

Presidente da Comissão de Pós-Graduação:

Prof. Titular Denis Vinicius Coury 


\section{DEDICATÓRIA}

Aos meus pais, Paulo Sergio Bohrer Lobosco (em memória) e Sandra Jahara Lobosco por me darem simplismente a vida. 


\section{AGRADECIMENTOS}

Ao longo de quatro anos de um trabalho científico o esforço é tão progressivo que conduz a uma imprecisão no tamanho do conhecimento adquirido. É olhando pelas minúcias desse trajeto que é possível perceber quanto suor foi derramado e quanto esforço alheio veio à agregar ao longo do caminho.

Certamente ninguém desenvolve um doutorado sozinho, tudo se inicia em um grande mestre disposto a transmitir sua sabedoria. Os anos de convivência assídua e de trabalho em conjunto, deixam um sentimento de eterna gratidão porque uma parte infinitesimal da conduta de um sábio vai estar sempre em seus discípulos. É com enorme consideração que eu agradeço o esforço do Prof. Harry Edmar Schulz com esse trabalho e ao fato dele acreditar no meu potencial como sua aluna.

Parte de mim, do que me agrega e me fortalece está baseado nas minhas raízes, na minha família e é o que me faz querer crescer um pouco mais. O grande salto da ambição pelo conhecimento vem amparado pelo imenso amor e devoção da minha mãe e da minha irmã Sandra Jahara Lobosco e Maria Paula Jahara Lobosco. Esses são os colos das horas difíceis e a coragem das horas de medo. Mas eu não poderia deixar de dizer que a maior parte da minha motivação pelo crescimento como pessoa vem da convivência com o meu querido pai, Paulo Sergio Bohrer Lobosco que me ensinou que qualquer conquista está baseada em uma oportunidade bem aproveitada.

A decisão de dedicar mais quatro anos à um trabalho na Universidade não foi simples. Migrar do status de Engenheira e sentar como aluna na sala de aula foi parte de um processo de insegurança. Entretanto a cada aula de Fenômenos de Transporte do Prof. Nivaldo Correa Aparecido e de Métodos Numéricos Aplicado 
à Recursos Hídricos do Prof. Edson Wendland a decisão parecia mais acertada. Agradeço enormemente a esses professores por essa motivação e pelo auxílio prestado ao longo do trabalho. Agradeço a CAPES ao CNPQ à FAPESP e ao grupo Santander pelo auxílio financeiro a esse projeto de pesquisa. Em especial agradeço ao Prof. Antônio Amador pelo estágio de pesquisa realizado sobre sua orientação no Instituto Politécnico de Setúbal.

Registro aqui o meu agradecimento a equipe de funcionários e técnicos do Departamento de Hidráulica e Saneamento que sempre foram tão prestativos e dos quais eu tanto solicitei auxílio. O André Canale Garcia que muitas vezes me ajudou nos serviços de informática, a Maria Auxiliadora de C. Altieri Pin que muito me esclareceu nos tramites burocráticos e formais da Universidade. A Flávia Gialorenço Canova e a Fernanda Maria Struzziatto Machado a quem eu sempre fiz milhares de perguntas sobres as possibilidades para melhor utilizar os auxílios financeiros.

O caminho entre o início e o fim de um trabalho de doutorado é longo. E estar apto para o início do mesmo faz parte de uma trajetória educacional. Neste contexto fica aqui registrado o meu agradecimento aos professores do IPRJ, porque foi lá que toda a minha trajetória profissional se iniciou. Em especial gostaria de agradecer ao Prof. Carlos Frederico Estrada Alves, meu orientador de iniciação científica, que foi capaz de manter um autêntico vinho do porto guardado em sua sala por alguns anos até a comemoração da minha formatura. Ao professor Francisco Moura Neto que sempre serviu como um exemplo a ser seguido, ao professor João Flávio de Vasconcelos e Juarez Mulayert que também solidificaram em mim a admiração pela atividade acadêmica.

Mas se eu fosse falar do princípio de toda a minha formação, teriam que me desculpar os demais professores porque a minha grande admiração sempre esteve com as áreas de matemática e Física e então as minhas melhores recordações da escola pertencem a professora Celma Bohrer.

E se existe alguém que nos acompanha em todas as etapas da vida esse alguém nada mais é do que um grande amigo. Pessoas com quem crescemos juntos 
e compartilhamos momentos. Agradeço a minha amiga Luciana Benvenutti Barbosa e ao meu amigo John Richardson. E aqueles a quem jamais retribuiremos a amizade nas devidas proporções, em especial ao Fernando e Dircea Figueiredo. 


\section{RESUMO}

\section{LOBOSCO, R. J. Investigação teórico-numérica da aeração em estru- turas de vertedouros em degraus com uso de software livre. 2013. $148 \mathrm{f}$.} Tese (Doutorado) - Escola de Engenharia de São Carlos, Universidade de São Paulo, São Carlos, 2013.

Em inúmeras aplicações práticas da engenharia a camada interfacial entre dois fluidos é de extrema importância para a correta caracterização do escoamento. Especificamente na Engenharia Ambiental e Hidráulica na interface entre o ar e a água existem propriedades capazes de relacionar a aeração e oxigenação. Focado na dinâmica dos processos turbulentos, o estudo proposto se aplica a problemas de sub-pressão em vertedores e visa analisar a troca de gases da interface ar-água em situações de fases dispersas e avaliar a qualidade da água a jusante dos mesmos. O objetivo maior é descrever a relação entre o comportamento da superfície da água, o desenvolvimento da camada limite e os regimes de escoamento de acordo com a vazão volumétrica. Para representar a distribuição da fração de vazios da fase dispersa, foram usados os princípios da formulação dos escoamentos em vertedores escalonados e da formulação para enlaçamento de ar. As argumentações e justificativas das formulações propostas para os perfis de concentrações foram baseadas na distribuição da fração de vazios prevista numericamente. A abordagem numérica do problema fluidodinâmico diferencia da maioria dos estudos encontrados na literatura, por estar baseada na quebra da superfície livre.

Palavras-chave: Enlaçamento de ar, turbulência, camada limite, superfície livre, escoamento gás-líquido. 


\begin{abstract}
LOBOSCO, R. J. Numerical-theoretic investigation of flow areation over stepped spillways using free software. 2013. 148 f. Tese (Doutorado) Escola de Engenharia de São Carlos, Universidade de São Paulo, São Carlos, 2013.

In many pratical aplications of engineering the interfacial layer between two fluids has a strong relevance in the process of right mesurements of the flow. Especifically in the enviromental and hydraulics engineering the interface between air and water is the property related with oxigen and areation of the flow. With focus on the dynamics of the turbulent processes, the proposed study is applied to sub-pressure problems in spillways. It investigates the gases exchange in the airwater interface in the dispersed phase and evaluate the water quality downstream. The major goal is to describe a relation between the boundary layer development and the flow regimes with discharge. To represent the distribution of void fractions of the dispersed phase, the physical formulation concepts of stepped spillways and entrapped air were used. The arguments and reasons to justify the proposed concentration profile formulation are based on the numerical provided void fraction distribution. The results as well as the physical model are in good agrement with described literature data. The Numerical approach of the fluid dynamics problem differs from major of described literature studies because it is based on the surface breakup.
\end{abstract}

Keywords: Air-entrainment, turbulence, boundary layer, free surface, gas-liquid flow. 


\section{SUMÁRIO}

Página

RESUMO vi

SUMMARY vii

LISTA DE FIGURAS - xi

LISTA DE TABELAS Xv

1 INTRODUÇÃO 1

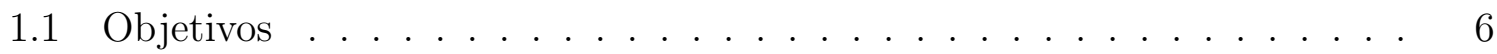

1.2 Objetivos Específicos . . . . . . . . . . . . . . . . . 6

1.3 Justificativa . . . . . . . . . . . . . . . . . . . . 7

2 CONTEXTUALIZAÇÃO DO PROBLEMA 9

2.1 A estrutura hidráulica . . . . . . . . . . . . . . . . . . . . . 9

2.2 Fenomenologia de Escoamento . . . . . . . . . . . . . . . . . . . . . 10

2.3 O fenômeno da cavitação . . . . . . . . . . . . . . . . . . . . . . . 13

2.4 Particularidades da aeração do escoamento em estruturas escalonadas . . 14

2.5 Desenvolvimento da camada limite . . . . . . . . . . . . . . . 17

2.6 Modelos de estruturas de vertedores . . . . . . . . . . . . . . . . . . 20

2.7 Artifícios numéricos . . . . . . . . . . . . . . . . . . . . . . . 21

2.8 Tratamento da interface entre dois fluidos . . . . . . . . . . . . . . . . . 24

2.9 Do contexto geral . . . . . . . . . . . . . . . . . . 25 
3 TEORIA E MÉTODOS $\quad 26$

3.1 Abordagem adotada . . . . . . . . . . . . . . . 26

3.2 Formulação do problema e equações governantes . . . . . . . . . . . . . 27

3.2 .1 Conservação da massa . . . . . . . . . . . . . . . . . . 27

3.2 .2 Conservação da quantidade de movimento . . . . . . . . . . . . . . . . 29

3.3 Abordagem multifásica . . . . . . . . . . . . . . . . . . 33

3.4 Abordagem numérica de escoamentos turbulentos . . . . . . . . . . . . 34

3.4.1 Abordagem de Média de Reynolds . . . . . . . . . . . . . . . . 36

3.4 .2 Modelos de fechamento . . . . . . . . . . . . . . 37

3.5 Ferramentas computacionais . . . . . . . . . . . . . . . 40

3.6 Equipamentos de Hardware . . . . . . . . . . . . . . . . . . . . . . . . . 42

3.7 Método numérico e forma de discretização . . . . . . . . . . . . . . . . 42

3.8 Condições de contorno . . . . . . . . . . . . . . . . . . . . . . . 44

3.8 .1 Condição de parede . . . . . . . . . . . . . . . . . 44

3.8.2 Tratamento numérico da superfície livre . . . . . . . . . . . . . 46

3.8 .3 Condição de simetria . . . . . . . . . . . . . . . . . . 47

3.8.4 Condição de entrada . . . . . . . . . . . . . . . . . . 47

3.8 .5 Condição de saída . . . . . . . . . . . . . . . . . . 47

3.8.6 Distribuição da pressão . . . . . . . . . . . . . . . . . . . 47

3.9 Conceitos de coerência em solução numérica . . . . . . . . . . . . . . 48

4 FORMULAÇÃO TEÓRICA $\quad 49$

4.1 Formulação teórica unidimensional para a forma da superfície . . . . . . 50

4.1.1 Solução 1 - Impondo Coeficientes Constantes . . . . . . . . . . . . . . 57

4.1.2 Solução 2 - Admitindo variação para o coeficiente $D_{T} / u L \quad \ldots$. . . . . 59

4.1.3 Solução 3 - Solução sem modelar o coeficiente $K$. . . . . . . . . . . 63

4.1.4 Considerações finais da formulação matemática . . . . . . . . . . . . . 66

$5 \quad$ RESULTADOS E DISCUSSÕES $\quad 67$

5.1 Análises preliminares . . . . . . . . . . . . . . . . 68 
5.1 .1 O modelo CEDEX . . . . . . . . . . . . . . . . 68

5.1 .2 Representação física . . . . . . . . . . . . . . . . . . 69

5.1 .3 O perfil de distribuição de pressão . . . . . . . . . . . . . . . . 70

5.2 Análise da superfície livre do escoamento multifásico . . . . . . . . . . 71

5.2.1 Análise do perfil de concentração - Influência do refinamento da malha 73

5.2.2 Perfis de concentração e análise dos regimes do escoamento . . . . . . . 80

5.2.3 Avaliação da concentração de ar - Alteração da vazão volumétrica . . . 86

5.2.4 Avaliação da concentração de ar - Considerações finais sobre o regime de escoamento . . . . . . . . . . . . . . . . . . . . 89

5.3 Verificando a influência do perfil de entrada . . . . . . . . . . . . 95

5.3.1 Expansão da superfície livre - comparação com a formulação teórica . . 95

5.4 Análise dos perfis de pressão . . . . . . . . . . . . . . . . . . . 101

5.5 O perfil de sobreposição . . . . . . . . . . . . . . . . . . 104

5.6 Influência da parede lateral do canal . . . . . . . . . . . . . . 106

6 CONCLUSÕES 109

$\begin{array}{ll}\text { ANEXOS } & 118\end{array}$ 


\section{LISTA DE FIGURAS}

Página

1.1 Tipos de vertedouros em degraus. (Imagens (a) e (c) foram gentilmente cedidas e fazem parte de projetos da empresa Engevix.) . . . . . . . . . 2

1.2 Bacias de dissipação. (A imagem (b) é a imagem de uma barragem Australiana. A foto foi gentilmente cedidas por Stuart Longley.) . . . . . . . 3

2.1 O perfil de Ogiva. . . . . . . . . . . . . . . . . . . 10

2.2 Tipos de escoamento. . . . . . . . . . . . . . . . . . 11

2.3 Características da aeração no escoamento em vertedores escalonados. (Imagens (a) e (b) foram gentilmente cedidas e faz parte de projetos da empresa Engevix.) . . . . . . . . . . . . . . . . . 12

2.4 O fenômeno da cavitação. . . . . . . . . . . . . . . . . . . . . 13

2.5 Zonas de aeração do escoamento. . . . . . . . . . . . . . . . . . . 15

2.6 Desenvolvimento da camada limite em uma placa plana . . . . . . . . . . 19

2.7 Perfis de entrada no vertedouro . . . . . . . . . . . . . . . 21

3.1 Volume de controle . . . . . . . . . . . . . . . . . . 27

3.2 Tensões atuantes em um elemento diferencial de fluido . . . . . . . . . 30

3.3 Condições de contorno . . . . . . . . . . . . . . . . . . . 48

4.1 Parâmetros considerados no estabelecimento da equação básica de enlaçamento de vazios (enlaçamento de ar) . . . . . . . . . . . . 50

4.2 Condição de escoamento e geométrica considerada no presente estudo. As variáveis estão definidas e se trata de uma região de expansão vertical do

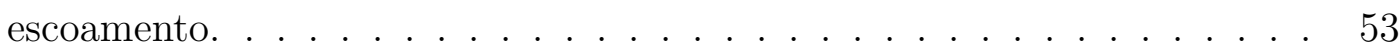


4.3 Expansão da coluna de água (mistura) com a inserção ou enlaçamento de ar. Toda a variação ocorre na dimensão vertical. Esta consideração é utilizada no equacionamento aqui apresentado. . . . . . . . . . . . . 55

4.4 Previsões obtidas com a Equação (4.35), em duas formas de adimensionalizar o eixo das ordenadas (profundidades adimensionalizadas). Adaptado de Schulz et al. (2011). . . . . . . . . . . . . . . . . . . . . 58

4.5 Dados de evolução de superfície coletados para o presente estudo, conforme relatados em Schulz et al. (2011). Em que Exp. representa o número do experimento efetuado.

4.6 Comparação entre os dados medidos (apresentados na Figura 4.5) e as previsões possíveis com a presente formulação. Observa-se que toda a evolução prevista ocorre para $s$ variando entre 0 e 1 , diferentemente da primeira quantificação apresentada na Figura 4.4(b) . . . . . . . . . . . .

4.7 Representação gráfica da Equação (4.59) para $h_{M}=2, \omega=-4$ e $\theta_{1}=0,1$. Esta solução não introduz modelos para o coeficiente $K$ da Equação (4.5). 65

5.1 Perfil CEDEX proposto por García and Mateos (1995). . . . . . . . . . 68

5.2 Perfil do escoamento . . . . . . . . . . . . . . . . . . . . 69

5.3 Perfil de distribuição de pressão. . . . . . . . . . . . . . . . . . . . . 71

5.4 Perfil de distribuição de pressão. Adaptado de Chen et al. (2002). . . . . . 72

5.5 Perfis de concentração: malha de 373.250 elementos, $q=1.0 \mathrm{~m}^{2} / \mathrm{s}$, incli-

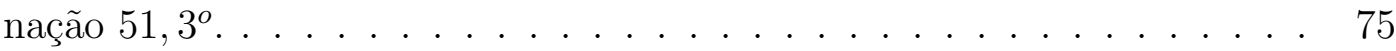

5.6 Perfis de concentração: malha de 373.250 elementos, $q=1.0 \mathrm{~m}^{2} / \mathrm{s}$, inclinação $51,3^{\circ} \ldots \ldots \ldots \ldots \ldots \ldots \ldots$. . . . . . . . . . . . . . . . . . . . .

5.7 Perfis de concentração: malha de 373.250 elementos, $q=1.0 \mathrm{~m}^{2} / \mathrm{s}$, inclinação $51,3^{\circ} \ldots \ldots \ldots \ldots$. . . . . . . . . . . . . . . 77

5.8 Perfis de concentração: malha de 373.250 elementos, $q=1.0 \mathrm{~m}^{2} / \mathrm{s}$, inclinação $51,3^{\circ} \ldots \ldots \ldots \ldots \ldots \ldots \ldots \ldots$. . . . . . . . . . . . . . . . . . .

5.9 Perfil de distribuição da concentração ao longo dos degraus: malha de

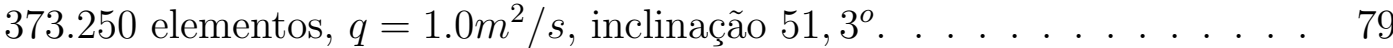


5.10 Perfil tridimensional da distribuição da concentração ao longo dos degraus: malha de 373.250 elementos, $q=1.0 \mathrm{~m}^{2} / \mathrm{s}$, inclinação $51,3^{\circ} \ldots$. . . 80

5.11 Perfis de concentração: malha de 2176794 elementos, $q=1.0 \mathrm{~m}^{2} / \mathrm{s}$, inclinação $51,3^{o} \ldots \ldots \ldots \ldots \ldots \ldots \ldots$

5.12 Perfis de concentração: malha de 2176794 elementos, $q=1.0 \mathrm{~m}^{2} / \mathrm{s}$, inclinação $51,3^{\circ} \ldots \ldots \ldots \ldots \ldots$

5.13 Perfis de concentração: malha de 2176794 elementos, $q=1.0 \mathrm{~m}^{2} / \mathrm{s}$, inclinação $51,3^{\circ}$

5.14 Perfis de concentração: malha de 2176794 elementos, $q=1.0 \mathrm{~m}^{2} / \mathrm{s}$, inclinação $51,3^{\circ}$.

5.15 Perfil de distribuição da concentração ao longo dos degraus: malha de 2176794 elementos, $q=1.0 \mathrm{~m}^{2} / \mathrm{s}$, inclinação $51,3^{\circ} \ldots \ldots \ldots$

5.16 Perfis de concentração: malha de 2176794 elementos, $q=1.3 \mathrm{~m}^{2} / \mathrm{s}$, inclinação $51,3^{\circ}$.

5.17 Perfil de distribuição da concentração ao longo dos degraus: malha de 2176794 elementos, $q=1.3 \mathrm{~m}^{2} / \mathrm{s}$, inclinação $51,3^{\circ}$.

5.18 Perfil tridimensional da distribuição da concentração ao longo dos degraus: malha de 2176794 elementos, $q=1.3 \mathrm{~m}^{2} / \mathrm{s}$, inclinação $51,3^{\circ}$. . . .

5.19 Perfis de concentração: malha de 2176794 elementos, $q=1.5 \mathrm{~m}^{2} / \mathrm{s}$, inclinação $51,3^{\circ}$

5.20 Perfis de concentração: malha de 2176794 elementos, $q=1.5 \mathrm{~m}^{2} / \mathrm{s}$, inclinação $51,3^{\circ}$

5.21 Perfis de concentração: malha de 2176794 elementos, $q=1.5 \mathrm{~m}^{2} / \mathrm{s}$, inclinação $51,3^{\circ}$.

5.22 Perfis de concentração: malha de 2176794 elementos, $q=1.5 \mathrm{~m}^{2} / \mathrm{s}$, inclinação $51,3^{\circ}$.

5.23 Perfil tridimensional da distribuição da concentração ao longo dos degraus: malha de 2176794 elementos, $q=1.5 \mathrm{~m}^{2} / \mathrm{s}$, inclinação $51,3^{\circ}$. 
5.24 Perfil de distribuição da concentração ao longo do sexto degrau - uma comparação entre as diferentes vazões [vazão inicial $1,0 \mathrm{~m}^{2} / \mathrm{s}$ em verde, intermediária $1,3 \mathrm{~m}^{2} / \mathrm{s}$ em azul e $1,5 \mathrm{~m}^{2} / \mathrm{s}$ em vermelho]. . . . . . . . . . 94

5.25 Perfis de concentração da estrutura com degraus de transição na entrada: malha de 4136000 elementos, inclinação $51,3^{\circ}$. . . . . . . . . . . . . 96

5.26 Perfis de concentração da estrutura com degraus de transição na entrada: malha de 4136000 elementos, inclinação $51,3^{\circ}$. . . . . . . . . . . . 97

5.27 Perfis de concentração da estrutura com degraus de transição na entrada: malha de 4136000 elementos, inclinação $51,3^{\circ}$. . . . . . . . . . . . . . . . 98

5.28 Perfis de concentração da estrutura com degraus de transição na entrada: malha de 4136000 elementos, inclinação $51,3^{\circ}$. . . . . . . . . . . . . 99

5.29 Perfil tridimensional da distribuição da concentração ao longo dos degraus: malha de 4136000 elementos, inclinação 51, $3^{\circ}$. . . . . . . . . . . . 99

5.30 Seção transversal do nono degrau simulado . . . . . . . . . . . . . . . . . 100

5.31 Perfil admensionalizado. Comparação entre os resultados numéricos e os experimentais Schulz et al. (2011) . . . . . . . . . . . . . . . . 100

5.32 Perfis de pressão (Unidades de Pressão em Pa) . . . . . . . . . . . . . . . 102

5.33 Perfis de velocidade . . . . . . . . . . . . . . . . 103

5.34 Perfis da interface entre o ar e a água. . . . . . . . . . . . . . . . . . . 104

5.35 Perfis da interface entre o ar e a água. . . . . . . . . . . . . . . . 105

5.36 Influência da parede lateral no escoamento de acordo com a variação da velocidade e do perfil de entrada. . . . . . . . . . . . . . . . 107

5.37 Refinamento da malha próximo à crista. . . . . . . . . . . . . . . . . . 108 


\section{LISTA DE TABELAS}

Página

1 Constantes empíricas do modelo $k-\varepsilon \ldots \ldots$. . . . . . . . . 40

2 Ferramentas utilizadas no processo de simulação do escoamento. . . . . . 41

3 Esquemas numéricos utilizados no processo de simulação do escoamento. 44

4 Leis básicas de conservação. . . . . . . . . . . . . . . . . . 52

5 Endereço eletrônico para download das ferramentas computacionais. . . . 120

6 Endereço eletrônico de sites de discussões sobre as ferramentas computacionais. . . . . . . . . . . . . . . . . . . . 121 


\section{INTRODUÇÃO}

As estruturas hidráulicas são conhecidas desde os primórdios da humanidade devido a demanda de água e a necessidade do seu armazenamento. Nas últimas seis décadas, grandes projetos da Engenharia civil e hídrica deram origem a construções de barragens de grande porte tais como: Gibel I em 2004 e Gibel III que deve entrar em operação em 2013 na Etiópia. A expectativa é de gerar 6500 GWh. Alguns países como Uganda, Sudão e Egito também devem se beneficiar da energia gerada pela hidrelétrica (Gibel, 2012). Na China a barragem Three Gorges, finalizada em 2008 representa a segunda maior produção de energia do mundo (Gorges, 2010), ultrapassada no critério de geração de energia elétrica, apenas por Itaipu que entrou em operação em 5 de maio de 1984 (Itaipu, 2010). A barragem Syncrude Tailings no Canadá é considerada a maior do mundo em termos de volume de material para construção, as obras tiveram início em 1973, e as operações em 1978.

No Brasil o potencial hidrelétrico é estimado em cerca de $260 G W$ dos quais 40,5\% estão localizados na bacia hidrográfica do Amazonas (Cepel, 2007). Conforme dados do portal Brasil, (PortalBrasil, 2013) algumas das usinas em processo de licitação ou em construção na Amazônia vão estar entre as dez maiores do país nos próximos anos. Dentre elas a hidroelétrica de Belo Monte que terá potência instalada de 11.233MW e de São Luiz dos Tapajós, 8.381MW. A maioria dessas barragens requer a construção de dispositivos que possibilite a passagem de água excedente. Seja em grandes ou em pequenas estruturas, os vertedouros são um exemplo de dispositivo utilizado para liberar o volume excedente controlando as vazões de jusante, evitando inundações. Quando indevidamente projetados, oferecem grandes riscos à estabilidade da estrutura hidráulica uma vez que devem garantir 
a integridade da obra durante a ocorrência de cheias. Ilustrações de exemplos de estruturas brasileiras de pequeno porte são encontradas na Figura (1.1).

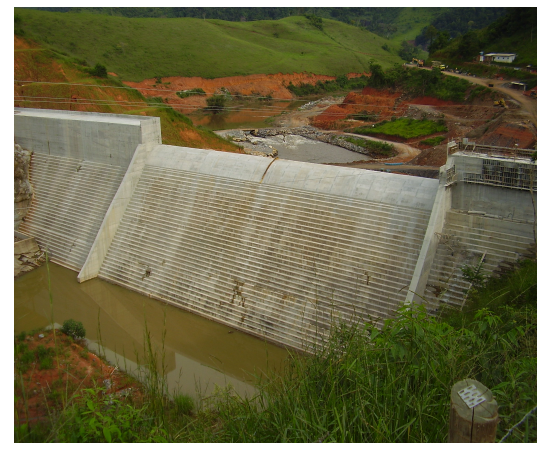

(a) Com perfil de Ogiva

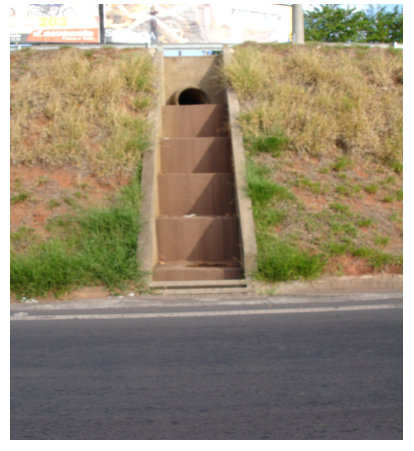

(b) Entrada pressurizada

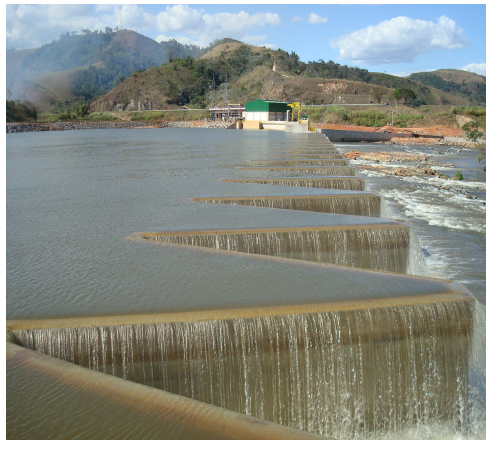

(c) Distribuição hidrostática

Figura 1.1: Tipos de vertedouros em degraus. (Imagens (a) e (c) foram gentilmente cedidas e fazem parte de projetos da empresa Engevix.)

Uma vez que as alterações climáticas mundiais fazem com que inundações e enchentes ocorram repetidamente em grandes escalas, em diferentes regiões do planeta, os vertedores ganham ainda mais relevância no processo de controle de desastres e de catástrofes ambientais. A decisão de abertura das comportas para liberação do fluxo excedente pode, algumas vezes, representar impactos não só no canal a jusante, mas também em cidades e regiões mais amplas. De forma geral os efeitos negativos decorrentes da presença de vertedouros são eliminados (ou minimizados) projetando bacias de dissipação, Chaudhry (2008).

Na Figura 1.2(a) é possível visualizar o escoamento sobre uma estrutura em degraus. A presença dos degraus acarreta em uma aumento da dissipação de energia e permite uma redução no tamanho da bacia de dissipação. Na extremidade inferior da estrutura lisa, Figura 1.2(b), é possível observar a declividade para salto do escoamento. Além dos artifícios do chamado "salto em esqui" utilizados em algumas estruturas lisas existem as chamadas barragens de dissipação com lâmina livre em que o jato é simplesmente incidido livremente. Em ambos os casos os riscos de erosão do solo precisam estar corretamente estimados nos parâmetros de projeto. O dimensionamento dessas estruturas é vinculado ao estudo de impacto de jatos de alta 
velocidade em que o fenômeno de auto aeração é o parâmetro que permite prever a dissipação de energia através dos jatos, Khlopenkov (1977) e Essery and Horner (1978).

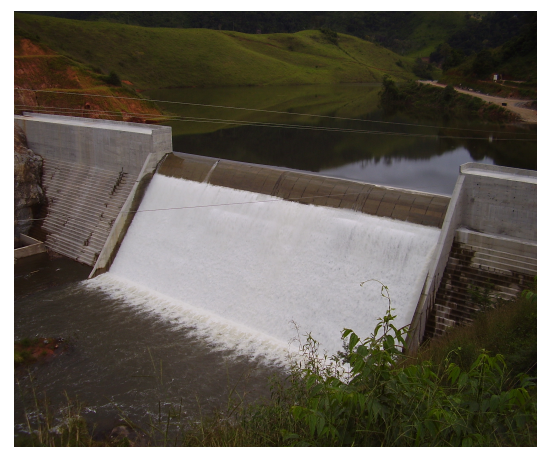

(a) Estrutura em degraus

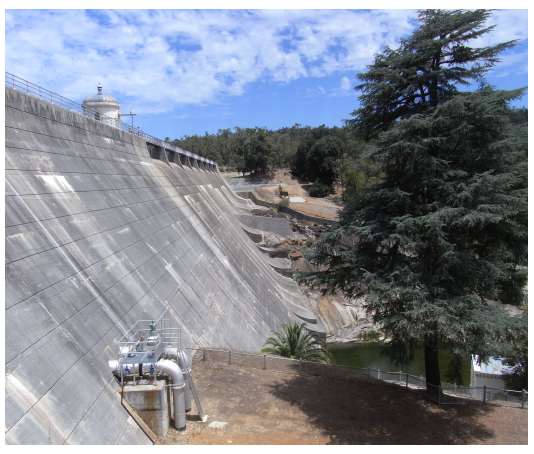

(b) Estrutura lisa

Figura 1.2: Bacias de dissipação. (A imagem (b) é a imagem de uma barragem Australiana. A foto foi gentilmente cedidas por Stuart Longley.)

O dimensionamento das bacias depende diretamente da capacidade prévia do vertedouro dissipar energia residual. As bacias de dissipação podem ter seu tamanho reduzido significativamente quando as estruturas hidráulicas apresentam alta eficiência, o que reduz significativamente o custo da construção, Frizel et al. (1977) e Simões et al. (2012).

Os contínuos avanços computacionais e numéricos permitem avaliar o escoamento sobre estruturas e aperfeiçoar as condições operacionais do projeto tanto no aspecto estrutural quanto no aspecto fluido dinâmico, Esmaeeli and Tryggvason (1999). O uso dessas ferramentas vem crescendo continuamente em aplicações da engenharia de recursos hídricos e contribuem cada vez mais no processo de controle e contenção de fenômenos climáticos, Jacobsen (2009) e Silva (2006).

Assim como a maioria dos escoamentos da vida cotidiana, o escoamento sobre vertedouros é altamente turbulento. Em geral, a maioria dos escoamentos com superfície livre já são turbulentos. Entretanto, quando degraus são inseridos na estrutura, são responsáveis pela intensificação da turbulência e pela antecipação da aeração do escoamento, contribuindo para uma maior dissipação de energia. A aná- 
lise de um escoamento inerentemente turbulento requer que o mesmo seja avaliado em sua forma tri-dimensional, uma vez que o fenômeno de turbulência é, em sua natureza, altamente rotacional e com flutuações tri-dimensionais. Embora a turbulência seja um fenômeno de difícil definição, todo escoamento turbulento tem uma sequência de características que o define, resumidas na literatura como "um comportamento caótico no espaço e no tempo". Essa complexidade evidentemente se repete no escoamento em vertedouros escalonados que além de ser turbulento, é multifásico, tri-dimensional, e possui superfície livre.

Para a resolução de um problema de fluido dinâmica na maneira computacional clássica, é necessário a execução de três etapas fundamentais. A primeira delas consiste na geração da geometria e da malha. Nesta fase são definidos os parâmetros geométricos do problema. A escolha da malha computacional deve ser feita de forma que permita a solução numérica com a resolução necessária. Uma malha ideal é aquela que, quanto mais refinada, não modifica mais o resultado da solução. Nesta etapa de pré-processamento, as informações do problema físico devem ser fornecidas para integrar as condições iniciais e de contorno. A segunda parte consiste na execução do solver, que serve para que a solução numérica seja processada. As equações que governam o movimento dos fluidos derivam das leis de movimento de Newton que dão origem as Equações de Navier Stokes. A resolução das equações de NavierStokes depende da geometria, das condições de contorno e do número de Reynolds do escoamento. Nesta etapa de processamento do solver, são basicamente executadas as rotinas computacionais que resolvem as equações diferenciais da conservação da massa, da quantidade de movimento e da energia. Na última fase, a chamada etapa de pós-processamento, os resultados são investigados e podem ser ilustrados de forma gráfica. Os diagramas de velocidade e pressão do escoamento servem para que a simulação seja calibrada, quando comparada com dados da literatura e dessa forma permitem o desenvolvimento dos modelos de aeração do escoamento, Amador (2005) e Schulz et al. (2011). Os diagramas de pressão também são utilizados para ilustrações das regiões de pressões negativas no escoamento, que consequentemente 
indicam as regiões de risco de cavitação, Chanson (1994) e Boes and Hager (2003).

A turbulência tem sido considerada como um dos últimos problemas da física clássica a ser resolvido. É, sem dúvida, um problema de grande relevância já que a maioria dos escoamentos reais da engenharia são turbulentos. Mesmo com o desenvolvimento de modelos complexos de turbulência, eles ainda representam uma aproximação por estarem baseados em hipóteses simplificadoras. A Simulação Numérica Direta, DNS, é o artifício que permite que a turbulência seja representada nas simulações computacionais sem simplificações, Rodi (1994). Entretanto, mesmo com os grandes avanços computacionais das últimas décadas, esse ainda é um método inviável em termos de custo computacional. Nesse trabalho a turbulência é abordada com o método de média de Reynolds (Com exceção da parte do domínio computacional que representa a interface) e utiliza modelos de fechamento das equações por uma questão de relação entre custo computacional e o benefício de precisão na solução numérica do problema físico.

O fenômeno interfacial entre dois fluidos é de fundamental relevância em diversos processos industriais e naturais. O fenômeno está diretamente relacionado com a aeração de oceanos e lagos assim como a aeração do escomento sobre estruturas hidráulicas.

Além de interferir na prevenção de danos à estrutura, a aeração do escoamento é o parâmetro que influencia na propagação de várias formas de vida como a dos micro-organismos e bactérias. Este trabalho investiga a ruptura e coalescência de bolhas em estruturas hidráulicas de grande declividade $\left(55,3^{\circ}\right)$ e pequenas vazões. A quebra da interface é o fenômeno responsável pela "auto" aeração do escoamento. Por sua vez, o início da aeração é dependente do desenvolvimento da camada limite, pois tem sua ocorrência inicial no instante em que o desenvolvimento da camada limite atinge a superfície livre. 


\subsection{Objetivos}

Investigações prévias (Gomes (2006) e Tozzi (1992)) demonstram que as maiores tensões de cavitação estão localizadas na região de desenvolvimento da camada limite. Este projeto de pesquisa está baseado nestas hipóteses e tem como objetivo investigar os perfis de concentração de ar ao longo do escoamento. Os testes com diferentes vazões volumétricas permitem associar a intensidade da cavitação e da aeração do escoamento à cada condição de regime operacional.

De forma resumida, pode-se dizer que o objetivo deste trabalho é progredir no entendimento da transferência de massa em escoamentos turbulentos.

Os escoamentos bifásicos gerados em vertedores são enfatizados, assim como suas conseqüências para a diminuição das subpressões e para o incremento da qualidade da água.

\subsection{Objetivos Específicos}

Como objetivos específicos, pode-se citar:

1. A reprodução numérica de relatos experimentais, mensurando a possibilidade de prever situações de protótipo com respeito ao escoamento e a absorção de ar na forma de bolhas.

2. Equacionamento da vazão de ar adicionada aos escoamentos em vertedores, fundamentando-se nos princípios físicos e comparando soluções numéricas.

3. Através de avanços no estudo e na simulação da aeração, descrever a distribuição da fração de vazios para então, avaliar a influência dos regimes de escoamento.

4. Investigar o estado de movimento da interface ar-água e suas propriedades físico-químicas que controlam a troca de gases entre os dois meios. Lembrando que o controle das subpressões e a aeração, em vertedouros, ocorrem na fase dispersa. 


\subsection{Justificativa}

O estudo do escoamento multifásico, turbulento, com superfície livre em geometria de vertedouros escalonados permite evoluir no entendimento e na caracterização do escoamento em barragens hidráulicas. Este maior entendimento ajuda no dimensionamento da estrutura, na prevenção de danos e permite influenciar que a água atinja a oxigenação em níveis adequados. Entretanto, do ponto de vista fluido-dinâmico este projeto de pesquisa consiste:

- No avanço do entendimento da transferência de massa do escoamento turbulento e multifásico ar-água;

- Na caracterização da influência do desenvolvimento da camada limite com o regime de escoamento;

- Na otimização do escoamento de forma que pressões negativas nos degraus sejam evitadas e, consequentemente, seja minorado o risco de cavitação;

- Na caracterização numérica de escoamentos propriamente aerados.

Neste trabalho foi priorizada a utilização de ferramentas computacionais gratuitas. Acredita-se que a possibilita de acesso total ao código computacional das rotinas numéricas e o completo entendimento da forma em que elas foram implementadas seja um elemento vantajoso no desenvolvimento de uma pesquisa científica. Além disso, o código livre permite que novos códigos sejam desenvolvidos e façam uso das bibliotecas matemáticas disponíveis.

O algoritmo de acoplamento da pressão para problemas incompressíveis, PISO; O método de volume de Fluido, VOF, para o tratamento da superfície livre; Os modelos de turbulência para o fechamento das equações na abordagem de média de Reynolds; são alguns dos modelos numéricos utilizados para a representação do escoamento. Eles precisam ser adequadamente aplicados para a correta representação do problema físico. 
Em geral existe uma grande disponibilidade de códigos numéricos desenvolvidos por pesquisas científicas. Muitos não disponibilizados publicamente e outros que muitas vezes não são testados para soluções específicas.

A capacidade e precisão de ferramentas gratuitas para a resolução de problemas complexos, como a simulação do escoamento em estruturas hidráulicas de grande declividade foi aqui avaliada. A calibração dos resultados, feita com dados experimentais e um modelo físico, permitiu verificar as soluções conceituais incorporadas nos códigos numéricos.

A complexidade da interação entre gotículas em escoamentos turbulentos é um dos aspectos que o torna ainda não totalmente compreendido, uma vez que a turbulência não possui um equacionamento definitivo. Os fenômenos de ruptura e coalescência de gotas ocorrem em diferentes condições e ainda necessitam de um aprofundamento científico nos dias atuais.

Este trabalho está estruturado da seguinte forma: No Capítulo 2 é, inicialmente, apresentada a revisão bibliográfica que permitiu contextualizar este projeto de pesquisa perante a literatura científica do tema em questão. O Capítulo 3 aborda os métodos utilizados como procedimento de elaboração para representação do problema físico. O Capítulo 4 aborda a elaboração matemática da formulação teórica enquanto o Capítulo 5 apresenta as predições qualitativas e quantitativas discutidas no Capítulo 4. No capítulo 6, as conclusões são deduzidas à respeito das considerações finais e pespectivas futuras. Por fim, nos Anexos, está disponível uma descrição das ferramentas numéricas utilizadas. 


\section{CONTEXTUALIZAÇÃO DO PROBLEMA}

Este capítulo faz referência a algumas das pesquisas desenvolvidas ao longo dos anos sobre o escoamento em estruturas hidráulicas. Este é apresentado com o intuito de abordar conceitos físicos, matemáticos e computacionais que de alguma forma localizam o presente trabalho no desenvolvimento e na compreensão que se tem a respeito do tema.

\subsection{A estrutura hidráulica}

Um vertedouro é composto de três partes principais: a crista, a calha e a bacia de dissipação.

A crista do vertedouro foi desenvolvida a partir de correlações empíricas. A pressão pode ser maior ou menor que a atmosférica dependendo do perfil, conforme mostra a Figura 2.1(a). O perfil é função da altura da coluna de água $H_{d}$ e, conforme Chaudhry (2008), existem restrições a essa altura para que o risco de cavitação seja evitado. Para escoamentos gerados por colunas de água com dimensões verticais menores que $H_{d}$ a crista age como um elemento de resistência e reduz a descarga de água. Entretanto para colunas de água maiores que $H_{d}$ a descarga pode ser incrementada devido à ocorrência de pressões negativas. Segundo Chatila and Tabbara (2004), a pressão negativa é favorável neste aspecto, porém não deve ser excessiva para evitar cavitação. A U.S Army Corps., USA (1965) propõe a crista com as dimensões da Figura 2.1(b).

O perfil de calha escalonada é proposto para vazões da ordem de 11 a $15 \mathrm{~m}^{3} / \mathrm{s} . \mathrm{m}$ de forma que os degraus exerçam influência no escoamento e o risco de 


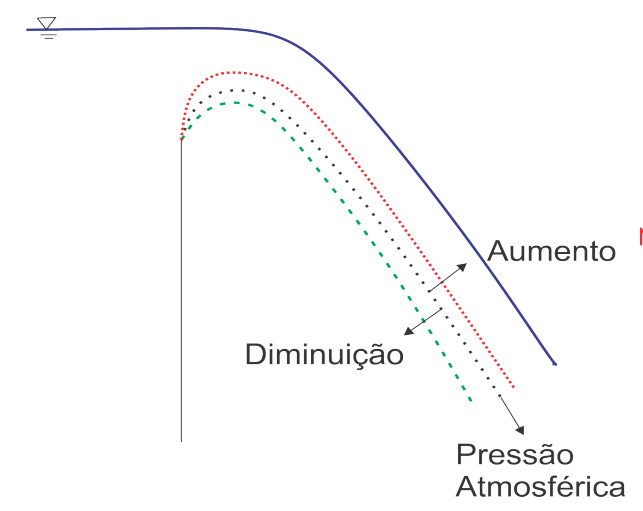

(a) Características da pressão

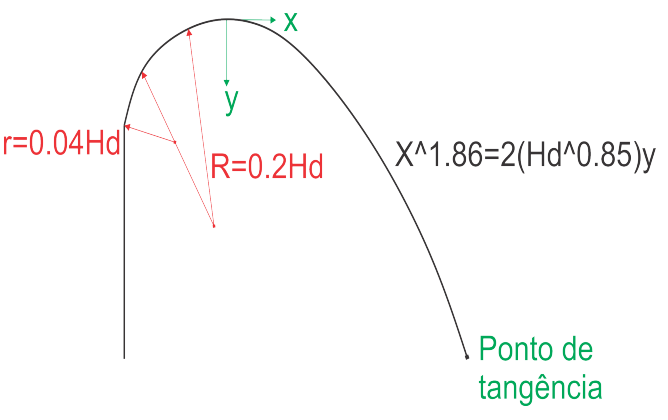

(b) As dimensões

Figura 2.1: O perfil de Ogiva.

cavitação à estrutura não seja excessivo. Existem projetos com diferentes tamanhos de degraus para variadas declividades de calha. As estruturas com degraus se tornaram viáveis na construção de barragens a partir do desenvolvimento do concreto compactado à rolo, RCC. A principal função dos degraus é antecipar a aeração do escoamento.

Necessário um cálculo preciso da energia cinética do escoamento a jusante da estrutura do vertedouro para que a bacia de dissipação seja bem projetada. Uma bacia de dissipação "padrão" cria um ressalto hidráulico e transforma o escoamento de supercrítico para subcrítico. Existem diferentes tipos de bacia de dissipação (Chaudhry, 2008) que são projetadas em função da vazão. Em uma análise sobre a bacia de dissipação, Simões et al. (2012) elaboraram definições para o comprimento do ressalto hidráulico a jusante de vertedores. A redução no tamanho das bacias de dissipação está diretamente relacionado com a redução nos custos de construção da estrutura hidráulica.

\subsection{Fenomenologia de Escoamento}

O escoamento multifásico ar-água nos vertedouros em degraus é geralmente classificado de acordo com os regimes de escoamento. Segundo Essery and Horner (1978) os regimes estão subdivididos em: Escoamento do tipo Nappe (ou que- 
das sucessivas), Figura 2.2(a); Escoamento do tipo Skimming (ou deslizamento sobre vórtices turbulentos), Figura 2.2(b) e Escoamento de transição. Chanson (1994) propôs que o escoamento de deslizamento sobre vórtices ocorre para vazões maiores que um dado valor crítico definido pela profundidade crítica $h_{c}$, dada por:

$$
\frac{h_{c}}{h}=1,057-0,465 \frac{S h}{I}
$$

Em que: $S_{h}$ é a altura do degrau, $I$ é a base do degrau e $h_{c}$ é a profundidade característica. Os dados foram obtidos para declividades variando de $11^{o}$ à $51,3^{\circ}$ e $S_{h} / I$ entre 0,2 e $1,3$.

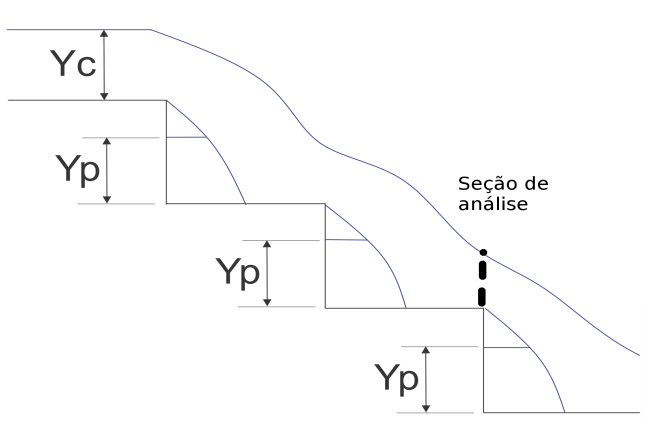

(a) Quedas sucessivas (Nappe).

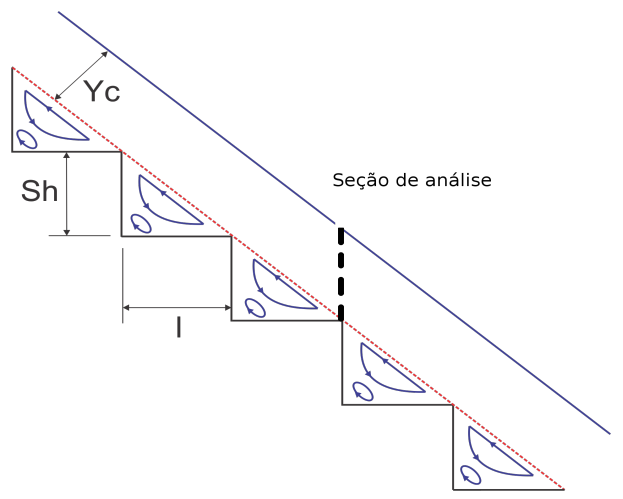

(b) Deslizamento sobre vórtices (Skimming).

Figura 2.2: Tipos de escoamento.

Porém, a melhor quantificação dos limites entre os diferentes regimes ainda é motivo de questionamento na literatura. Chanson (1994) demostra que grandes perdas de energia ocorrem no escoamento do tipo skimming devido ao cisalhamento existente nos degraus. A energia é dissipada para manter a recirculação dos vórtices na cavidade abaixo do pseudo-fundo. Já em um escoamento do tipo Nappe, a dissipação de energia se deve ao impacto do jato e às recirculações. Alguns autores sugerem que a dissipação de energia possa ser maior em um escoamento do tipo Nappe (Chamani and Rajaratnam, 1994).

Em casos de vertedouros para grande capacidade de descarga, o regime 
de escoamento predominante é geralmente do tipo skimming (deslizamento sobre vórtices).

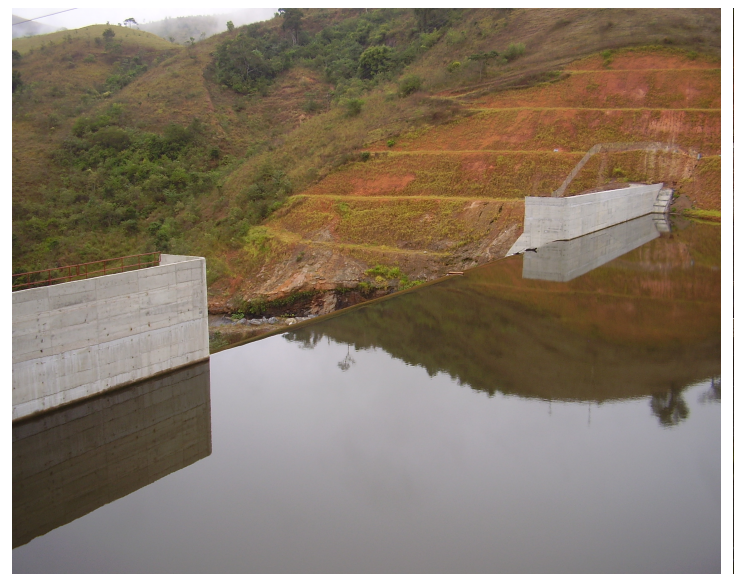

(a) Escoamento na região à montante da estrutura hidráulica.

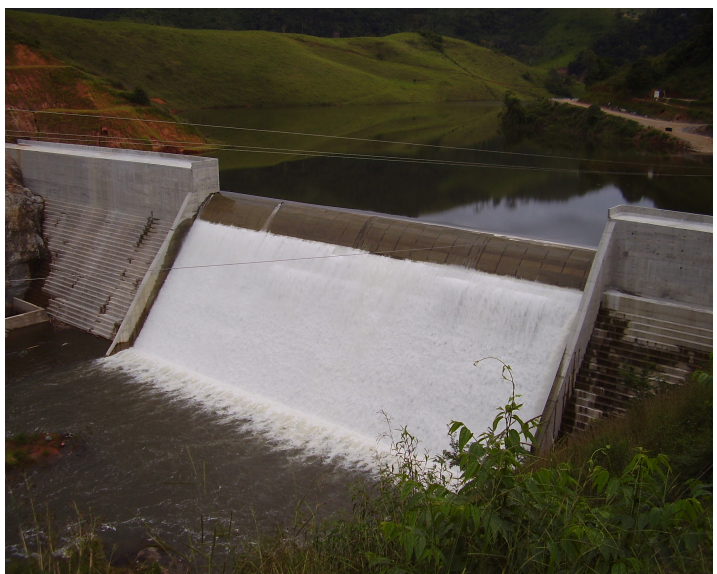

(b) Região à jusante do vertedor em degraus.

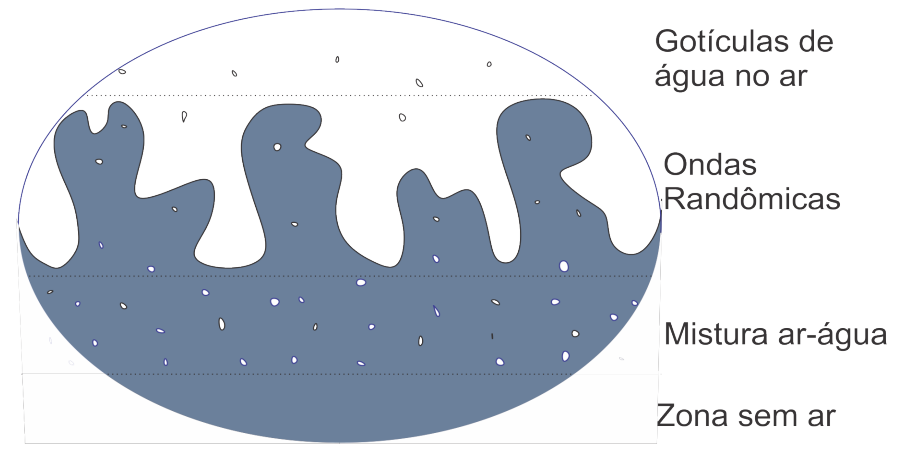

(c) Zonas verticais do escoamento aerado.

Figura 2.3: Características da aeração no escoamento em vertedores escalonados. (Imagens (a) e (b) foram gentilmente cedidas e faz parte de projetos da empresa Engevix.)

Em termos de sucessão de características ao longo de um escoamento, tem-se que, próximo à crista, o escoamento é não aerado e ocorre o desenvolvimento da camada limite. Até que o desenvolvimento da camada-limite esteja completo, a superfície pode ser caracterizada como "bem comportada" e o escoamento fora da camada limite é praticamente irrotacional, conforme mostra a Figura 2.3(a). Qualquer parcela de ar presente nesta região se deve aos distúrbios gerados pela vorticidade e 
ondulações no reservatório. No ponto em que a camada limite atinge a superfície livre, o denominado ponto de início da aeração, ocorrem alterações na superfície livre, com a incidência de múltiplos vórtices, que tornam o escoamento turbulento, conforme pode ser visualizado na Figura 2.3(b). À jusante do ponto de início da aeração ocorre a incorporação (ou enlaçamento) de ar pelo escoamento. Porém, percebe-se que o fundo da calha não é atingido imediatamente pela aeração e a camada de mistura ar-água se estende gradativamente ao longo do escoamento da água, como pode ser visto no esquema da Figura 2.3(c).

\subsection{O fenômeno da cavitação}

A cavitação (formação e colapso de bolhas de vapor) é um dos problemas capazes de causar danos à estrutura dos vertedouros. O fenômeno inicia-se quando o escoamento gera pressões da ordem de grandeza da pressão de vapor do líquido, Franc and Michel (2004). É possível visualizar, no diagrama de fases, (Figura 2.4(a)) a passagem do estado líquido para vapor em condições de baixa pressão. Nos vertedores em degraus o paramento vertical do degrau é a região mais atingida pelo fenômeno. A Figura 2.4(b) ilustra os efeitos da cavitação no rotor de uma bomba hidráulica.

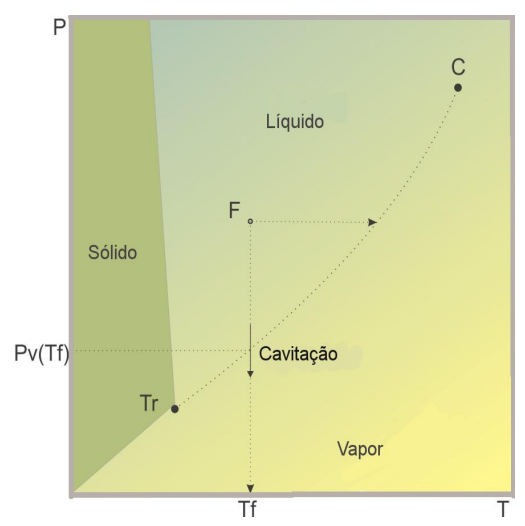

(a) Diagrama de fases.

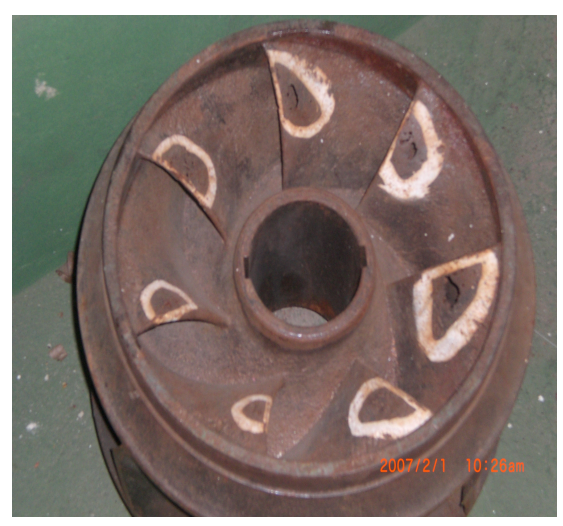

(b) Efeito da cavitação no rotor de uma bomba hidráulica.

Figura 2.4: O fenômeno da cavitação. 
A severidade dos danos causados estará diretamente relacionada à intensidade do fenômeno de cavitação e ao tempo de atuação Arndt (2002). Segundo Chanson (1994) existem quatro maneiras de evitar os danos a estrutura causados pela cavitação:

1) Reduzindo o número crítico da cavitação (por exemplo reduzindo as irregularidades da superfície); 2) Aumentando a resistência do material; 3) Diminuindo o colapso de bolhas nas fronteiras sólidas; 4) Induzindo a aeração do escoamento. Isso se deve ao fato da presença do ar aumentar a transferência de gases atmosféricos dissolvidos para a água, bem como a compressibilidade da mistura ar-água, o que amortece o colapso de bolhas próximo à estrutura.

\subsection{Particularidades da aeração do escoamento em estrutu- ras escalonadas}

De acordo com Peterka (1953), uma concentração de ar em torno de $7 \%$ é suficiente para evitar o risco de cavitação em superfícies de concreto. Isso se deve à compressibilidade da mistura ar-água, que é capaz de absorver o impacto do colapso das bolhas vaporizadas.

Além disso, a aeração também permite a re-oxigenação, o que possui relevância no aspectos ambiental pois influência na qualidade da água. A análise da qualidade da água a jusante de barragens e os danos de cavitação à estrutura têm sido alvo de estudos cada vez mais detalhados da engenharia hidráulica, principalmente nas últimas três décadas, Frizell and Melford (1991), Chen et al. (2002). A posição de início da aeração foi investigada por: Tozzi (1992) e Povh (2000). Estudos experimentais e teóricos acerca de aeração de vertedouros podem ser encontrados em Arantes et al. (2010b) e Lima et al. (2010).

Em escoamento de baixa velocidade, a entrada de ar não ocorre nem mesmo na interseção da camada limite com a superfície livre. É necessário que exista um nível específico de turbulência no escoamento para que a entrada de ar ocorra 
Chaudhry (2008). Escoamentos turbulentos que envolvem a entrada de ar estão divididos em quatro zonas. A camada superior consiste em pequenas gotículas de ar que são projetadas pela camada inferior, chamada camada de mistura. Esta camada de mistura possui ondas randômicas que representam a interface entre o ar e a água. A transferência de massa que ocorre na interface está baseada na teoria da camada limite. A região inferior à interface é uma região bifásica e abaixo desta existe uma região isenta de ar, conforme mostra a Figura 2.3(c).

Nos vertedouros, o alcance do equilíbrio entre as fases depende da declividade. De acordo com a aeração do escoamento, este pode ser dividido em quatro regiões (Chaudhry, 2008). 1) Região sem aeração, 2) parcialmente aerada, 3) completamente aerada, e 4) escoamento aerado completamente desenvolvido. A região não aerada precede a interseção da camada limite com a superfície livre. $\mathrm{Na}$ região parcialmente aerada o ar não alcança o fundo da calha, o que ocorre na região completamente aerada. Em ambas as regiões, parcialmente e completamente aerada, a concentração de ar varia ao longo do comprimento da calha. A partir da posição em que a concentração de ar não varia com a distância, o escoamento passa a ser considerado completamente desenvolvido conforme mostra a Figura (2.5).

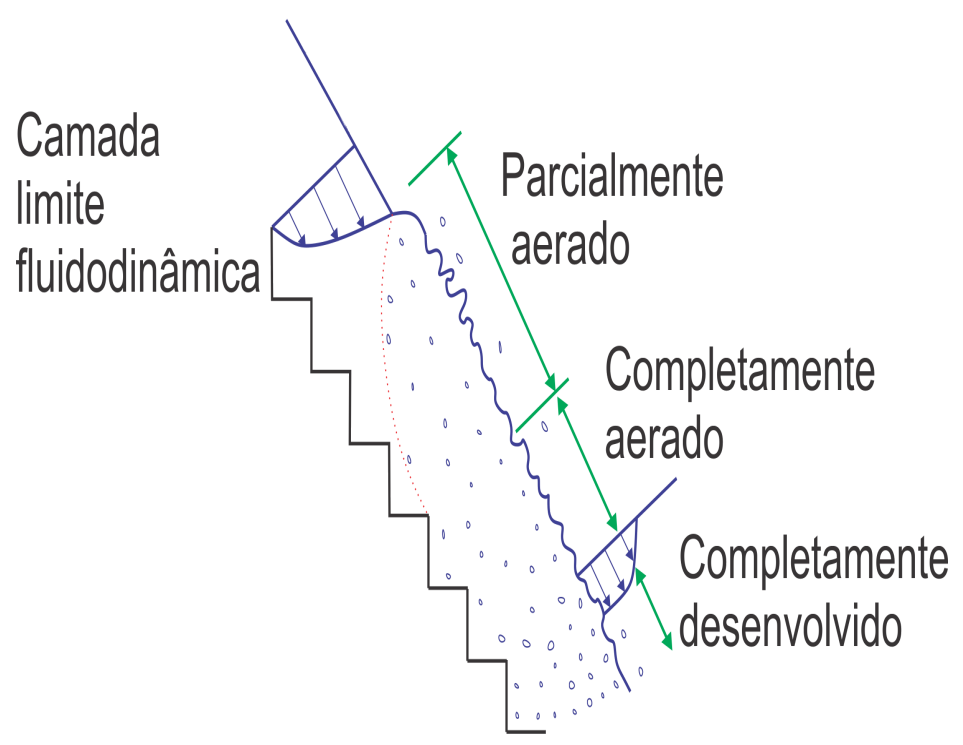

Figura 2.5: Zonas de aeração do escoamento. 
A posição de início da aeração no escoamento varia com a vazão, deslocando-se para a jusante à medida que a vazão aumenta. Existem diferentes abordagens para a análise da aeração de vertedouros escalonados. Amador (2005) fez análises do perfil de velocidade de quatro degraus na região de entrada da estrutura e definiu através de investigações da região não aerada o início da aeração.

Várias equações foram geradas para o enlaçamento de ar em função do perfil de concentração de bolhas e diversificadas equações foram obtidas em função do número de Froude para o chamado ponto de início da aeração. Chanson (2001) define que a difusão das bolhas de ar na região de escoamento completamente desenvolvido conduz a um perfil de concentração de bolhas de ar dado pela Equação (2.2).

$$
C=1-\tanh ^{2}\left(K^{\prime}-\frac{y}{2 D^{\prime} Y_{90}}\right)
$$

$C$ é a fração de vazios (ou concentração de bolhas de ar), y é a altura perpendicular ao pseudo-fundo, $Y_{90}$ é a altura em que a concentração de ar é de $90 \%, D^{\prime}$ é a difusividade turbulenta, $K^{\prime}$ é uma constante de integração. $D^{\prime}$ e $K^{\prime}$ são funções apenas da concentração média de ar na altura $Y_{90}$.

No escoamento ar-água sobre vertedores, a altura característica é comumente definida a partir do pseudo-fundo formado pelas fronteiras dos degraus e a concentração de ar de 90\% (Matos et al. (1999), Boes and Hager (2003)).

Ainda com base na equação de difusão, Toombes and Chanson (2005) propuseram um perfil de fração de vazios envolvendo a função erro. Como sempre, hipóteses simplificadoras foram adotadas, como a velocidade constante e características de difusão iguais para as diferentes frações de vazios. Também fundamentados na equação de Advecção-Difusão Schulz et al. (2004) e Schulz and Alamy Filho (2005) investigaram o fenômeno de sedimentação considerando a conservação da massa e da quantidade de movimento. Dessa forma compensaram o movimento de partículas das regiões de maior concentração para as de menor concentração, gerando perfis para a condição de equilíbrio. Ademais, obtiveram equações de velocidade de partículas em ambientes com altas concentrações a partir de considerações de energia para con- 
juntos de partículas. Uma metodologia similar permitiu que perfis de concentração fossem traçados para o fenômeno de ascensão de bolhas, e que formulações fossem obtidas para a velocidade de ascensão de conjuntos de bolhas com base nos mesmos princípios físicos.

Alguns estudos deram origem a investigação da concentração média de ar ao longo da estrutura, dentre eles podemos citar Tozzi (1992) que realizou um estudo sobre a distribuição da concentração de ar e descreveu a concentração média ao longo dos degraus para uma estrutura com declividade $1 \mathrm{~V}: 0,775 \mathrm{H}$.

Realizando experimentos em condições controladas, Lima (2004) estimou valores para a descarga de ar e obteve perfis de concentrações de vazios ao longo da superfície inferior do jato de um aerador de fundo. Esses resultados permitiram comparar valores de vazão de ar incorporadas no escoamento de água com as medidas efetuadas na entrada do aerador de fundo. Lima et al. (2010) apresentaram os resultados de Lima (2004), quantificando o ar realmente incorporado e o ar apenas presente entre ondulações da superfície, sem de fato ser enlaçado pela água. Meireles et al. (2007) analisaram a entrada de ar experimentalmente buscando definir o comportamento da superfície livre e fizeram uma análise do desenvolvimento da concentração média de ar.

Uma primeira análise numérica foi apresentada em Arantes et al. (2010b) que buscou quantificar a vazão incorporada em aeradores de fundo, atingindo resultados adequados em termos de ordens de grandeza, porém evidenciando a necessidade de maiores detalhamentos e estudos.

\subsection{Desenvolvimento da camada limite}

O conceito de camada limite está associado ao escoamento de um fluido sobre uma superfície estacionária. A parte do fluido que toca a superfície tem velocidade igual a zero devido a tensão de cisalhamento com a parede, o chamado princípio da aderência (Potter and Wiggert, 2004). A velocidade do fluido cresce a medida que este se afasta da parede. A região em que existe um perfil de velocidade devido 
à tensão de cisalhamento com a parede é a camada limite (Bird and Stewart, 1997).

A medida que o fluido escoa ao longo da superfície, mais subcamadas do fluido são desaceleradas devido ao cisalhamento entre elas e isso causa o aumento na espessura da camada limite. A espessura é definida como a distância da parede ao ponto em que a velocidade é $99 \%$ da velocidade de corrente livre, ou seja, para escoamentos externos à camada limite os efeitos de cisalhamento podem ser desconsiderados.

Em resumo, com o aumento da espessura, tanto o gradiente de velocidade como a tensão de cisalhamento diminuem. As forças viscosas advindas das tensões de cisalhamento mantém inicialmente as partículas do fluido em movimento constante e em lâminas. Entretanto, com o crescimento da espessura e a diminuição das tensões de cisalhamento, as tensões no fluido não conseguem manter o escoamento em camadas e surgem instabilidades que produzem vórtices.

A partir do instante que o escoamento produz vórtices, a camada limite passa a ser chamada de turbulenta, Figura (2.6). Na camada limite turbulenta existe uma região imediatamente posterior à superfície, da ordem de centésimos de milímetros, onde as forças viscosas mantém o escoamento na forma de laminas, região denominada subcamada laminar. A velocidade e suas derivadas variam na camada limite de acordo com o gradiente de pressão e deste fato advém o interesse deste projeto de pesquisa em determinar perfis do desenvolvimento da camada limite que variam de acordo com diferentes condições de entrada. Na região próximo a parede, diferentes escalas do processo físico são dominantes e embora a condição de não deslizamento seja apropriada para a velocidade, adjacentemente à parede existe a sub camada viscosa e o modelo de fechamento do tratamento da turbulência por média de Reynolds, não reproduzem por si só essa sub camada sem erros significativos. Por isso, no modelo computacional, é necessário a utilização de funções de parede.

O desenvolvimento da camada-limite é muito importante no controle da cavitação porque seu afloramento coincide com a origem da aeração do escoamento. 


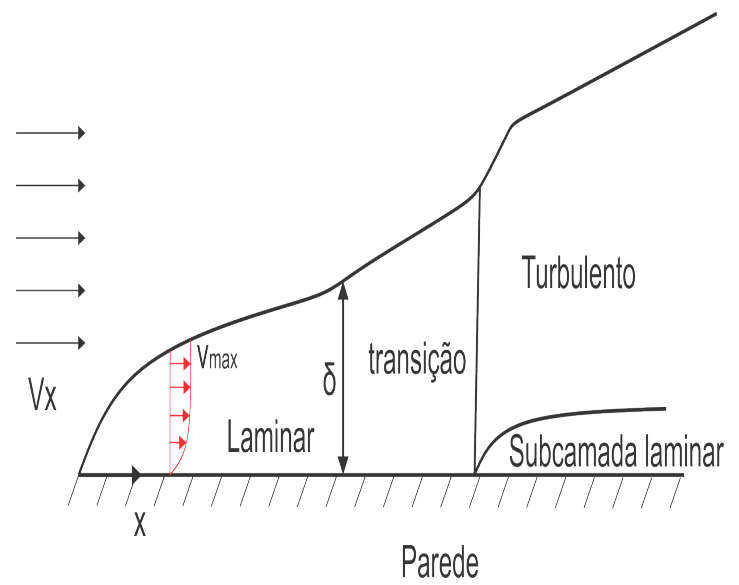

Figura 2.6: Desenvolvimento da camada limite em uma placa plana

É interessante mencionar que os esforços mais críticos são registrados próximo a região de afloramento da camada limite, conforme Matos et al. (1999) e Gomes et al. (2005). Os núcleos cavitacionais chegam à fronteira sólida através de grandes estruturas turbilhonares que migram para o interior da camada limite, conforme descrito em Arndt (2002).

Baseado em uma análise estatística de previsão de pressões, Amador (2005) sugere vazões específicas para evitar a ocorrência de cavitação. O autor estipula que a velocidade máxima na região de desenvolvimento da camada limite não deve ultrapassar 15m/s (O estudo foi desenvolvido em degraus de 0,6 e 1,2m).

Se o perfil de velocidade é conhecido, as equações integrais da conservação da massa e da quantidade de movimento permitem prever a espessura da camada limite laminar que perde energia e fica mais espessa a medida que o escoamento se desenvolve (Potter and Wiggert, 2004). Alternativamente, com base em resultados experimentais, Tozzi (1992) e Chanson (1994) determinaram essa espessura relativamente à distância entre o seu início e o ponto de incepção de ar, para calhas escalonadas de declividade 1V:0,75H, obtendo expressões como a Equação (2.3).

$$
\frac{\delta}{L_{A}}=0,080\left(\frac{L_{A}}{k_{a}}\right)^{-0,233}
$$


$\delta$ é a espessura da camada limite no ponto incipiente (de fato é a profundidade do escoamento neste ponto), $L_{A}$ é a distância entre o início de desenvolvimento da camada limite e o ponto incipiente e $k_{a}$ é a altura da rugosidade, dada por: $k_{a}=h \cos (\phi)$, sendo $\phi$ a declividade do canal.

Neste trabalho de pesquisa o desenvolvimento da camada limite é investigado como consequência da aeração do escoamento.

\subsection{Modelos de estruturas de vertedores}

Chanson (2006) investigou as propriedades dos escoamentos em vertedouros escalonados com diferentes condições de entrada e relatou variações no desenvolvimento da camada limite de acordo com a geometria. Na sequência de seus desenvolvimentos, uma estimativa prévia da velocidade residual do escoamento foi desenvolvida. Porém, diversos questionamentos ainda precisam ser elucidados.

Chanson (2006) abordou duas configurações de entrada envolvendo o perfil de ogiva, sendo que em uma das configurações a geometria envolve uma redução no tamanho dos primeiros degraus, conforme mostram as Figuras 2.7(a) e 2.7 (b). A terceira configuração envolvia uma entrada pressurizada, de forma que a pressão nessa região era maior que a pressão hidrostática, Figura 2.7(c). A última configuração substitui o perfil de ogiva por uma entrada horizontal com distribuição hidrostática da pressão, conforme mostra a Figura 2.7(d).

Em suas discussões, Chanson (2006) ressalta que a configuração de entrada altera todo o campo de velocidade, influência no posicionamento do ponto de início da aeração e afeta as propriedades do regime de escoamento do tipo skimming (deslizamento sobre vórtices). De forma geral, parece que o ponto de início da aeração se localiza mais a jusante com entradas pressurizadas e que, nesse caso, gera espessuras de jato menores. Entretanto, mais dados são necessários para concluir corretamente acerca dessas características. Chanson (2006) ainda supõe que as diferenças entre as diversas entradas aumentam a medida que o número de Froude do escoamento de entrada aumenta. Mais uma vez, essas proposições devem ser testadas 
para verificar sua validade geral.

Neste trabalho de pesquisa, os vertedores escalonados com entrada em crista foram avaliados em condições de regimes operacionais diferenciados, no que tange às características fluido-dinâmicas e de transporte de ar nesses escoamentos.

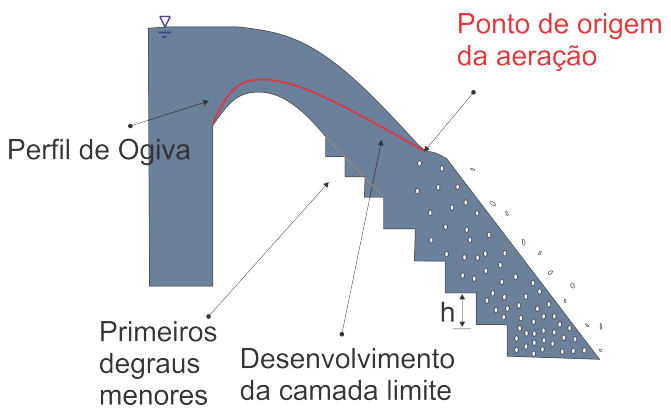

(a) Perfil de Ogiva com os primeiros degraus em tamanho reduzido.

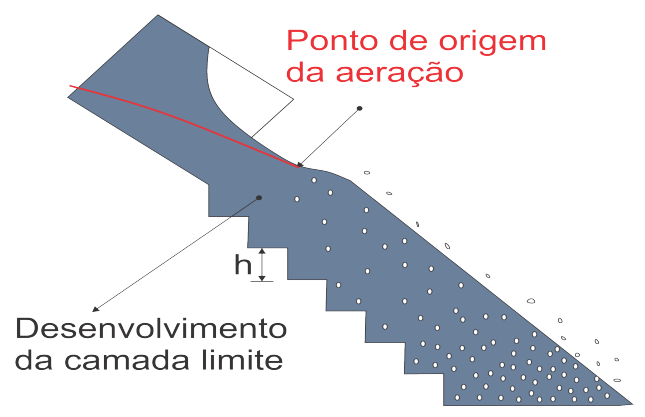

(c) Pressurizada.

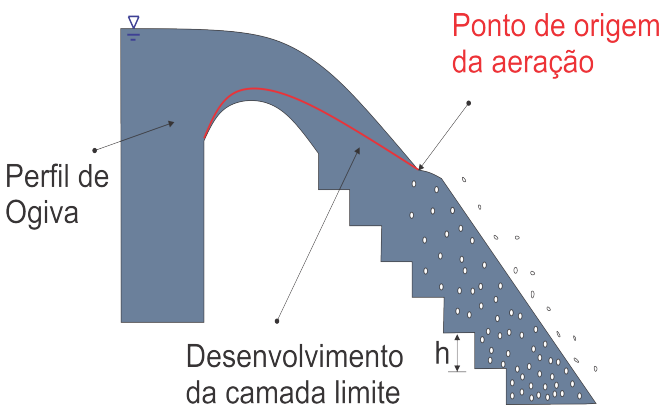

(b) Perfil de Ogiva.

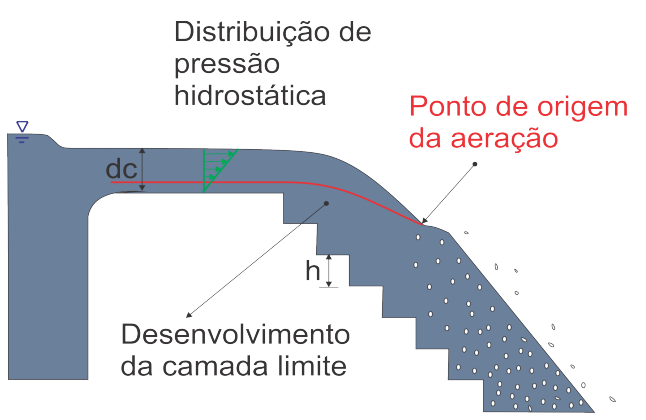

(d) Distribuição de pressão hidrostática.

Figura 2.7: Perfis de entrada no vertedouro

\subsection{Artifícios numéricos}

Simulações que possuem superfície livre agregam um grau de dificuldade maior para caracterização do escoamento porque a localização da superfície não é previamente conhecida. Essa região exige uma malha suficientemente refinada e um alto número de iterações. Os contínuos avanços computacionais e numéricos permitem avaliar o escoamento sobre estruturas hidráulicas e otimizar as condições operacionais do projeto tanto no aspecto estrutural quanto no aspecto fluido dinâmico. Pode-se ressaltar que a utilização dessas ferramentas vem crescendo continuamente 
em aplicações da engenharia de recursos hídricos, conforme apontado por Arantes et al. (2010b) e Chen et al. (2002).

Muitos autores já mencionaram que uma das características mais importantes de um escoamento turbulento é a multiplicidade de escalas que o caracteriza (ver, por exemplo, Silveira Neto (2007)). A observação de um escoamento turbulento mostra que as menores instabilidades podem gerar instabilidades sobre si mesmas. Esse processo apenas é compensado em espaços bem reduzidos, quando a viscosidade amortiza as instabilidades. As instabilidades, ou as escalas nas quais essas se desenvolvem, representa o número de graus de liberdade do escoamento, sendo este número estimado em função do número de Reynolds. Sabe-se que a análise de um problema turbulento passa pela solução de sistemas lineares compostos por um número de equações igual ou número de graus de liberdade, representado por $\mathrm{Ngl}$.

$$
N g l=\left(\frac{L}{l_{d}}\right)^{3}=R e_{L}^{9 / 4}
$$

Neste contexto $L$ é o maior comprimento característico do escoamento, $l_{d}$ é o menor comprimento característico desse escoamento e Re é o número de Reynolds. Dessa forma é possível constatar que até mesmo sistemas com baixo número de Reynolds são inviáveis de serem resolvidos em todos os graus de liberdade. Em outras palavras, o número de nós de uma malha numérica, que iguala $N g l$, ainda é excessivamente alto. Ainda que sejam utilizados super computadores, o custo computacional é excessivo.

Segundo Rodi (1994), no escoamento em um canal plano com $R e=10^{5}$ o número de pontos na malha deve ser da ordem de $10^{9}$ e se o número de Reynolds aumentar para $R e=10^{6}$ o número de pontos aumenta para $10^{12}$. Para minimizar as incapacidades numéricas de processamento, processos de decomposições das equações foram propostos, através da análise do comportamento médio do escoamento e modelagem de suas flutuações. Esse procedimento é geralmente conhecido como modelagem da turbulência com equações de fechamento. Neste contexto os fenômenos de turbulência podem ter duas abordagens principais usadas na simulação 
de escoamentos turbulentos, a determinística e a estatística. A primeira abordagem possui um custo computacional muito elevado, o LES (Large Eddy Simulation) requerendo malhas computacionais muito refinadas. A segunda abordagem tem sido amplamente utilizada na literatura mostrando ser capaz de simular importantes características do escoamento turbulento. Esta abordagem teve inicio numa proposta de Reynolds (Decomposição de Reynolds), onde as variáveis instantâneas do escoamento turbulento são representadas pela soma de um valor médio no tempo e um flutuante.

Para os termos não lineares surge uma nova incógnita ao sistema de equações originais denominada tensões de Reynolds. As divergências dos fluxos turbulentos que aparecem nas equações do movimento e de transporte de escalares, quando escritas a Reynolds, são termos não lineares que precisam de modelos "heurísticos"para fechar o sistema de equações. Muitos modelos "heurísticos" são encontrados na literatura de turbulência, e um grande número desses modelos de turbulência estão disponíveis no software OpenFoam que foi utilizado para as simulações computacionais, conforme descrito no Capítulo 3.

Dentre os modelos de turbulência encontra-se o tradicional modelo k $\epsilon$ e suas variações. O uso das equações de movimento e transporte, juntamente com os modelos de turbulência, exige cuidados especiais junto aos contornos devido ao problema de diferentes escalas do processo físico. Por exemplo, as equações de média de Reynolds necessitam de uma discretização apropriada na fronteira ou na camada limite, exigindo elementos com uma razão de aspecto adequada (Lohner, 2008).

O desenvolvimento da camada limite tem o papel primordial na relação entre as tensões de cisalhamento e consequente ruptura da superfície livre. Um número de Reynolds grande, associado a pequena viscosidade cinemática da água é suficiente para considerar o escoamento completamente turbulento. Quase todo escoamento com superfície livre é turbulento e ao longo das estruturas hidráulicas de grande declividade o escoamento está diretamente associado a uma grande dissipação de energia e altas velocidades. 


\subsection{Tratamento da interface entre dois fluidos}

Alternativas recentes tem sido propostas para a representação de escoamentos com superfície livre, dentre elas, os chamados Smoothed Particle Hydrodynamics. A facilidade da metodologia de simulação sem o uso de malha agrega benefícios na diminuição do custo computacional e elimina as dificuldades de otimização da malha. Entretanto, esse método ainda apresenta dificuldades no que diz respeito a geometria do problema (Pelo menos em versões disponibilizadas gratuitamente, dentre elas podemos citar Gómez-Gesteira et al. (2010)). Não podendo ser importada através de um arquivo de desenho (CAD), a geometria deve ser criada através de um arquivo de texto com as respectivas coordenadas. Essa limitação dificulta a simulação de problemas físicos com geometrias mais complexas.

Dentre os métodos de tratamento da interface entre dois fluidos, encontra-se o método de Volume de fluido (VOF) atualmente utilizado pelo solver interFoam do OpenFoam, solver do qual fez-se uso neste trabalho de pesquisa (Lobosco et al., 2011c).

Novas abordagens desses métodos de tratamento da interface vem sendo investigadas, e estão em fase de implementação através de pesquisas científicas inclusive no próprio OpenFoam. Quando desenvolvidas em softwares privados ou de acesso restrito, muitas vezes esses aprimoramentos numéricos não se tornam imediatamente disponíveis para uso comercial ou científico.

Através de alterações de métodos originais de coalescência Coyajee and Boersma (2009) sugeriram uma metodologia otimizada de interação entre os métodos de Level-Set e Volume de fluido (VOF) com uma precisão de segunda ordem. Com essa metodologia, a espessura do filme pode ser muito menor do que o raio da gota, dependendo apenas do tamanho da gota e das propriedades dos fluidos. A representação dessa espessura de filme exige um extremo refinamento da malha. Como alternativa à exigências da malha, ferramentas numérica de remalhagem adaptativa são sugeridas. Entretanto, a remalhagem contribui ainda mais para um aumento na complexidade numérica da representação do fenômeno físico. Os métodos tradici- 
onais de captura da interface não são capazes de representar a colisão entre gotas porque quando a interface entre elas colide, as gotas são automaticamente acopladas através do chamado fenômeno de coalescência numérica.

Através dessa nova funcionalidade numérica Coyajee and Boersma (2009) evitaram a coalescência numérica de gotas e da interface multifásica sem exigir um excessivo refinamento da malha no local. O método numérico implementado foi comparado com resultados experimentais de Kassim and Longmire (2003) e com resultados numéricos propostos em Esmaeeli and Tryggvason (1999). A validação da implementação numérica garantiu um aprimoramento na representação dos efeitos de tensão superficial da interface multifásica. As escalas de tempo da coalescência de gotas ainda não são muito bem definidas na literatura e requerem aprimoramento.

No caso do interFoam, o método de volume de fluido com correções no tratamento da interface através de uma aproximação do método de Simulação Numérica Direta, apresenta benefícios com relação aos métodos tradicionais.

\subsection{Do contexto geral}

Encerra-se este capítulo reposicionando o trabalho no contexto da modelagem da interface entre dois fluidos (ar e água). As características do escoamento e algumas propriedades dos modelos numéricos foram apresentadas baseando-se na experiência de algumas das principais referências da literatura sobre o assunto, Chanson (1997), Sarfaraz et al. (2012), Chakib (2013) e Wang-ru et al. (2013).

Com o intuito de prosseguir no entendimento do processo de coalescência e ruptura de gotas em escoamentos multifásicos, este projeto de pesquisa pretende conduzir novas análises para prever o comportamento das gotas, de forma a definir uma escala característica do enlaçamento de ar pela água através dos perfis de concentração de ar ao longo do escoamento na estrutura hidráulica. Com o avanço e aprimoramento dos métodos numéricos maiores precisões podem ser alcançadas pelos resultados computacionais. 


\section{TEORIA E MÉTODOS}

Este capítulo traz uma abordagem teórica dos fenômenos físicos e do tratamento computacional e busca definir matematicamente o problema. Do ponto de vista teórico, são descritos os princípios fundamentais dos escoamentos em vertedores. Do ponto de vista computacional, são adotados métodos e algoritmos capazes de reproduzir os fenômenos físicos.

\subsection{Abordagem adotada}

Hipóteses simplificadoras precisam ser adotadas para que o estudo e simulação da aeração possa ser realizado. Dentre outras hipóteses podemos descrever:

- Escoamento médio unidimensional;

- Escoamento isotérmico;

- A estrutura hidráulica é de pequeno porte;

- Canal de declividade $(\alpha)$ constante ao longo do eixo longitudinal (x);

- Canal prismático, retangular, com fundo coincidente com o pseudo-fundo;

- A fase gasosa é tratada como um gás ideal;

- A fase líquida é tratada como fluido incompressível e tem comportamento de fluido newtoniano. 


\subsection{Formulação do problema e equações governantes}

$\mathrm{Na}$ forma integral as equações de conservação podem ser deduzidas a partir de uma superfície de controle, conforme a Figura (3.1).

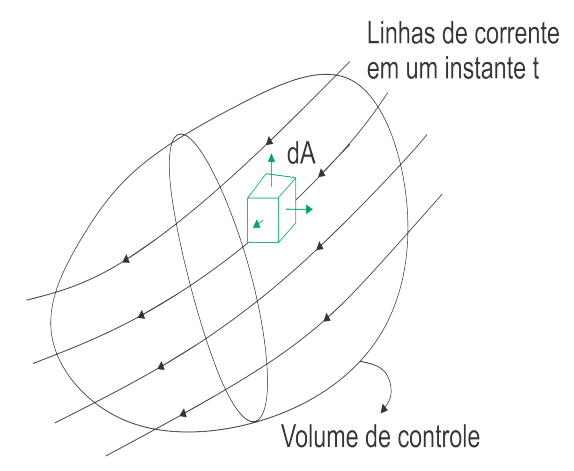

Figura 3.1: Volume de controle

\subsubsection{Conservação da massa}

A taxa de acúmulo de massa no volume de controle é representado pela Equação (3.1).

$$
\frac{\partial}{\partial t} \iiint_{V} \rho d V
$$

O fluxo líquido de massa na superfície de controle é dado pela Equação (3.2) que representa a variação da massa no volume de controle. Esta é obtida a partir da integração na superfície de controle.

$$
-\iint_{s} \rho \vec{v} \hat{n} d A
$$

Na integração, é considerada apenas a componente normal porque esta é a única superfície em que entra e sai massa do volume de controle.

O sinal negativo é apenas uma convenção para consistência entre entrada e saída, Bird and Stewart (1997). Considerando o fluxo líquido e a taxa de acúmulo é possível escrever a variação da massa contida no volume de controle, 
Equação (3.3), que é a Equação da conservação da massa em sua forma integral conservativa.

$$
\frac{\partial}{\partial t} \iiint_{V} \rho d V=-\iint_{s} \rho \vec{v} \hat{n} d A
$$

A única hipótese adotada até então na formulação matemática, é o tratamento do volume de controle como um meio contínuo. A hipótese do contínuo é a consideração de que o meio fluido é um meio contínuo, Potter and Wiggert (2004). Esta hipótese assume que o fluido é dividido por partículas suficientemente pequenas de forma que todas as suas propriedades, como temperatura e densidade, sejam consideradas uniformes. Entretanto as partículas devem ser consideradas grande o suficiente para que exista um número razoável de moléculas colidindo umas com as outras e com objetos sólidos.

Para casos em que a hipótese do contínuo não é válida, métodos de mecânica estatística devem ser utilizados porque toda a abordagem clássica da mecânica dos fluidos, simplesmente não é válida.

Através da aplicação do teorema de Green ou teorema da divergência é possível escrever a Equação (3.3) na forma diferencial da conservação da massa. Pelo teorema da divergência de Gauss, conforme Bird and Stewart (1997), sendo $\vec{f}$ uma função da posição e do tempo e $v$ uma região delimitada no espaço, tem-se que: $\vec{f}=f$ (posição,tempo) e logo:

$$
\iint_{s}(\vec{f} \hat{n}) d s=\iiint_{V}(\nabla \vec{f}) d V
$$

Sendo $\alpha$ um escalar é possível afirmar que:

$$
\iint_{s}(\alpha \vec{f} \hat{n}) d s=\iiint_{V}(\nabla \alpha \vec{f}) d V
$$

Após a aplicação do teorema da divergência a Equação (3.3) torna-se:

$$
\frac{\partial \rho}{\partial t}+\nabla(\rho \vec{v})=0
$$

Ao utilizar o conceito de derivada material ou seja, de acompanhamento do fluido no volume de controle, obtêm-se que a derivada material é igual a soma da variação 
em um ponto fixo e a variação do acompanhamento do fluido, Equação (3.7).

$$
\frac{D \rho}{D t}=\frac{\partial \rho}{\partial t}+\vec{v} \cdot \nabla \rho
$$

Ao substituir o conceito de derivada material e usar a propriedade distributiva é possível escrever a Equação da conservação da massa na forma diferencial não conservativa, Equação (3.8).

$$
\frac{D \rho}{D t}+\rho \nabla \vec{v}=0
$$

O conceito de equação conservativa está associado ao fato das variáveis da equação diferencial parcial estarem dentro das derivadas, Versteeg (1995). Uma solução analítica não sofre interferência da forma em que as equações diferenciais foram escritas. Entretanto, um resultado numérico apresenta variações de acordo com a representação das equações diferenciais.

\subsubsection{Conservação da quantidade de movimento}

A equação da quantidade de movimento é dada pela segunda lei de Newton. Ou seja, a força resultante que age em um sistema é igual a taxa de variação da quantidade de movimento do sistema quando medida em um referencial inercial.

O somatório de todas as forças que age no volume de controle inclui as forças de superfície resultantes do meio circundante, que agem sobre a superfície de controle, e as forças de massa, resultante de campos gravitacionais e magnéticos.

$$
\sum \vec{F}=\frac{d}{d t}(m \vec{v})
$$

A Figura (3.2) demonstra as tensões que atuam em um elemento de fluido. As tensões podem ser de dois tipos: normais ou tangenciais, também chamadas de tensão de cisalhamento. Por convenção, um componente de tensão é positivo se a tensão e o vetor normal externo a superfície de ação seguirem ambos a mesma orientação dos eixos, seja ela positiva ou negativa. 


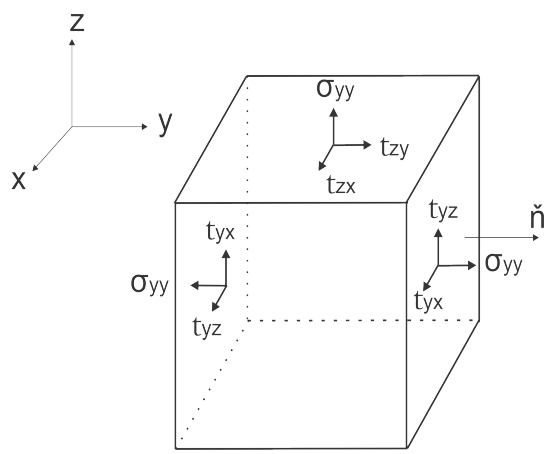

Figura 3.2: Tensões atuantes em um elemento diferencial de fluido

Em termos de nomenclatura o primeiro sub-índice da tensão indica a direção normal ao plano e o segundo indica a direção de atuação. Dessa forma o tensor de tensões que representa a tensão em um ponto de um elemento fluido é dada pela Equação (3.10).

$$
\check{T}=\left[\begin{array}{ccc}
\sigma_{x x} & \tau_{x y} & \tau_{x z} \\
\tau_{y x} & \sigma_{y y} & \tau_{y z} \\
\tau_{z x} & \tau_{z y} & \sigma_{z z}
\end{array}\right]
$$

No fluido em repouso existem apenas as tensões normais que são idênticas em todas as direções, $\sigma_{x x}=\sigma_{y y}=\sigma_{z z}=-p$. Dessa forma, a Equação (3.11) representa o tensor de tensões de um fluido em repouso, sendo $I$ a matriz identidade.

$$
\check{T}=-p \check{I}
$$

Para um fluido em movimento as tensões normais possuem valores diferentes de acordo com a componente ou seja, $\sigma_{x x} \neq \sigma_{y y} \neq \sigma_{z z}$. Neste caso as tensões de cisalhamento também estão presentes no fluido e o tensor de tensões é escrito conforme a Equação (3.12).

$$
\check{T}=-\bar{p} \check{I}+\check{\tau}
$$

O $\bar{p}$ é dado pela expressão da Equação (3.13), sendo $\lambda$ uma propriedade do fluido considerada segunda viscosidade. Para os gases $\lambda=-2 / 3 \mu$ e como os líquidos são 
incompressíveis $\nabla \vec{v}=0$

$$
-\bar{p}=-p+\lambda \nabla \vec{v}
$$

$\mathrm{Na}$ forma integral não conservativa o elemento diferencial acompanha o fluido e não sofre variação no volume de controle (abordagem lagrangiana), descrita pela Equação (3.14).

$$
\frac{D}{D t} \iiint_{V} \rho \vec{v} d V=0
$$

A partir do teorema de Reynolds é possível transformar a equação da forma conservativa para a forma não conservativa. A variação da quantidade de movimento é dada pela Equação (3.15).

$$
\frac{\partial}{\partial t} \iiint_{V} \rho \vec{v} d V=-\iint_{s} \rho \vec{v}(\vec{v} \cdot \hat{n}) d s-\iint_{s} P \hat{n} d s+\iint_{s} \tilde{\tau} \hat{n} d s+\iiint_{V} \rho f d V
$$

Como a pressão absoluta é sempre positiva, esta sempre tem um sentido contrário a $\hat{n}$. Os dois últimos termos da Equação (3.15) representam as forças de campo, em que $\iint_{s} \tilde{\tau} \hat{n} d s$ é o termo das tensões de cisalhamento e $\iiint_{V} \rho f d V$ representa por exemplo, a gravidade.

Através do teorema da divergência é possível passar da forma integral para a forma diferencial, utilizada em fluido dinâmica computacional, Equação (3.16).

$$
\frac{\partial(\rho \vec{v})}{\partial t}+\nabla(\rho \vec{v} \vec{v})=-\nabla P+\nabla \tau+\rho \vec{f}
$$

Novamente foi apenas adotada a hipótese do volume de controle ser um meio contínuo.

Em um fluido Newtoniano as tensões viscosas são proporcionais às taxas de deformação. Dessa forma ao representar as tensões de cisalhamento por tensões normais, acrescenta-se a hipótese de fluido newtoniano e a equação da quantidade de movimento passa também a ser chamada de Equação de Navier-Stokes, que pode ser escrita conforme a Equação (3.17).

$$
\check{\nabla} \vec{v}=\frac{1}{2}\left[\check{\nabla} \vec{v}+\check{\nabla} \vec{v}^{T}\right]
$$


A matriz dos tensores em sua forma normal é dado pela Equação (3.18), e em sua forma transposta pela Equação (3.19).

$$
\begin{gathered}
\check{\nabla \vec{v}}=\left[\begin{array}{lll}
\frac{\partial v_{x}}{\partial x} & \frac{\partial v_{x}}{\partial y} & \frac{\partial v_{x}}{\partial z} \\
\frac{\partial v_{y}}{\partial x} & \frac{\partial v_{y}}{\partial y} & \frac{\partial v_{y}}{\partial z} \\
\frac{\partial v_{z}}{\partial x} & \frac{\partial v_{z}}{\partial y} & \frac{\partial v_{z}}{\partial z}
\end{array}\right] \\
\check{\nabla} \vec{v}^{T}=\left[\begin{array}{lll}
\frac{\partial v_{x}}{\partial x} & \frac{\partial v_{y}}{\partial x} & \frac{\partial v_{z}}{\partial x} \\
\frac{\partial v_{x}}{\partial y} & \frac{\partial v_{y}}{\partial y} & \frac{\partial v_{z}}{\partial y} \\
\frac{\partial v_{x}}{\partial z} & \frac{\partial v_{y}}{\partial z} & \frac{\partial v_{z}}{\partial z}
\end{array}\right]
\end{gathered}
$$

Para fluido newtoniano, o tensor de tensões é dado por $\check{T}=-p \check{I}+2 \mu \check{D}$. Os termos da matriz simétrica $\check{D}$ estão escritos nas Equações (3.20).

$$
\begin{aligned}
D_{x x} & =\frac{1}{2}\left(2 \frac{\partial v_{x}}{\partial x}\right)=\frac{\partial v_{x}}{\partial x} \\
D_{x y} & =\frac{1}{2}\left(\frac{\partial v_{x}}{\partial y}+\frac{\partial v_{x}}{\partial x}\right)=D_{y x} \\
D_{x y} & =\frac{1}{2}\left(\frac{\partial v_{x}}{\partial z}+\frac{\partial v_{z}}{\partial x}\right)=D_{z x} \\
D_{y y} & =\frac{1}{2}\left(2 \frac{\partial v_{y}}{\partial y}\right)=\frac{\partial v_{y}}{\partial y} \\
D_{z z} & =\frac{\partial v_{z}}{\partial z} \\
D_{y z} & =\frac{1}{2}\left(\frac{\partial v_{y}}{\partial z}+\frac{\partial v_{z}}{\partial y}\right)=D_{z y}
\end{aligned}
$$

Se os efeitos viscosos e os efeitos de troca de calor forem desprezados, exceto por convecção, a equação da quantidade de movimento passa a ser chamada de equação de Euler. Na camada limite existem efeitos viscosos significativos. Entretanto se a camada limite for fina e não houver descolamento, a equação de Euler pode ser utilizada.

Também é possível transitar entre a forma integral e diferencial da equação da energia. Como este trabalho de pesquisa adota a hipótese de escoamento isotérmico, o balanço da conservação da energia não será aqui explicitado. 
Em fluido dinâmica computacional a grande dificuldade não está em resolver as equações diferenciais, mas em ter uma boa discretização do domínio que seja capaz de representar os fenômenos turbulentos que causam problemas de escala às simulações.

Após as respectivas abordagens físicas e matemáticas para representar a mistura ar-água e as características a que esse trabalho se propõe, o modelo de volumes finitos é aplicado na discretização das equações de conservação de massa e de quantidade de movimento. Dessa forma, investigações a respeito da transferência de massa na interface gás-liquido podem ser realizadas.

\subsection{Abordagem multifásica}

Considerando a validade de princípios físicos da conservação de massa e da quantidade de movimento, aplicar-se-á um modelo multifásico de forma a representar as diferentes fases ou misturas dos fluidos presentes no escoamento (Versteeg, 1995). O método de Euler determina as grandezas características do campo do escoamento em função do tempo, na superfície de controle e no volume de controle. Já os modelos multifásicos lagrangeanos estudam o comportamento individual de cada molécula ou partícula em um sistema isolado (Gómez-Gesteira et al., 2010). Os modelos multifásicos eulerianos são divididos em dois grupos: homogêneo e não homogêneo. No modelo homogêneo, as equações que representam o escoamento são resolvidas de forma compartilhada para todos os fluidos, o que torna menor o número de equações a serem resolvidas. Em um modelo não-homogêneo, cada fluido possui um sistema de equações representativas. As interações entre as fases são calculadas por meio de um termo de transferência. A modelagem das fases gasosa e líquida através de conceitos eulerianos homogêneos impede a distinção entre a ocorrência de cada fase, fornecendo uma concentração volumétrica de fases que reflete uma média volumétrica e temporal de sua ocorrência (Versteeg, 1995).

Simulações que possuem superfície livre agregam um grau de dificuldade maior para caracterização do escoamento porque a localização da superfície não 
é previamente conhecida, Idelsohn and Oñate (1994) e Zienkiewicz (1991). Essa região exige uma malha suficientemente refinada e um alto número de iterações. Este projeto de pesquisa utiliza o método de volume de fluido (VOF) para captura da interface e assume dois fluidos imiscíveis, ar e água. Um indicador escalar alpha é usado para definir o volume do fluido 1 , denotado por $V_{1}$, em cada elemento. Dessa forma, $V_{2}$ (o volume do segundo fluido) é simplesmente $1-\alpha$. Como alpha é também a fração de volume da célula ocupada por um determinado fluido temos que $\alpha=V_{1} / V$. O valor unitário corresponde à célula cheia de um determinado fluido enquanto o valor nulo indica que a célula não contém esse fluido. Células com valores entre zero e um representam que existe a interface. O acompanhamento da interface ar-água é dado pela solução da equação da continuidade, Equação (3.7).

\subsection{Abordagem numérica de escoamentos turbulentos}

O tratamento analítico ainda possui níveis extremamente reduzidos de solução para escoamentos turbulentos. A complexidade e aleatoriedade das flutuações de velocidade é que causam esta dificuldade. As alternativas comumente utilizadas são dados experimentais utilizados em um tratamento semi-teórico.

Em termos computacionais existem duas abordagens principais usadas na simulação de escoamentos turbulentos, a determinística e a estatística. A primeira abordagem possui um custo computacional muito elevado, como os modelos DNS (Direct Numerical Simulation) e o LES (Large Eddy Simulation) que requerem malhas computacionais muito refinadas. A segunda abordagem tem sido amplamente utilizada na literatura e mostra-se capaz de simular importantes características do escoamento turbulento através do uso de computadores de pequeno porte. Esta abordagem teve início em uma proposta de Reynolds (Decomposição de Reynolds), em que as variáveis instantâneas do escoamento turbulento são representadas pela soma de um valor médio no tempo e um flutuante (Schulz, 2003). Para os termos não lineares surge uma nova incógnita ao sistema de equações originais denominada tensões de Reynolds. 
As divergências dos fluxos turbulentos que aparecem nas equações do movimento e de transporte de escalares, quando escritas a Reynolds, são termos não lineares que precisam de modelos para fechar o sistema de equações. Modelos de turbulência $\mathrm{k}-\epsilon$ não lineares que representam um avanço sobre modelos de viscosidade turbulenta clássicos (linear), serão aqui empregados para o domínio computacional, exceto na interface.

O regime turbulento é mais encontrado na prática, não apenas porque ocorre em velocidades elevadas, mas também porque promove transferência de calor e massa (Patankar, 1982). A turbulência consiste num espectro de diferentes escalas sendo que a maior escala é da ordem da geometria do escoamento e as menores escalas são determinadas pelas forças que dissipam a energia e à transforma em interna. Segundo Silveira Neto (2007), a ordem das pequenas escalas está associada à energia interna. A interação entre gradiente de velocidade e vorticidade de um escoamento é o que cria a turbulência e à mantém. É na migração do regime laminar para o turbulento que os distúrbios são ampliados e passam a ser flutuações randômicas e tri-dimensionais (Potter and Wiggert, 2004).

Embora a turbulência seja descrita como caótica, ela é determinada pelas equações de Navier-Stokes (Bird and Stewart, 1997). Todo escoamento turbulento é altamente dissipativo. No processo de dissipação a energia cinética é transformada em energia interna. Durante um escoamento, energia é transmitida de forma que as grandes escalas forneçam energia para o escoamento, que por sua vez, transmite energia às escalas menores (Lohner, 2008). Este é o processo que transforma as instabilidades turbulentas em um fenômeno recursivo. A conhecida escala de Kolmogorov é definida como a menor escala em que a dissipação de energia ocorre. Como, durante um escoamento, parte da energia cinética passa a ser destruída pelas forças viscosas, a determinação das escalas da turbulência depende da viscosidade cinemática e da quantidade de energia dissipada $\epsilon$. 


\subsubsection{Abordagem de Média de Reynolds}

Na abordagem de média de Reynolds, as variáveis são divididas em uma parte independente do tempo que representa uma média temporal, e em uma parte flutuante. Considerando uma variável qualquer $\zeta$ o somatório do termo médio com o termo de flutuação pode ser escrito como $\zeta=\bar{\zeta}+\zeta^{\prime}$. O termo da média é definido conforme a Equação (3.21).

$$
\bar{\zeta}=\frac{1}{t} \int_{0}^{t} \zeta d t
$$

Essa decomposição é feita quando o interesse é nos valores das variáveis e não em suas variações temporais. As quantidades flutuantes possuem média nula em relação ao tempo conforme pode ser deduzido pelas Equações (3.22).

$$
\left\{\begin{array}{l}
\bar{\zeta}=\frac{1}{t} \int_{0}^{t}\left(\bar{\zeta}+\zeta^{\prime}\right) d t \\
\bar{\zeta}=\bar{\zeta}+\overline{\zeta^{\prime}} \\
\log o \overline{\zeta^{\prime}}=0
\end{array}\right.
$$

Ao considerar duas variáveis genéricas $\eta$ e $\psi$ tem-se que a média da soma é a soma das médias $\overline{\eta+\psi}=\bar{\eta}+\bar{\psi}$, mas o mesmo não ocorre com o produto, ou seja, não vale, de forma geral, a igualdade $\overline{\eta \cdot \psi}=\bar{\eta} \cdot \bar{\psi}$. Vale ressaltar que sendo $\bar{\eta}$ e $\bar{\psi}$ nulos, não necessariamente $\overline{\eta \psi}$ será nulo (Versteeg, 1995).

Ao considerar ainda $n$ uma coordenada espacial tem-se que a média da diferencial é a diferencial da variável média, Equação (3.23).

$$
\frac{\overline{\partial C}}{\partial n}=\frac{\partial \bar{C}}{\partial n}
$$

Esse é um artifício utilizado para simplificar a solução numérica das equações de Navier Stokes.

Pela decomposição das variáveis a Equação da conservação da massa para escoamento incompressível, $\nabla \cdot \vec{v}=0$, pode ser escrita conforme a Equação (3.24). 


$$
\left(\frac{\partial \overline{v_{x}}}{\partial x}+\frac{\partial \overline{v_{y}}}{\partial y}+\frac{\partial \overline{v_{z}}}{\partial z}\right)=0
$$

A hipótese do contínuo ainda é valida no tratamento da turbulência porque ainda que as escalas de um escoamento turbulento sejam pequenas, esta ainda é muito maior que a escala molecular. O tensor de tensões turbulentas (ou de Reynolds), Equação (3.25) é obtido após as seguintes etapas: Substituição das variáveis de pressão e velocidade pela soma de um termo médio com um termo flutuante nas equações de Navier Stokes (fluido newtoniano em regime incompressível); Aplicação das propriedades matemáticas anteriormente descritas.

$$
\check{T}=\left[\begin{array}{ccc}
\sigma_{x x} & \tau_{x y} & \tau_{x z} \\
\tau_{y x} & \sigma_{y y} & \tau_{y z} \\
\tau_{z x} & \tau_{z y} & \sigma_{z z}
\end{array}\right]=\left[\begin{array}{ccc}
-\rho\left(\overline{v_{x^{\prime}}}\right)^{2} & -\rho \overline{v_{x^{\prime}} v_{y^{\prime}}} & -\rho \overline{v_{x^{\prime}} v_{z^{\prime}}} \\
-\rho \overline{v_{y^{\prime}} v_{x^{\prime}}} & -\rho\left(\overline{v_{y^{\prime}}}\right)^{2} & -\rho \overline{v_{y^{\prime}} v_{z^{\prime}}} \\
-\rho \overline{v_{z^{\prime}} v_{x^{\prime}}} & -\rho \overline{v_{z^{\prime}} v_{y^{\prime}}} & -\rho\left(\overline{v_{z^{\prime}}}\right)^{2}
\end{array}\right]
$$

O tensor de tensões turbulentas compõe o segundo termo da Equação (3.17) anteriormente chamado de $\check{\Omega}$.

O termo referente as tensões de Reynolds é um tensor simétrico, mas como este é desconhecido, surge o chamado "problema de fechamento" em que o número de variáveis desconhecidas é maior do que o número de equações do sistema a ser resolvido. Na resolução de problemas isotérmicos de fluidos newtonianos pela abordagem de média de Reynolds (em que são resolvidas apenas as equação da continuidade e de Navier Stokes escrita para as componentes médias e flutuantes) surgem as seguintes incógnitas: três componentes da velocidade, a pressão e seis tensões. Na próxima secção encontram-se descritos alguns métodos que podem ser utilizados como modelos de fechamento.

\subsubsection{Modelos de fechamento}

Conforme descrito anteriormente, os produtos de flutuações de velocidade acrescentam a necessidade de modelos "ad hoc"que permitam quantificá-los. Esta secção descreve alguns modelos gerais que podem ser usados nas equações de 
média de Reynolds em sua forma tridimensional. Alguns destes modelos estão baseados na hipótese de Boussinesq e as tensões de Reynolds são calculadas através de uma relação entre as tensões, o gradiente de velocidade e a viscosidade turbulenta. Outros modelos como o Algébrico e o não linear, usam apenas o conceito de viscosidade turbulenta. A hipótese proposta por Boussinesq em 1877 introduz o conceito de viscosidade turbulenta baseado na viscosidade laminar, Equação (3.26).

$$
\tau_{i j}=-\rho \overline{v_{i^{\prime}} v_{j^{\prime}}}=\mu_{t}\left(\frac{\partial \overrightarrow{v_{i}}}{\partial x_{j}}+\frac{\partial \overrightarrow{v_{j}}}{\partial x_{i}}\right)
$$

Conforme enumerado em Versteeg (1995) existem as seguintes classificações de modelos de turbulência:

- Modelos algébricos:

Os modelos algébricos são também conhecidos como modelos de comprimento de mistura. Fazem uso de uma equação algébrica para calcular a viscosidade turbulenta em cada ponto. Entretanto, não consideram a produção, transporte ou dissipação da turbulência por considera-lá em equilíbrio local. O modelo é de fácil implementação numérica, entretanto não apresenta alta precisão.

- Modelos de uma equação:

Nestes modelos a equação de transporte é geralmente resolvida para energia cinética turbulenta. Obtém o comprimento da escala turbulenta à partir de uma expressão algébrica e a viscosidade turbulenta é calculada pela hipótese de Boussinesq.

- Modelo de duas equações:

O transporte de dois escalares (por exemplo a energia cinética turbulenta $k$, e a taxa de dissipação $\varepsilon$ ) é descrita por duas equações de transporte. O tensor de tensões de Reynolds é calculado através de uma hipótese que relaciona o tensor com o gradiente da velocidade e com viscosidade turbulenta.

- Modelos de tensões de Reynolds:

Uma das equações de transporte é derivada do tensor de Reynolds e a outra 
equação é adicionada para determinar o comprimento da escala da turbulência. Em geral, uma equação é utilizada para a dissipação epsilon.

A complexidade, a capacidade de modelamento e o custo em termos computacionais aumentam nos modelos de turbulência descritos acima, na mesma ordem em que foram listados. Com os avanços computacionais, é possível priorizar cada vez mais por modelos mais precisos. Com respeito aos modelos de fechamento, o custo de implementação dos modelos mais sofisiticados, tem um aspecto mais relevante do que o aumento em termos de processamento. O mesmo não ocorre com relação ao tratamento da interface, por exemplo.

A representação do tensor de tensões turbulentas, considerando $k$ a energia cinética turbulenta é dado pela Equação (3.27).

$$
\check{T}^{t u r b}=-\frac{2}{3} \rho k I+\check{\tau}^{t u r b}
$$

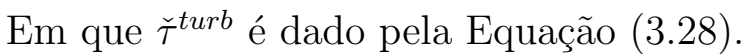

$$
\check{\tau}^{t u r b}=2 \mu_{t} \check{D}
$$

O modelo $k-\varepsilon$ de duas equações apesar de só tratar turbulência isotrópica, é bastante utilizado em aplicações de problemas multifásicos e tem apresentado resultados satisfatórios para esse tipo de solução (Versteeg, 1995). O modelo é válido para escoamentos completamente turbulentos. As escalas da turbulência presentes no escoamento são diretamente influenciadas pelo valor da energia cinética turbulenta $k$ de forma análoga, a taxa de dissipação $\varepsilon$ é dependente das escalas turbulentas. Dessa forma, existe um acoplamento para o cálculo das variáveis que permitem calcular a viscosidade turbulenta local, Equação (3.29).

$$
\mu_{t}=C_{\mu} \frac{k}{\varepsilon}
$$

As equações de transporte adicionadas para as variáveis são respectivamente as Equação (3.30) e (3.31). 


$$
\begin{gathered}
\frac{D k}{D t}=\frac{\partial}{\partial x_{j}}\left[\left(\mu+\frac{\mu_{t}}{\sigma_{k}}\right) \frac{\partial k}{\partial x_{j}}\right]+2 \mu_{t} \overline{\tau_{i j}} \overline{\tau_{i j}}-\varepsilon \\
\frac{D \varepsilon}{D t}=\frac{\partial}{\partial x_{j}}\left[\left(\mu+\frac{\mu_{t}}{\sigma_{\varepsilon}}\right) \frac{\partial \varepsilon}{\partial x_{j}}\right]+C_{1 \varepsilon} \frac{\varepsilon}{k}-2 \overline{\tau_{i j}} \overline{\tau_{i j}}-C_{2 \varepsilon} \frac{\varepsilon^{2}}{k}
\end{gathered}
$$

As cinco constantes do modelo $k-\varepsilon$ estão listadas na Tabela 1.

\begin{tabular}{|c|c|c|c|c|}
\hline$C_{\mu}$ & $C_{1 \varepsilon}$ & $C_{2 \varepsilon}$ & $\sigma_{k}$ & $\sigma_{\varepsilon}$ \\
\hline \hline 0,09 & 1,44 & 1,92 & 1,0 & 1,3 \\
\hline
\end{tabular}

Tabela 1: Constantes empíricas do modelo $k-\varepsilon$.

\subsection{Ferramentas computacionais}

O estudo de escoamentos em vertedouros escalonados envolve características bi-fásicas e hidrodinâmicas complexas, sendo necessário lançar mão de ferramentas computacionais. O software de CFD selecionado para a investigação do escoamento em vertedouros em degraus é denominado OpenFoam (Open Field Operation and Manipulation) (OpenFOAM, 2012) e é produzido pela OpenCFD ltda. Além de ser gratuito, este software vem recebendo contribuições contínuas da comunidade científica que necessitava de uma ferramenta aberta, capaz de incorporar as contribuições decorrentes dos problemas estudados nos mais diferentes países. O pré-processamento no OpenFoam consiste na definição dos arquivos que contém as condições de contorno e demais controles das simulações, das propriedades físicas e dos modelos adicionais do problema.

Uma das interfaces menos desenvolvidas para esta ferramenta aberta é o software de geração de malhas. Neste sentido, uma dificuldade inerente ao OpenFoam é gerar malhas em geometrias complexas. Assim, também foi adotado o software de análise estrutural gratuito denominado Salome, desenvolvido pela Open Cascade. 
O software Salome, (Salome, 2012) permite que a malha gerada seja exportada para o OpenFoam, tendo uma interface gráfica amigável e de fácil utilização. Uma funcionalidade adicional que o software Salome agrega à etapa de pré-processamento é a possibilidade da geometria e da malha serem criadas através da execução de um script escrito na linguagem de programação Python. Essa capacidade do software implica em facilidades relevantes quando se fazem necessárias modificações consecutivas da geometria estudada ou da própria malha.

Com exceção do solver do OpenFoam, o release de versões das demais ferramentas não interfere diretamente no resultado numérico. Todos os resultados numéricos aqui apresentados foram processados pela versão 2.1.0 do OpenFoam.

Os resultados das simulações são visualizados e analisados no Pósprocessador do OpenFoam, denominado ParaFoam, que é uma versão do software livre ParaView produzido pela Kitware Inc.

A Tabela (2) descreve as ferramentas que foram utilizadas para cada etapa do processo de simulação deste projeto de pesquisa e suas respectivas versões. Entretanto, ao longo do desenvolvimento deste trabalho ocorreram algumas migrações de versões preliminares para as mais recentes.

Tabela 2: Ferramentas utilizadas no processo de simulação do escoamento.

\begin{tabular}{||ccc||}
\hline Etapa & Procedimento & Ferramenta \\
\hline Pré-Processamento & Criação da Geometria & Salome 5.4 \\
& Geração da Malha & Salome 5.4 \\
Solver & Solução do problema & OpenFoam 2.1.0 \\
Pós-Processamento & Visualização dos resultados & ParaFoam 2.1.0 \\
Análise de resultados & Plotagem de dados & GnuPlot 4.2 \\
Ambiente de desenvolvimento & Linux & OpenSuSe 12.1 \\
\hline
\end{tabular}

Por serem códigos abertos, os softwares mencionados permitem que alterações sejam feitas no código fonte e que novas funcionalidades sejam implemen- 
tadas. Esse fato garantiu que qualquer limitação apresentada pelos softwares para representação dos problemas a serem simulados fosse suprida através de novas implementações. Vale ainda frisar que já existia, na literatura, algum relato de investigação de escoamento em estruturas hidráulicas como vertedores com o uso do OpenFoam, conforme pode ser visto, por exemplo, em Jacobsen (2009). Detalhes sobre o uso das ferramentas computacionais são descritas no Anexo I.

\subsection{Equipamentos de Hardware}

A disponibilidade de equipamentos para o desenvolvimento desse projeto de pesquisa não foi apenas um fator beneficiante em termos de custo computacional, mas foi preponderante para que as simulações fossem realizadas. Sem a posse do mesmo, a utilização de máquinas com configurações tradicionalmente simplificadas apresentaram incapacidades de memória Ram para processamento numérico. Esse projeto fez uso do cluster do Laboratório de Reologia e Turbulência que pertence ao Departamento de Hidráulica na Escola de Engenharia de São Carlos. O computador possui 24 processadores que foram utilizados em paralelo, o que permitiu que os 64GB de Ram fossem distribuídos. A possibilidade de multiprocessamento com armazenamento dos dados em uma mesma máquina serviu como facilitador para que os resultados não precisassem ser transmitidos para outros computadores. Além do risco de perda de informação durante a transmissão de dados, essa operação consumiria um tempo significativo, uma vez que o tamanho da memória para armazenamento das simulações é bastante excessivo.

\subsection{Método numérico e forma de discretização}

O método de volumes finitos é o método numérico mais usado em Fluido Dinâmica Computacional. A interpretação física do método e a sua formulação conservativa, torna-o adequado para a resolução de equações diferenciais de leis conservativas, como as da fluidodinâmica (Gomes et al., 2005). 
O algoritmo PISO (Pressure-Implicit with Splitting of Operator) é utilizado como método de aclopamento pressão-velocidade. O algoritmo pode ser utilizado no software OpenFoam para problemas transientes e está baseado em procedimentos iterativos, capazes de avaliar a solução num dado instante de tempo e corrigi-la (Hemida, 2008).

Como critério de estabilidade é utilizado o número de Courant que caracteriza a extensão relativa das oscilações numéricas. O adimensional é uma variável local do domínio fluido que representa o fluxo advectivo em cada volume. Por definição o número de Courant é representado conforme a Equação (3.32).

$$
C o=\frac{B_{i} \Delta T}{\Delta x_{i}}
$$

Em que $\Delta T$ é o incremento de tempo, $\Delta x_{i}$ é o comprimento característico de um elemento da malha e $B_{i}$ é o termo convectivo (velocidade) da equação de transporte.

Um dos critério de convergência mais comum para obtenção de precisão física e estabilidade do cálculo é o parâmetro CFL, Courant-Friedrichs-Lewy. Este parâmetro é a condição de limitação do número de Courant, ou seja, é um multiplicador do passo de tempo que fornece um Número de Courant igual à unidade. Um cálculo transiente explícito (sem iterações no espaço) exige que o Número de Courant de cada volume da malha seja no mínimo inferior à unidade em todo o domínio.

Dessa forma, uma das maneiras de garantir que um modelo seja estável, é garantir que a distância percorrida durante o passo de cálculo do modelo seja inferior à dimensão das células do mesmo, ou seja, inferior à resolução com que o espaço é resolvido no modelo. Deste modo, $\Delta T$ tem que ser tão menor quanto for o $\Delta x_{i}$.

A Tabela (3.7) descreve os esquemas numéricos que foram utilizadas no processo de simulação.

O único esquema de discretização que existe disponível no solver para o cálculo do gradiente, divergente e laplaciano é o esquema de discretização de Gauss. Na escolha de discretização dos termos laplacianos, $\nabla(\mu \nabla U)$ é preciso especificar 
também um esquema para a discretização do gradiente normal à superfície $\nabla U$ no diretório ControlDict do OpenFoamß).

\subsection{Condições de contorno}

Os problemas de Fluido dinâmica computacionais são definidos através de condições iniciais e de contorno. As condições iniciais são necessárias apenas aos problemas transientes e representam informações da solução no instante de tempo zero. Pela discretização das equações no método de volumes finitos as condições de contorno são basicamente dos seguintes tipos: Entrada, saída, parede, simetria, distribuição de pressão, periodicidade. A condição de periodicidade é utilizada para a simplificação de problemas cíclicos, esta condição de contorno não foi usada nas simulações realizadas neste trabalho. As demais condições encomtram-se descritas nos próximos sub-items. Vale ressaltar que as regiões são préviamente definidas na geometria, etapa preliminar a geração da malha.

\subsubsection{Condição de parede}

Em problemas turbulentos a interação entre o fluido e a parede tem uma importância significativa porque é onde existem grandes gradientes de velocidade que geram intensa turbulência. Fora dessa região os efeitos convectivos são muito mais importantes que as tensões viscosas. Entretanto, dentro da camada limite os

Tabela 3: Esquemas numéricos utilizados no processo de simulação do escoamento.

\begin{tabular}{||ccc||}
\hline Termo & Esquema & Discretização \\
\hline Derivada temporal $\frac{\partial}{\partial t}$ & Euler & Primeira ordem \\
Gradiente $\nabla$ (termo difusivo) & Gauss linear & Segunda ordem \\
Divergente $\nabla$ (termo convectivo) & Gauss linear & Segunda ordem \\
Laplaciano, $\nabla^{2}$ & Gauss linear & Primeira ordem \\
Gradiente normal à superfície, $\nabla U$ & Corrigido & Segunda ordem \\
\hline
\end{tabular}


termos convectivos da equação de Navier-Stokes podem ser desprezados.

A chamada região de difusão viscosa (região da subcamada) é extendida da parede até aproximadamente a região chamada de 5 unidades de parede, ou seja $y^{+} \approx 5$. É justamente nessa subcamada viscosa que os maiores gradientes de velocidade ocorrem. A complexidade do escoamento próximo a parede faz com que o tamanho da malha computacional influencie na condições de contorno, conforme mostra a Equação (3.33). O índice + representa à unidades de parede, $u_{*}$ é a velocidade de fricção na parede e $\nu$ é a viscosidade cinemática.

$$
y^{+}=\frac{y u_{*}}{\nu}
$$

Quando o domínio computacional é muito grande, o que normalmente ocorre em problemas da engenharia hidráulica quando simulados em tamanho real, a malha próximo a parede se torna pouco refinada e a condição de não deslizamento é adotada. Ao adotar a condição de escorregamento nulo, a componente normal da velocidade é zero. Isso facilita, por exemplo, a definição das condições de contorno em problemas viscosos. Mas para que a condição de deslizamento seja aplicada, a distância do primeiro nó até a parede deve ser de no máximo, $y^{+} \approx 1$, e isso traz grandes restrições ao tamanho da malha. Dessa forma, essa condição, quando aplicada exige que um modelo de turbulência de baixo Reynolds seja usado porque os modelos implementados para escoamentos turbulentos completamente desenvolvidos não são aplicáveis à região próxima à parede.

Como alternativa ao refinamento exessivo na região da parede existem as chamadas leis de parede. Estas permitem que o $y^{+}$esteja na faixa de $30 \leq y^{+} \geq$ 100. Neste caso o campo de velocidade próximo à parede não é resolvido e o campo de velocidade é calculado pela lei logaritmica da parede, Equação (3.34). $\bar{u}_{t}$ é a componente da velocidade paralela à parede, $y$ é a distância normal à parede, $u_{*}$ é a velocidade de cisalhamento, $k$ é a constante de von Kármán e $E$ é o parâmetro da rugosidade.

$$
\bar{u}_{t}=\frac{u_{*}}{k} \ln \left(\frac{y u_{*} E}{\nu}\right)
$$


Dessa forma as tensões de cisalhamento são calculadas pela velocidade de cisalhamento na parede $\tau_{\omega}=\rho u_{*}{ }^{2}$.

\subsubsection{Tratamento numérico da superfície livre}

Quando a fronteira externa não coincide com a superfície do corpo, a ideia é posicionar o domínio computacional dentro de uma grande malha com um tratamento especial dos elementos e pontos próximos a superfície.

Como a malha não é coformal ela não precisa se mover e as equações diferenciais parciais que descrevem o escoamento podem ser tratadas na forma euleriana até mesmo para superfícies móveis. Em cada passo de tempo os elementos e pontos próximos ou dentro da superfície imersa são identificados e a condição de contorno própria é aplicada.

De forma geral, o tratamento da camada limite, por si só, exige uma malha mais refinada. Já para problemas de superfície livre, algumas técnicas computacionais como a remalhagem adaptativa podem otimizar o processo de localização da interface, entretanto agregam um custo computacional significativo. No OpenFoam todas as simulações de superfície livre podem ser vistas como uma simulação numerica direta, DNS, devido ao fato da aproximação por média de Reynolds não tratar realisticamente a camada "infinitamente" fina entre o ar e a água. Esse tratamento traz exigências de refinamento da malha e utiliza o método de volume de fluido, VOF. Nessa abordagem de captura da interface, as partículas do fluido são consideradas deformáveis e o acompanhamento da superfície pode ser modelado. Um único campo de escoamento é considerado e a fase dispersa se distingue da contínua pelas variações das propriedades do fluido através da interface (Hemida, 2008).

Através do uso do solver InterFoam do OpenFoam foi possível tratar a interface entre os dois fluidos como uma Simulação Numérica Direta enquanto as demais partes do domínio computacional foram tratadas por um modelo de turbulência $(K-\varepsilon)$. Dessa forma o solver permitiu caracterizar a ruptura da interface e quantificar a entrada de ar no escoamento. Na sequência, pôde-se investigar a 
evolução dos perfis de concentração e o nível de aeração ao longo do escoamento na estrutura escalonada. Este procedimento representa um avanço bastante relevante no estudo de aeração superficial em estruturas escalonadas.

\subsubsection{Condição de simetria}

A condição de simetria reduz o processo de simulação, permitindo que através de um processo de espelhamento apenas metade do domínio computacional tenha a solução processada.

\subsubsection{Condição de entrada}

Como condição de entrada optou-se por um fluxo de entrada na região inferior à montante do escoamento para que a altura da coluna de água não precisasse ser previamente definida, mas que fosse parte da solução processada. No OpenFoam não existe disponível uma condição de contorno que permita que a entrada seja função da solução do problema.

\subsubsection{Condição de saída}

Em geral, a condição de saída em um escoamento é definida através da extrapolação das propriedades. Ou seja, em geral é considerada uma condição de contorno de segundo tipo.

\subsubsection{Distribuição da pressão}

A condição de distribuição de pressão é a condição que permite simular a coluna de água em instantes anteriores a abertura da comporta de uma barragem. Ela permite o processo de simulação de entrada com distribuição de pressão hidrostática. As condições de contorno e suas aplicações na geometria encontram-se ilustradas na Figura 3.3. 


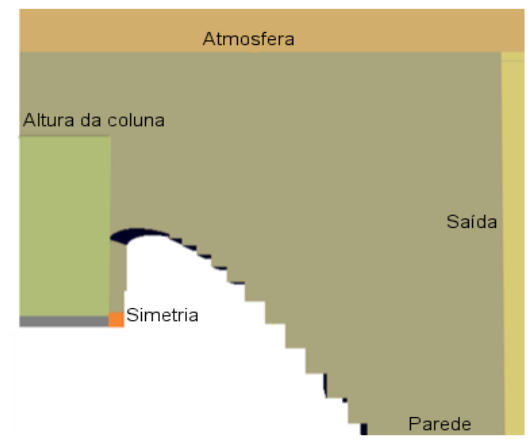

Figura 3.3: Condições de contorno

\subsection{Conceitos de coerência em solução numérica}

Uma análise de estabilidade numérica deve considerar o erro de truncamento, que está baseado na forma de discretização, e o erro de arredondamento, que está relacionado à precisão do software. O crescimento do erro de arredondamento pode gerar instabilidades porque ele é cumulativo e cresce com o número de utilizações daquele valor arredondado. No processo de verificação da convergência da malha não é necessário uma investigação do erro da solução, basta verificar o valor das variáveis. Vale lembrar que as condições de contorno são parâmetros que influenciam diretamente na precisão do código. 


\section{FORMULAÇÃO TEÓRICA}

O estudo das interfaces entre o ar e uma mistura de ar e água, a assim chamada "água branca" em escoamentos multifásicos, não possui nem uma formulação definitiva, nem uma conceituação definitiva que vincule quantitativamente o ar que é enlaçado pelo líquido e as características do escoamento, no tocante, por exemplo, à expansão da coluna de água derivada desta mistura.

Podem ser mencionados aqui estudos que consideram o perfil de concentração na água (por exemplo, Chanson (2006) e Meireles et al. (2007)), ou estudos numéricos que consideram essa possibilidade (Sarfaraz et al. (2012) e Sabbagh-Yazdi et al. (2008)), mas não há procedimentos que permitam vincular, por exemplo, a forma média da fronteira entre a mistura e o ar e localizar os parâmetros que auxiliam essa quantificação.

Talvez o estudo que tenha apresentado os resultados mais promissores seja aquele originado na linha de pesquisa que também contém o presente trabalho de doutorado. Considera-se aqui a publicação Schulz et al. (2011), que trás a explanação de conceitos básicos anteriormente apresentados por Schulz and Simões (2011), mas que gerou o primeiro resultado descritivo da interface atmosfera/escoamento bifásico, que será denominada aqui mais brevemente de interface "ar/mistura". Esta publicação foi originária de um esforço em avaliar uma possível forma para a interface. O presente estudo consistiu o entorno no qual a idéia foi desenvolvida. 


\subsection{Formulação teórica unidimensional para a forma da su- perfície}

Inicialmente vale lembrar as considerações básicas efetuadas por Schulz and Simões (2011) para obter uma formulação na forma de uma "lei básica" para o enlaçamento de ar. Este parâmetro foi quantificado considerando a taxa de enlaçamento de vazios, ou a taxa de geração de vazios, indicada por $\stackrel{c}{c}$ e com dimensão de $s^{-1}$. A Figura 4.1 apresenta as principais características que levaram ao estabelecimento da equação básica.
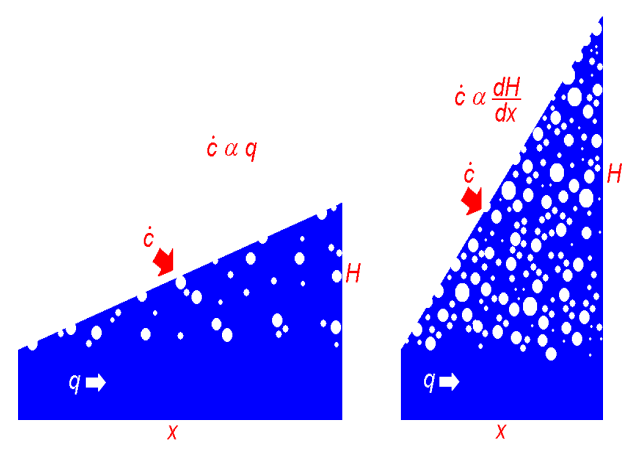

Figura 4.1: Parâmetros considerados no estabelecimento da equação básica de enlaçamento de vazios (enlaçamento de ar).

A figura mostra esquematicamente que uma interface ar/mistura pode apresentar diferentes declividades. Inicialmente, mantendo uma declividade constante, infere-se que a taxa de enlaçamento $\stackrel{\circ}{c}$ será tanto maior quanto mais água passar carregando o ar que entrou. Isso implica que se pode sugerir uma proporcionalidade entre $\stackrel{\complement}{c}$ e a vazão de água passante $Q$. Eventualmente, dependendo da situação estudada, também pode-se considerar a vazão específica $q$ (vazão por unidade de largura do canal, que foi o parâmetro utilizado por Schulz and Simões (2011) e Schulz et al. (2011). Ou seja, tem-se:

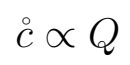

Em um segundo estágio, mantendo a vazão constante, pode-se inferir 
que a mistura expandirá mais se mais ar for enlaçado pelo escoamento. Expandir mais implica em aumentar a profundidade da mistura, ou seja, em termos de proporcionalidade,

$$
\stackrel{\circ}{\complement} \propto H
$$

Mas também é evidente, com o mesmo argumento, que a taxa de enlaçamento será tanto maior quanto menor for o comprimento necessário para aumentar a profundidade, ou seja, em termos de proporcionalidade,

$$
\stackrel{\circ}{\propto} \frac{1}{\triangle x}
$$

Seguindo os procedimentos usuais nesse tipo de abordagem, como mostrado em Schulz (2003), o produto dessas proporcionalidades, considerando uma região pequena (um "ponto" na superfície), produz:

$$
\stackrel{\circ}{\llcorner} Q \frac{d H}{d x}
$$

Finalmente, introduzindo uma constante de proporcionalidade, $K$, tem-se

$$
\stackrel{\circ}{c}=K Q \frac{d H}{d x}
$$

Esta constante mede a facilidade com que a interface permite o enlaçamento de ar (ou a geração de vazios) pode ser função, por exemplo, da posição ao longo do escoamento. A sua dimensão é $m^{-3}$ (no sistema SI).

Evidencia-se que esta equação lembra as leis básicas utilizadas em Fenômenos de Transporte e em outras áreas das ciências aplicadas, por exemplo, conforme apresentado na Tabela 4.

A Equação (1) da Tabela 4 representa o fluxo de massa, a Equação (2) representa o fluxo de calor, a Equação (3) representa o fluxo de quantidade de movimento, a Equação (4) representa o fluxo volumétrico de água em aquíferos (velocidade) e a Equação (5) representa o fluxo elétrico em um condutor. Em cada equação as variáveis possuem significados específicos e os coeficientes multiplicativos dos gradientes são "constantes" de proporcionalidade. Esse conjunto de equações mostra 
que há uma analogia bastante grande entre a presente formulação (Equação 4.5) e aquelas existentes na literatura para os equacionamentos básicos de transporte.

Essas equações básicas podem ser utilizadas isoladamente, isto é sem equações auxiliares. Entretanto, é mais comum estarem vinculadas a pelo menos um princípio de conservação, derivado dos princípios básicos da mecânica racional. No presente estudo considerou-se o princípio da conservação de massa, expresso pela assim denominada "equação de advecção e difusão de massa", na forma:

$\frac{\partial C}{\partial t}+u \frac{\partial C}{\partial x}+v \frac{\partial C}{\partial y}+w \frac{\partial C}{\partial z}=\left[\frac{\partial}{\partial x}\left(D_{T} \frac{\partial^{2} C}{\partial x^{2}}\right)+\frac{\partial}{\partial y}\left(D_{T} \frac{\partial^{2} C}{\partial y^{2}}\right)+\frac{\partial}{\partial z}\left(D_{T} \frac{\partial^{2} C}{\partial z^{2}}\right)\right]+\stackrel{\circ}{p}$

Em que $C$ é a concentração mássica. $x, y$ e $z$ são componentes das coordenadas

Tabela 4: Leis básicas de conservação.

\begin{tabular}{|c|c|c|}
\hline$(1)$ & Lei de Fick & $\stackrel{\circ}{m}=-D \frac{d C}{d x}$ \\
\hline$(2)$ & Lei de Fourier & $\stackrel{\circ}{q}=-K \frac{d T}{d x}$ \\
\hline$(3)$ & Lei da Viscosidade de Newton & $\tau=\mu \frac{d V_{x}}{d y}$ \\
\hline$(4)$ & Lei de Darcy & \\
\hline$(5)$ & Lei de Ohm diferencial & $j=\frac{1}{\rho} \frac{d V}{d x}$ \\
& & \\
\hline
\end{tabular}


cartesianas. $u, v$ e $w$ componentes do vetor velocidade. $t$ é o tempo, $D_{T}$ é o coeficiente de difusão mássica e $\stackrel{p}{p}$ é o termo fonte.

Entende-se que se está trabalhando com as grandezas médias, o mesmo ocorrendo com a Equação (4.5). As Equação (4.5) e (4.6) foram aplicadas na região de expansão da mistura ar-água, após o ponto de início de aeração. Dessa forma, a região de aplicação foi idealmente considerada como aquela entre uma seção totalmente isenta de ar (água preta) e uma seção totalmente preenchida de mistura (água branca). Essa região de expansão corresponde àquela cujo comprimento é quantificado pelo "comprimento de transição" definido e medido em vários estudos desta linha de pesquisa, como em Schulz et al. (2011). Para vislumbrar a geometria dessa expansão fornece-se o esquema simplificado da Figura 4.2.

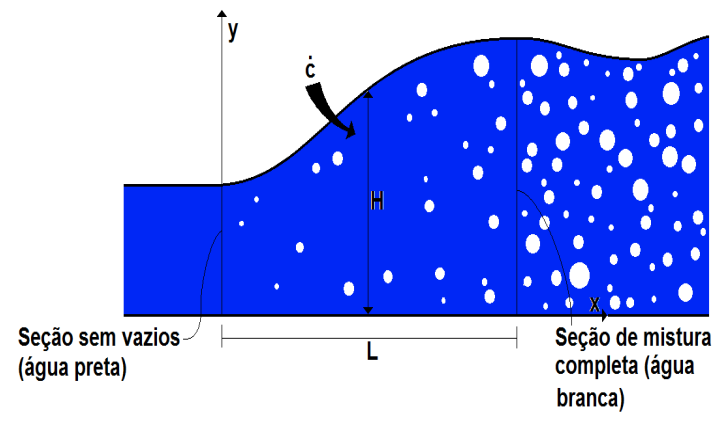

Figura 4.2: Condição de escoamento e geométrica considerada no presente estudo. As variáveis estão definidas e se trata de uma região de expansão vertical do escoamento.

A Equação (4.6) é considerada na sua forma unidimensional, na situação de regime permanente. Isto a simplifica para

$$
u \frac{\partial C}{\partial x}=\left[\frac{\partial}{\partial x}\left(D_{T} \frac{\partial C}{\partial x}\right)\right]+\stackrel{\circ}{p}
$$

Para que as soluções possam ser generalizadas, efetuou-se uma adimensionalização, apresentada em Schulz et al. (2011), porém os autores não detalharam as relações entre alguns dos parâmetros que foram utilizados. No presente texto esse detalhamento é apresentado.

Inicialmente considerou-se que o escoamento atinge uma situação de 
mistura completa, após percorrer o comprimento $L$ mostrado na Figura 4.2. Assim a dimensão $x$ foi adimensionalizada como:

$$
s=x / L
$$

Também a concentração de ar, $C$, foi adimensionalizada. Nesse caso, $C$ é fornecido originalmente como a massa de ar dividida pelo volume da mistura. $\mathrm{Na}$ presente formulação trabalhou-se com a fração de vazios, $\phi$, ou seja, o volume ocupado pelo ar dividido pelo volume da mistura (adimensional). Para que se possa converter uma variável na outra, utilizam-se as definições:

$$
\begin{gathered}
C=\frac{\text { Massa de ar }}{\text { Volume da mistura }}=\frac{\rho_{\text {ar }} \text { Volume de ar }}{\text { Volume da mistura }} \\
\phi=\frac{\text { Volume de ar }}{\text { Volume da mistura }}
\end{gathered}
$$

De (4.9) e (4.10) segue imediatamente que:

$$
C=\rho_{a r} \phi
$$

As Equações (4.7), (4.8) e (4.11) produzem:

$$
\frac{\partial \phi}{\partial s}=\frac{1}{u} \frac{\partial}{\partial s}\left(\frac{D_{T}}{L} \frac{\partial \phi}{\partial s}\right)+\frac{\stackrel{p}{p} L}{u \rho_{a r}}
$$

Nota-se que a velocidade encontra-se separada da razão $D_{T} / L$. O produto $D_{T} / u L$ é um parâmetro adimensional, mas a possibilidade de união das variáveis ainda deverá ser demonstrada. O termo que indica a produção de ar, ou seu enlaçamento, $\stackrel{p}{p}$, é quantificado pela Equação básica (4.5), evidamente adimensionalizada. Tem-se, inicialmente:

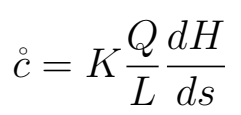

Também aqui é preciso considerar as Equações (4.9) e (4.10). A taxa $\stackrel{\circ}{p}$ é definida em $\mathrm{kg} \mathrm{m}^{-3} \mathrm{~s}^{-1}$, enquanto que $\stackrel{\circ}{c}$ é definido como $\mathrm{s}^{-1}$. Portanto, tem-se: 


$$
\stackrel{\circ}{p}=\stackrel{\circ}{c} \rho_{a r}
$$

Unindo as Equações (4.12), (4.13) e (4.14) resulta:

$$
\frac{\partial \phi}{\partial s}=\frac{1}{u} \frac{\partial}{\partial s}\left(\frac{D_{T}}{L} \frac{\partial \phi}{\partial s}\right)+\frac{K Q}{u} \frac{d H}{d s}
$$

Para avançar na adimensionalização e na solução, algumas relações entre as variáveis dependentes da Equação (4.15) devem ser antes estabelecidas. Considera-se inicialmente que toda a expansão da mistura é vertical. Ou seja, em enlaçando ar, a expansão se dará para cima, conforme mostra o esquema da Figura 4.3 .

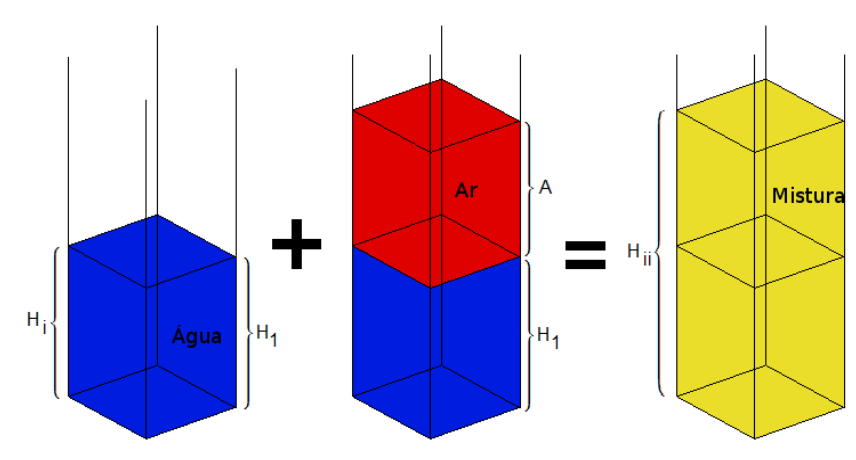

Figura 4.3: Expansão da coluna de água (mistura) com a inserção ou enlaçamento de ar. Toda a variação ocorre na dimensão vertical. Esta consideração é utilizada no equacionamento aqui apresentado.

Isto permite dizer que as frações volumétricas de ar e água são dadas, respectivemente, pelas equações a seguir:

$$
\begin{gathered}
\phi_{a r}=\frac{A}{H}=\frac{A}{A+H_{1}} \\
\phi_{\text {agua }}=\frac{H_{1}}{H}=\frac{H_{1}}{A+H_{1}}
\end{gathered}
$$

A massa específica da mistura é dada pela expressão:

$$
\rho=\frac{\text { massa de ar }+ \text { massa de agua }}{\text { volume da mistura }}=\frac{\rho_{a r} A+\rho_{\text {agua }} H_{1}}{H}
$$


Para duas posições $i$ e $i i$ no escoamento, a razão entre as massas específicas é, portanto:

$$
\frac{\rho_{i}}{\rho_{i i}}=\frac{\frac{\rho_{a r} A_{i}+\rho_{a g u a} H_{1}}{H_{i}}}{\frac{\rho_{a r} A_{i i}+\rho_{a g u a} H_{1}}{H_{i i}}}
$$

Como a massa específica do ar é sempre muito menor que a massa específica da água, isto é $\rho_{a r} \ll \rho_{a g u a}$, a Equação (4.19) se torna:

$$
\frac{\rho_{i}}{\rho_{i i}}=\frac{H_{i i}}{H_{i}}
$$

Considerando a equação da conservação de massa para a mistura, na região de expansão, em regime permanente, tem-se:

$$
\rho_{i} A_{i} u_{i}=\rho_{i i} A_{i i} u_{i i}
$$

Como a largura do canal é a mesma em ambas as seções, e considerando a Equação (4.20), a Equação (4.21) se torna:

$$
\rho_{i} H_{i} u_{i}=\rho_{i} \frac{H_{i}}{H_{i i}} H_{i i} u_{i i}
$$

A conclusão da Equação (4.22) é, portanto:

$$
u_{i}=u_{i i}=u
$$

Ou seja, a velocidade é constante na região considerada. A Equação (4.23) permite escrever a Equação (4.15) na forma:

$$
\frac{\partial \phi}{\partial s}=\frac{\partial}{\partial s}\left(\frac{D_{T}}{u L} \frac{\partial \phi}{\partial s}\right)+\frac{K Q}{u} \frac{d H}{d s}
$$

Vê-se que foi possível obter o parâmetro adimensional $D_{T} / u L$ na equação. Para que esta equação seja integrável é preciso ainda relacionar $H$ e $\phi$. Da Equação (4.16) tem-se que $\phi_{a r}=A / H^{\prime}$, ou, de forma mais simples, que $A=H \phi$. Sabendo que a soma das Equações (4.16) e (4.17) iguala a unidade (1), tem-se:

$$
1=\frac{H_{1}+A}{H}=\frac{H_{1}+H \phi}{H}
$$


A Equação (4.13) pode ser rearranjada, produzindo

$$
H=\frac{H_{1}}{1-\phi}
$$

$\mathrm{Ou}$

$$
\phi=1-\frac{H_{1}}{H}
$$

As Equações (4.24) e (4.26) produzem:

$$
\frac{\partial \phi}{\partial s}=\frac{\partial}{\partial s}\left(\frac{D_{T}}{u L} \frac{\partial \phi}{\partial s}\right)+\frac{K Q H_{1}}{u} \frac{\partial(1-\phi)^{-1}}{d s}
$$

$\mathrm{Ou}$

$$
\frac{\partial \phi}{\partial s}=\frac{\partial}{\partial s}\left(\frac{D_{T}}{u L} \frac{\partial \phi}{\partial s}\right)+\frac{K Q H_{1}}{u(1-\phi)^{2}} \frac{\partial \phi}{d s}
$$

A Equação (4.28) é uma equação governante para $\phi$, que pode ser integrada para casos simples dos coeficientes multiplicativos. No presente estudo alguns casos são considerados.

\subsubsection{Solução 1 - Impondo Coeficientes Constantes}

Schulz et al. (2011) apresentaram uma primeira integração da Equação (4.29) considerando constantes os parâmetros adimensionais $D_{T} / u L$ e $\frac{K Q H_{1}}{u(1-\phi)^{2}}$. No segundo parâmetro apenas $K$ pode variar, de forma que, para que o parâmetro seja constante, é preciso que $K=K^{\prime}(1-\phi)^{2}$.

Da Equação (4.26) tem-se que:

$$
1-\phi=\frac{H_{1}}{H}
$$

Portanto:

$$
K=K^{\prime}\left(\frac{H_{1}}{H}\right)^{2}
$$

Isto mostra que, com esta consideração, o coeficiente de transferência de ar na Equação (4.5) é inversamente proporcional à profundidade elevada ao quadrado. Esta possibilidade é fisicamente aceitável, uma vez que este coeficiente 
depende da turbulência, sendo a origem da turbulência o fundo do canal e sendo ela inibida enquanto difunde a partir da origem até a superfície. A Equação (4.29) foi então representada como:

$$
\frac{\partial \phi}{\partial s}=\theta_{1} \frac{\partial^{2} \phi}{\partial s^{2}}+\theta_{2} \frac{\partial \phi}{\partial s}
$$

Aqui se tem $\theta_{1}=D_{T} / u L$ e $\theta_{2}=\frac{K^{\prime} Q H_{1}}{u}$ (coeficientes adimensionais). Esta equação de segunda ordem é portanto linear com coeficientes constantes, podendo ser rapidamente integrada. Isto produz:

$$
\phi=\phi_{\infty}-\left(\phi_{\infty}-\phi_{0}\right) e^{-\left(\theta_{2}-1\right) s / \theta_{1}}
$$

Nesse caso, as condições de contorno utilizadas foram: Em s $=0, \phi=\phi_{0}$ e em $s \rightarrow \infty, \phi=\phi_{\infty}$. Definindo $I J=\left(\theta_{2}-1\right) / \theta_{1}$ e considerando $\phi_{0}=0$ tem-se:

$$
\phi=\phi_{\infty}\left(1-e^{-I J s}\right)
$$

Rearranjando:

$$
H=\frac{H_{1}}{1-\phi_{\infty}\left(1-e^{-I J s}\right)}
$$

As previsões obtidas com esta Equação (4.35) são mostradas nas Figu$\operatorname{ras} 4.4(\mathrm{a})$ e $4.4(\mathrm{~b})$.

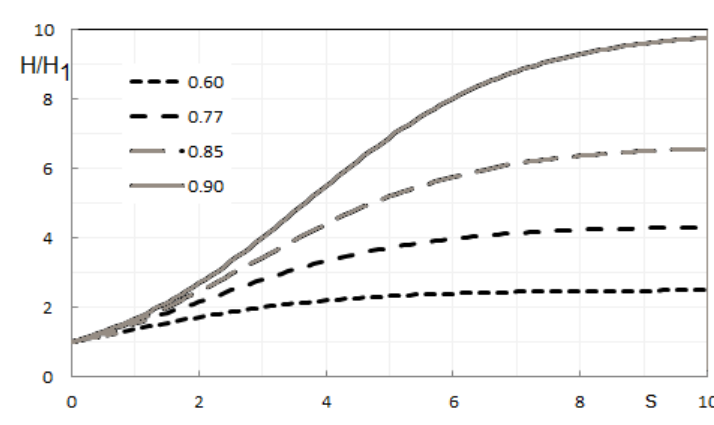

(a) Admensionalização $H / H_{1}$

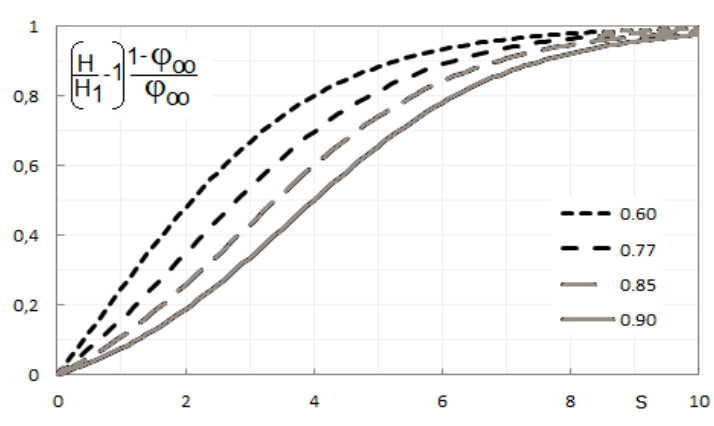

(b) Admensionalização $\left(H / H_{1}\right)-1$

Figura 4.4: Previsões obtidas com a Equação (4.35), em duas formas de adimensionalizar o eixo das ordenadas (profundidades adimensionalizadas). Adaptado de Schulz et al. (2011).

O comportamento previsto, de crescimento contínuo e podendo apresentar uma evolução sigmoide (em "S"), é observado em dados experimentais. A 
Figura 4.5 mostra dados obtidos na linha de pesquisa do presente estudo, gerados para verificar as possibilidades de previsão com os modelos teóricos propostos. Apesar da coincidência comportamental, ainda há aspectos a serem melhorados, uma vez que as previsões da Figura 4.4(b) mostram comprimentos cerca de dez vezes superiores (eixo das abscissas).

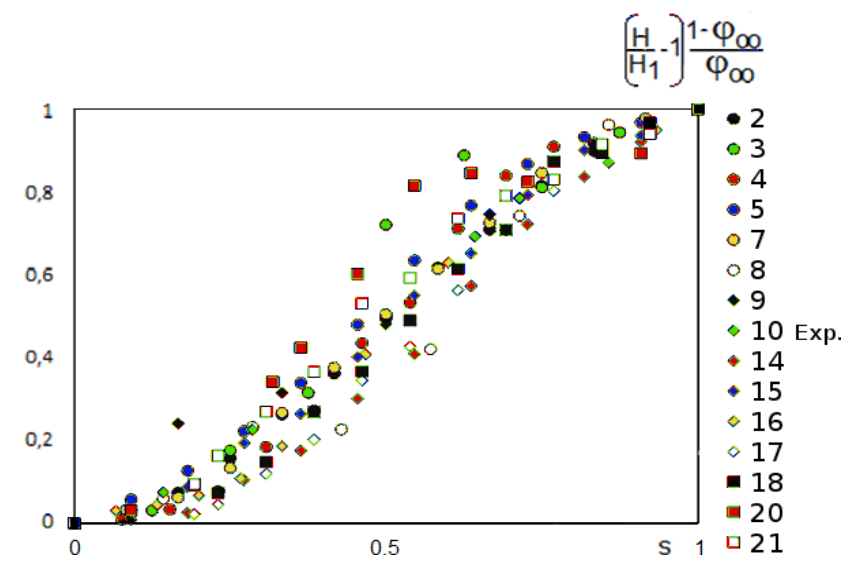

Figura 4.5: Dados de evolução de superfície coletados para o presente estudo, conforme relatados em Schulz et al. (2011). Em que Exp. representa o número do experimento efetuado.

\subsubsection{Solução 2 - Admitindo variação para o coeficiente $D_{T} / u L$}

Conforme Schulz et al. (2011) comentam, os coeficientes da Equação (4.24) não necessariamente são constantes ao longo do escoamento. As considerações, entretanto, que levaram à Equação (4.32), mostraram-se plausíveis fisicamente quanto à constância de $\theta_{2}=\frac{K^{\prime} Q H_{1}}{u}$. Assim, nesta segunda análise, este parâmetro foi também mantido constante. A Equação (4.24) passa, então, a ser escrita como:

$$
\frac{\partial \phi}{\partial s}=\frac{\partial}{\partial s}\left(\frac{D_{T}}{u L} \frac{\partial \phi}{\partial s}\right)+\theta_{2} \frac{\partial \phi}{\partial s}
$$

Uma vez que $u$ e $L$ são constantes (ver Equação 4.23), o único parâmetro que pode variar no coeficiente $D_{T} / u L$ é $D_{T}$, que representa um "coeficiente de dispersão interfacial". Não há ainda formas de evolução de $D_{T}$ com "s" que tenham 
sido estudadas para o problema de enlaçamento e transporte de bolhas (pelo menos que seja do conhecimento desta linha de pesquisa). Assim, admitiu-se aqui uma função de potência genérica. Como na origem já ocorre a captura de bolhas e sua inserção no escoamento, cuidou-se para que $D_{T}$ não fosse nulo em $s=0$. Note-se que o enlaçamento de ar pode ser compensado por perdas de bolhas de ar para a atmosfera ao longo do escoamento, podendo este parâmetro eventualmente também ser influenciado por esse fenômeno, vindo a anular-se. Mas aqui se tomou cuidado para que isto não ocorresse na origem. Matematicamente:

$$
D_{T}=D_{T o}(1+\alpha s)^{\beta}
$$

Nesta função de potência, $\alpha$ e $\beta$ são constantes adimensionais quaisquer (a serem determinadas empiricamente) e $D_{T o}$ é o valor de $D_{T}$ em $s=0$ (igualmente a ser determinado empiricamente). Com a definição (4.37) a Equação (4.36) passa a ser expressa como:

$$
\left.\frac{\partial \phi}{\partial s}=\frac{\partial}{\partial s}\left[\theta_{0}(1+\alpha s)^{\beta}\right) \frac{\partial \phi}{\partial s}\right]+\theta_{2} \frac{\partial \phi}{\partial s}
$$

Nesta equação $\theta_{o}=D_{T o} / u L$. Apesar dos coeficientes serem nãoconstantes, a Equação (4.38) continua sendo uma equação de segunda ordem linear, admitindo integração bastante simples. A primeira integração produz:

$$
\frac{\left(1-\theta_{2}\right)}{\theta_{o}} \phi+\gamma=(1+\alpha s)^{\beta} \frac{\partial \phi}{\partial s}
$$

$\mathrm{Ou}$

$$
\frac{\partial s}{(1+\alpha s)^{\beta}}=\frac{\partial \phi}{\frac{\left(1-\theta_{2}\right)}{\theta_{o}} \phi+\gamma}
$$

$\gamma$ é uma constante de integração. Para a situação $\beta \neq 1$, a segunda integração desta equação produz: 


$$
\phi=E\left[e^{\theta_{3}}\left[\frac{(1+\alpha s)^{1-\beta}-1}{\alpha(1-\beta)}\right]-1\right]
$$

Utilizou-se o contorno de que em $s=0$ tem-se $\phi=0$. O coeficiente $E$ envolve a nova constante de integração. $\theta_{3}$ é uma combinação das constantes anteriores, na forma:

$$
\theta_{3}=\frac{\left(1-\theta_{2}\right)}{\theta_{0}}
$$

Em princípio, não se pretende que a formulação se estenda a $s \rightarrow$ $\infty$, havendo apenas a necessidade de que valha para $0 \leq s \leq 1$. Uma análise do comportamento da Função (4.41) foi feita utilizando a sua derivada. Nesse caso, lembrando da Equação (4.26), que exprime $H$ como função de $\phi$ na forma $H=\frac{H_{1}}{1-\phi}$ e considerando a Figura (4.5), que mostra que em $s=1$ atinge-se uma situação de máximo para $H$, ou seja, a sua derivada é nula nessa posição, isto implica também que a derivada de $\phi$ é nula nesta posição. Para que isto ocorra, é preciso que:

- a constante $\beta$ seja negativa. Isto faz com que se use $\delta=1-\beta(\delta$ é positivo)

- a constante $\alpha$ seja $\alpha=-1$.

Adicionalmente, ainda considerando a análise da derivada da Função (4.41), o conteúdo de vazios deve crescer ao longo do escoamento, enquanto se avança sobre $s$ de 0 a 1 . Isto implica que a derivada dessa função deve ser positiva, o que também foi considerado para a posição $s=0$. Para que isto ocorra, é preciso que a constante $\theta_{3}$ seja negativa. A Equação (4.41) fica expressa como:

$$
\phi=E\left[e^{-\theta_{3}}\left[\frac{(1-s)^{\delta}-1}{\delta}\right]-1\right]
$$

Para utilizar menos variáveis sem sentido físico claro, vale ainda considerar que em $s=1$ tem-se um valor máximo de $\phi$, indicado por $\phi_{M}$. Lançando isto na Equação (4.43) resulta: 


$$
\phi=\phi_{M}\left[\frac{e^{-G[1-s]^{\delta}-1}-1}{e^{G}-1}\right]
$$

Na Equação (4.44) definiu-se $G=\theta_{3} / \delta$ (uma constante com valor negativo). Finalmente, para obter a variação da profundidade $H$ utiliza-se a Equação (4.26) em conjunto com a Equação (4.44), produzindo:

$$
H=\frac{H_{1}}{1-\phi_{M}\left[\frac{e^{-G\left[(1-s)^{\delta}-1\right]}-1}{e^{G}-1}\right]}
$$

Esta equação substitui a Equação (4.35), obtida para todos os coeficientes constantes. Para obter uma formulação que produza gráficos similares aos apresentados nas Figura 4.4(b) e 4.5, o termo entre chaves pode ser representado por $W$ para simplificação de notação, e se demonstra que:

$$
\begin{gathered}
\frac{H-H_{1}}{H_{M}-H_{1}}=\frac{\left(\frac{H_{1}}{1-W \phi_{M}}\right)-H_{1}}{\left(\frac{H_{1}}{1-\phi_{M}}\right)-H_{1}}=\frac{\left(1-\phi_{M}\right) W}{1-W \phi_{M}} \\
\frac{\left(1-\phi_{M}\right) W}{1-W \phi_{M}}=\frac{W \phi_{M}}{1-W \phi_{M}} \frac{1-\phi_{M}}{\phi_{M}}=\left(\frac{H}{H_{1}}-1\right)\left(\frac{1-\phi_{M}}{\phi_{M}}\right)
\end{gathered}
$$

Ou seja, a mesma forma de apresentação das figuras mencionadas pode ser feita. Isto é mostrado na Figura (4.6).

As constantes ajustadas para produzir a curva da Figura (4.6) foram: $\delta=2,3, G=-0,1$ e $\phi_{M}=0,8$. Evidentemente pode-se traçar uma família de curvas para diferentes valores dessas constantes, de modo a obter uma maior sensibilidade acerca da sua influência no estabelecimento da posição da interface ar/mistura. Este resultado corresponde, provavelmente, à primeira previsão teórica com valores numéricos adequadamente posicionados, da evolução da posição da interface ar/mistura.

Evidentemente, no estudo do detalhamento de cada uma das variáveis relevantes que quantificam esta evolução, as hipóteses simplificadoras devem 


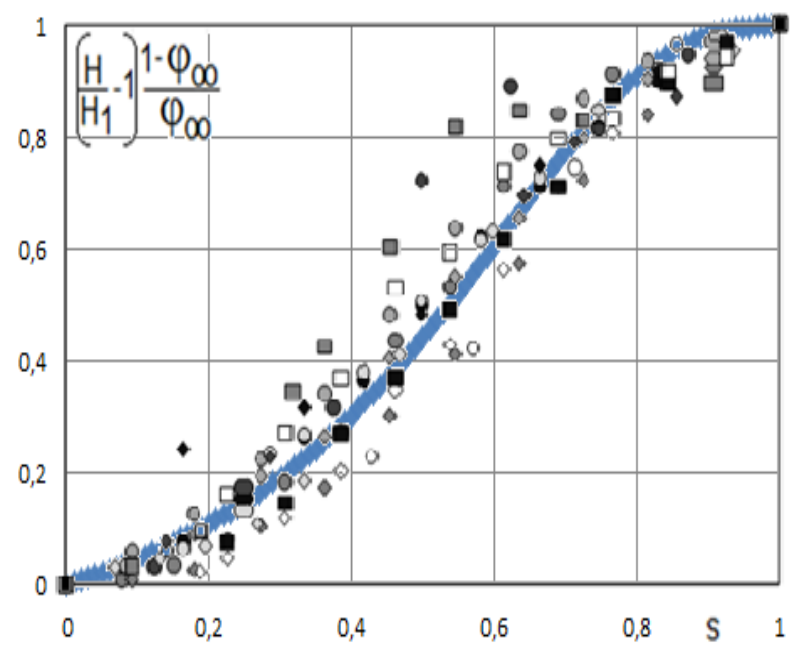

Figura 4.6: Comparação entre os dados medidos (apresentados na Figura 4.5) e as previsões possíveis com a presente formulação. Observa-se que toda a evolução prevista ocorre para $s$ variando entre 0 e 1, diferentemente da primeira quantificação apresentada na Figura 4.4(b).

ser averiguadas. Onde couber, avaliações mais representativas dos fenômenos físicos envolvidos deverão ser consideradas.

\subsubsection{Solução 3 - Solução sem modelar o coeficiente $K$}

Após verificar a viabilidade de previsões quantitativas a partir desta formulação, efetuou-se uma verificação da possibilidade de obter soluções sem inserir modelos para o coeficiente $K$ da Equação (4.28), reproduzida abaixo:

$$
\frac{\partial \phi}{\partial s}=\frac{\partial}{\partial s}\left(\frac{D_{T}}{u L} \frac{\partial \phi}{\partial s}\right)+\frac{K Q H_{1}}{u} \frac{\partial(1-\phi)^{-1}}{d s}
$$

Sem acrescentar novas informações e considerando constância para $D_{T} / u L^{\prime}$, tem-se

$$
\frac{\partial \phi}{\partial s}=\theta_{1} \frac{\partial^{2} \phi}{\partial s^{2}}+\theta_{2} \frac{\partial(1-\phi)^{-1}}{\partial s}
$$

Em que $\theta_{1}=D_{T} / u L$ e $\theta_{2}=K Q H_{1} / u$. Lembrando que $H=H_{1} /\left(1-\phi^{\prime}\right)$, define-se: 


$$
\frac{H}{H_{1}}=h=\frac{1}{1-\phi}
$$

e

$$
\phi=1-\frac{1}{h}
$$

A integração da Equação (4.49) produz:

$$
\phi-\frac{\theta_{2}}{1-\phi}+\theta_{3}=\theta_{1} \frac{\partial \phi}{\partial s}
$$

$\theta_{3}$ é uma constante de integração. Unindo as Equações (4.51) e (4.52) resulta:

$$
\left(1+\theta_{3}\right) h^{2}-h-\theta_{2} h^{3}=\theta_{1} \frac{\partial h}{\partial s}
$$

Esta equação é de primeira ordem, mas é não-linear. Para verificar as possibilidades de integração mantendo a realidade física em vista, foram analisadas suas características gerais. No domínio de estudo de $s$ o valor de $\frac{\partial h}{\partial s}$ é positivo, podendo ser nulo nas extremidades, idealmente em $s=0$ e em $s=1$. Considerando a Equação (4.51), sabe-se que idealmente em $s=0$ tem-se $\phi=0$ e, consequentemente, $h=1$. Para que $\frac{\partial h}{\partial s} \geq 0$ é preciso que:

$$
\left(1+\theta_{3}\right) h^{2}-h-\theta_{2} h^{3} \geq 0
$$

Note-se, entretanto, que a equação não trás informações sobre a posição $s$, mas apenas de $h$ e $\frac{\partial h}{\partial s}$. Como comentado, se se admitir que a derivada é nula em $h=1$, isto implica em:

$$
\theta_{2}=\theta_{3}
$$

Para derivada nula em $h=h_{M}$, tem-se:

$$
\left(1+\theta_{2}\right) h_{M}-1-\theta_{2} h_{M}^{2}=0
$$

ou $\theta_{2}=\frac{1}{h_{M}}$. As Equações (4.53), (4.55) e (4.56) produzem:

$$
h\left[\frac{1}{h_{M}} h^{2}-\left(1+\frac{1}{h_{M}}\right) h+1\right]=-\theta_{1} \frac{\partial h}{\partial s}
$$


Apesar da não-linearidade, esta equação é integrável (o polinômio em $h$ é produto entre uma equação de segundo grau e a variável dependente $h$ ). Para integrar, a separação de variáveis produz:

$$
\frac{\partial s}{\theta_{1}}=\frac{\partial h}{h\left[-\frac{1}{h_{M}} h^{2}+\left(1+\frac{1}{h_{M}}\right) h-1\right]}
$$

A solução desta equação é bastante extensa. Em termos explícitos tem-se

$$
\frac{s}{\theta_{1}}+\omega=-\frac{1}{2} \ln \left(\frac{h^{2}}{-\left[\frac{1}{h_{M}} h^{2}-\left(1+\frac{1}{h_{M}}\right) h+1\right]}\right)-\frac{\left(1+\frac{1}{h_{M}}\right)}{\left(1-\frac{1}{h_{M}}\right)} \operatorname{Artanh}\left[-\frac{\frac{2 h}{h_{M}}-\left(1+\frac{1}{h_{M}}\right)}{1-\frac{1}{h_{M}}}\right]
$$

Não se buscou representar a solução nos mesmos moldes das Figura 4.4(b) e 4.6, dada sua complexidade formal. Entretanto, esta é a solução que envolve menos considerações heurísticas (modelos para as variáveis envolvidas), mostrando a viabilidade da formulação, o que justifica o seu estudo e manutenção no presente desenvolvimento. A Figura 4.7 foi obtida para $h_{M}=2, \omega=-4$ e $\theta_{1}=0,1$. A significância prática desses ou de outros conjuntos de valores deve ser verificada em estudos específicos voltados para os detalhes desta formulação.

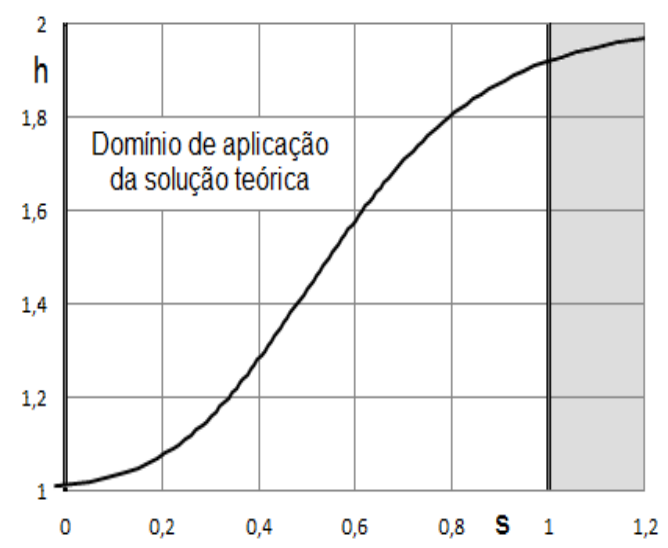

Figura 4.7: Representação gráfica da Equação (4.59) para $h_{M}=2, \omega=-4$ e $\theta_{1}=$ 0, 1. Esta solução não introduz modelos para o coeficiente $K$ da Equação (4.5). 
A Equação (4.59) mostra que as condições ótimas, apesar de terem sido preenchidas para $h$ e suas derivadas, não implicam em terem sido preenchidas nas posições $s=0$ e $s=1$. Isto ocorre porque a equação original não trazia explicitamente a variável $s$. A Equação (4.59) mostra que os valores limites de $h=1 \mathrm{e}$ $h=h_{M}$ são atingidos em situações extremas, para $s$ tendendo ao infinito positivo ou negativo. Não obstante esta característica, a solução apresenta-se viável e deverá ser estudada adiante nesta linha de pesquisa.

\subsubsection{Considerações finais da formulação matemática}

A presente seção tratou de uma abordagem original relacionada ao comportamento da região bifásica ar/mistura (onde o termo mistura refere-se ao escoamento bifásico de ar e água). Esta abordagem envolveu o estabelecimento de uma equação básica para o enlaçamento de ar (Equação 4.5); na geração de uma equação governante, no caso unidimensional, para a fração de vazios em escoamento com enlaçamento de ar (Equação 4.28); e na proposta de diferentes soluções para esta equação, introduzindo modelos ou admitindo constância de seus coeficientes. Como mensionado, foram consideradas as proposições de Schulz (2013), elaboradas no contexto dessa pesquisa. Os resultados obtidos foram comparados com medidas efetuadas especificamente para este estudo, no contexto desta linha de pesquisa, evidenciando-se a sua adequação qualitativa e quantitativa. Não se tem informações de equacionamentos similares, que tenham sido estabelecidos a partir da consideração do princípio físico de conservação de massa e de uma equação para o transporte de ar (enlaçamento de ar na interface ar/mistura). A boa qualidade dos resultados aponta para a adequação da metodologia seguida, sugerindo-se a continuidade desses estudos. 


\section{RESULTADOS E DISCUSSÕES}

Este capítulo elucida os detalhes dos procedimentos numéricos e demonstra o resultado das simulações computacionais. Vale ressaltar que o capítulo está basicamente dividido em duas partes. A seção inicial faz uma descrição das primeiras simulações elaboradas (Seção 5.1) enquanto as seções subsequentes abrangem o progresso obtido com as simulações numéricas, no decorrer da pesquisa científica, que são relacionados com a formulação teórica no intuito de alcançar os objetivos propostos por este trabalho.

As análises preliminares permitiram um melhor aprendizado e fixação dos métodos e procedimentos numéricos. Naturalmente partiu-se de investigações mais simplificadas até que fossem atingidos os casos mais complexos de investigação da aeração do escoamento. Dessa maneira, foi possível avaliar através das simulações descritas na Seção 5.1 a capacidade das ferramentas numéricas para representação do problema físico e a necessidade computacional para o processamento do problema proposto. A partir de então, foi possível prever a necessidade de um processador com configurações avançadas para que a precisão do problema físico fosse adequada.

Para as simulações iniciais (Seção 5.1) foram utilizados dois computadores DualCore com 2GB de memória Ram. Já nos primeiros avanços computacionais foi possível prever a necessidade de mais memória para o processamento das soluções numéricas. Para as análise descritas nas Seções 5.3, 5.4, 5.5 e 5.6 fez-se uso de um computador de 24 processadores com 64GB de memória Ram. As soluções foram multiprocessadas e permitiram um aumento significativo no refinamento da malha. Vale destacar que a capacidade computacional foi um fator preponderante no que diz respeito à correta representação do problema. 


\subsection{Análises preliminares}

Investigações iniciais foram realizadas para análise das características do escoamento em vertedouros em degraus em um modelo conhecido como CEDEX que atende as representações da Figura (5.1). Esta fase do trabalho consistiu simplesmente na realização de um conjunto de simulações que verificasse se o modelo reproduzia as propriedades do sistema em estudo conhecidas a priori, maiores informações podem ser encontradas em Lobosco and Schulz (2010).

\subsubsection{O modelo CEDEX}

O modelo proposto por García and Mateos (1995), conforme a Figura 5.1(a), é caracterizado por possuir os primeiros degraus em tamanhos menores. A declividade da calha é $0,75: 1(h: v)$. A coluna de água possui a dimensão: $H_{d}=2,15 \mathrm{~m}$. No vertedouro existem ao todo 12 degraus, numerados de 1 a 12 , de cima para baixo.

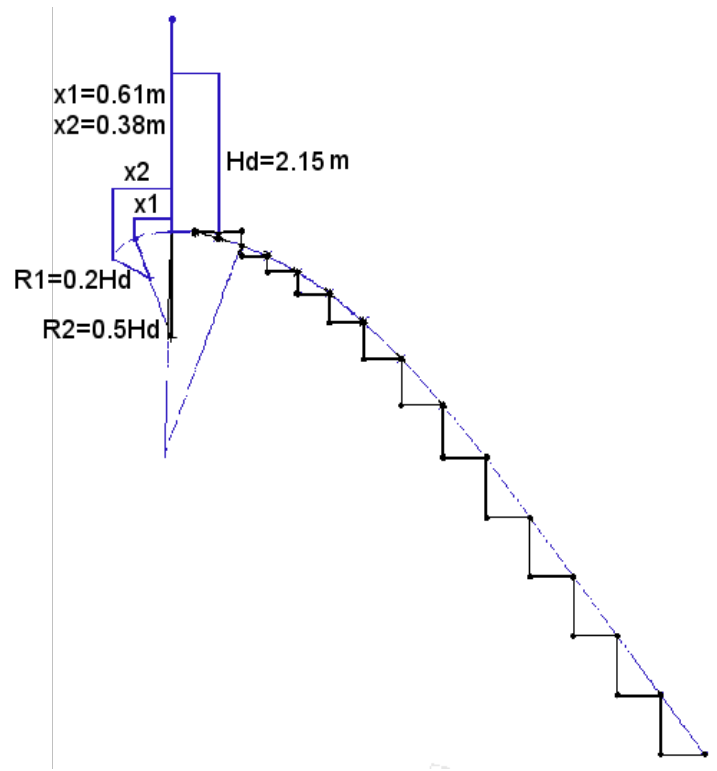

(a) Dimensionamento

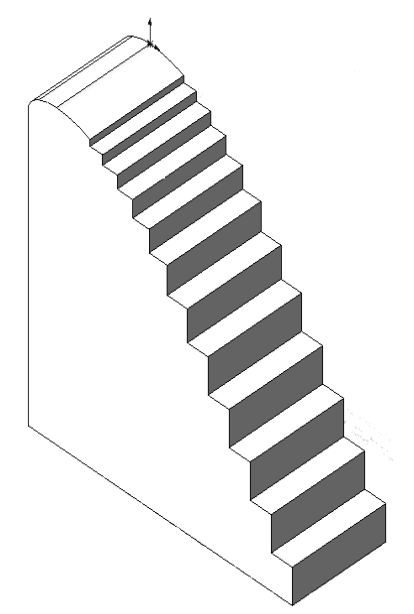

(b) Visualização em três dimensões

Figura 5.1: Perfil CEDEX proposto por García and Mateos (1995).

Na análise dos escoamentos, o campo de pressão evidenciou caracte- 
rísticas locais relevantes conforme descrito em Lobosco et al. (2011a) e Lobosco and Schulz (2010). No caso de escoamento em vertedouros escalonados o diagrama de pressão se modifica de acordo com a fração de vazios. As simulações demonstraram as prováveis regiões de ocorrência de cavitação de acordo com as regiões de baixa pressão.

\subsubsection{Representação física}

O problema proposto analisou as condições de pressão para o escoamento transiente tridimensional, de uma coluna de água, $H_{d}$, que era liberada para escoar sobre o perfil escalonado do vertedouro até a condição de repouso. Os resultados obtidos foram comparados com a distribuição de pressões investigadas em condições operacionais de regime permanente, conforme apresentados em Chen et al. (2002) e Gomes (2006). A Figura 5.2(b) representa o perfil do escoamento em um dado instante de tempo, enquanto a Figura 5.2(a) representa fisicamente os instantes anteriores à liberação da coluna de água (que pode ser associado à abertura da comporta sobre o vertedor). Lembrando que alpha é a fração volumétrica.

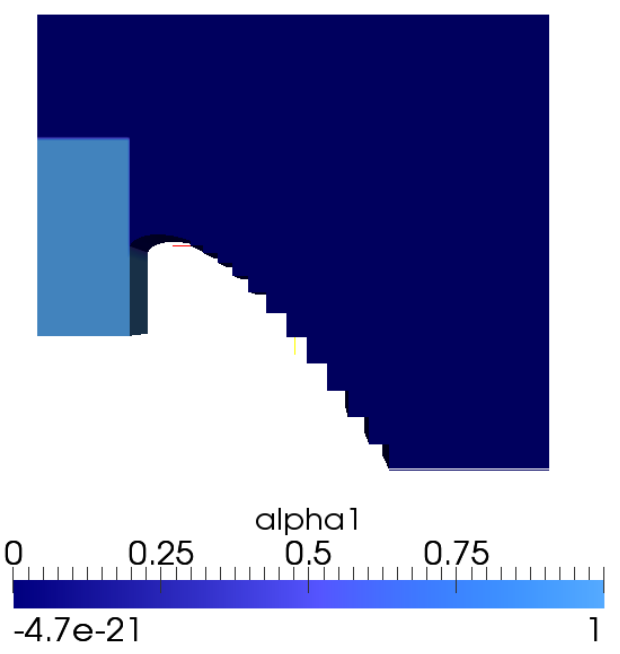

(a) Coluna no instante $\mathrm{t}=0 \mathrm{~s}$
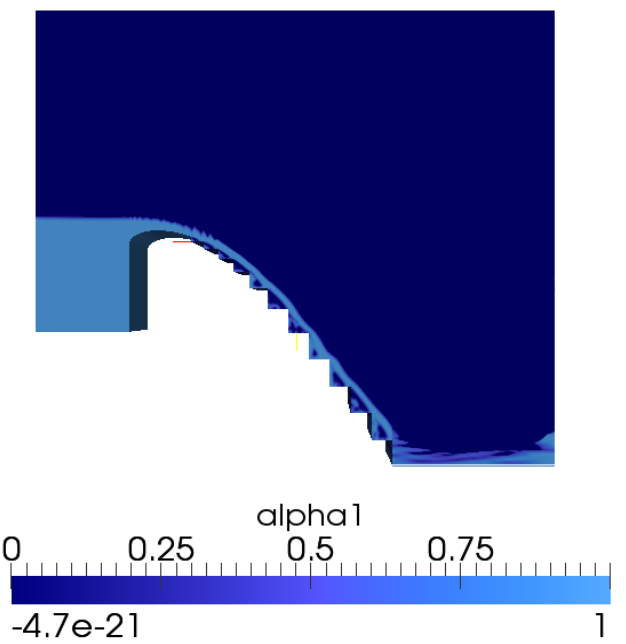

(b) Escoamento no instante $\mathrm{t}=7 \mathrm{~s}$

Figura 5.2: Perfil do escoamento

A tensão superficial entre o ar e a água é dada por: $\eta=0,07 N / m$. As 
simulações começaram no tempo $t=0$ com uma coluna de fluido inicialmente estacionária de altura $H_{d}$. A condição de contorno na saída foi definida como gradiente de velocidade nulo. As paredes foram tratadas com um valor fixo de velocidade nula. As propriedades da água foram consideradas a temperatura de $298 \mathrm{~K}$.

\subsubsection{O perfil de distribuição de pressão}

Os resultados obtidos na presente simulação computacional assemelham-se qualitativamente aos descritos por Frizell and Melford (1991). Os autores mencionam que o trecho mais sujeito à cavitação é a parte superior do paramento vertical do degrau. Conforme a Figura (5.3) esta é justamente a região que apresenta as pressões aqui obtidas com os valores mais baixos.

As distribuições de pressão obtidas numericamente foram comparadas com as descritas por Chen et al. (2002). É possível perceber que a região de impacto do jato sofre influência do escoamento a montante que, por sua vez, irá influenciar na região de colisão a jusante.

No caso transiente, essas regiões de impacto variam ao longo do tempo, Figura (5.4). Esse pode ser o motivo da diferença nos valores obtidos através da presente simulação quando comparados aos dados de Chen et al. (2002), que realizaram sua simulação em regime permanente. Entretanto existe consistência nos resultados com relação as regiões críticas para ocorrência de cavitação. As diferenças podem ser minimizadas em se considerando regime permanente.

No presente estudo adotou-se um instante de tempo arbitrário para comparação com os dados da distribuição de pressão em regime permanente. Novas análises em outros regimes de operação foram realizadas, entretanto nessa análise preliminar foi possível constatar que as regiões críticas ao risco de cavitação estavam coerentes com os resultados da literatura.

A simulação deste caso mais simples demosntra não apenas a capacidade dos métodos numéricos, mas também das ferramentas computacionais utilizadas para o tratamento de casos mais complexos, conforme é demonstrado a seguir. 


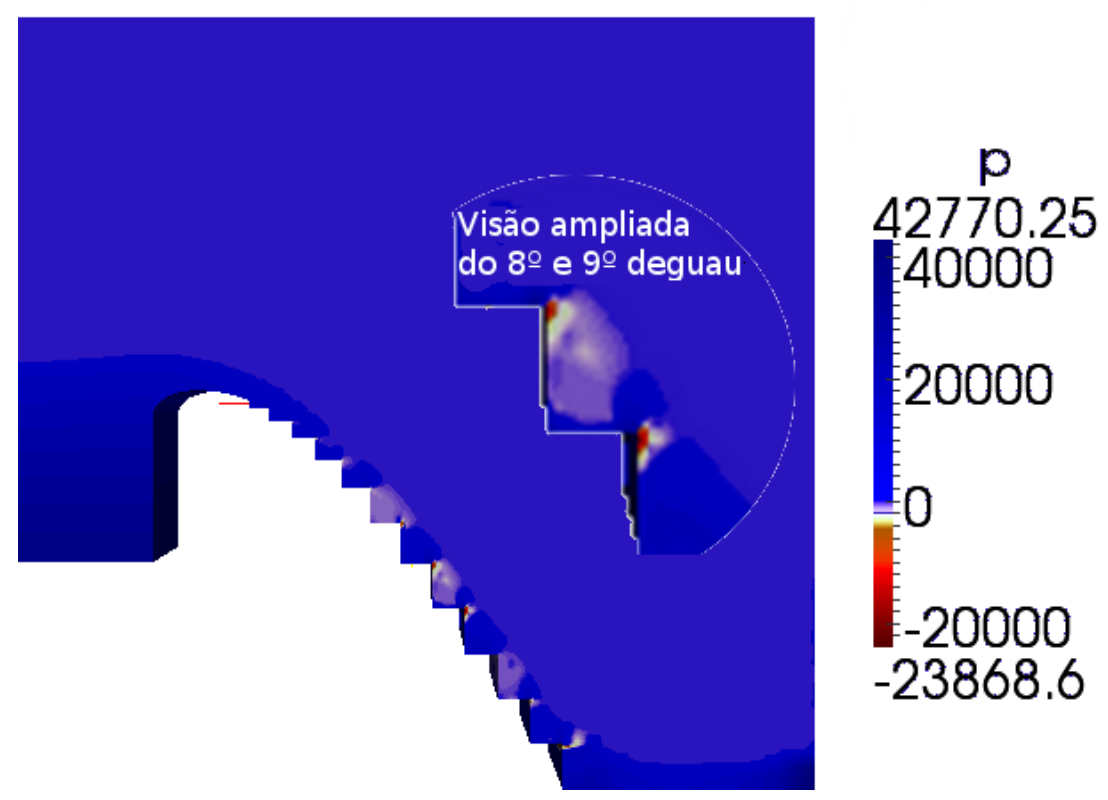

Figura 5.3: Perfil de distribuição de pressão.

\subsection{Análise da superfície livre do escoamento multifásico}

É conveniente lembrar que a busca pela representação computacional da superfície livre de um escoamento multifásico requer o uso de uma série de formulações numéricas. Diante disso, pode-se, por exemplo, citar que a grande declividade do vertedor (superior a $45^{\circ}$ ) e o fenômeno de auto aeração agregam uma complexidade adicional para a correta representação do problema físico. Conforme citado anteriormente, foi utilizado para o desenvolvimento das análises numéricas, o solver InterFoam do OpenFoam em condição de regime transiente (não-estacionária).

De maneira geral, as simulações para investigação da aeração seguiram procedimentos semelhantes no que diz respeito ao tratamento do domínio de escoamento. Foram modificadas, nos diferentes casos, as condições hidrodinâmicas (condições de contorno na entrada), condições de refinamento da malha e configurações de entrada da estrutura hidráulica.

Na representação do domínio do escoamento foi utilizada uma malha hexaédrica, cartesiana, estruturada, cujo refinamento sofreu variações de acordo com 


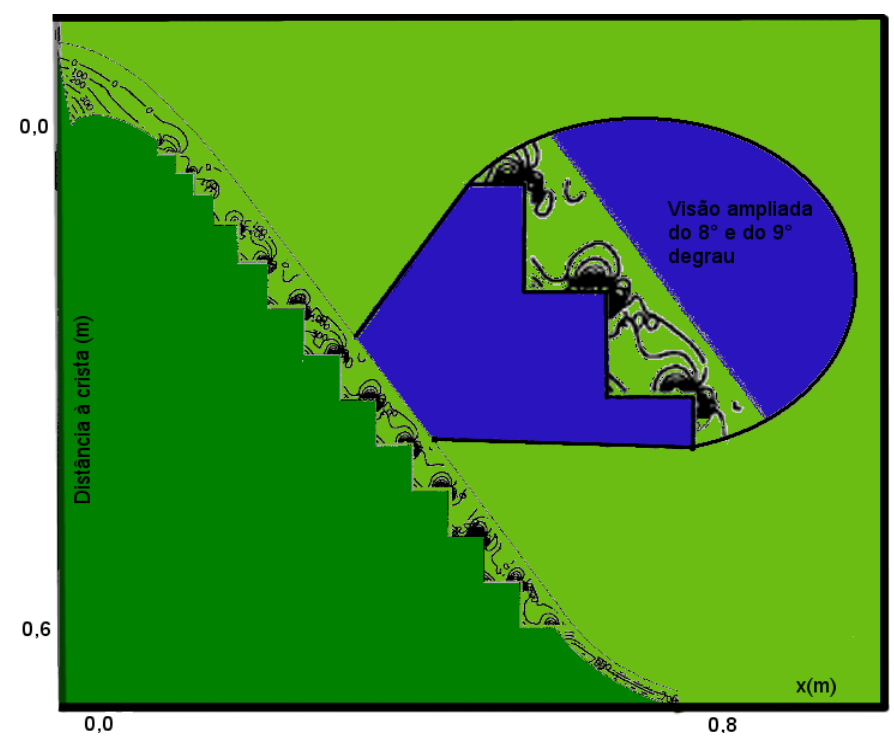

Figura 5.4: Perfil de distribuição de pressão. Adaptado de Chen et al. (2002).

as descrições das simulações. Todas as malhas deste trabalho de pesquisa foram geradas no software Salome através da importação da geometria em um formato de CAD ".step". É no software Salome que foram definidas as faces para a aplicação das condições de contorno. Dentre os algoritmos de geração de malha, o que mais se adequou as necessidades de refinamento e as propriedades da geometria, tendo em vista as limitações dos algoritmos, foi o de malha hexaédrica. Vale ressaltar que existe no software algumas possibilidades de geração de malhas com elementos uni e bi-dimensional entretanto, o OpenFoam só trabalha com elementos tri-dimensionais. Após a geração da malha, a exportação se dá através do formato ".unv" e no OpenFoam as propriedades da malha podem ser corretamente verificadas. Encontra-se no Anexo II, os arquivos de dados das simulações numéricas.

Na condição inicial uma pequena coluna de água é definida à montante do vertedor (no solver InterFoam é necessário que ao menos uma célula do domínio computacional contenha a segunda fase à ser modelada), ou seja, o domínio computacional foi simulado como se estivesse ocupado por um único fluido com excessão de uma pequena região inferior à montante.

Na condição de entrada todas as variáveis do escoamento são especi- 
ficadas conforme publicado em Lobosco et al. (2011c). Para que o nível de água a montante não precisasse ser previamente definido, mas fosse obtido como parte do resultado numérico, um perfil uniforme de velocidade foi imposto como condição de entrada na região inferior à montante.

À jusante da estrutura fez-se uso de um domínio estendido de cálculo. Derivadas normais nulas foram impostas na saída, quando o escoamento atinge a condição de "completamente desenvolvido" (sem mais alterações longitudinais). Os limites laterais foram tratados como fronteiras de simetria clássicas.

A parede inferior foi modelada como fronteira sólida. Nas regiões próximas à parede, diferentes escalas de movimento e geométricas estão presentes e a condição de não deslizamento é apropriada para a velocidade na parede. Entretanto imediatamente adjacente à parede existe a sub-camada viscosa e o modelo $k-\varepsilon$ adotado para o escoamento não reproduz por si só essa sub-camada sem erros significativos. Verificou-se também que mesmo o número de pontos necessários para resolver todos os parâmetros da camada limite turbulenta não seriam suficientes, dessa forma optou-se por utilizar a função de parede para paredes rugosas, denominada "epsilonWallFunction", existente no OpenFoam.

Em termos das propriedades físicas, considerou-se um escoamento de água a uma temperatura de $20^{\circ} \mathrm{C}$, o que fornece uma viscosidade dinâmica fixa de $\mu=10^{-3} \mathrm{Kg} /(\mathrm{m} . \mathrm{s})$.

Feita à apresentação dos parâmetros numéricos de solução das equações governantes do escoamento, as próximas seções descrevem o progresso da investigação da concentração de ar.

\subsubsection{Análise do perfil de concentração - Influência do refinamento da malha}

Almejando investigar a solução numérica com relação às propriedades da malha, foi inicialmente gerada uma malha hexaédrica com 373.250 elementos. Vale ressaltar que mesmo sendo considerada grosseira para análise dos resultados, 
esta levou em torno de 20 dias para multi-processar a solução de 40s em uma máquina de configuração Core i7.

As Figuras 5.5 a 5.8 estão representadas em uma sequência de duas imagens. Enquanto a primeira delas (a) ilustra o gráfico da fração volumétrica temporal média ao longo da seção do degrau, a segunda (b) traz a ilustração da região de captura selecionada no domínio computacional. É possível visualizar, em rosa a região na qual os dados dos elementos da malha foram capturados. Esta seleção varia entre as extremidades da seção transversal (conforme ilustrado previamente nas Figuras 2.2(a) e 2.2(b)) e demonstra a captura da fração volumétrica na região da interface variando entre o ar (zero) e à água (valor unitário). O mesmo procedimento descritivo se deu para a extremidade de cada um dos 11 degraus da estrutura hidráulica. Dessa forma, foi possível acompanhar e mensurar as oscilações da superfície livre ao longo do escoamento.

Percebe-se através da Figura 5.5(a) que ao longo da seção transversal a fração volumétrica parte do valor exato (um) na extremidade do degrau e atinge a fração volumétrica (zero) em uma distância em torno de $0.35 \mathrm{~m}$. Vale ressaltar que esses dados são baseados na evolução temporal média da concentração de ar. Também é possível perceber, a partir da Figura 5.5(c) que no segundo degrau, a fração volumétrica atinge o valor (zero) em uma distância em torno de $0.24 \mathrm{~m}$. Esta intermitência no valor da altura de atingimento da fração volumétrica (zero) se mantém entre os degraus pares e ímpares ao longo da estrutura e permite considerações à respeito do regime de escoamento (Conforme pode ser visto nas Figuras 5.5(e) e 5.6(a), (c) e (e)).

Das Figuras 5.7 e 5.8 é possível observar que para uma mesma quantidade de elementos selecionados ao longo da seção transversal, os degraus 9 e 11 não chegam à alcançar a fração volumétrica nula, isto realça à intermitência entre os degraus pares e ímpares e indica que os dados precisam ser capturados ao longo de uma seção transversal maior uma vez que ocorre ao longo da estrutura um crescimento da região de mistura. 


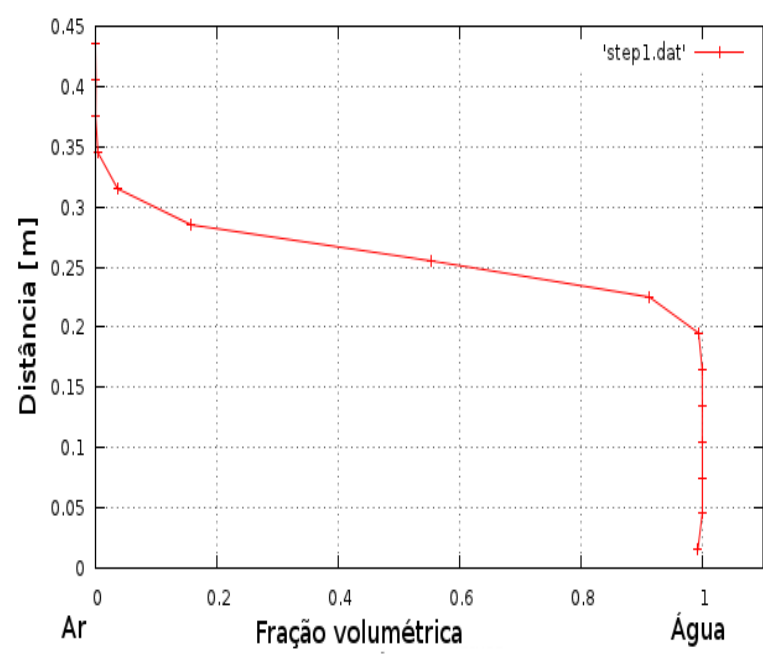

(a) Média Temporal - Degrau 1

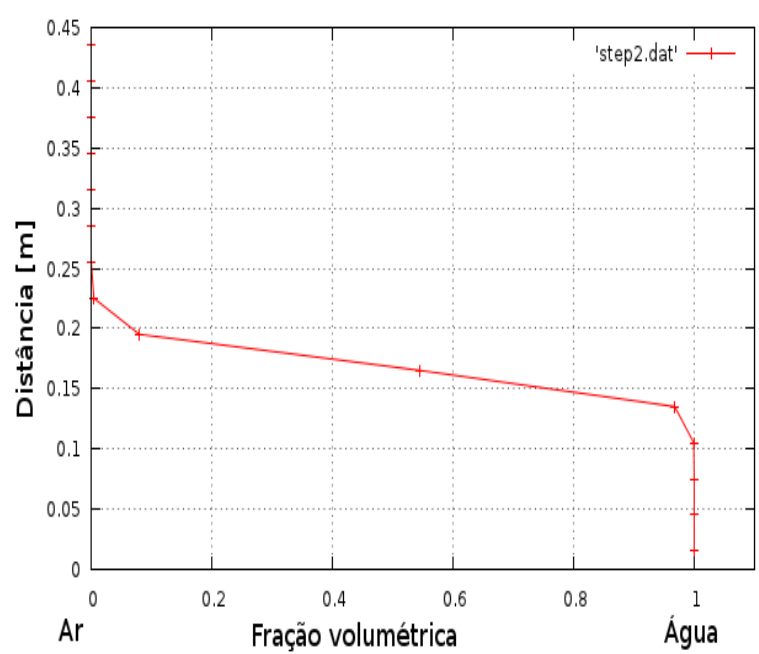

(c) Média Temporal - Degrau 2

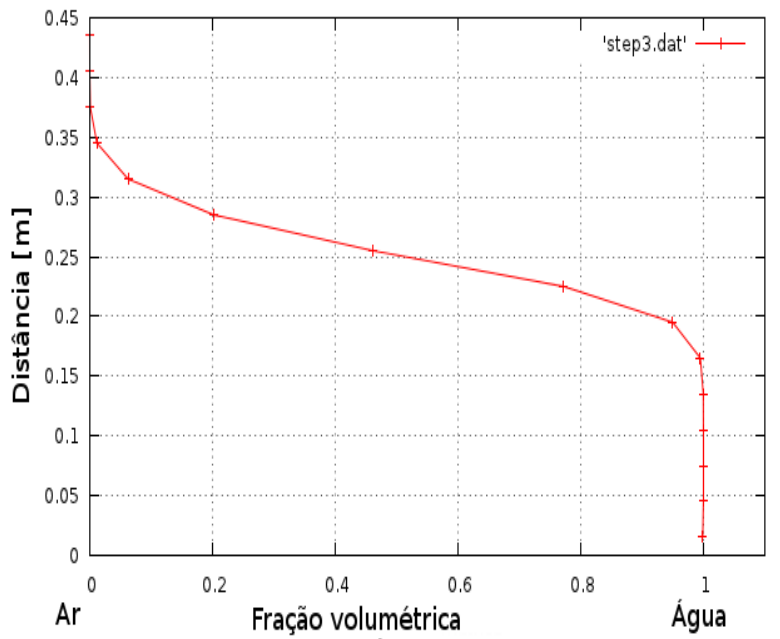

(e) Média Temporal - Degrau 3

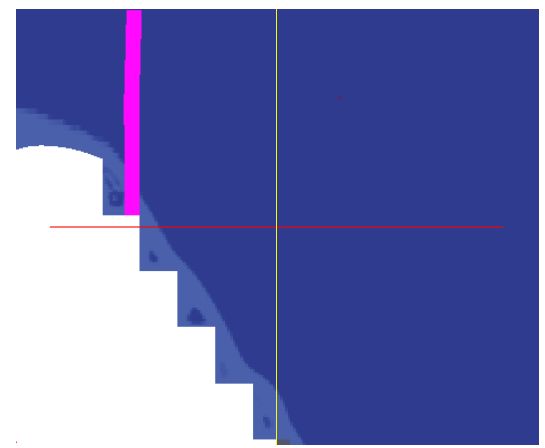

(b) Ilustração do Instante $t=25 \mathrm{~s}$

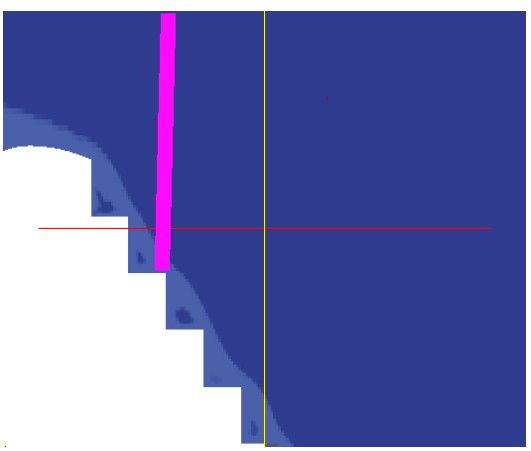

(d) Ilustração do Instante $t=25 \mathrm{~s}$

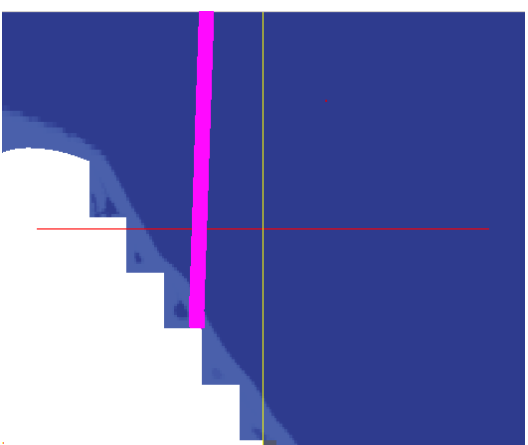

(f) Ilustração do Instante $t=25 \mathrm{~s}$

Figura 5.5: Perfis de concentração: malha de 373.250 elementos, $q=1.0 \mathrm{~m}^{2} / \mathrm{s}$, inclinação $51,3^{\circ}$. 


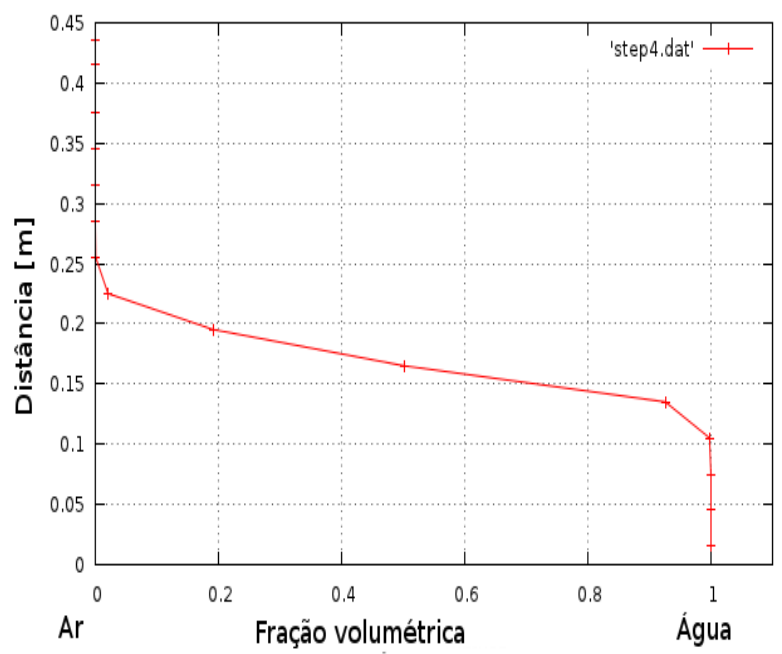

(a) Média Temporal - Degrau 4

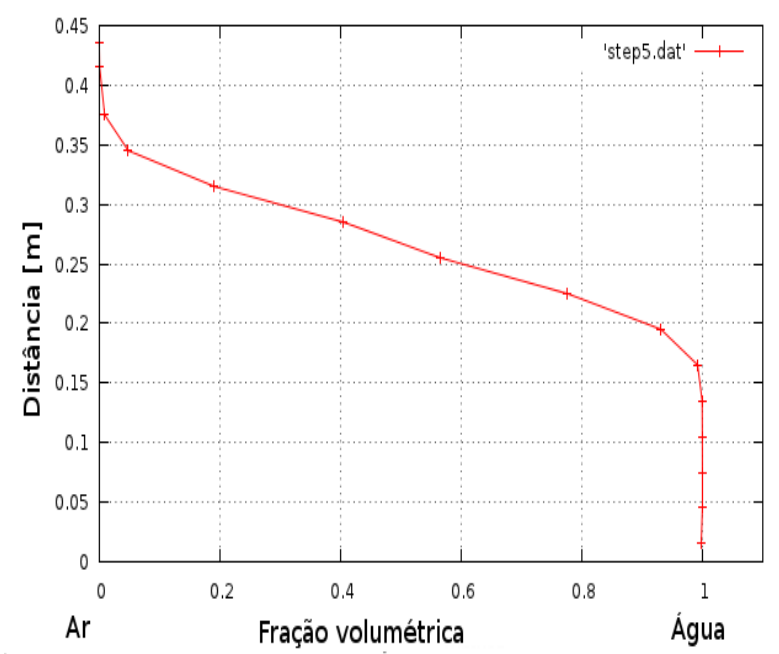

(c) Média Temporal - Degrau 5

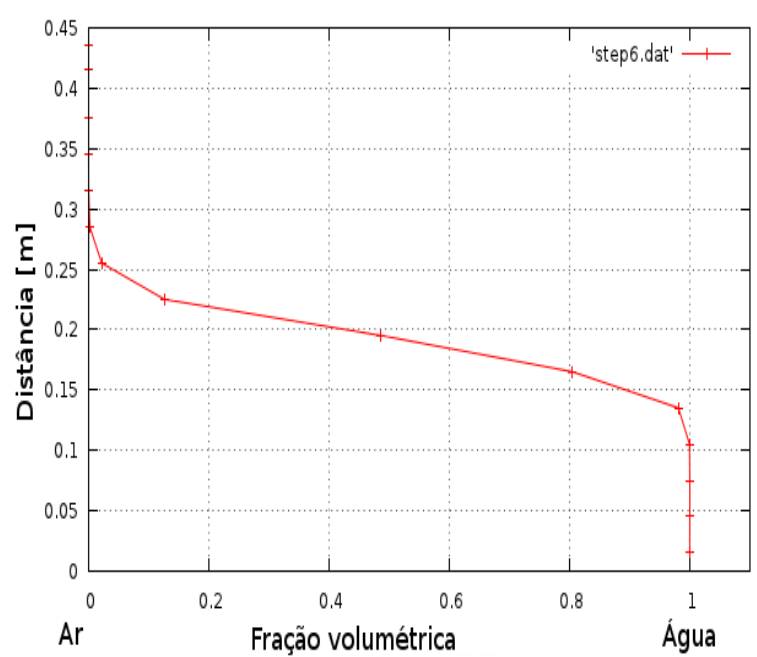

(e) Média Temporal - Degrau 6

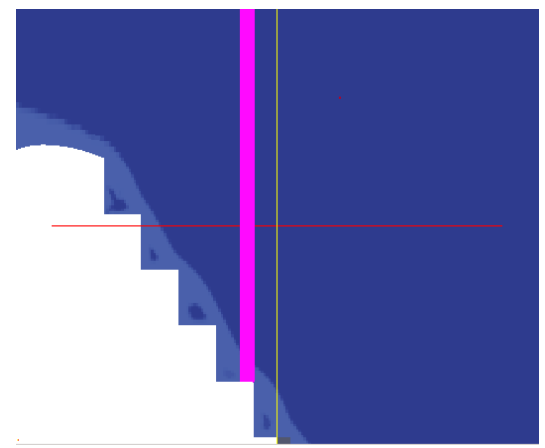

(b) Ilustração do Instante $t=25 \mathrm{~s}$

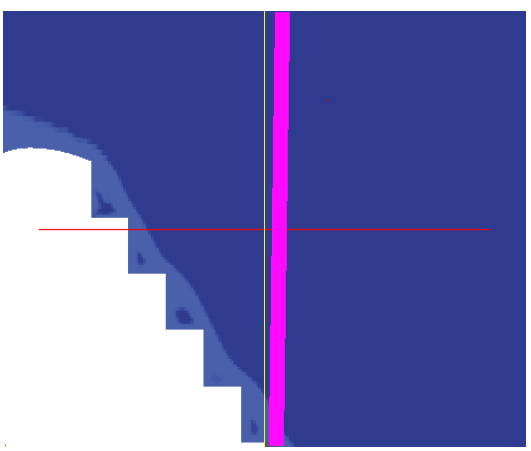

(d) Ilustração do Instante $t=25 \mathrm{~s}$

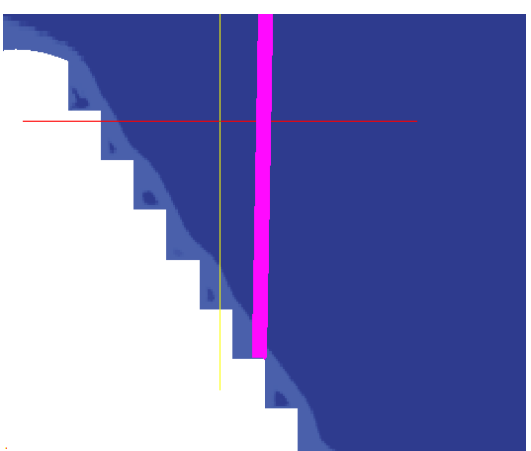

(f) Ilustração do Instante $t=25 \mathrm{~s}$

Figura 5.6: Perfis de concentração: malha de 373.250 elementos, $q=1.0 \mathrm{~m}^{2} / \mathrm{s}$, inclinação $51,3^{\circ}$. 


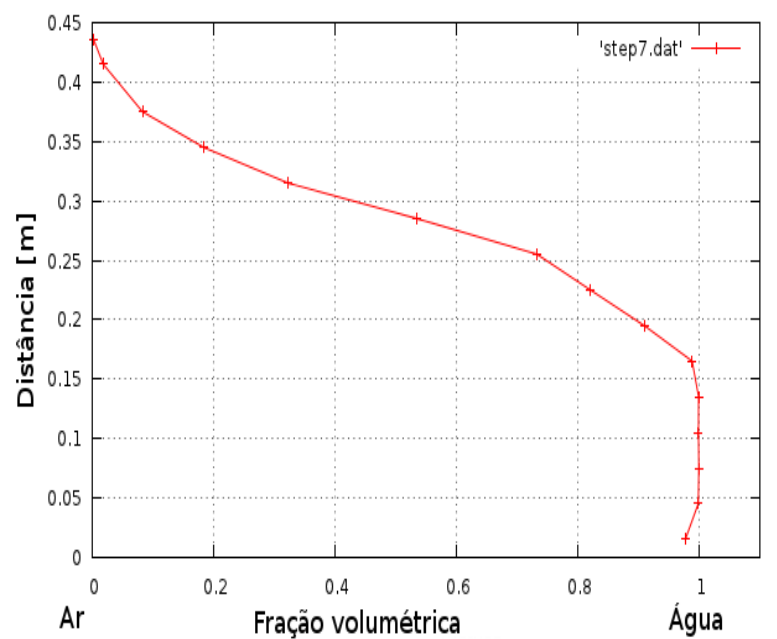

(a) Média Temporal - Degrau 7

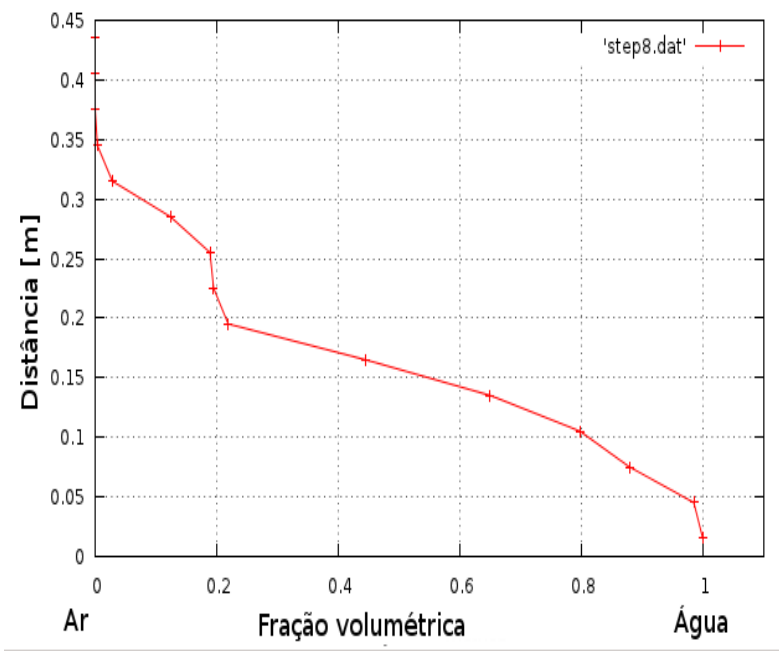

(c) Média Temporal - Degrau 8

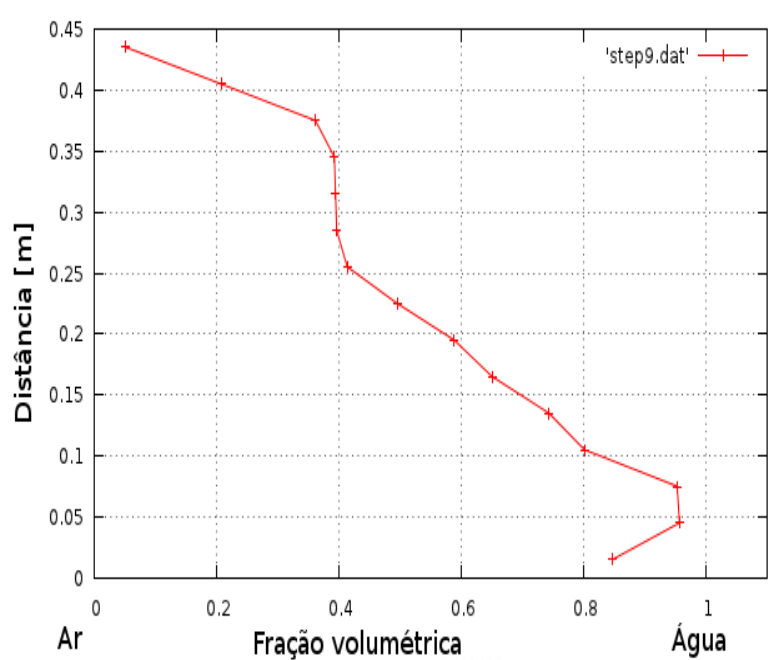

(e) Média Temporal - Degrau 9

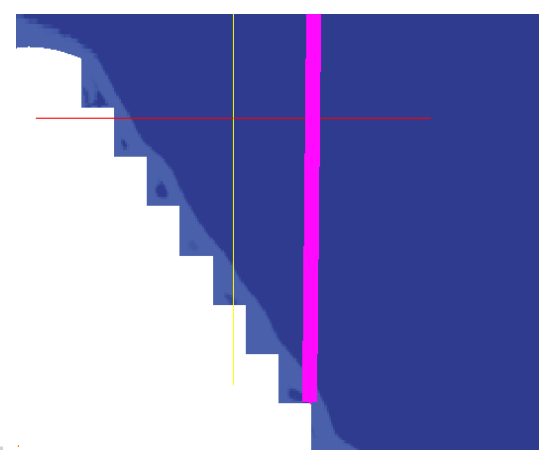

(b) Ilustração do Instante $t=25 \mathrm{~s}$

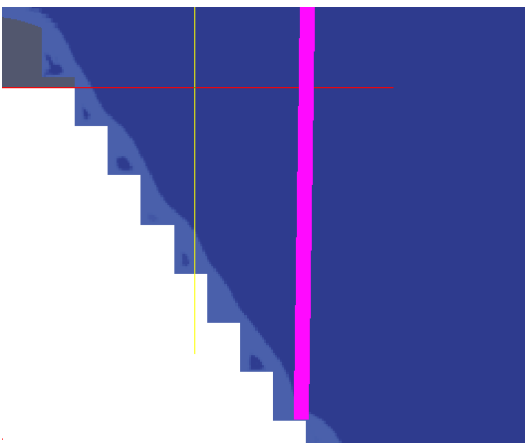

(d) Ilustração do Instante $t=25 \mathrm{~s}$

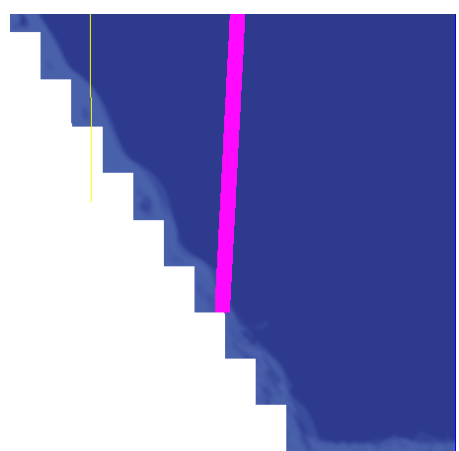

(f) Ilustração do Instante $t=25 \mathrm{~s}$

Figura 5.7: Perfis de concentração: malha de 373.250 elementos, $q=1.0 \mathrm{~m}^{2} / \mathrm{s}$, inclinação $51,3^{\circ}$. 

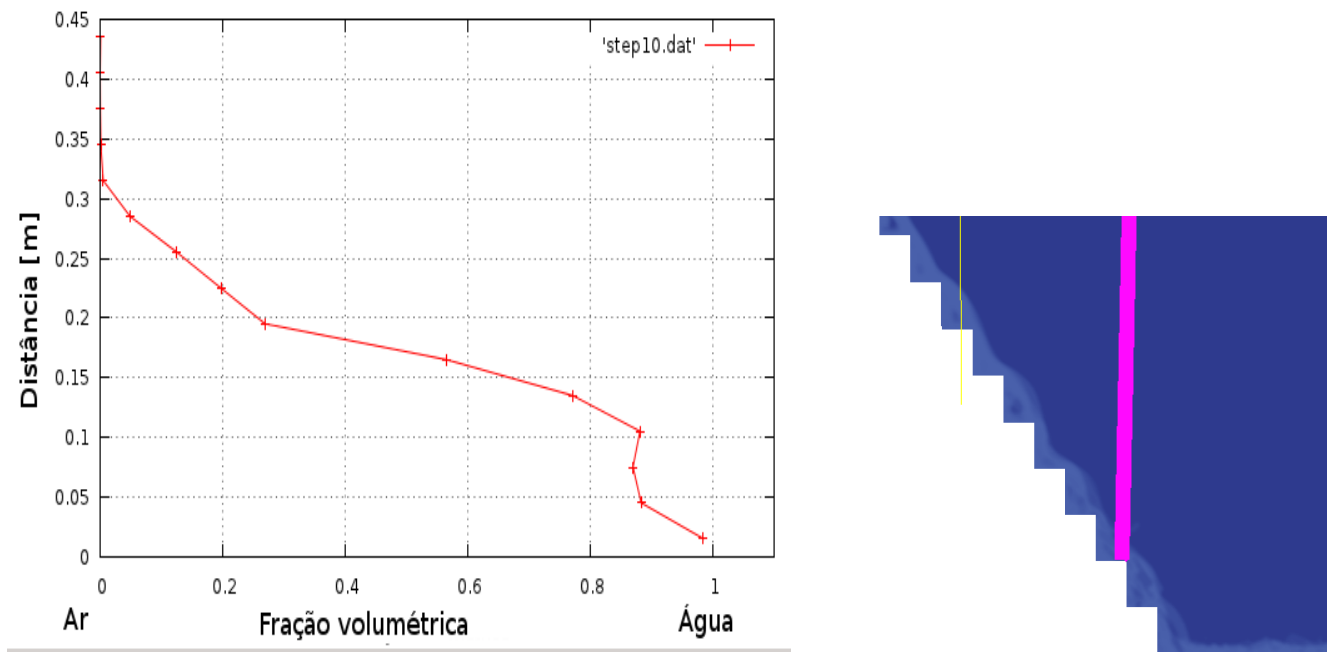

(a) Média Temporal - Degrau 10

(b) Ilustração do Instante $t=25 \mathrm{~s}$
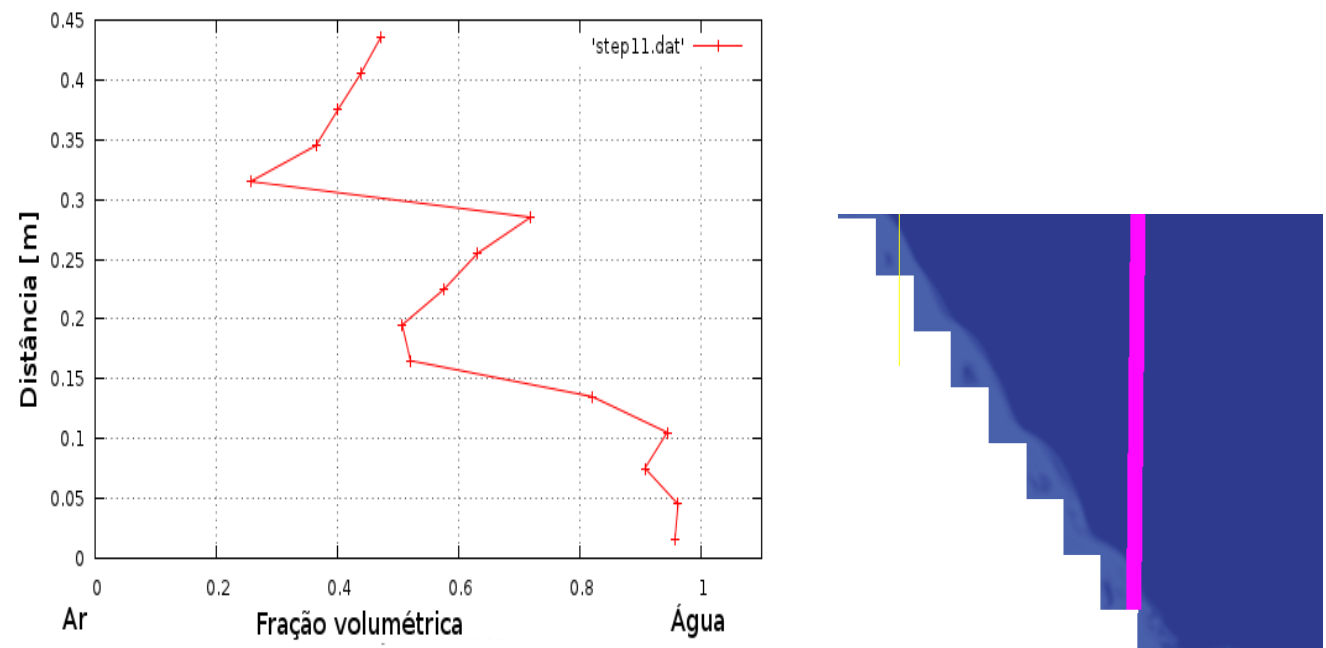

(c) Média Temporal - Degrau 11

(d) Ilustração do Instante $t=25 \mathrm{~s}$

Figura 5.8: Perfis de concentração: malha de 373.250 elementos, $q=1.0 \mathrm{~m}^{2} / \mathrm{s}$, inclinação $51,3^{\circ}$. 


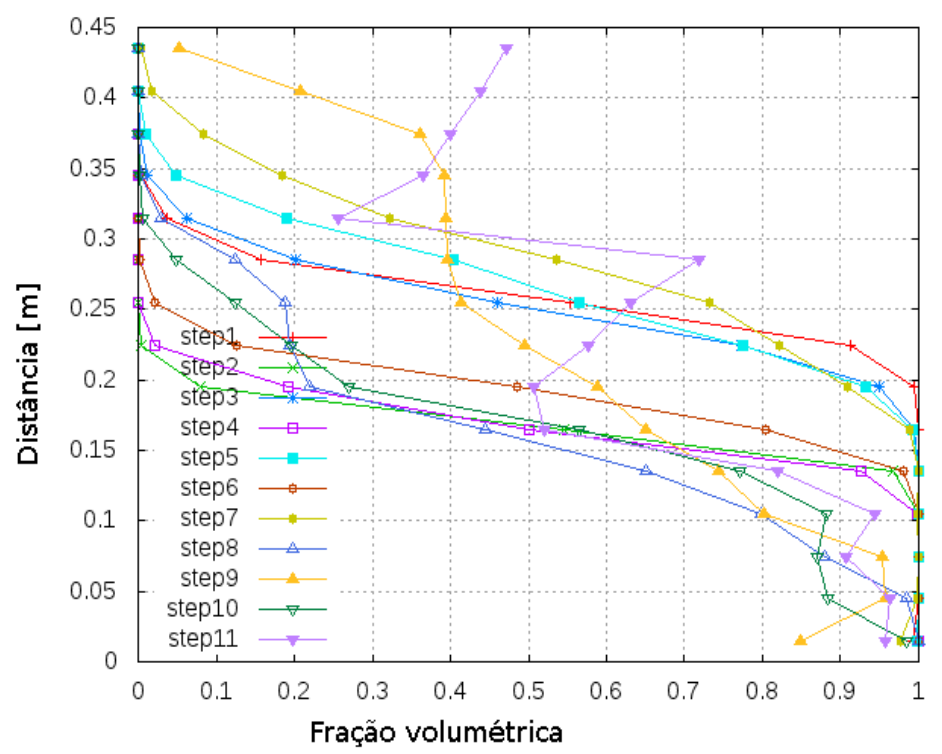

Figura 5.9: Perfil de distribuição da concentração ao longo dos degraus: malha de 373.250 elementos, $q=1.0 \mathrm{~m}^{2} / \mathrm{s}$, inclinação $51,3^{\circ}$.

As Figuras 5.9 e 5.10 reunem as variações da concentração média ao longo da seção transversal de cada um dos 11 degraus da estrutura hidráulica.

Enquanto a Figura 5.9 permite avaliar de forma geral o comportamento da variação da concentração média e compará-la entre os degraus, a Figura 5.10 permite avaliar de forma quantitativa as oscilações da variação da concentração ao longo da estrutura hidráulica com relação à altura perpendicular ao degrau.

Dessa forma, foi possível, pela análise da variação da concentração média ao longo da seção transversal dos degraus caracterizar o escoamento, em uma etapa intermediária (ou de transição) a partir da definição dos regimes de quedas sucessivas e deslizamento sobre vórtices (Conforme descritos na Seção 2.2 e ilustrados pelas Figuras 2.2(a) e (b)).

Os resultados obtidos reforçam ainda mais à coerência e capacidade numérica das ferramentas computacionais utilizadas para tratamento do problema físico proposto. Entretanto, para identificação e análise da região da camada limite em um escoamento é necessário assegurar um refinamento apropriado da malha con- 


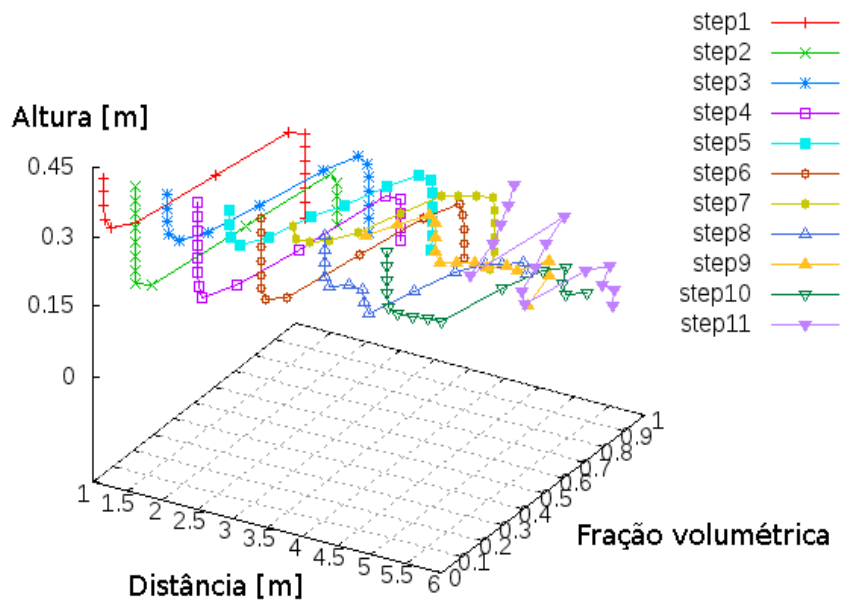

Figura 5.10: Perfil tridimensional da distribuição da concentração ao longo dos degraus: malha de 373.250 elementos, $q=1.0 \mathrm{~m}^{2} / \mathrm{s}$, inclinação $51,3^{\circ}$.

forme descrito na Seção 3.8.1. Dessa forma, buscando aprofundamentos na solução e investigação da concentração e inserção de ar foram realizados refinamentos na malha computacional, conforme descrito nas seções à seguir.

\subsubsection{Perfis de concentração e análise dos regimes do escoamento}

Uma concisa avaliação da simulação com os mesmos parâmetros da simulação da Seção 5.2.1 permitiu investigar a influência do refinamento da malha sobre o resultado numérico obtido na seção anterior para a partir de então dar início às análises do comportamento da superfície livre. Os gráficos da Figura 5.15 foram obtidos para a mesma descarga inicial $\left(q=1 \mathrm{~m}^{2} / \mathrm{s}\right)$, entretanto com uma malha de 2176794 elementos. A caracterização do escoamento multifásico e consequentemente da quebra e ruptura de bolhas está diretamente relacionado com as propriedades da malha computacional. Conforme descrito anteriormente, durante o processamento das simulações o passo de tempo foi ajustado pelo número de Courant máximo que depende de características do tamanho dos elementos. 
Pelas imagens da região de captura de dados, Figuras 5.11(d) e (f) já é, na região de entrada da estrutura, possível verificar mudanças significativas no que diz respeito a representação de bolhas de ar na água. As diferenças se tornam ainda mais acentuadas ao longo do escoamento conforme mostra as Figuras 5.12 (a) e (b).

Vale ressaltar que as intermitências entre os degraus ímpares e pares foram minoradas no presente experimento devido a uma maior precisão da evolução temporal média da concentração de ar e consequentemente, maior precisão na captura da interface. Uma vez que o refinamento da malha permite maior precisão à solução numérica. Entretanto é possível ver claramente pelas figuras de evolução do escoamento ao longo da estrutura hidráulica as oscilações consecutivas na interface fluidodinâmica (Figuras 5.12 (b) e 5.12 (d)), características de um regime de transição.

Outro fator que merece destaque são os volumes de bolhas de ar na água. Sua percepção se torna tão mais acentuada que elas são claramente visualizadas nos gráficos cuja variação da concentração não se inicia no valor unitário (fração volumétrica da água), conforme mostra as Figura 5.12 (a). Na Figura 5.12 (b) fica claro, pela posição da bolha de ar a sua influência na fração volumétrica do perfil de concentração fazendo com que próximo à superfície do degrau ela não atinja o valor unitário, o mesmo se repete (também em grande intensidade) no oitavo degrau conforme mostra as Figuras 5.13 (c) e (d).

A grande influência do refinamento da malha pode ser observado em uma comparação entre a representação dos Gráficos 5.9 e 5.15.

Vale ressaltar que conforme a classificação do escoamento em regime de transição (feita na Seção 5.2.1) é possível prever que as bolhas de ar próximo a região dos degraus evidenciam o ínicio das regiões de vórtices nas cavidades dos degraus. Este fato conduz a uma investigação mais detalhada a cerca da vazão volumétrica utilizada como condição de entrada, conforme descrito na próxima seção. 


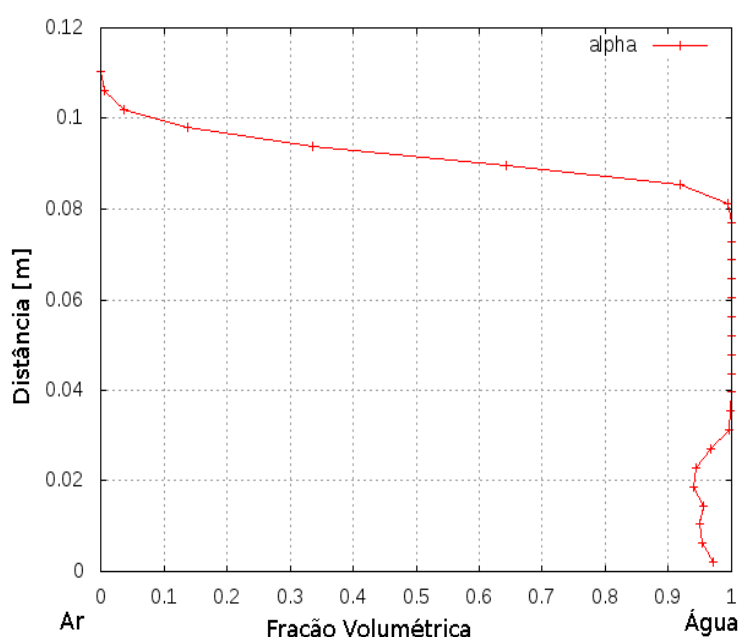

(a) Média Temporal - Degrau 1

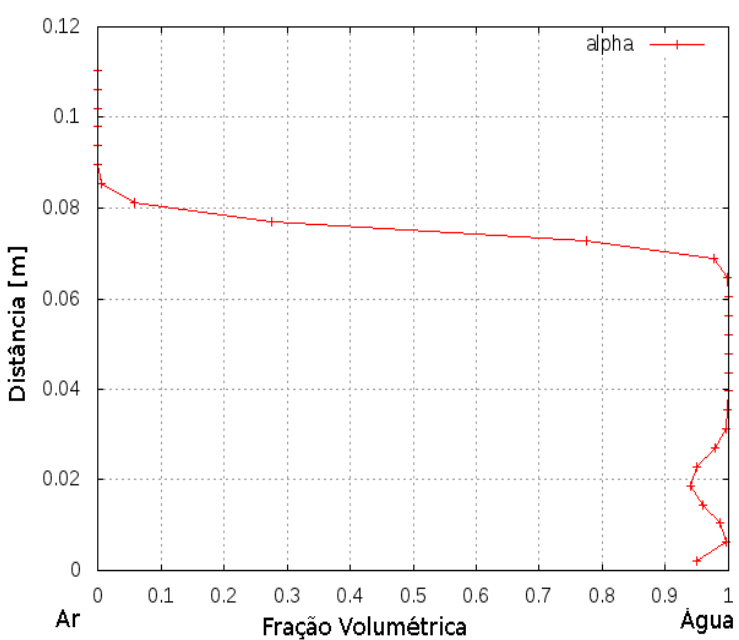

(c) Média Temporal - Degrau 2

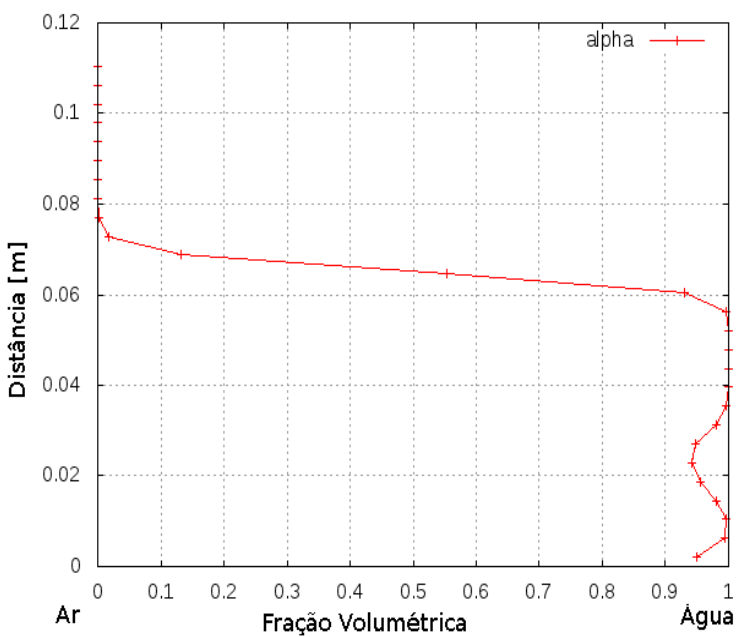

(e) Média Temporal - Degrau 3

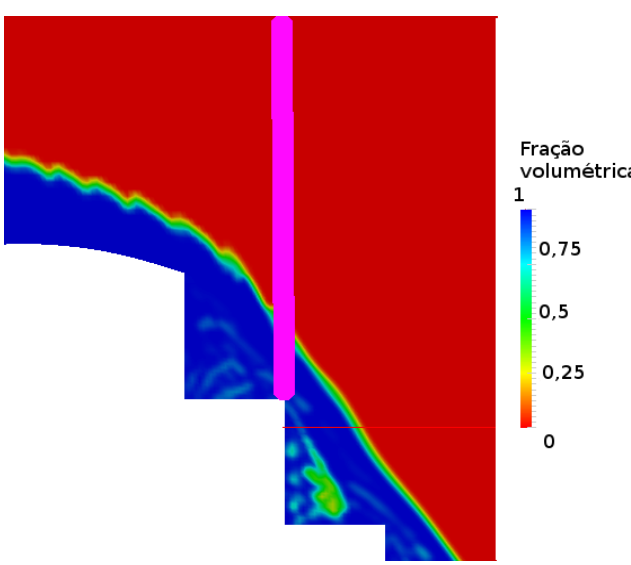

(b) Ilustração do Instante $t=25 \mathrm{~s}$

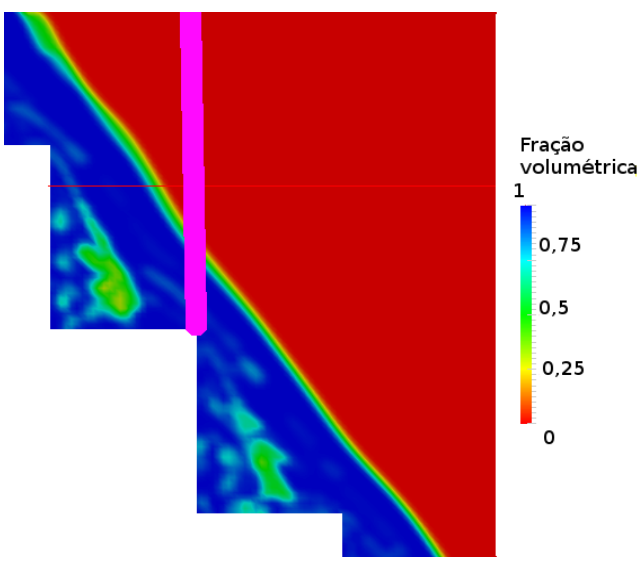

(d) Ilustração do Instante $t=25 \mathrm{~s}$

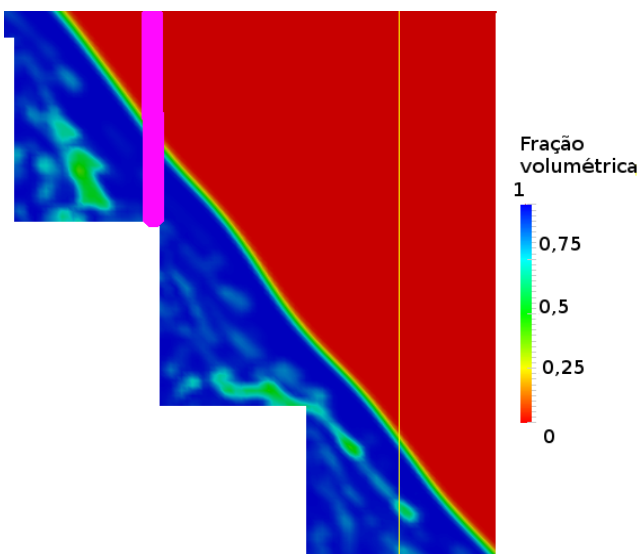

(f) Ilustração do Instante $t=25 \mathrm{~s}$

Figura 5.11: Perfis de concentração: malha de 2176794 elementos, $q=1.0 \mathrm{~m}^{2} / \mathrm{s}$, inclinação $51,3^{\circ}$. 


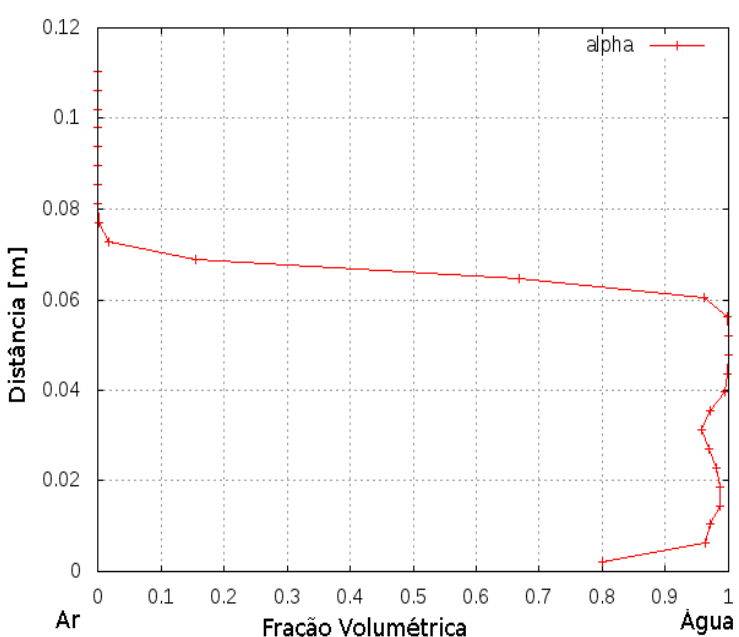

(a) Média Temporal - Degrau 4

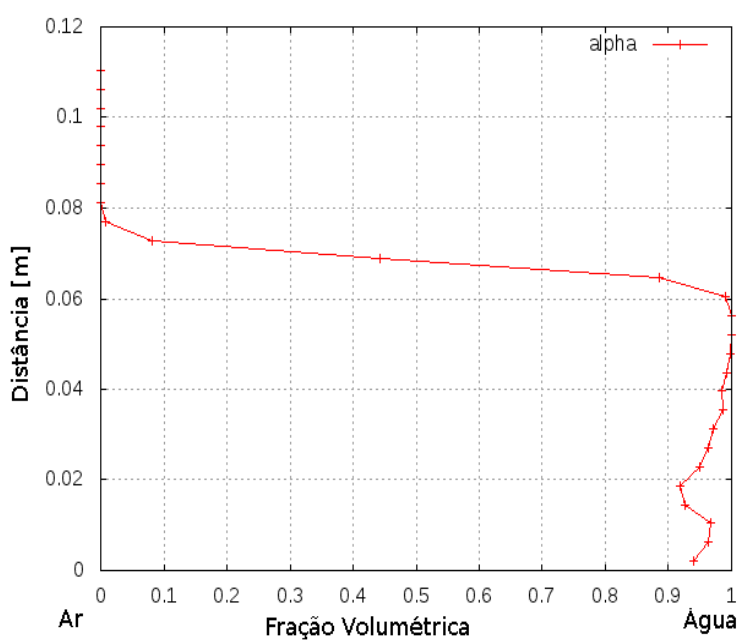

(c) Média Temporal - Degrau 5

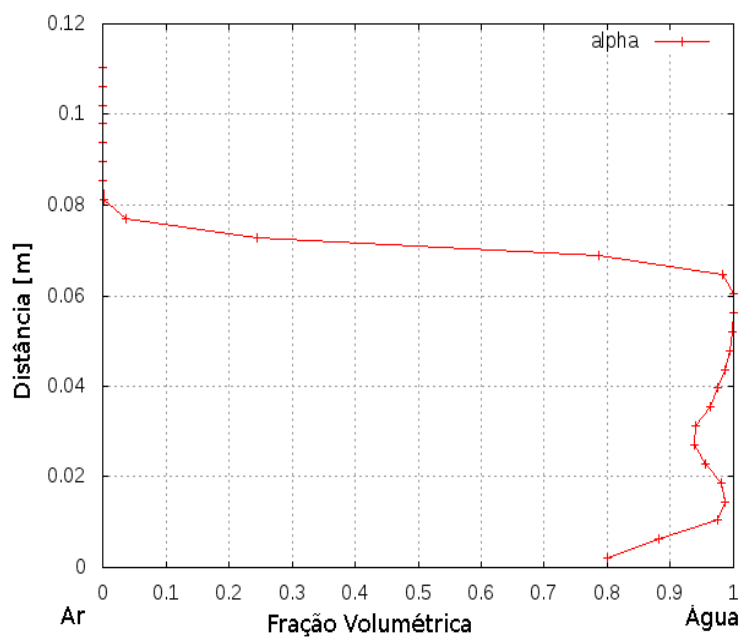

(e) Média Temporal - Degrau 6

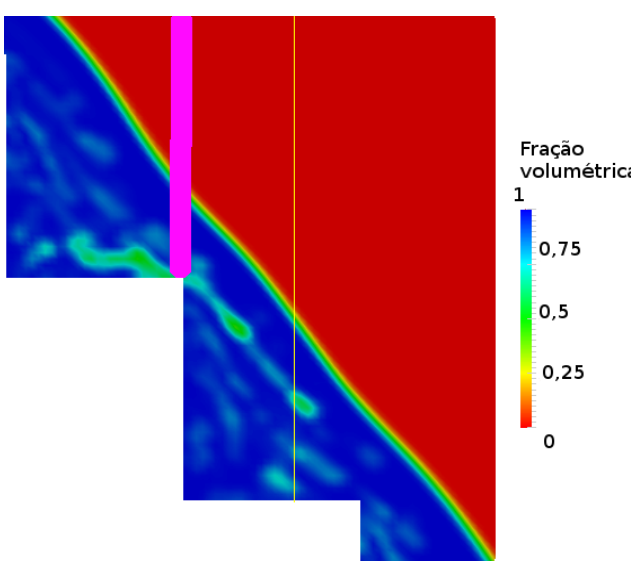

(b) Ilustração do Instante $t=25 \mathrm{~s}$

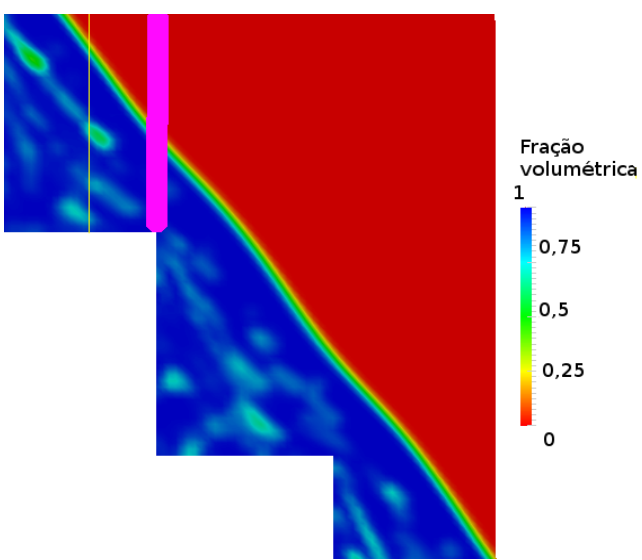

(d) Ilustração do Instante $t=25 \mathrm{~s}$

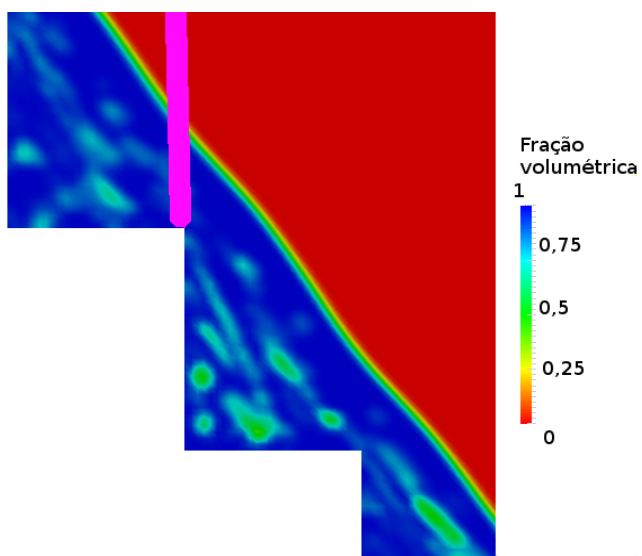

(f) Ilustração do Instante $t=25 \mathrm{~s}$

Figura 5.12: Perfis de concentração: malha de 2176794 elementos, $q=1.0 \mathrm{~m}^{2} / \mathrm{s}$, inclinação $51,3^{\circ}$. 


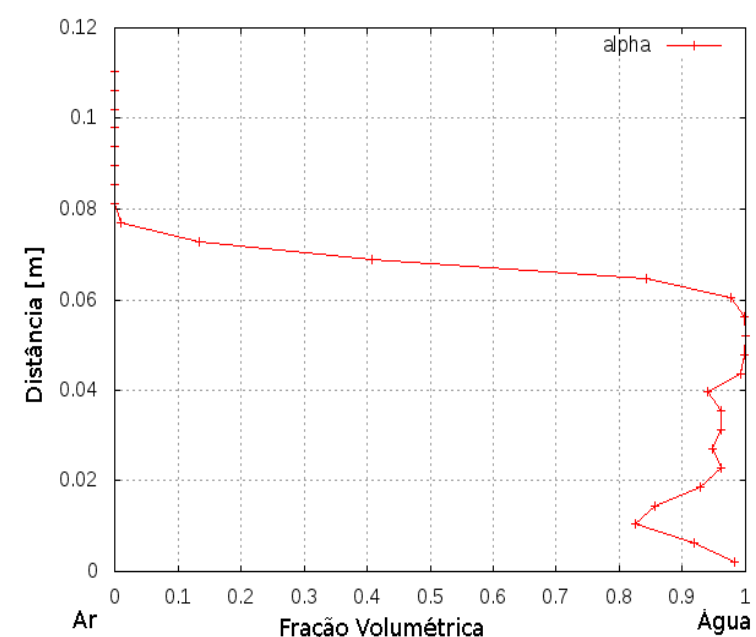

(a) Média Temporal - Degrau 7

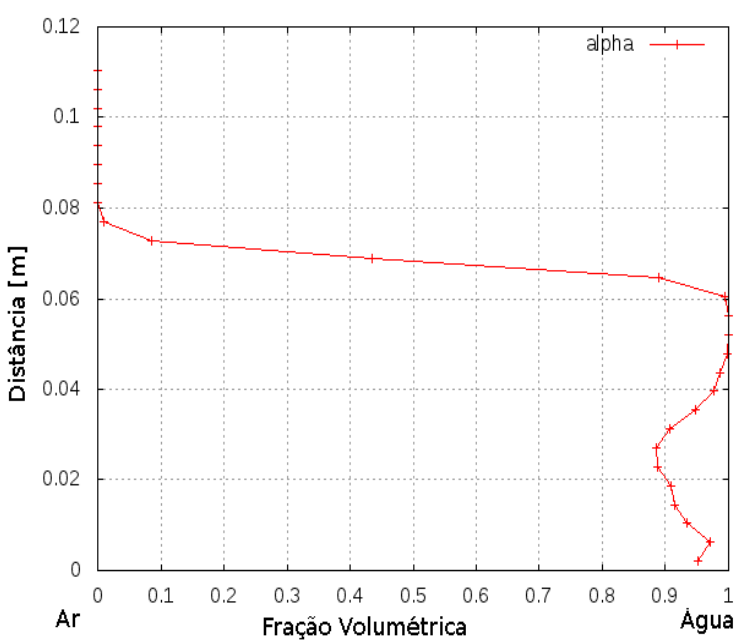

(c) Média Temporal - Degrau 8

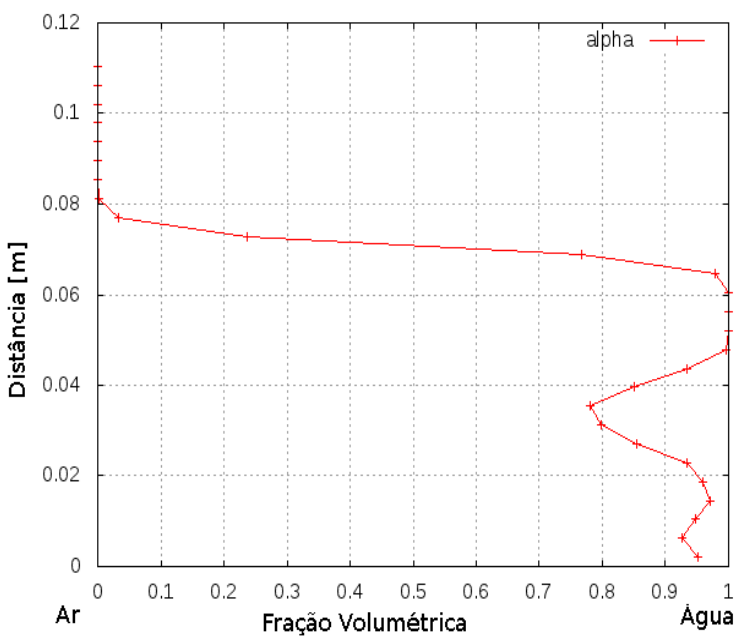

(e) Média Temporal - Degrau 9

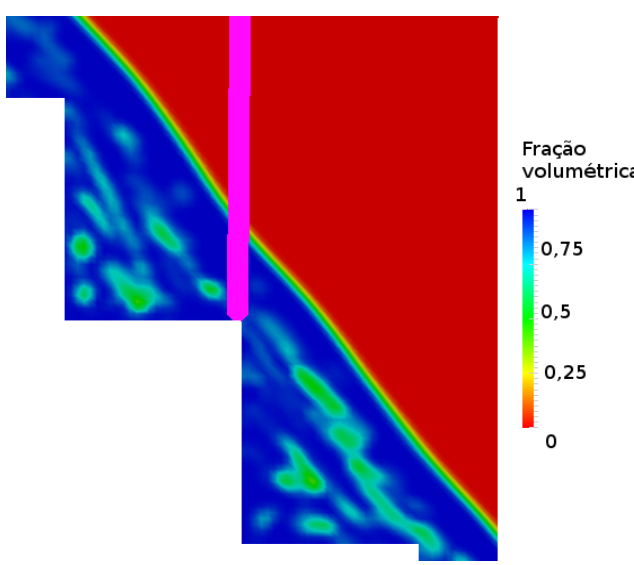

(b) Ilustração do Instante $t=25 \mathrm{~s}$

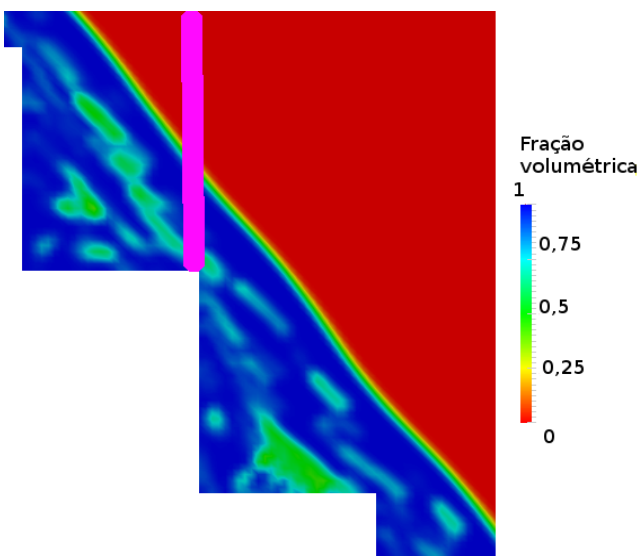

(d) Ilustração do Instante $t=25 \mathrm{~s}$

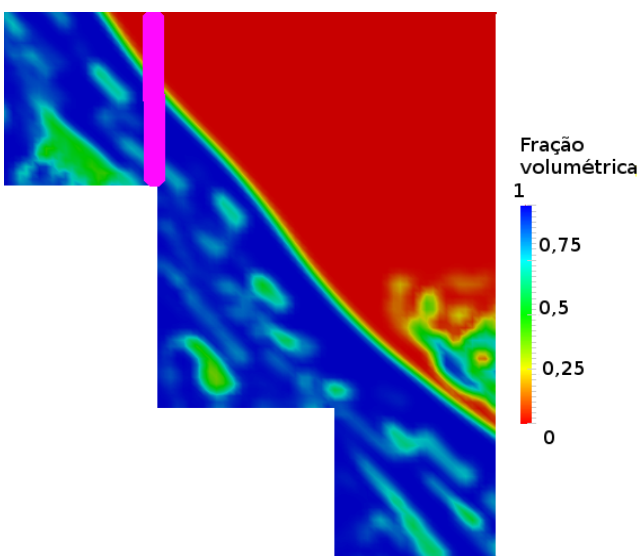

(f) Ilustração do Instante $t=25 \mathrm{~s}$

Figura 5.13: Perfis de concentração: malha de 2176794 elementos, $q=1.0 \mathrm{~m}^{2} / \mathrm{s}$, inclinação $51,3^{\circ}$. 


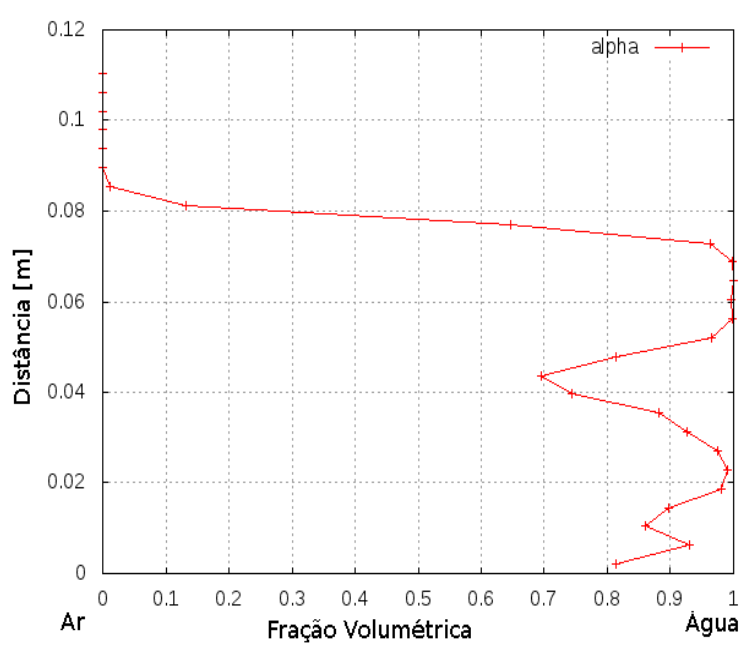

(a) Média Temporal - Degrau 10

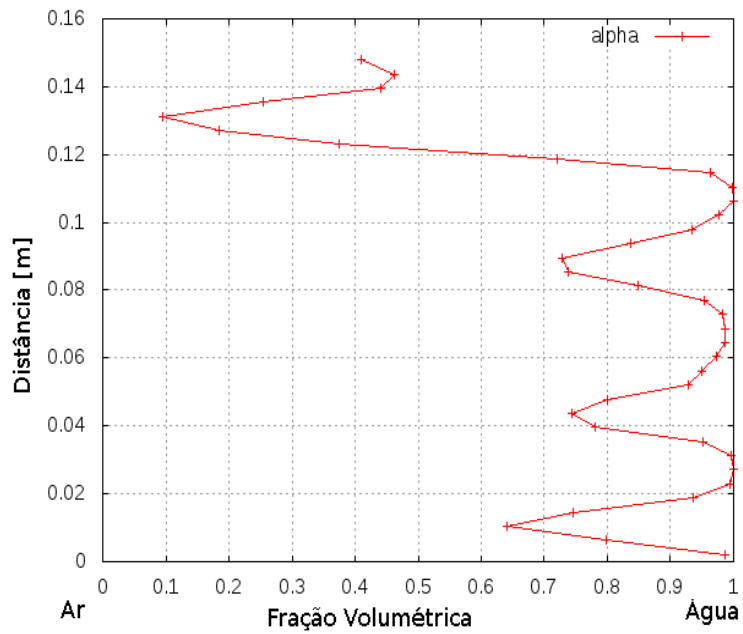

(c) Média Temporal - Degrau 11

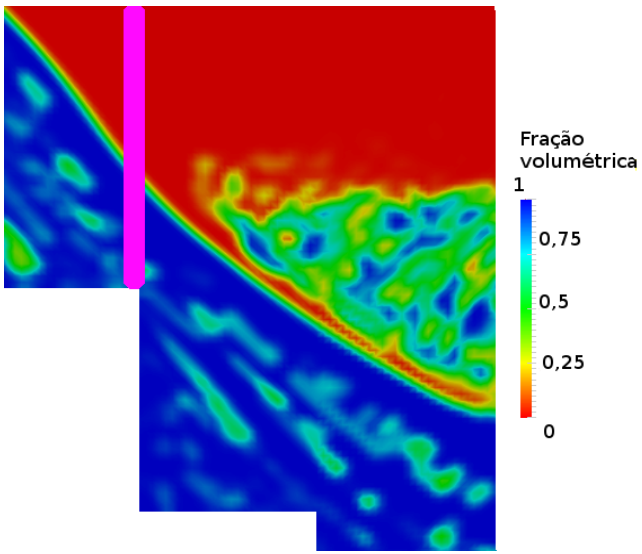

(b) Ilustração do Instante $t=25 \mathrm{~s}$

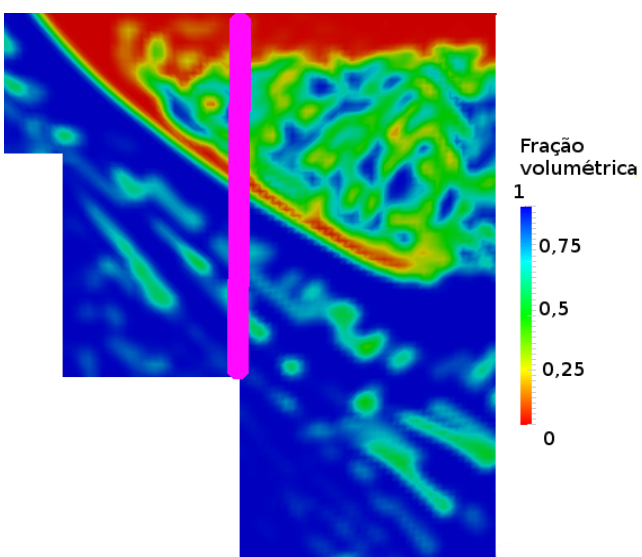

(d) Ilustração do Instante $t=25 \mathrm{~s}$

Figura 5.14: Perfis de concentração: malha de 2176794 elementos, $q=1.0 \mathrm{~m}^{2} / \mathrm{s}$, inclinação $51,3^{\circ}$. 


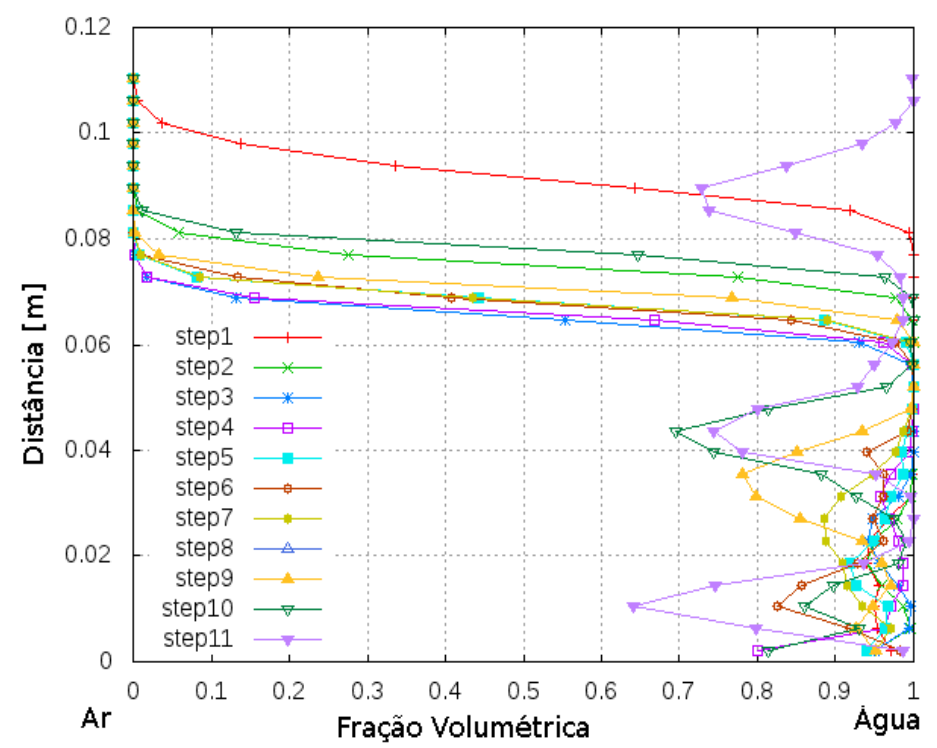

Figura 5.15: Perfil de distribuição da concentração ao longo dos degraus: malha de 2176794 elementos, $q=1.0 \mathrm{~m}^{2} / \mathrm{s}$, inclinação $51,3^{\circ}$.

Pelas Figuras 5.14 (b) e 5.14 (d) é possível observar a região de formação do ressalto hidráulico em que as perturbações da superfície livre são intensificadas. Conforme pode ser visto na Figura 5.14 (c) um maior número de elementos foram capturados ao longo da seção transversal e as oscilações na fração volumétrica média demonstram a intensificação da presença de gotas de ar disperças na água.

\subsubsection{Avaliação da concentração de ar - Alteração da vazão volumétrica}

Com o intuito de avaliar a influência do regime de escoamento, novos perfis de concentração foram obtidos para o escoamento submetido à vazões volumétricas maiores. Os resultados deram origem aos gráficos das Figuras 5.17 e 5.18 . Sendo eles para uma vazão volumétrica da ordem de 30\% maior que a vazão utilizada da Seção 5.2.2 e mesma malha computacional.

Pelas imagens que demonstram a sequência do escoamento ao longo da estrutura, Figura 5.16, é possível perceber que existe uma notável diminuição nas intermitências entre os degraus. 


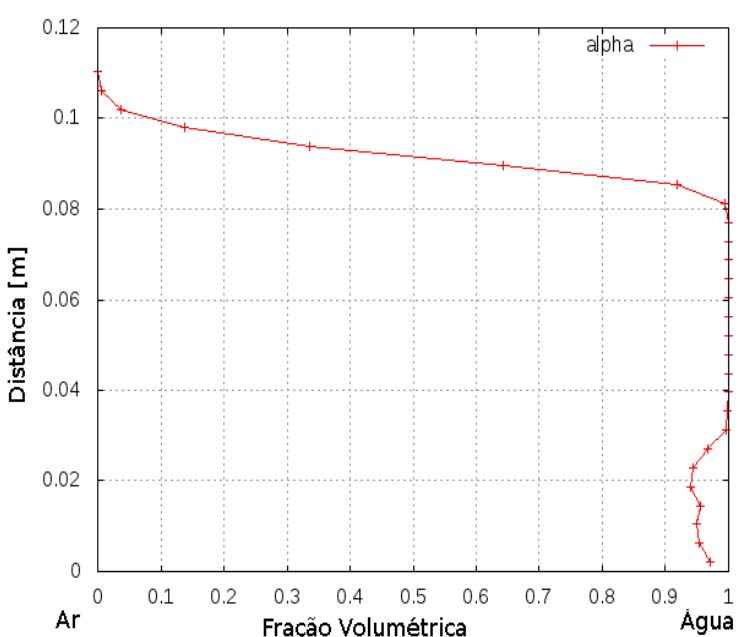

(a) Média Temporal - Degrau 3

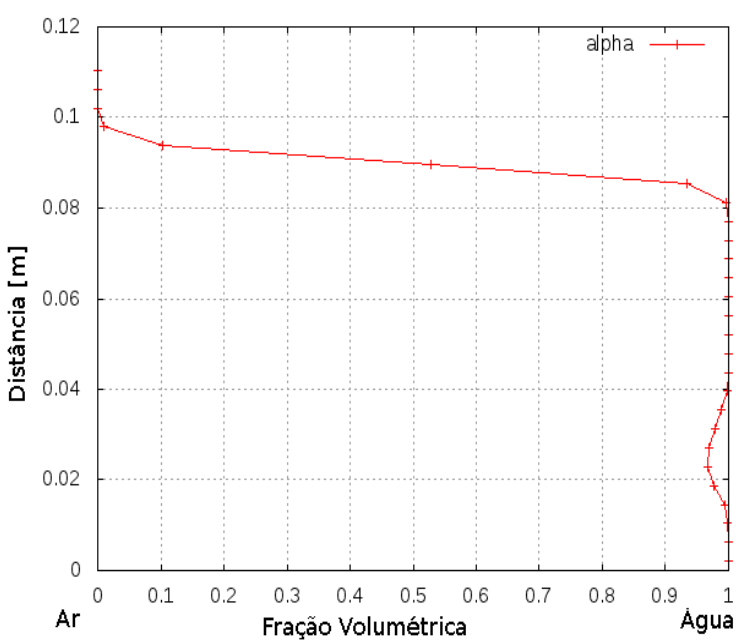

(c) Média Temporal - Degrau 6

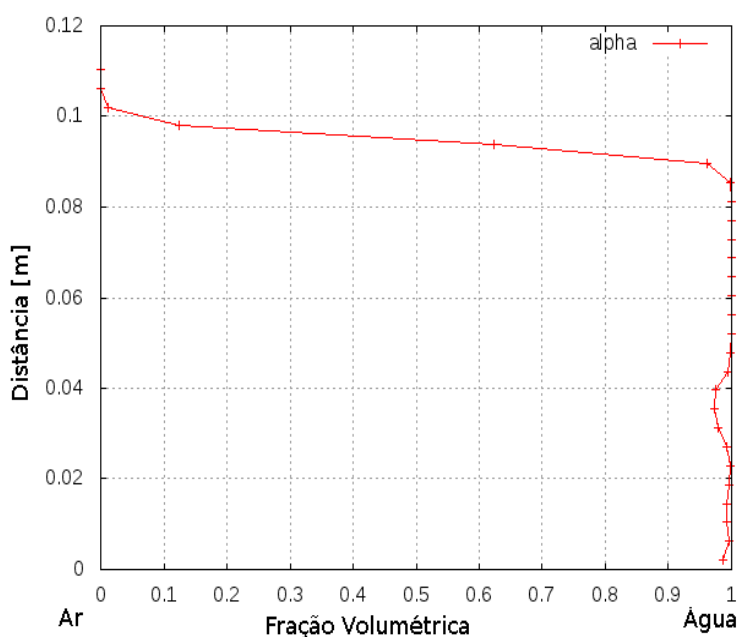

(e) Média Temporal - Degrau 9

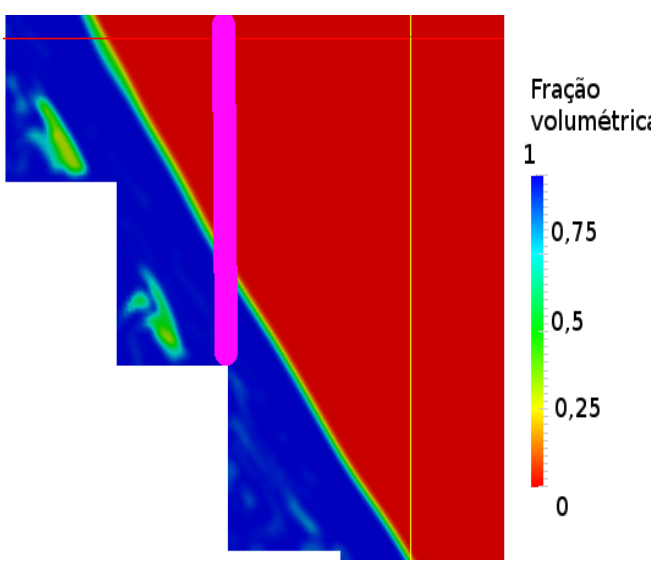

(b) Ilustração do Instante $t=25 \mathrm{~s}$

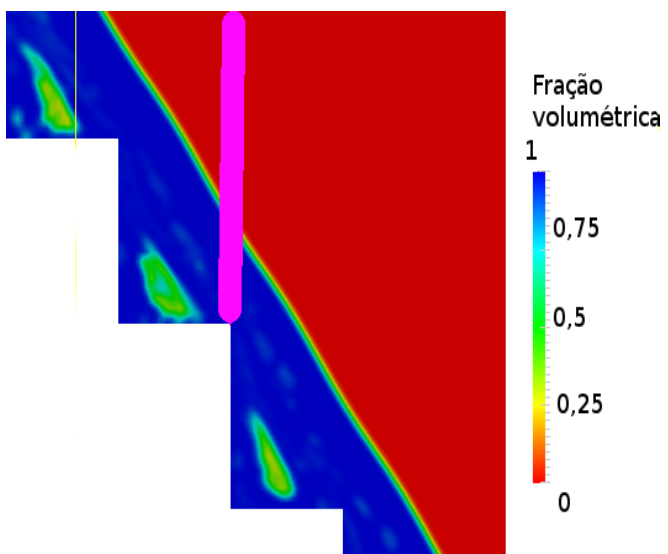

(d) Ilustração do Instante $t=25 \mathrm{~s}$

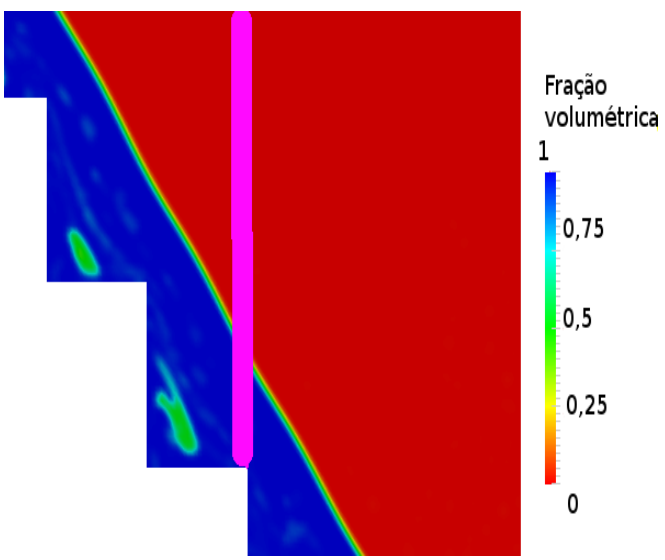

(f) Ilustração do Instante $t=25 \mathrm{~s}$

Figura 5.16: Perfis de concentração: malha de 2176794 elementos, $q=1.3 \mathrm{~m}^{2} / \mathrm{s}$, inclinação $51,3^{\circ}$. 


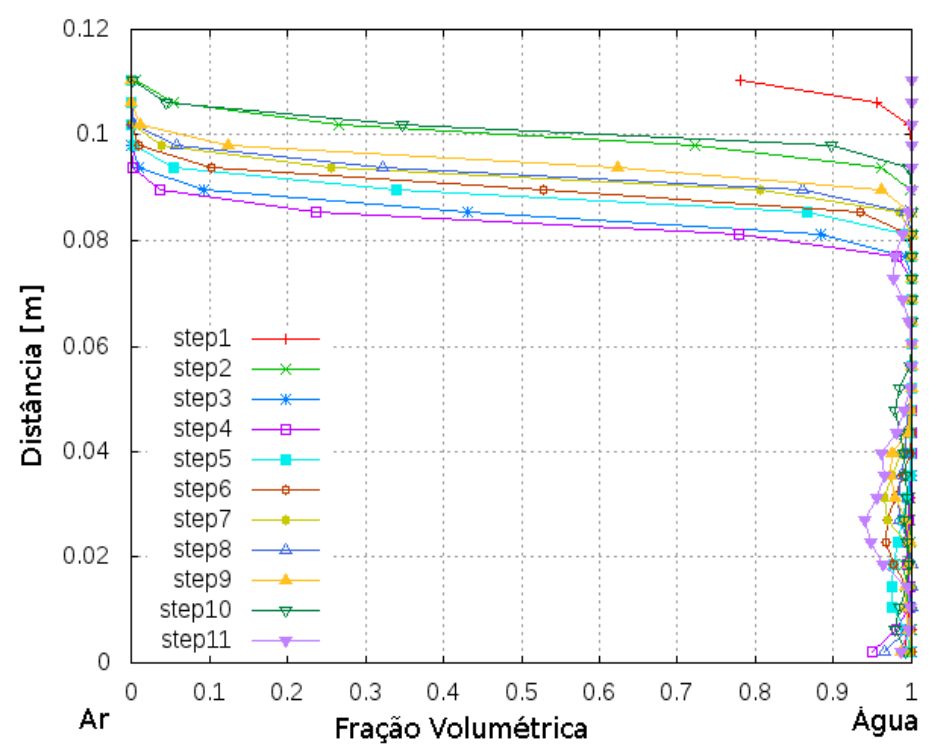

Figura 5.17: Perfil de distribuição da concentração ao longo dos degraus: malha de 2176794 elementos, $q=1.3 \mathrm{~m}^{2} / \mathrm{s}$, inclinação $51,3^{\circ}$.

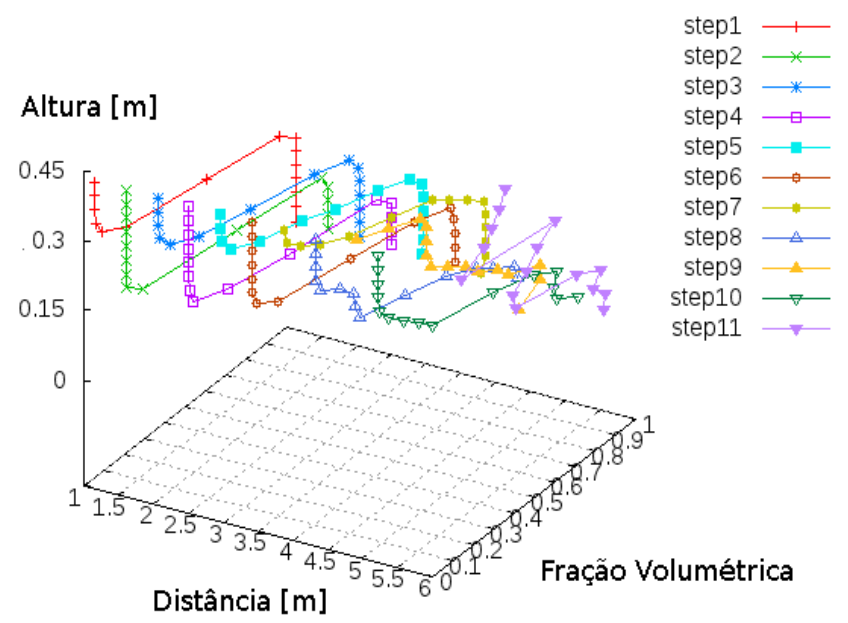

Figura 5.18: Perfil tridimensional da distribuição da concentração ao longo dos degraus: malha de 2176794 elementos, $q=1.3 \mathrm{~m}^{2} / \mathrm{s}$, inclinação $51,3^{\circ}$. 
Conforme esperado, os vórtices de recirculação na cavidade interna dos degraus tornaram-se bem definidos e podem ser visualizados nas Figuras 5.16(b), 5.16 (d) e 5.16 (f) . Quando comparado com os gráficos da Seção 5.2.2. eles tornam ainda mais evidentes as características dos regime dos escoamentos.

O efeito do posicionamento dos vórtices na cavidade interna do degrau pode ser notado na Figura 5.17 em que a fração volumétrica para a região próxima dos degraus tomada ao longo da seção transversal se mantém próxima da unidade, em contraste com os resultados ilustrados na Figura 5.15.

\subsubsection{Avaliação da concentração de ar - Considerações finais sobre o regime de escoamento}

Com um novo incremento na vazão volumértica anteriormente proposta, foi utilizada uma vazão da ordem de $50 \%$ superior à inicial. O resultado da avaliação da concentração ao longo de todos os degraus pode ser visualizado na Figura 5.23. Os vórtices do pseudo fundo acentuam-se visivelmente com relação a vazão anterior. A submersão dos últimos degraus é o fator que causa o comportamento diferenciado do $11^{\circ}$ degrau ao longo dos gráficos. O comportamento de um escoamento do tipo deslizamento sobre vórtices pode, entretanto ser constatado. Os perfis de pressão e velocidade, são analisados adiante e complementam a caracterização do escoamento com respeito à dissipação de energia e a aeração propriamente dita.

O Gráfico 5.24 faz uma comparação da alteração do perfil de concentração para o sexto degrau em relação a descarga medida em $\mathrm{m}^{3} / s . m$. O gráfico pode ser comparado com os resultados publicados por Sarfaraz et al. (2012) que fez uma análise numérica para diferentes vazões em vertedores em degraus. Pelo gráfico é fácil notar a influência da posição das bolhas de ar com as vazões do escoamento, ou seja, com o aumento da vazão os vórtices de recirculação se posicionam na cavidade interna do degrau. 


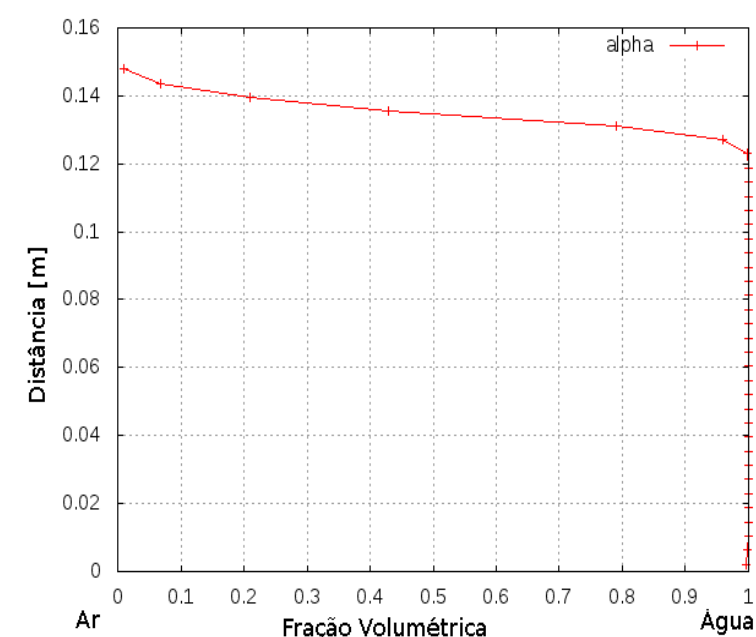

(a) Média Temporal - Degrau 1

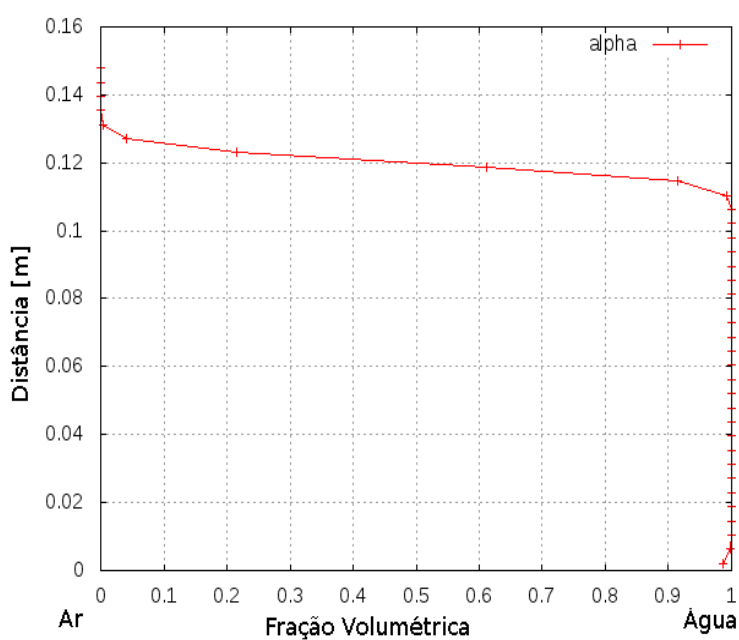

(c) Média Temporal - Degrau 2

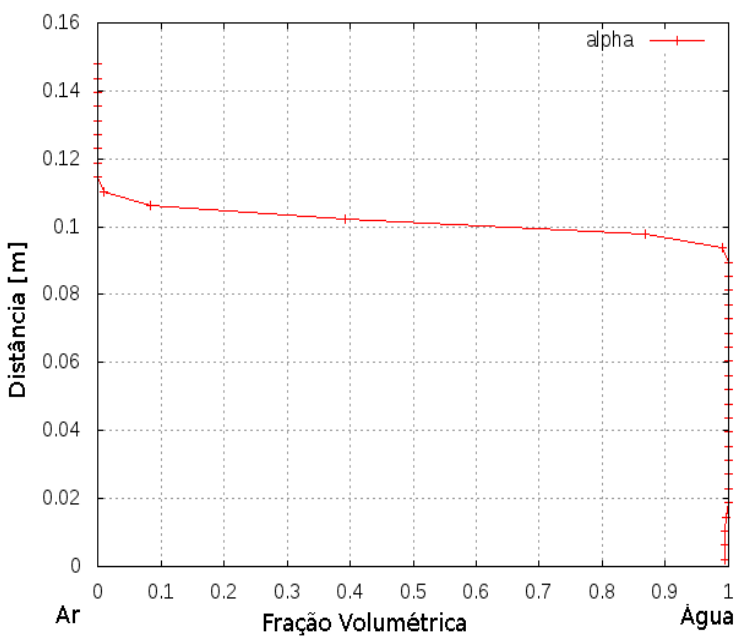

(e) Média Temporal - Degrau 3

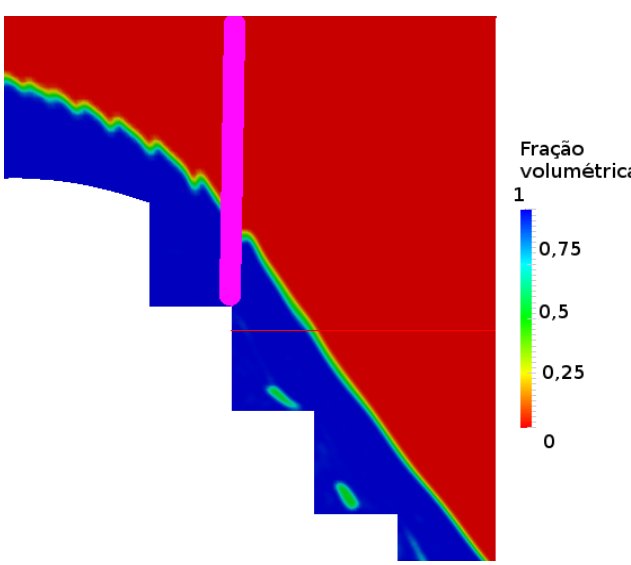

(b) Ilustração do Instante $t=25 \mathrm{~s}$

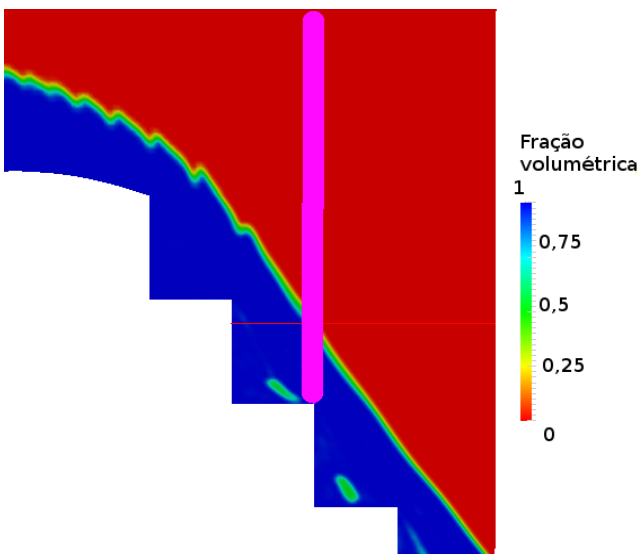

(d) Ilustração do Instante $t=25 \mathrm{~s}$

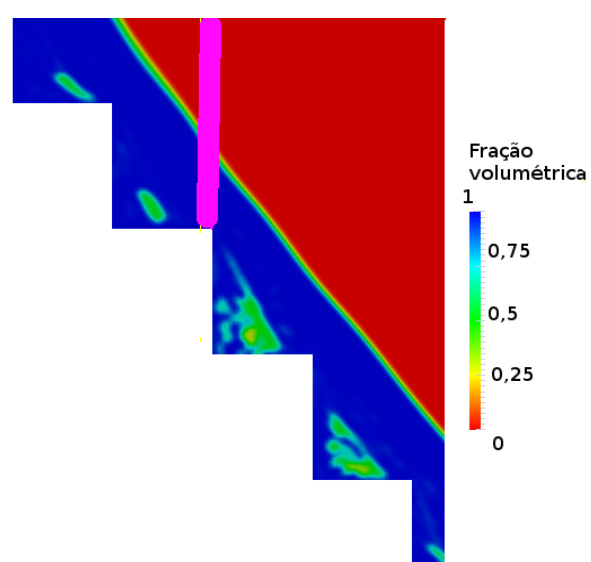

(f) Ilustração do Instante $t=25 \mathrm{~s}$

Figura 5.19: Perfis de concentração: malha de 2176794 elementos, $q=1.5 \mathrm{~m}^{2} / \mathrm{s}$, inclinação $51,3^{\circ}$. 


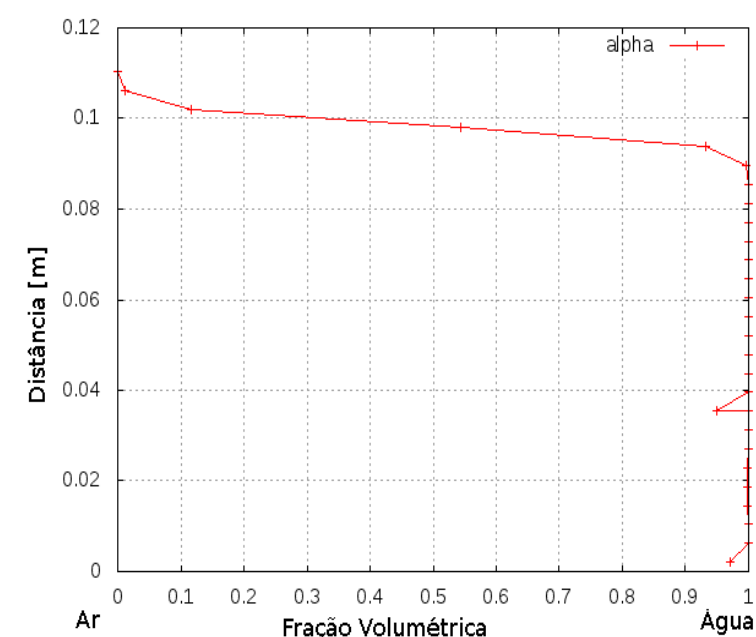

(a) Média Temporal - Degrau 4

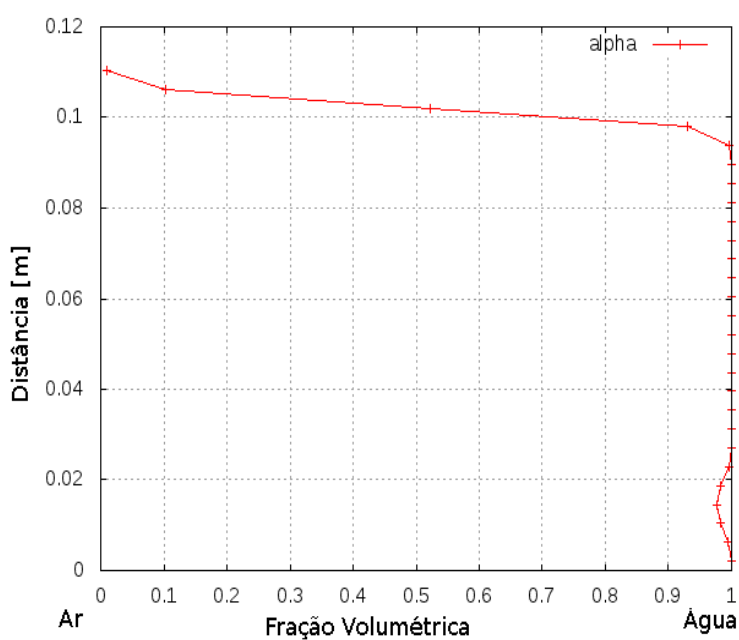

(c) Média Temporal - Degrau 5

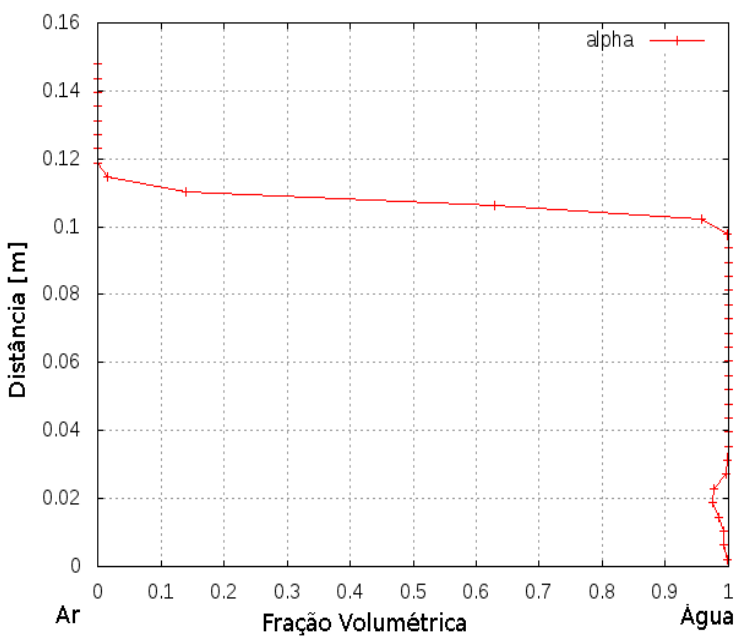

(e) Média Temporal - Degrau 6

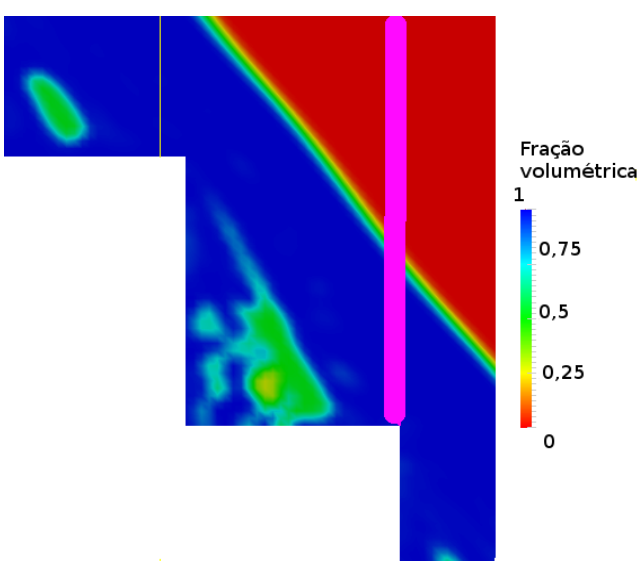

(b) Ilustração do Instante $t=25 \mathrm{~s}$

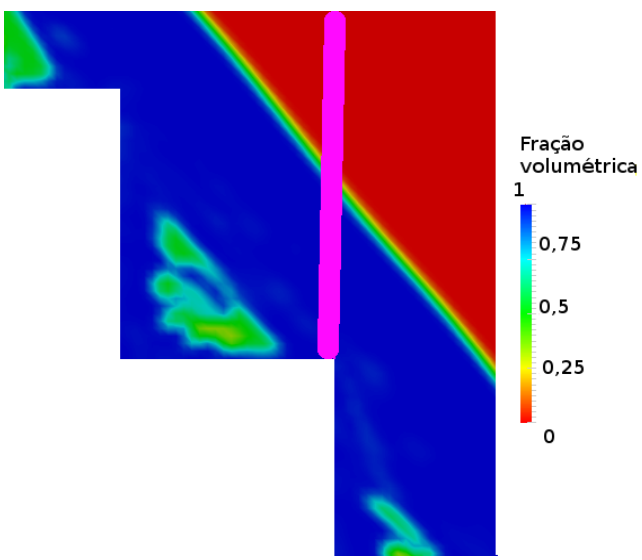

(d) Ilustração do Instante $t=25 \mathrm{~s}$

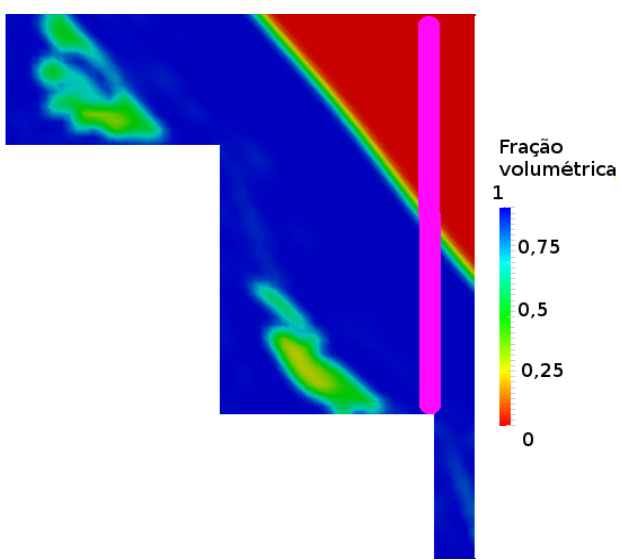

(f) Ilustração do Instante $t=25 \mathrm{~s}$

Figura 5.20: Perfis de concentração: malha de 2176794 elementos, $q=1.5 \mathrm{~m}^{2} / \mathrm{s}$, inclinação $51,3^{\circ}$. 


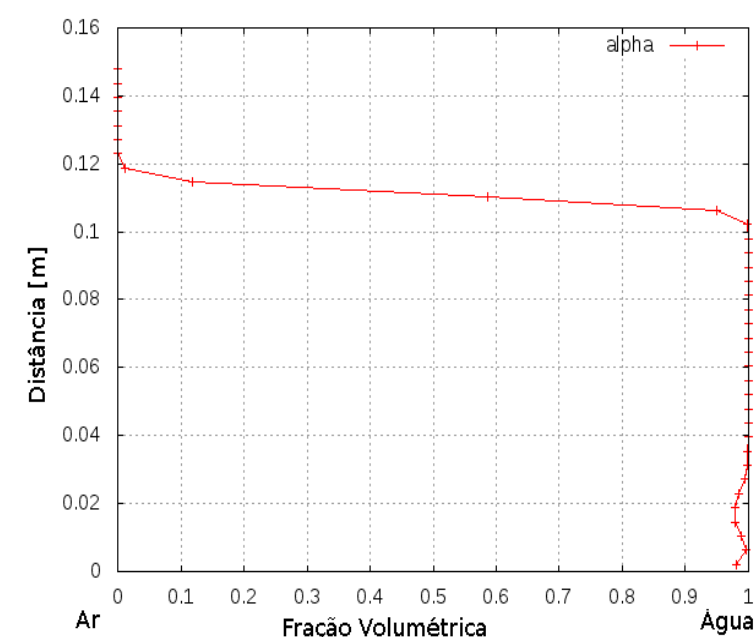

(a) Média Temporal - Degrau 7

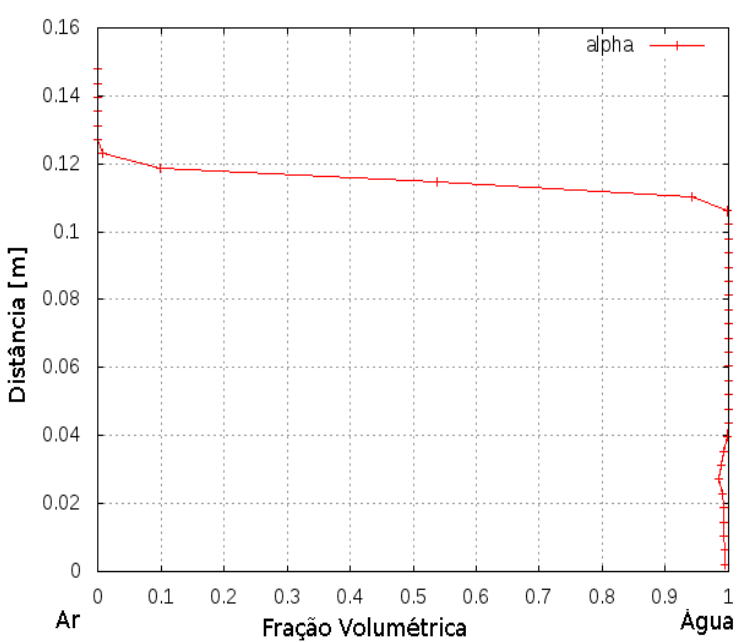

(c) Média Temporal - Degrau 8

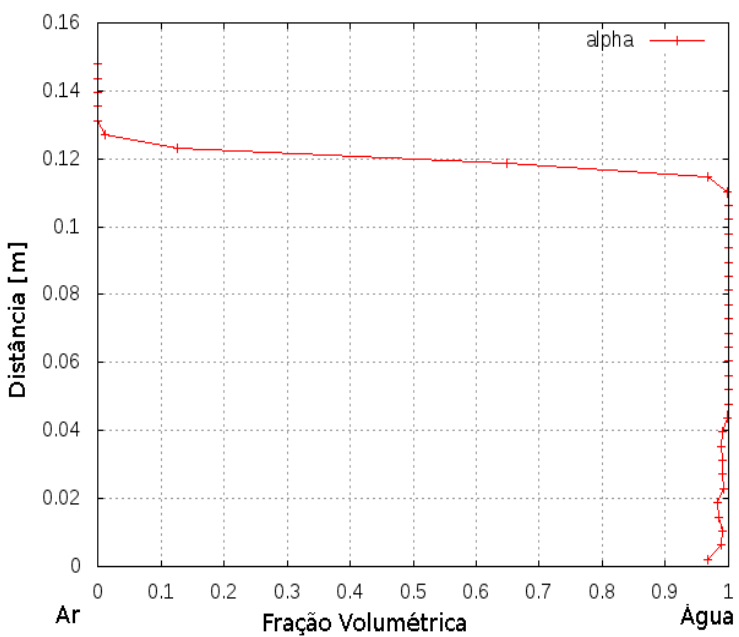

(e) Média Temporal - Degrau 9

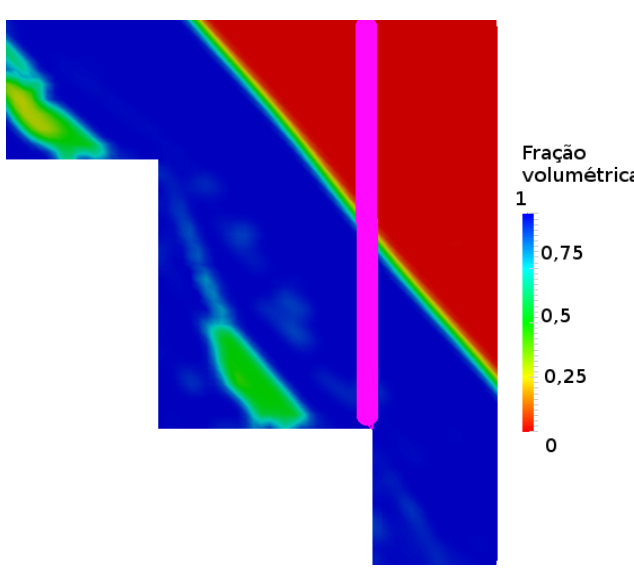

(b) Ilustração do Instante $t=25 \mathrm{~s}$

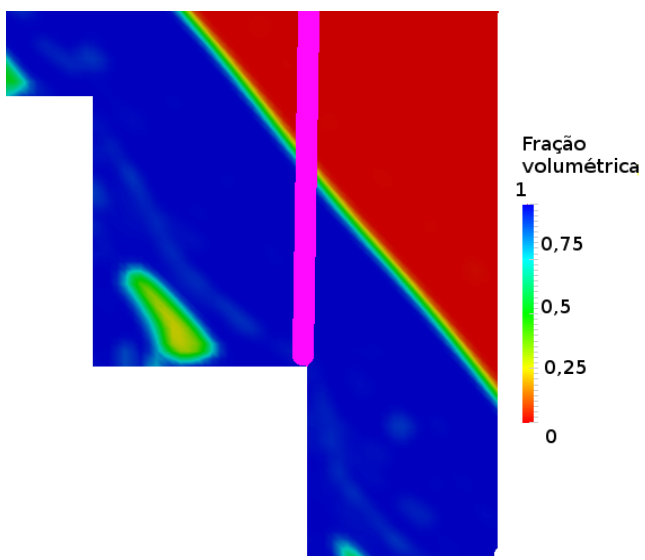

(d) Ilustração do Instante $t=25 \mathrm{~s}$

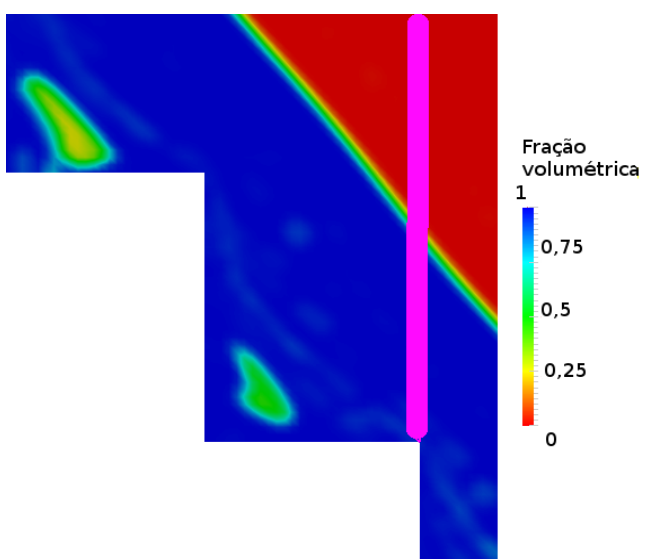

(f) Ilustração do Instante $t=25 \mathrm{~s}$

Figura 5.21: Perfis de concentração: malha de 2176794 elementos, $q=1.5 \mathrm{~m}^{2} / \mathrm{s}$, inclinação $51,3^{\circ}$. 


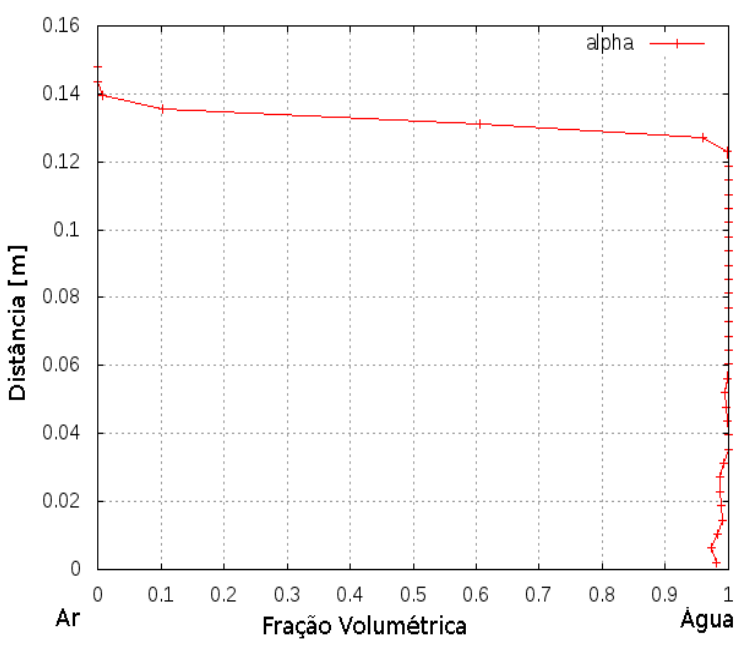

(a) Média Temporal - Degrau 10

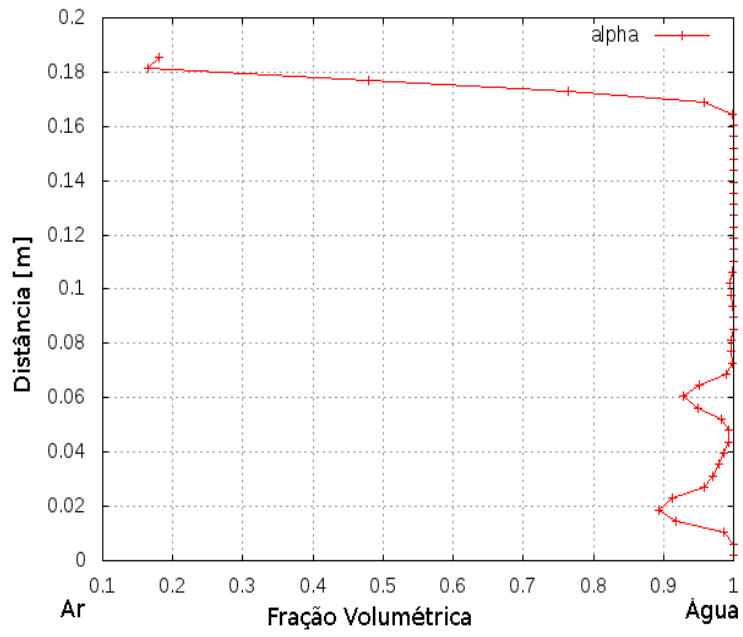

(c) Média Temporal - Degrau 11

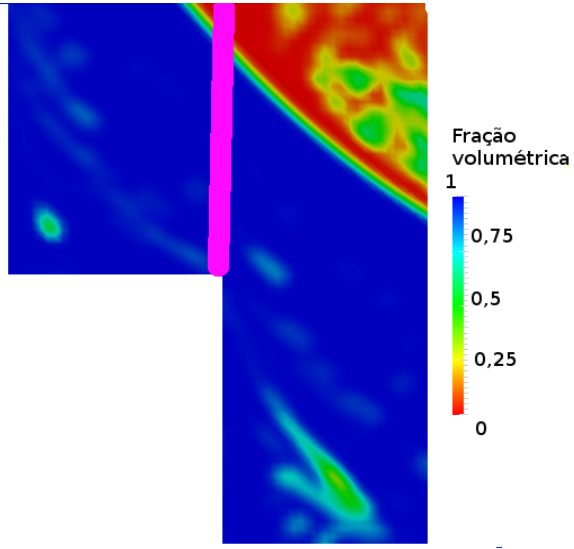

(b) Ilustração do Instante $t=25 \mathrm{~s}$

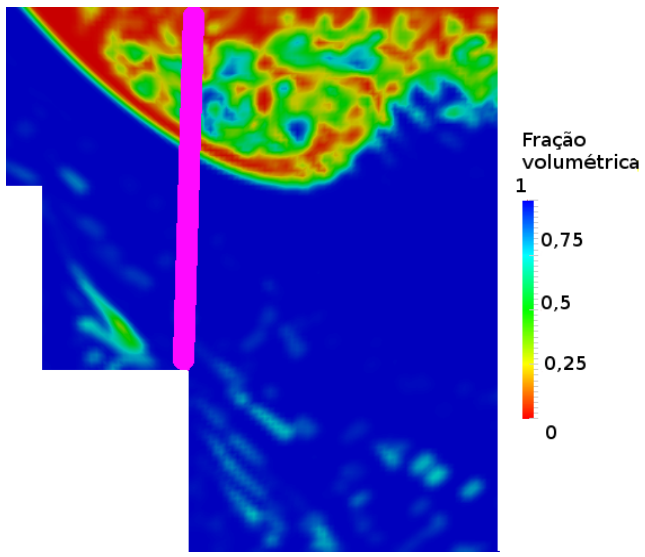

(d) Ilustração do Instante $t=25 \mathrm{~s}$

Figura 5.22: Perfis de concentração: malha de 2176794 elementos, $q=1.5 \mathrm{~m}^{2} / \mathrm{s}$, inclinação $51,3^{\circ}$. 


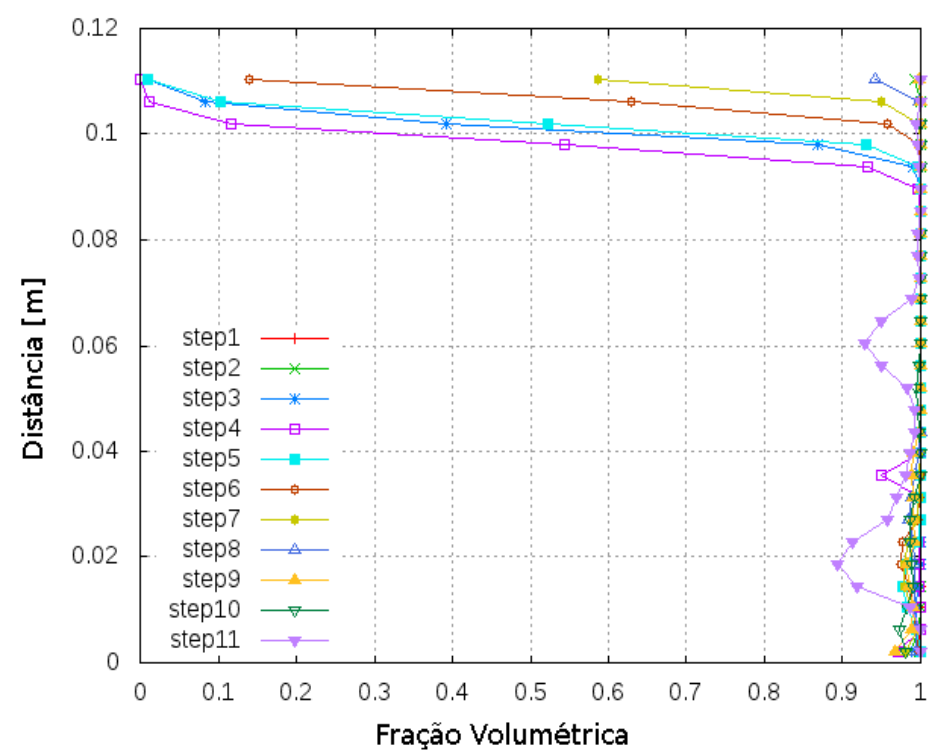

Figura 5.23: Perfil tridimensional da distribuição da concentração ao longo dos degraus: malha de 2176794 elementos, $q=1.5 \mathrm{~m}^{2} / \mathrm{s}$, inclinação $51,3^{\circ}$.

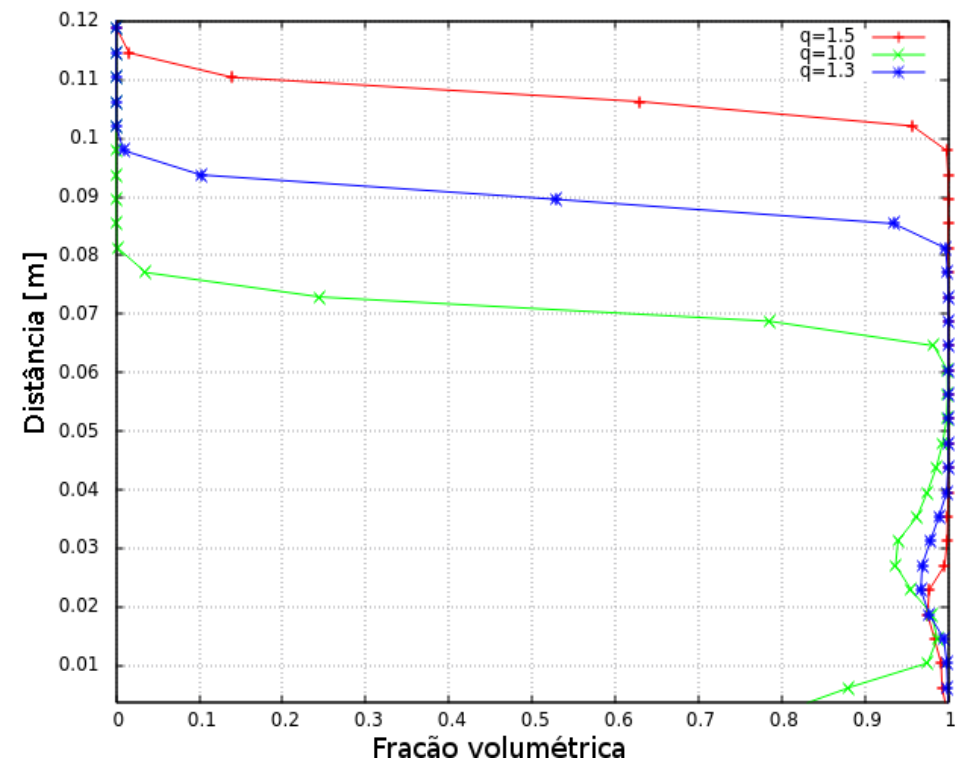

Figura 5.24: Perfil de distribuição da concentração ao longo do sexto degrau - uma comparação entre as diferentes vazões [vazão inicial $1,0 \mathrm{~m}^{2} / \mathrm{s}$ em verde, intermediária $1,3 \mathrm{~m}^{2} / \mathrm{s}$ em azul e $1,5 \mathrm{~m}^{2} / \mathrm{s}$ em vermelho]. 


\subsection{Verificando a influência do perfil de entrada}

Buscando uma análise da influência dos degraus de transição na entrada do vertedouro sobre o desenvolvimento da interface entre o ar e a água, uma geometria com degraus de transição foi analisada. A malha hexaédrica de representação do domínio computacional possui 4136000 elementos. Os perfis obtidos, deram origem ao gráfico da Figura 5.29. Os perfis de pressão e velocidade, foram analisados na próxima seção e permitem à completa caracterização do escoamento.

Através das Figuras 5.25 (d) e 5.26 (b) é possível afirmar que o regime de escoamento de deslizamento sobre vórtices está bem representadado.

Considerações à respeito da perturbação da interface na região inicial da estrutura hidráulica (conforme mostra as Figuras 5.25(d) e 5.25(f)) são feitas na Seção 5.6.

\subsubsection{Expansão da superfície livre - comparação com a formulação teórica}

Para análise da expansão da superfície livre fez-se uso das frações volumétricas médias ao longo da seção transversal dos degraus e das condições operacionais acima descritas. A expansão do escoamento pela entrada de ar pode ser mensurada, pelas regiões das alturas características, conforme descrito na Seção 2.4.

A Figura 5.30(f) demosntra a seção transversal ao longo do segundo e do nono degrau. Pelo cálculo da vazão de ar incorporada é possível prever que no nono degrau a vazão de ar é de $1,41 \mathrm{~m}^{3} / \mathrm{s}$ enquanto no segundo degrau é $0,78 \mathrm{~m}^{3} / \mathrm{s}$.

Fazendo uso de uma analogia dos dados obtidos numericamente e a formulação teórica podemos visualizar o perfil normalizado, em que a linha vermelha representa os dados obtidos numericamente através da simulação, conforme mostra a Figura 5.31. 


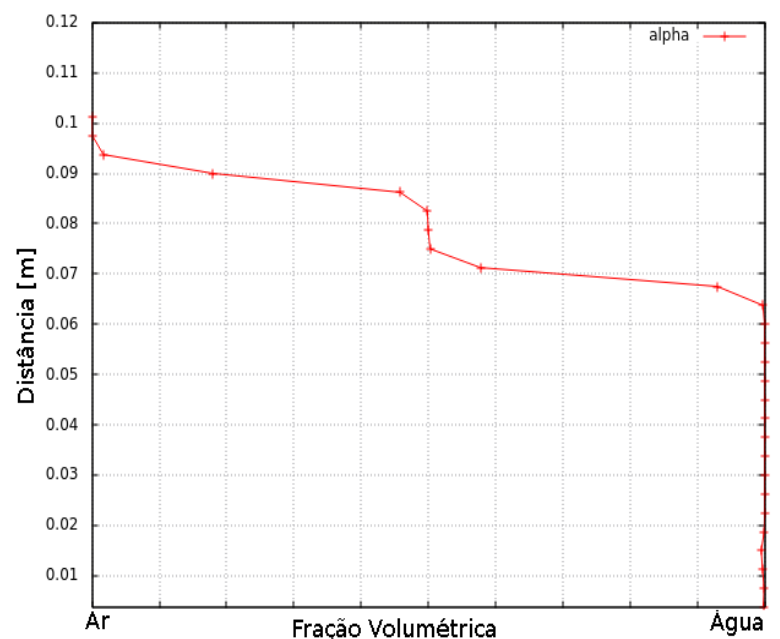

(a) Média Temporal - Degrau 1

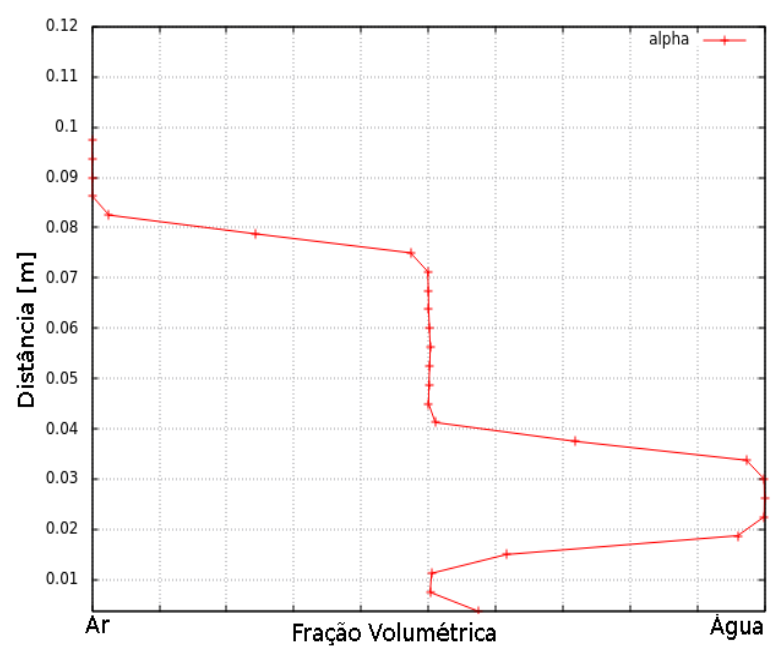

(c) Média Temporal - Degrau 2

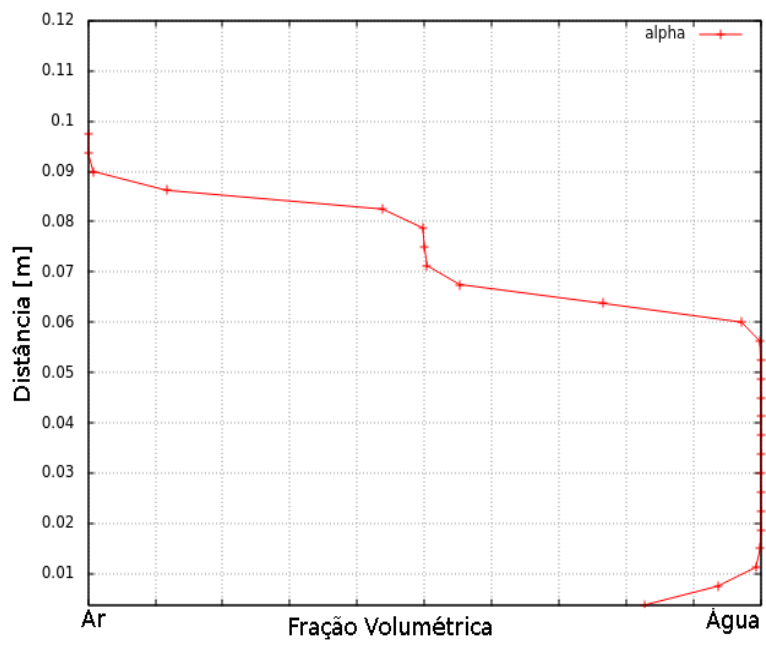

(e) Média Temporal - Degrau 3

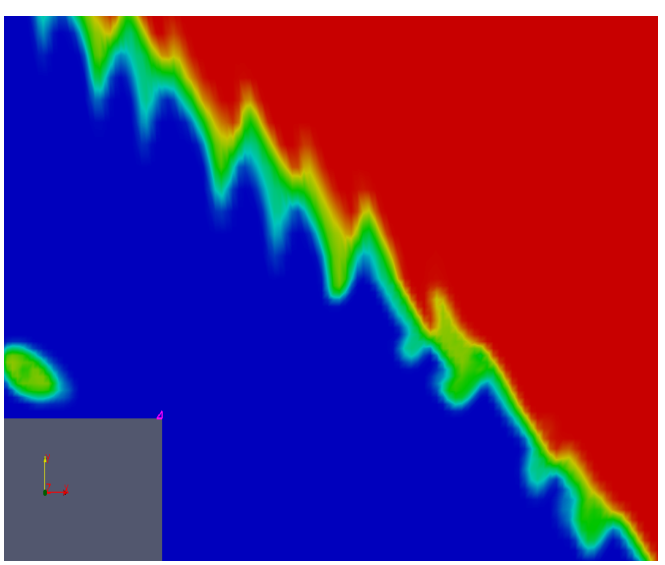

(b) Ilustração do Instante $t=25 \mathrm{~s}$

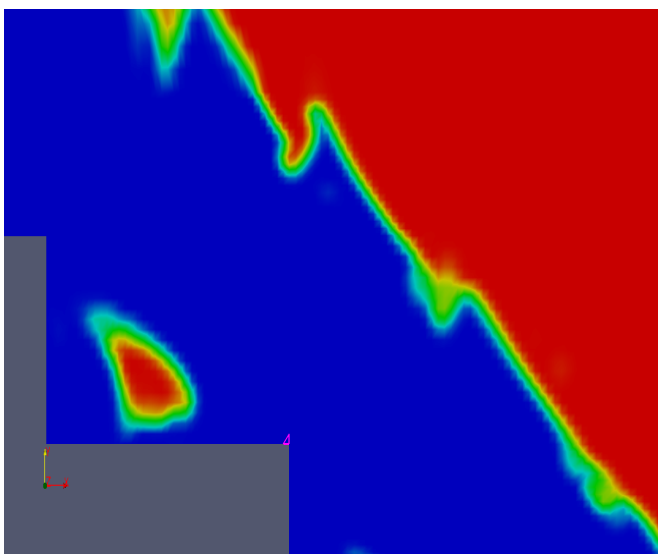

(d) Ilustração do Instante $t=25 \mathrm{~s}$

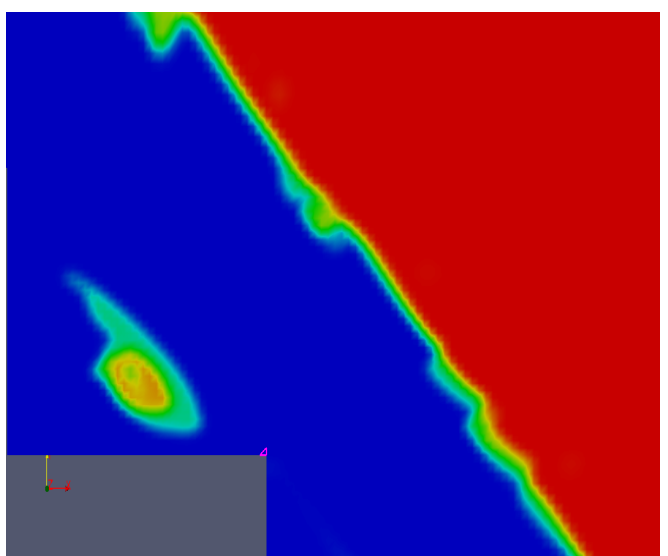

(f) Ilustração do Instante $t=25 \mathrm{~s}$

Figura 5.25: Perfis de concentração da estrutura com degraus de transição na entrada: malha de 4136000 elementos, inclinação $51,3^{\circ}$. 


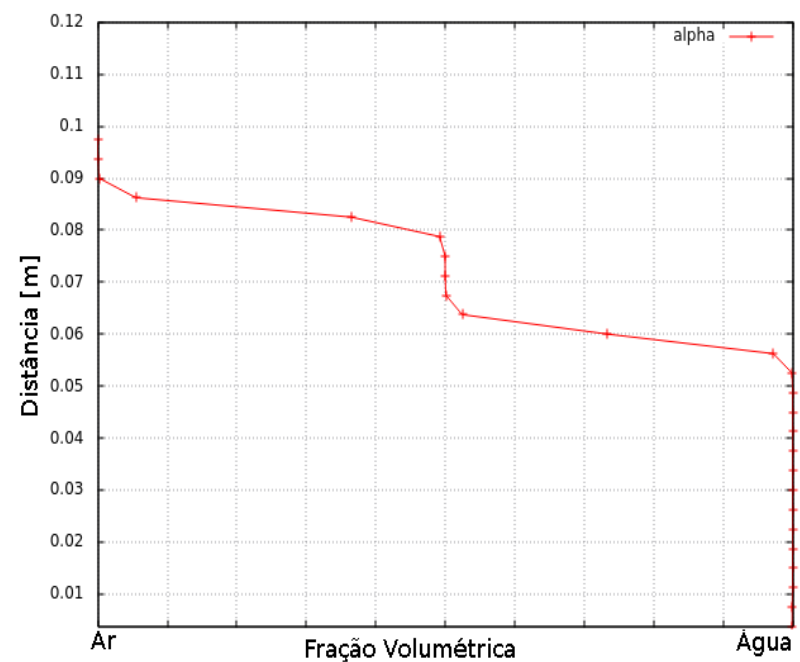

(a) Média Temporal - Degrau 4

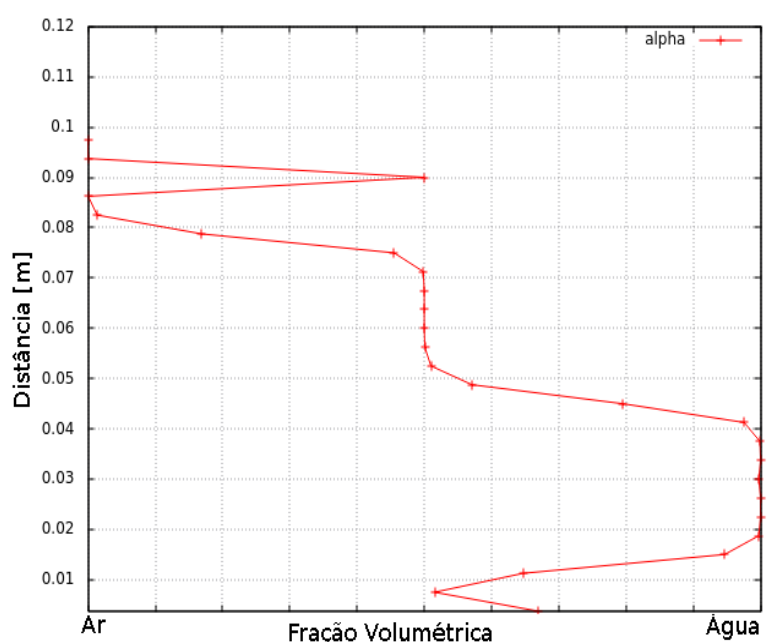

(c) Média Temporal - Degrau 5

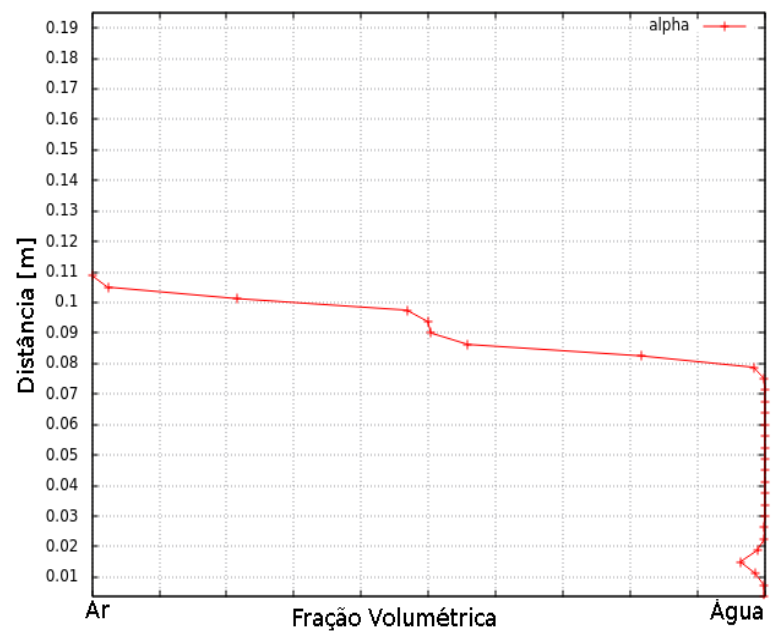

(e) Média Temporal - Degrau 6

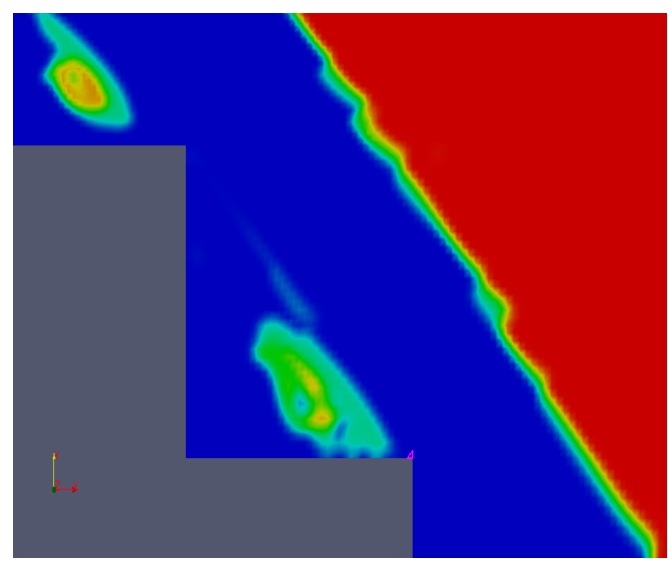

(b) Ilustração do Instante $t=25 \mathrm{~s}$

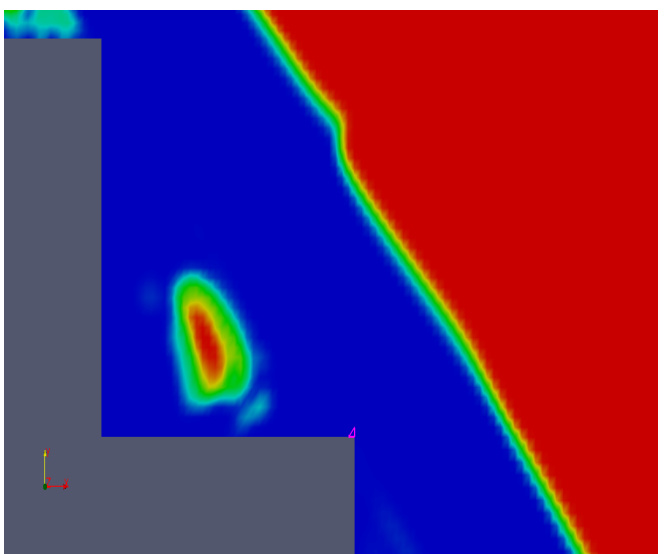

(d) Ilustração do Instante $t=25 \mathrm{~s}$

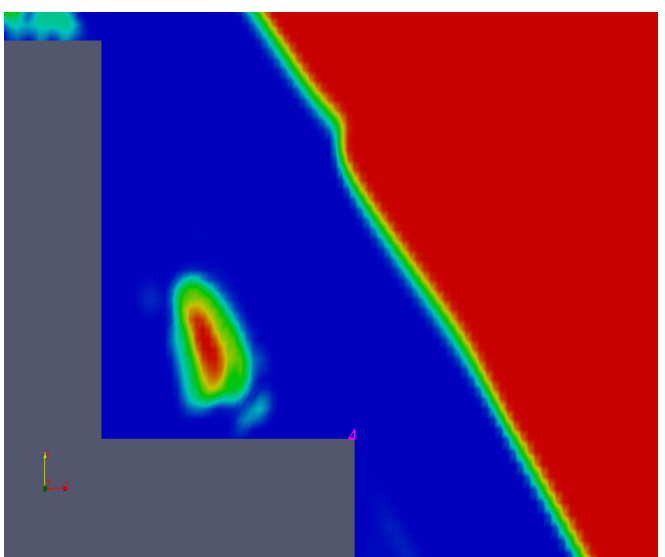

(f) Ilustração do Instante $t=25 \mathrm{~s}$

Figura 5.26: Perfis de concentração da estrutura com degraus de transição na entrada: malha de 4136000 elementos, inclinação $51,3^{\circ}$. 


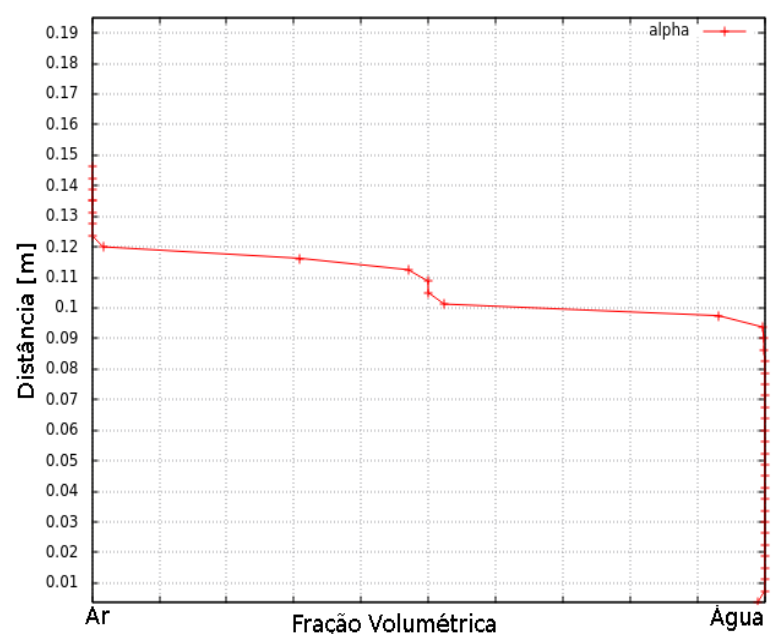

(a) Média Temporal - Degrau 7

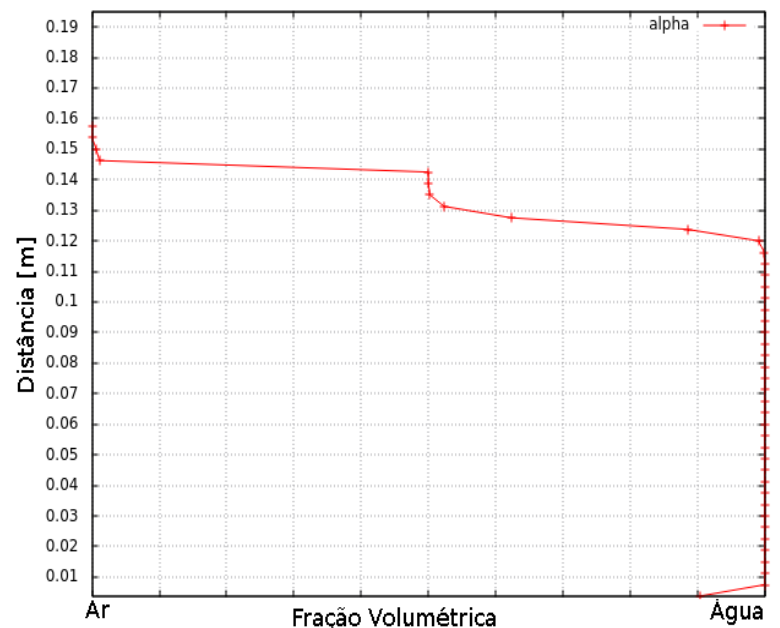

(c) Média Temporal - Degrau 8

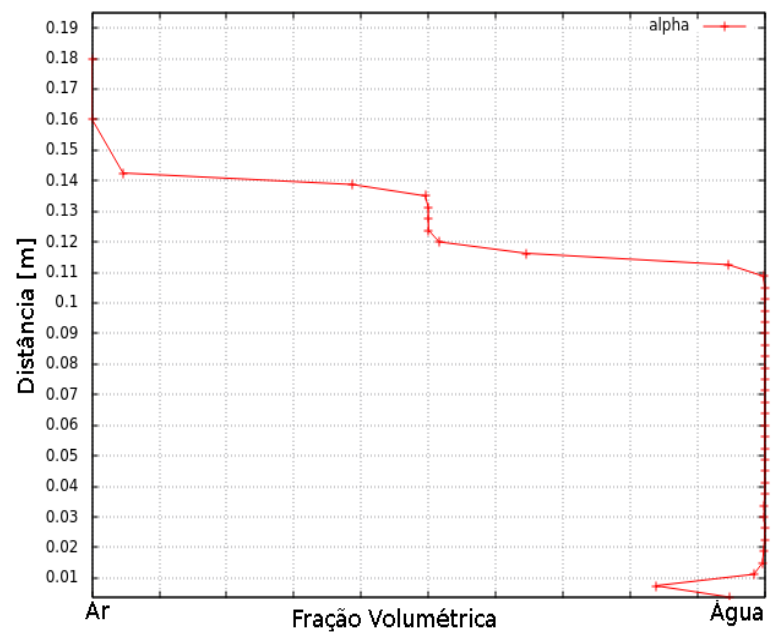

(e) Média Temporal - Degrau 9

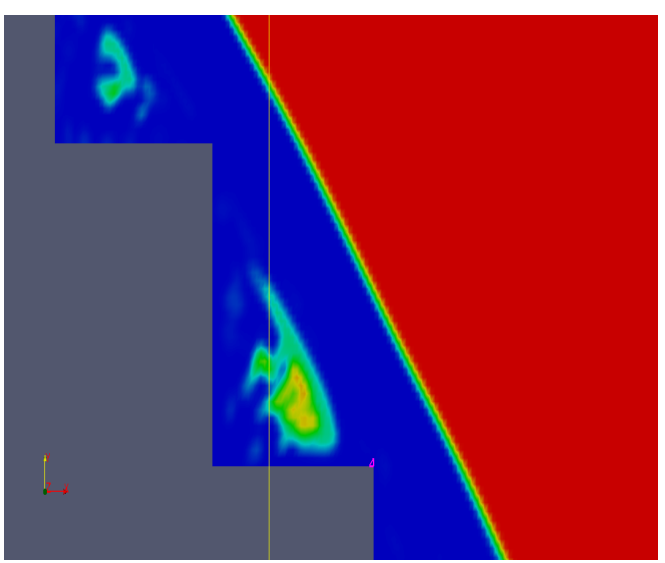

(b) Ilustração do Instante $t=25 \mathrm{~s}$

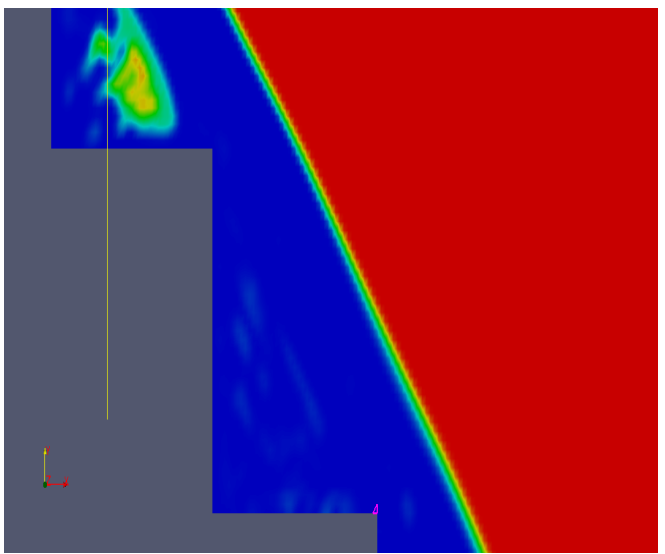

(d) Ilustração do Instante $t=25 \mathrm{~s}$

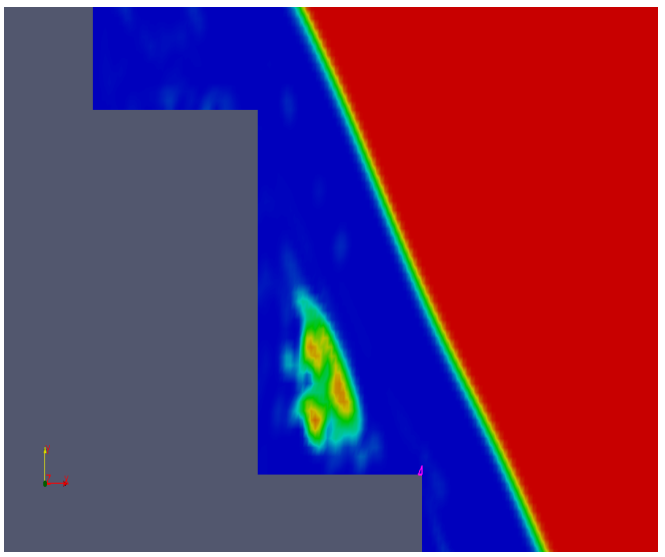

(f) Ilustração do Instante $t=25 \mathrm{~s}$

Figura 5.27: Perfis de concentração da estrutura com degraus de transição na entrada: malha de 4136000 elementos, inclinação $51,3^{\circ}$. 


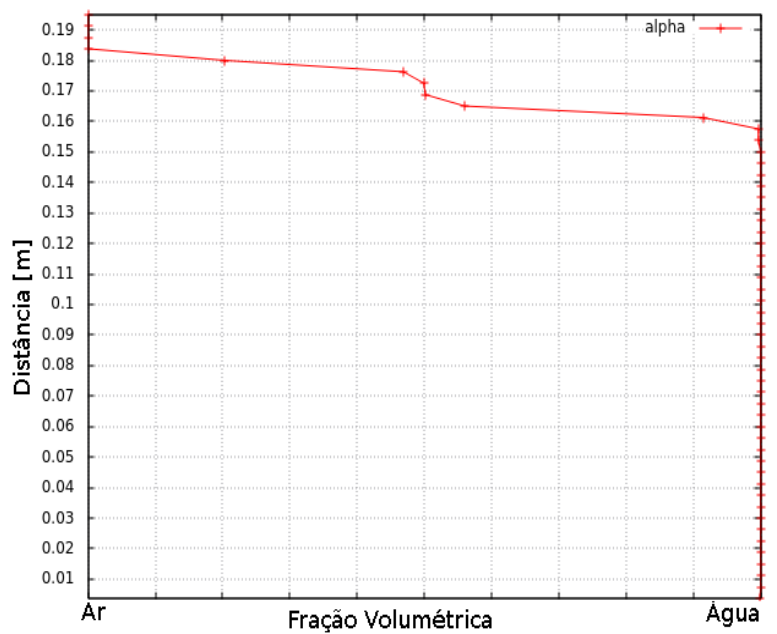

(a) Média Temporal - Degrau 10

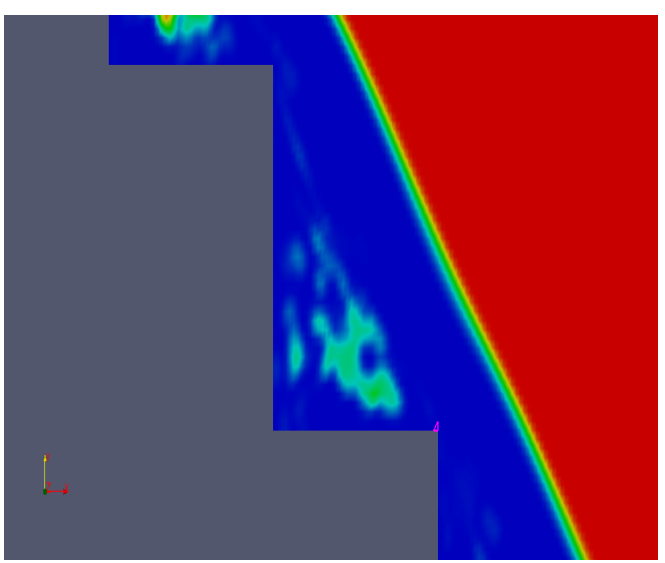

(b) Ilustração do Instante $t=25 \mathrm{~s}$

Figura 5.28: Perfis de concentração da estrutura com degraus de transição na entrada: malha de 4136000 elementos, inclinação $51,3^{\circ}$.

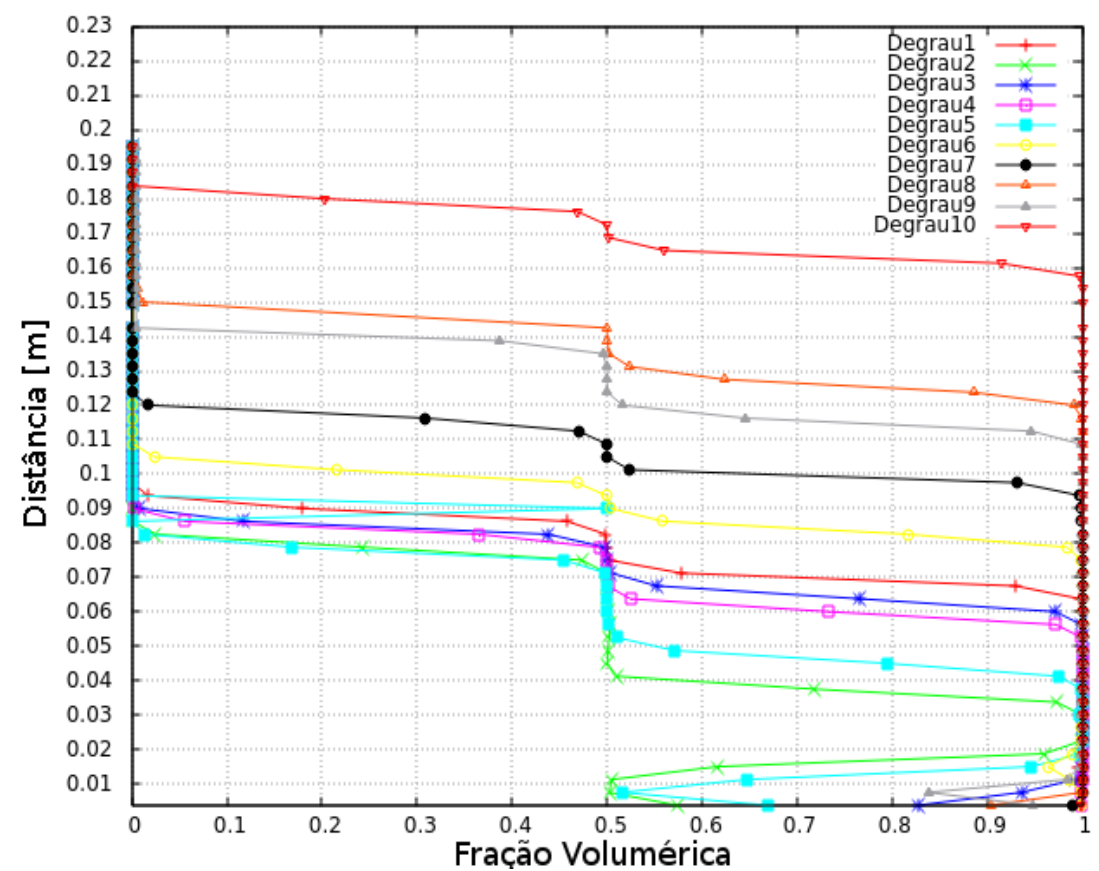

Figura 5.29: Perfil tridimensional da distribuição da concentração ao longo dos degraus: malha de 4136000 elementos, inclinação 51, $3^{\circ}$. 

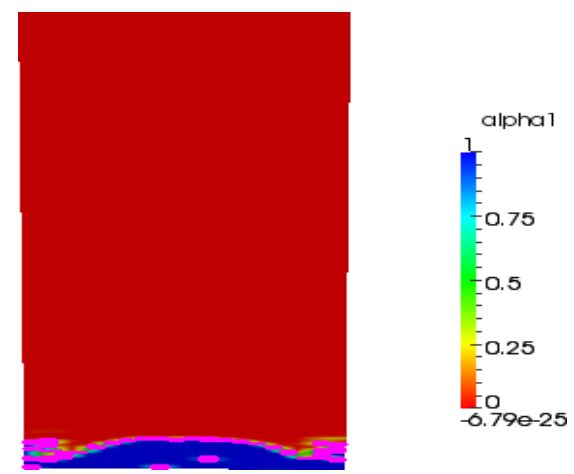

Figura 5.30: Seção transversal do nono degrau simulado

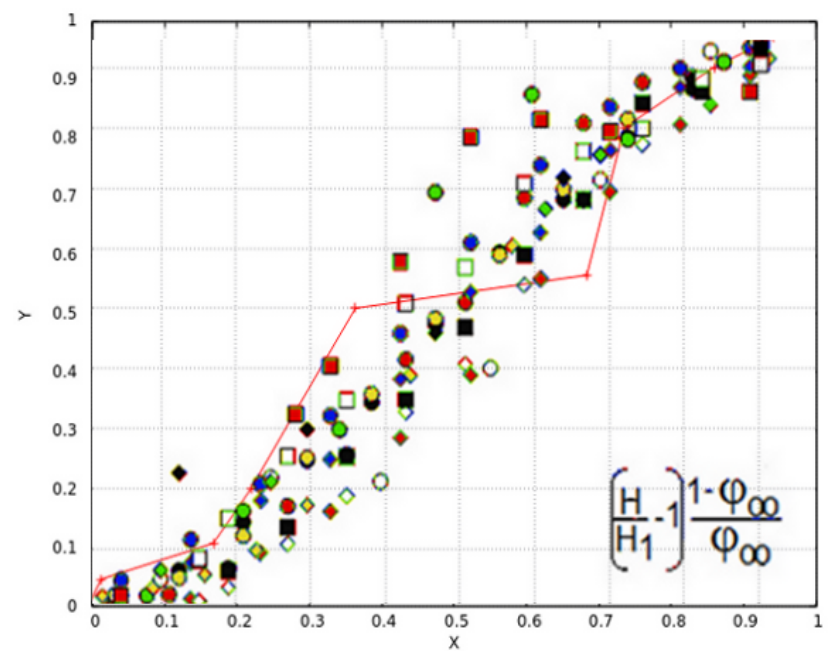

Figura 5.31: Perfil admensionalizado. Comparação entre os resultados numéricos e os experimentais Schulz et al. (2011) 


\subsection{Análise dos perfis de pressão}

É através do perfil de pressão que é possível prever as regiões de pressão relativa negativa e consequentemente estimar as regiões que estão expostas ao risco de cavitação. Uma comparação dos diagramas encontra-se descritos nas Figuras 5.32.

Os registros das menores pressões do escoamento encontram-se na região de desenvolvimento da camada limite, conforme descrito e citado na Seção 2.5. Através de uma análise da distribuição média das pressões sobre os degraus é possível observar que elas são menores nas extremidades externas dos espelhos e maiores nas extremidades externas do paramento, conforme publicado em Lobosco et al. (2011b).

Pela Figura 5.32(d) é possível avaliar a influência dos degraus de transição e as regiões de baixa pressão que occorem na região de desenvolvimeno da camada limite. A transição dos degraus acarreta em uma redução das regiões de baixa pressão e redução do impacto do jato sobre os degraus iniciais da estrutura hidráulica.

Em seu estudo computacional Arantes et al. (2010a) comparou o perfil de velocidade obtido numericamente com os resultados obtidos experimentalmente por Amador (2005). Uma comparação das características do perfil de velocidade também pode ser vista na Figura 5.33. Os perfis obtidos por Amador (2005) atavés da técnica de PIV (particle image velocimetry) em uma análise bidimensional também foram investigados por Arantes et al. (2010a) conforme mostra as Figuras 5.33(a) e 5.33(b). Os perfis de velocidade obtidos pelas simulações realizadas no OpenFoam estão ilustrados na Figuras 5.33(c) e Figuras 5.33(d). As características das isolinhas se assemelham tanto ao perfil de velocidade obtido por Arantes et al. (2010a) no software CFX quanto ao perfil experimental de Amador (2005) que, ao traçar perfis de velocidade, caracterizou a região de início da aeração através do perfil de velocidade da região não aerada. 

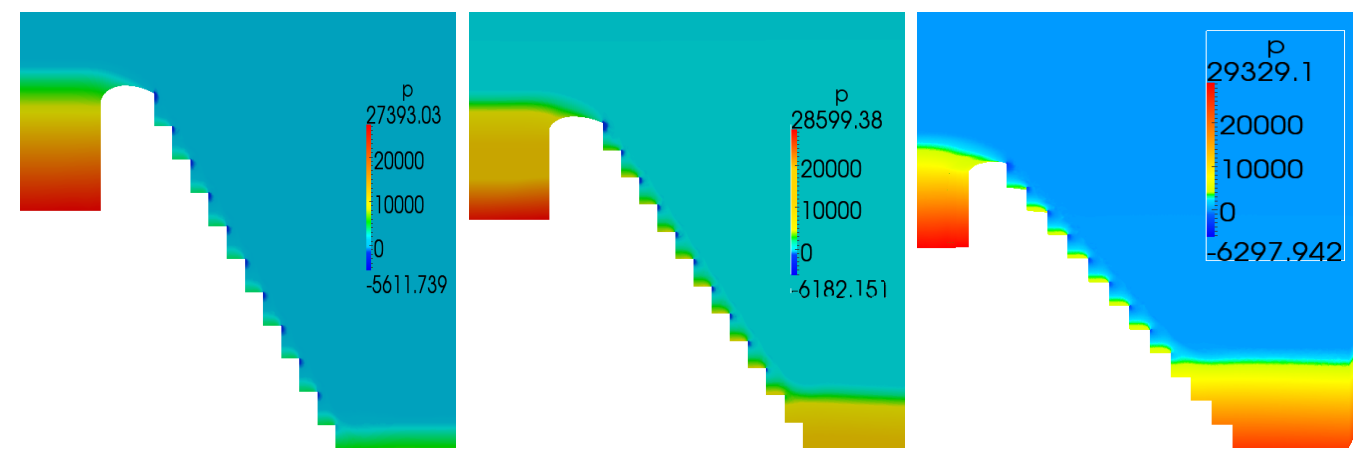

(a) Perfil com velocidade de (b) Perfil com velocidade de (c) Perfil com velocidade de entrada 1.0 entrada 1.3 entrada 1.5
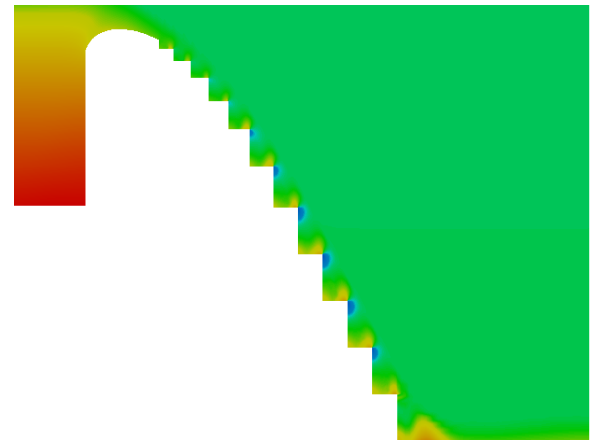

$p$
$p 8803.35$
20000
10000
0
-9240.54

(d) Perfil da estrutura com degraus de transição

Figura 5.32: Perfis de pressão (Unidades de Pressão em Pa) 

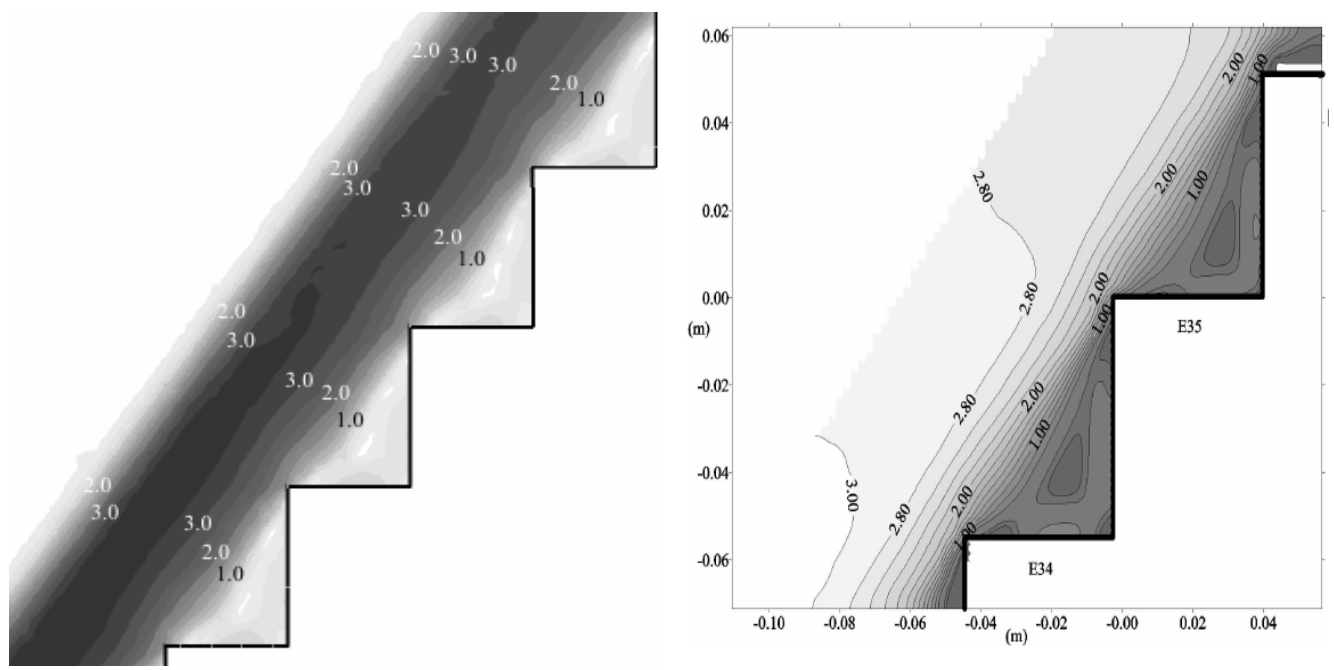

(a) Perfil de velocidade apresentado por (b) Perfil de velocidade apresentado por Arantes et al. (2010a) Amador (2005)
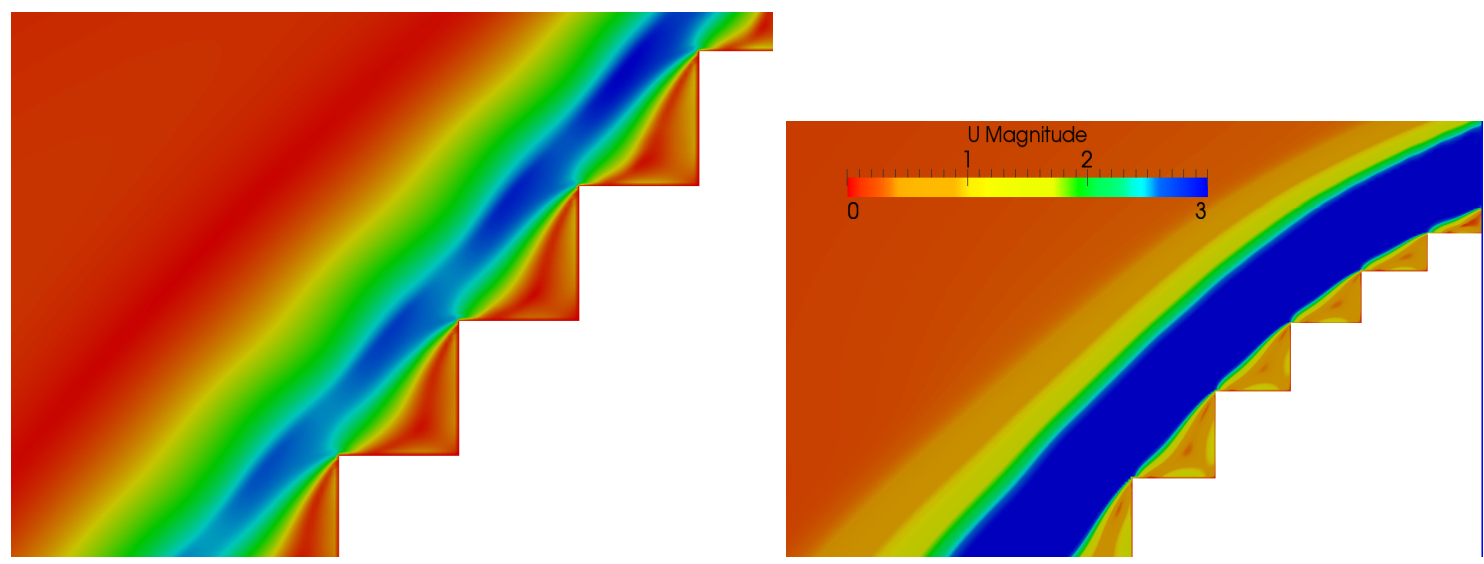

(c) Perfil de velocidade ao longo dos degraus (Si- (d) Perfil da estrutura com degraus de transimulado) ção (Simulado)

Figura 5.33: Perfis de velocidade 


\subsection{O perfil de sobreposição}

Criando uma sobreposição de instantes da interface entre o ar e a água é possível prever o movimento da mesma assim como a sua expansão. A Figura 5.34 demostra alguns dos instantes capturados e a sobreposição dos mesmos. Ao todo foram feitas 17 capturas individuais, os resultados dessa sobreposição foram publicados em Schulz et al. (2011).

De maneira análoga foram montados os gráficos de sobreposição das simulações descritas nas Seções 5.2.4 e 5.3.

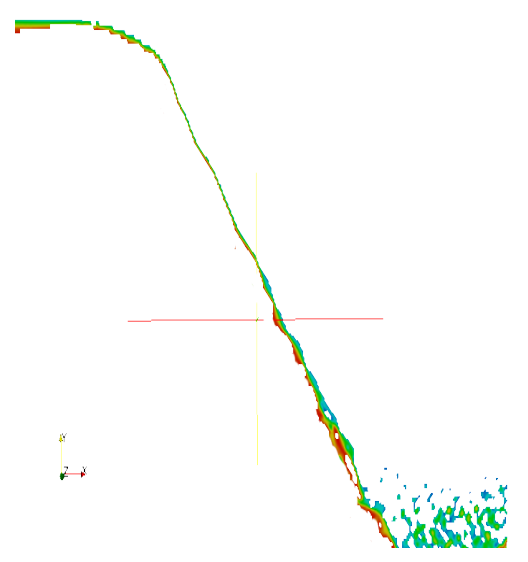

(a) Instante 12

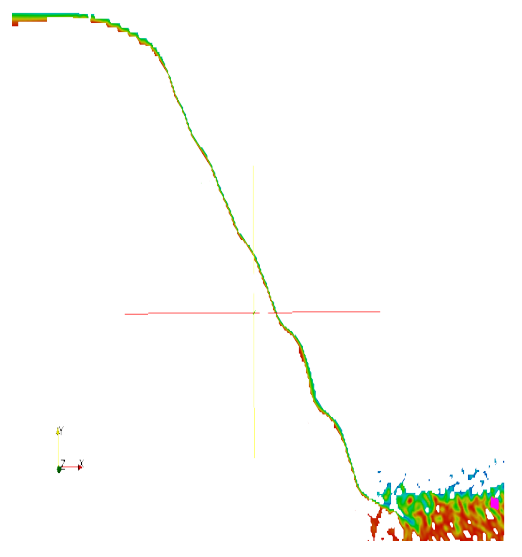

(c) Instante 14

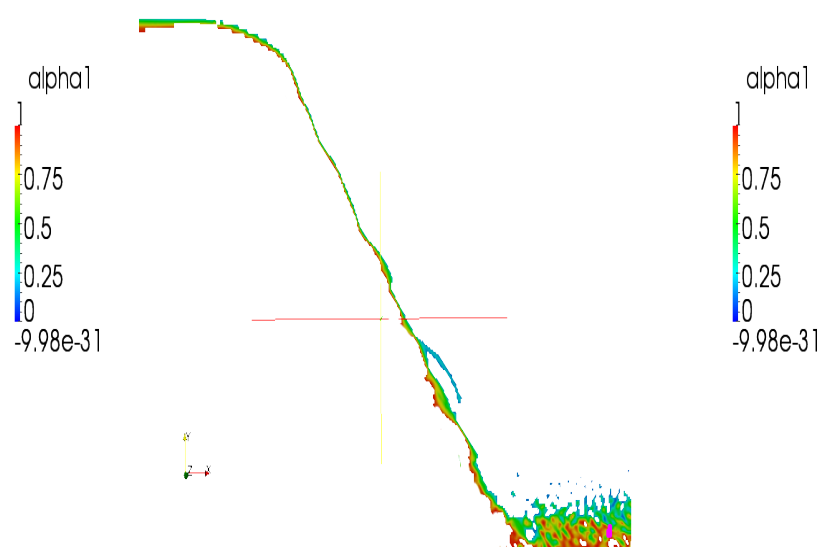

(b) Instante 13

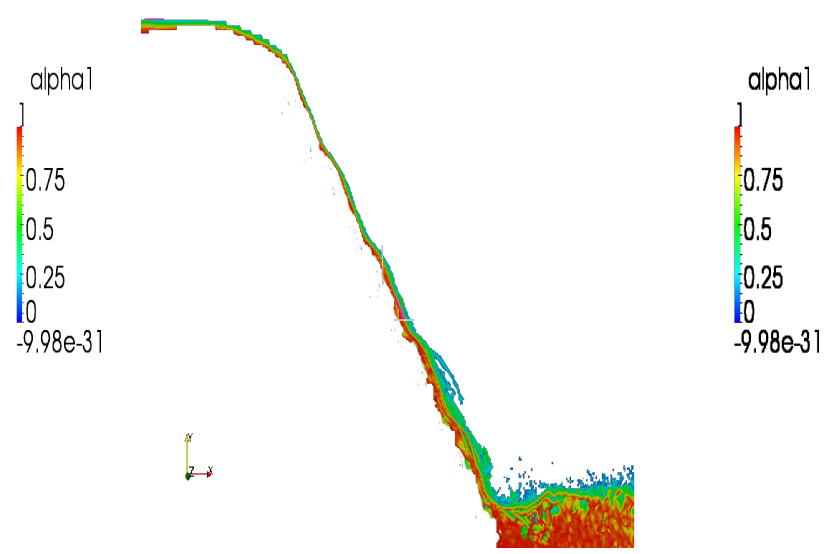

(d) Sobreposição de 17 instantes de tempo.

Figura 5.34: Perfis da interface entre o ar e a água. 
As Figuras 5.35 ilustram três casos distintos sendo eles: Figura 5.35(a) a sobreposição de instantes de tempo do escoamento com baixa velocidade $(v=$ $1,0 \mathrm{~m} / \mathrm{s}$ ) conforme descrito na seção 5.2.2. É possível verificar um aumento gradativo das oscilações da superfície livre à jusante. Vale ressaltar que essa captura é apenas da região interfacial entre o ar e à àgua.
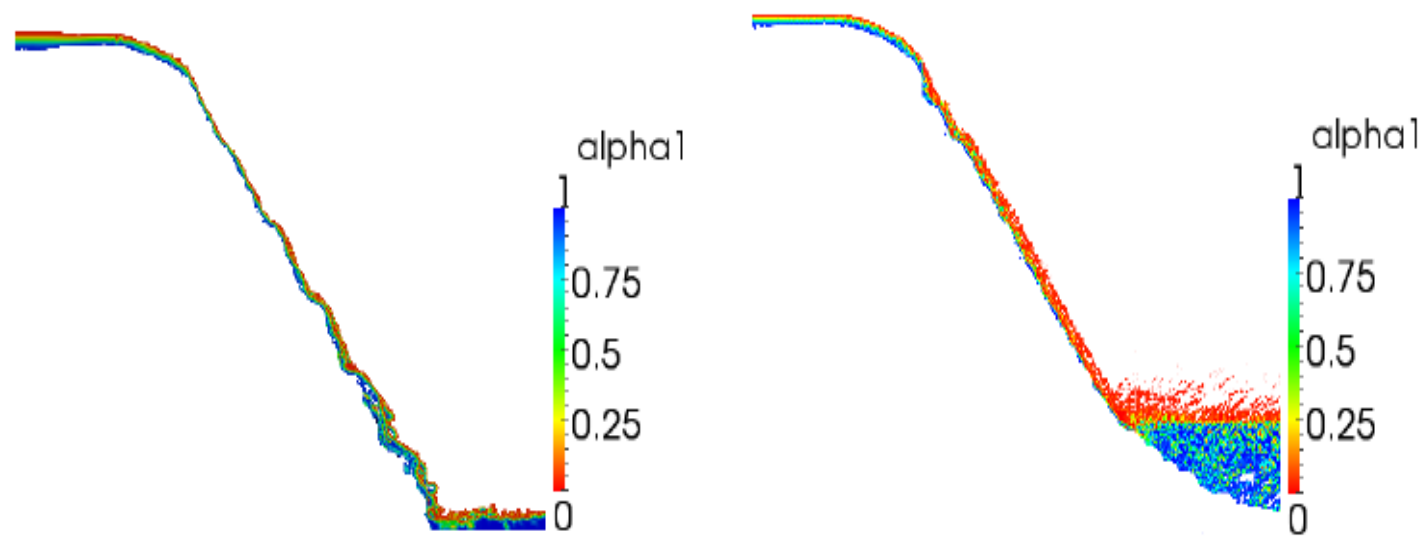

(a) Previsões da expansão da superfície livre, (b) Previsões da expansão da superfície livre, caso descrito na seção 5.2.2 caso descrito pela seção 5.2.4.

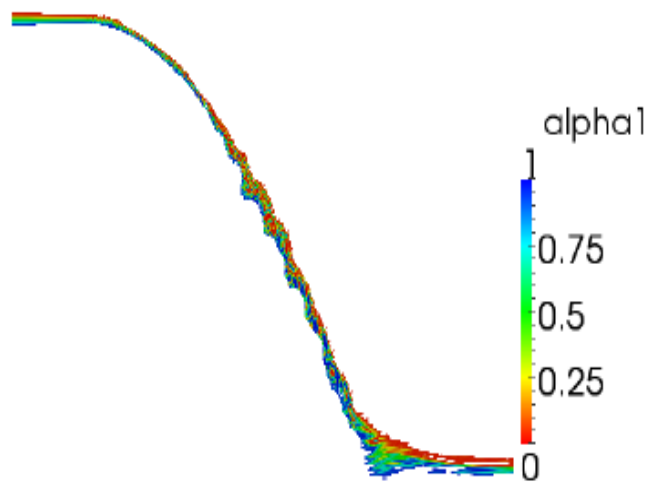

(c) Previsões da expansão da superfície livre, caso descrito pela sobreposição entrada com degraus de transição, seção 5.4 .

Figura 5.35: Perfis da interface entre o ar e a água.

A Figura 5.35(b) mostra a sobreposição de instantes de tempo da simulação descrita na seção 5.2.4. Com o aumento da velocidade do escoamento, existe, 
no primeiro degrau, uma expansão da região multifásica através da dispersão de gotículas de água no ar. A região avermelhada demonstra uma grande dispersão das gotículas. A terceira ilustração, Figura 5.35(h) corresponde a simulação da estrutura com degraus de transição descrita na seção 5.3. Pela Figura é possível constatar que as oscilações da região interfacial passam a ocorrer em uma distância maior da crista, o que condiz com as análises do perfil de pressão analisados na seção 5.4 e as informações da influência dos degraus de entrada que existem na literatura, Amador (2005) e Chanson (2006).

\subsection{Influência da parede lateral do canal}

Desde o início deste estudo e das simulações iniciais algumas perturbações foram notadas na região próximo à crista do vertedouro. Diferentes testes foram executados com o refinamento da malha entretanto existe uma forte relação entre as perturbações e a definição de parede das superfícies laterais do vertedouro. Para as definições de parede foi utilizado o modelo de parede com o modelo de turbulencia $k-\varepsilon$.

A Figura 5.36 ilustra algumas das condições simuladas ao longo deste trabalho de pesquisa e faz uma comparação entre as regiões centrais do escoamento e as regiões próximo da superfície sólida.

Um grande número de modelos de parede estão disponíveis na última versão do OpenFoam (2.2.0) lançado em 6 de Março de 2013. Entretanto, houveram variações dos modelos de parede ao longo das versões. Ao definir uma das faces da geometria como "Wall" é possível aplicar uma condição de parede como condição de contorno.

Através da Figuras 5.37 é possível visualizar o refinamento da malha bem como as oscilações da superfície livre e perceber que o refinamento da malha é muito inferior as oscilações da superfície livre. 

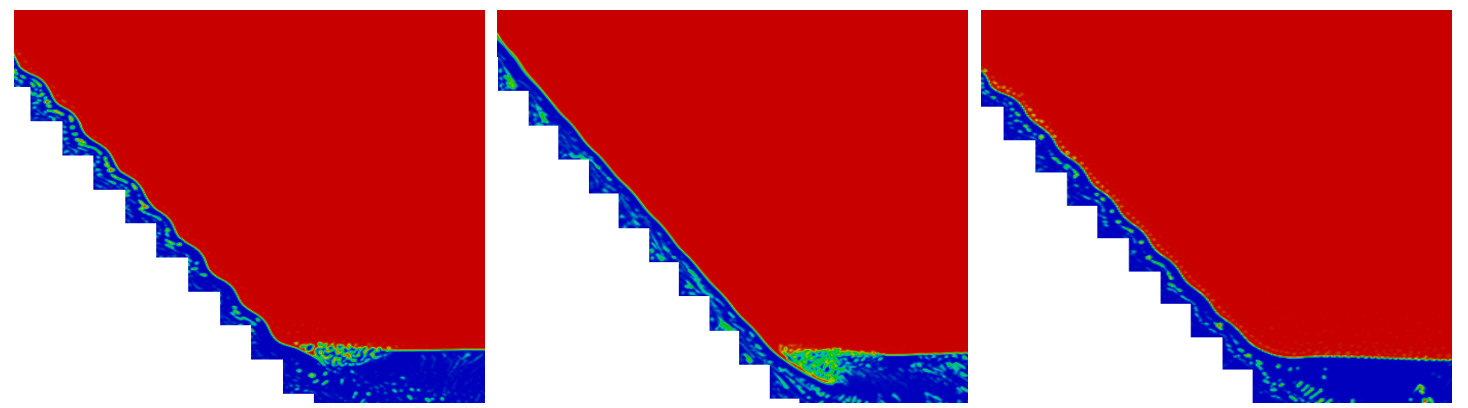

(a) Velocidade 1.0 - Escoa- (b) Velocidade 1.0 - Escoa- (c) Velocidade 1.3 - Escoamento próximo à parede mento distante da superfície só- mento próximo à parede lida
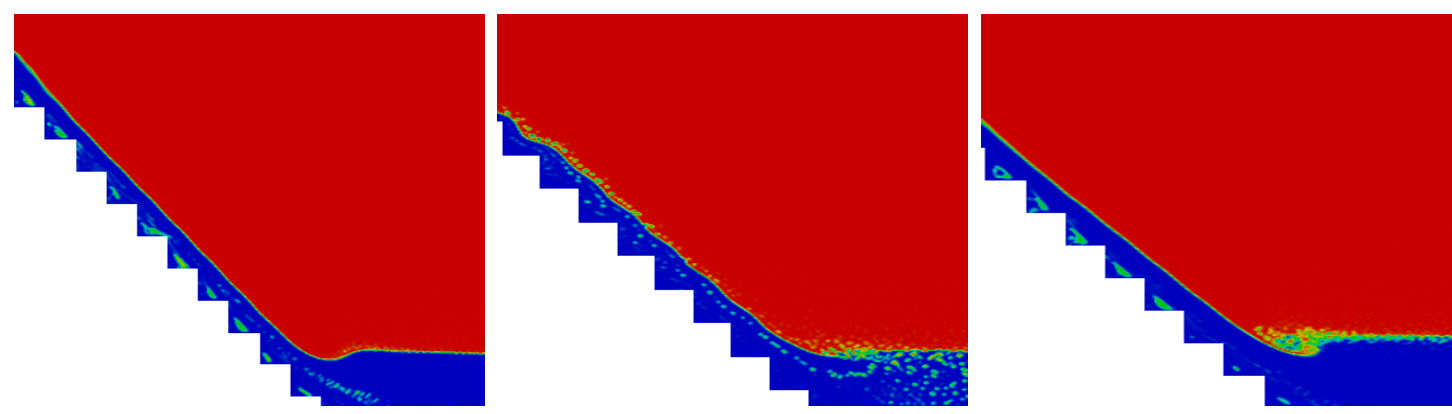

(d) Velocidade 1.3 - Escoa- (e) Velovidade 1.5 - Escoa- (f) Velocidade 1.5 - Escoamento distante da superfície só- mento próximo à parede mento distante da superfície sólida lida
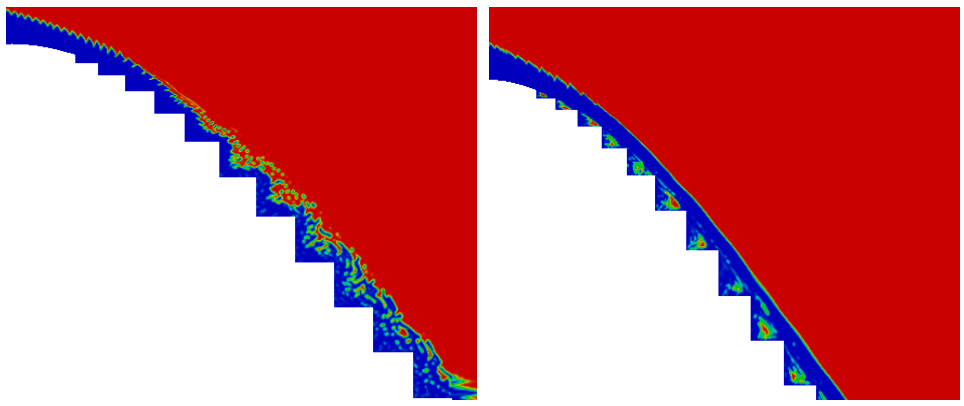

(g) Perfil de entrada com de- (h) Perfil de entrada com degraus de transição - próximo à graus de transição - distante da parede superfície sólida

Figura 5.36: Influência da parede lateral no escoamento de acordo com a variação da velocidade e do perfil de entrada. 


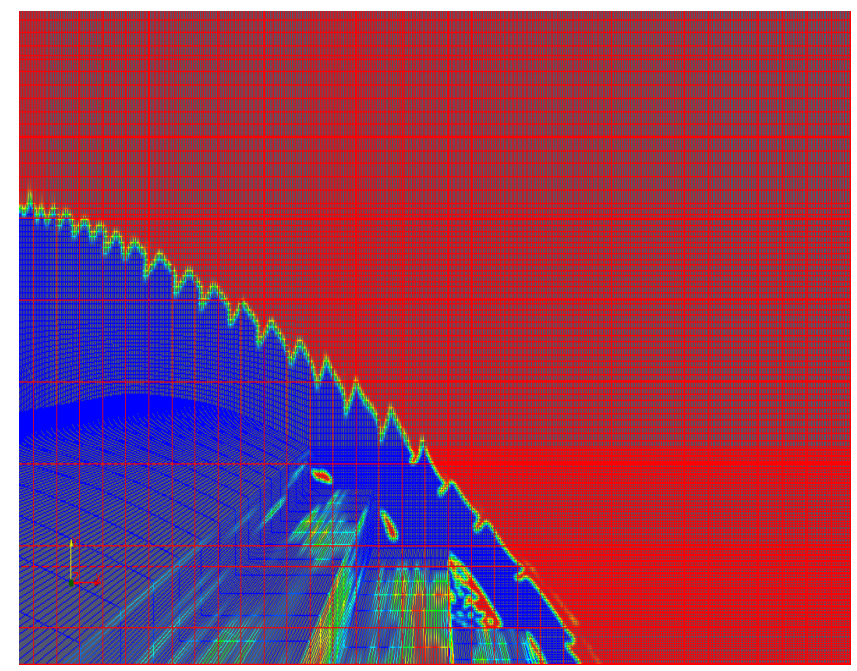

Figura 5.37: Refinamento da malha próximo à crista.

As malhas são hexaédricas e foram geradas no software Salome após uma pesquisa detalhada das possibilidades dos geradores de malha gratuitos. Entretanto existe uma grande dificuldade e limitação dos algoritmos para a geração da malha em geometrias mais complexas. Para que demais testes de malha sejam feitos, sugere-se a seleção de algum outro gerador de malha. 


\section{CONCLUSÕES}

Diante dos resultados anteriormente apresentados, pode-se alcançar uma conclusão geral de que as metodologias utilizadas e desenvolvidas ao longo deste trabalho de pesquisa indicam uma direção fisicamente coerente para o estudo da aeração do ar em estruturas de vertedores escalonados.

Este trabalho incorporou análises que permitiram reproduzir numericamente os relatos experimentais.

Através da investigação dos perfis de concentração da fração volumétrica ao longo das seções dos degraus foi possível descrever a distribuição da fração de vazios e caracterizar os regimes de escoamento de acordo com a vazão volumétrica na entrada. Os regimes de transição e de deslizamento sobre vórtices foram claramente evidenciados em suas característica.

Para a correta representação do problema físico foram realizadas análises do refinamento da malha e representação da camada limite. Das análises preliminares, realizadas em um modelo com perfil de ogiva na entrada e primeiros degraus em tamanho reduzido foi possível gerar dados relacionados com a evolução da pressão junto aos degraus do vertedouro. As análises dos diagramas de pressão mostraram que os trechos mais sujeitos à cavitação estão na região do paramento vertical do degrau conforme descrito na literatura, confirmando a hipótese de necessidade da intensificação da aeração do escoamento.

Considerando o movimento da interface ar-água, a representação da superfície livre foi investigada através dos perfis de concentração do escoamento que permitiram definir a expansão da superfície livre como uma função da altura característica. 
Ademais, foram apresentados desenvolvimentos semi-empíricos que levaram a correlações entre dados e equações com ajustes muito bons. Considerando o aspecto inovador dos procedimentos teóricos aqui adotados, este trabalho de pesquisa adquire um caráter de relevância no progresso dos estudos de escoamentos turbulentos propriamente aerados. O equacionamento da vazão de ar adicionada aos escoamentos em vertedores foi fundamentada nos princípios físicos e seu resultado foi comparado com soluções numéricas. Frisa-se que os estudos teóricos fundamentamse nas diretrizes da própria linha de pesquisa, relatados em parte, por exemplo, em Schulz et. al. (2011).

A análise numérica da superfície se diferencia da abordagem numérica tradicional porque a maioria das simulações computacionais encontradas na literatura para a representação do escoamento multifásico sobre estruturas de vertedouros escalonados não trata a ruptura da interface entre o ar e a água e, consequentemente, não aborda a coalescência de bolhas e demais fenômenos relacionados à presença de bolhas no interior da água. Tal fato se deve aos modelos de turbulência usados pelas simulações da literatura na região da interface. Por exemplo, quando utilizado um modelo de média de Reynolds para todo o domínio computacional do escoamento bifásico, verifica-se que as flutuações da interface são, de certa forma, negligenciadas. 


\section{Referências}

Amador, A. (2005). Comportamiento Hidráulico de los Aliaderos escalonados em presas de hormigón compactado. PhD thesis, Universitat Politécnica de Cataluya, Barcelona.

Arantes, E. J., Porto, R. M., Gulliver, J. S., and Lima, A. C. M. (2010a). Lower nappe aeration in smooth channels: experimental data and numerical simulation. Anais da Academia Brasileira de Ciências, 82:521-537.

Arantes, E. J., Porto, R. M., Gulliver, J. S., Lima, A. C. M., and Schulz, H. (2010b). Lower nappe aeration in smooth channels: experimental data and numerical simulation. Anais da, 82(2):521-537.

Arndt, R. E. A. (2002). Cavitation in fluid vortical flows. Annual Rev. of Fluid Mechanic, 534:143-175.

Bird, R. and Stewart, W. (1997). Fenômenos de Transporte. LTC.

Boes, R. M. and Hager, W. H. (2003). Hydraulic design of stepped spillways. Jounal of Hydraulic Engineering, 129(9):671-679.

Cepel (2007). Manual de inventário hidroelétrico de bacias hidrográficas. Technical report, Ministério de Minas e Energia.

Chakib, B. (2013). Numerical computation of inception point location for flat-sloped stepped spillway. International Journal of Hydraulic Engineering, 2(3).

Chamani, M. R. and Rajaratnam, N. (1994). Jet flow on stepped spillways. Journal of Hydraulic Engineering, 120:254-259. 
Chanson, H. (1994). Aeration and de-aeration at bottom aeration devices on spillways. Canadian Journal of Civil Engineering, 21(3):404-409.

Chanson, H. (1997). Air bubble entrainment in free surface turbulent shear flows. Academic Press, page 401.

Chanson, H. (2001). Hydraulic design of stepped spillways and downstream enegry dissipators. Dam engineering, 11:205-242.

Chanson, H. (2006). Hydraulics of skimming flows on stepped chutes: The effects of inflow conditions? Journal of Hydraulic Research, 44:51-60.

Chatila, J. and Tabbara, M. (2004). Computational modeling of flow over an ogee spillway. Computers \& Structures, 82:1805-1812.

Chaudhry, M. (2008). Open Channel flow. Springer.

Chen, X., Dai, G., and Liu, H. (2002). Volume of fluid model for turbulence numerical simulation of stepped overflow. Journal of Hydraulic Engineering, 128(7):683-688.

Coyajee, E. and Boersma, B. J. (2009). Numerical simulation of drop impact on a liquid-liquid intreface with a multiple marker front-capturing method. Journal of Computational Physics, 228:4444-4467.

Esmaeeli, A. and Tryggvason, G. (1999). Direct numerical simulations of bubbly flows part 2. moderate reynolds number arrays. Journal of Fluid Mechanics, $385: 325-3587$.

Essery, I. T. S. and Horner, M. W. (1978). The hydraulic design of stepped spillways. Technical report, CIRIA.

Franc, J. P. and Michel, J. M. (2004). Fundamentals of Cavitation (Fluid Mechanics and Its Applications). Springer. 
Frizel, K. W., P., K. J., and J., M. (1977). Stilling basin performance for stepped spillways of mild to steep slopes - type iii basins. Journal of Hydrotechnical Construction, 11:730-736.

Frizell, K. H. and Melford, B. W. (1991). Designing spillways to prevent cavitation damage. Concrete International, 13:58-64.

García, E. V. and Mateos, I. C. (1995). Aliviaderos escalonados. diseno de la transición entre el umbral y la rápida escalonada. Ingeniería Civil, 99:3323-3341.

Gibel (2012). http://www.gibe3.com.et/. Acessado em 20 de setembro de 2012.

Gomes, J. F. (2006). Campo de Pressões: Condiçôes de incipiência à cavitação em vertedouros em degraus com declividade $1 \mathrm{~V}: 0,75 \mathrm{H}$. $\mathrm{PhD}$ thesis, Universidade Federal do Rio Grande do Sul.

Gomes, J. F., Sanagiotto, D. G., Dai Prá, M., Wiest, R. A., Bastos, J., Endres, L., and Marques, M. (2005). Influência da declividade e da aeração sobre o campo de pressões em vertedouros em degraus. In XVI Simpósio Brasileiro de Recursos hídricos, João Pessoa, Brasil.

Gorges (2010). www.chicold.org.cn. Chinese National Committee on Large Dams, Acessado em 20 de setembro de 2010.

Gómez-Gesteira, M., Rogers, B. D., Dalrymple, R. A., Crespo, A. J. C., and Narayanaswamy, M. (2010). User guide for the sphysics code v2.0. http://wiki.manchester.ac.uk/sphysics, 1.

Hemida, H. (2008). Openfoam tutorial: Free surface tutorial using interfoam and rasinterfoam. Technical report, Division of Fluid Dynamics, Department of Applied Mechanics, Chalmers University of Technology.

Idelsohn, S. and Oñate, E. (1994). Finite element and finite volumes. two good friends. 37:3323-3341. 
Itaipu (2010). http://www.itaipu.gov.br/en/energy/energy. Acessado em 20 de setembro de 2010.

Jacobsen, F. (2009). Application of openfoam for designing hydraulic water structures. Open source CFD Iternational conference.

Kassim, Z. M. and Longmire, E. K. (2003). Drop impact on a liquid-liquid interface. Journal of Physics Fluids, 15:3263-3273.

Khlopenkov, P. R. (1977). Multistage jet deflection on ski jumps with flow energy dissipation by compression of the entrained air. Journal of Hydrotechnical Construction, 11:730-736.

Lima, A. C. M., Schulz, H. E., and Gulliver, J. S. (2010). Air uptake along the lower nappe of a spillway aerator. Journal of Hydraulic Research, 46:839-843.

Lima, M. C. A. (2004). Caracterização da estrutura turbulenta em escoamentos aerados em canal de forte declividade com auxilio de técnicas de velocimetria a laser. PhD thesis, Universidade de São Paulo, Escola de Engenharia de São Carlos.

Lobosco, R. J. and Schulz, H. E. (2010). Análise computacional do escoamento em estruturas de vertedouros em degraus. Mecánica Computacional, XXIX:35933600.

Lobosco, R. J., Schulz, H. E., Brito, R. J. R., and Simões, A. L. A. (2011a). Análise computacional da aeração em escoamentos bifásicos sobre vertedouros em degraus. 6 Congresso Luso-Moçambicano de Engenharia e 3 Congresso de Engenharia de Moçambique, Maputo, 1:1-10.

Lobosco, R. J., Schulz, H. E., Oliveira, A. B. F., and Corrêa, N. A. (2011b). Numerical simulation of stepped spillway flow. Proceedings of 21st International Congress of Mechanical Engineering, 1:14302. 
Lobosco, R. J., Schulz, H. E., and Simões, A. L. A. (2011c). Analysis of two phase flows on stepped spillways. Hydrodynamics - Optimizing Methods and Tools, II:125 .

Lohner, R. (2008). Applied computational fluid dynamics techniques. John Wiley \& Sons, Ltda.

Matos, J. S. G., Sanchez-Juny, M., Quintela, A., and Dolz, J. (1999). Characteristic depth and pressure profiles over stepped spillways. In In proceedings of XXVIII IAHR Congress, Graz, Austria.

Meireles, I., Matos, J., and Frizell, K. (2007). Measuring air entrainment and flow bulking in skimming flow over steeply sloping stepped chutes. Technical report, prepared by U.S Bureau of Reclamation employee.

OpenFOAM (2012). http://www.openfoa.com/. The Open Source Computational Fluid Dynamics, Acessado em 20 de setembro de 2012.

Patankar, S. (1982). Numerical Heat Transfer and Fluid Flow. McGrall Hill.

Peterka, A. J. (1953). The effect of entrained air on cavitation pitting. In 5th IAHR Congress, Minneapolis, 50\%-518.

PortalBrasil (2013). www.brasil.gov.br/infraestrutura/2011/potencial-hidreletricobrasileiro. Acessado em 30 de agosto de 2013.

Potter, M. C. and Wiggert, D. C. (2004). Mecânica dos Fluidos. Thonson.

Povh, P. H. (2000). Avaliação da energia residual a jusante de vertedouros em degraus com fluxos em regime skimming flow. PhD thesis, Departamento de tecnologia, Universidade Federal do Paraná.

Rodi, W. (1994). Simulation approaches for turbulent flows, Computational Fluids Dynamics. John Wiley and Sons. 
Sabbagh-Yazdi, S. R., Mastorakis, N. E., and Safaieh, R. (2008). 3d modeling strategies for computing aerated skimming flow parameters over stepped chutes using depth averaged flow solver. International Journal of Mathematics and Computers in Simulation, 2:134-144.

Salome (2012). http://www.salome-platform.org/. The Open Source Integration for Numerical Simulation, Acessado em 10 de abril de 2011.

Sarfaraz, M., Attari, J., and Pfister, M. (2012). Numerical computation of inception point location for steeply sloping stepped spillways. 9th International Congress on Civil Engineering,Isfahan University of Technology (IUT)., May 8-10.

Schulz, H. E. (2003). O essencial em fenômenos de transporte. EDUSP.

Schulz, H. E. (2013). Informações pessoais fornecidas à autora e decorrentes das atividades desenvolvidas para o estudo ora apresentado. Technical report, Universidade de São Paulo.

Schulz, H. E. and Alamy Filho, J. E. (2005). Velocidade de sedimentação para conjuntos de partículas e sua depêndencia para com a concetração de sedimentos. Ciência \& Engenharia, 14:99-106.

Schulz, H. E., Alamy Filho, J. E., and Villela, S. M. (2004). Fundamentals on equilibrium concentration curves for sedimentation and diffusion of particles in fluids. Revista Minerva, 1:37-43.

Schulz, H. E., Lobosco, R. J., and Simões, A. L. A. (2011). Multiphase analysis of entrained air in skimming flows along stepped chutes. Fifth International Conference on Advanced Computational Methods in Engineering, ACOMEN, University of Liège, 2011, Nov 14-11.

Schulz, H. E. and Simões, A. L. A. (2011). Alternative equations for transition lengths in aerated flows: analogies with basic equations of transport phenomena 
[text in portuguese]. Technical report, Laboratory of Reheology and Turbulence, School of Engineering at São Carlos, University of São Paulo.

Silva, L. F. L. R. (2006). Desenvolvimento de metodologias para simulação de escoamentos polidispersos. PhD thesis, Universidade Federal do Rio de Janeiro.

Silveira Neto, A. (2007). Fundamentos da turbulência nos fluidos. Technical report, Universidade Federal de Uberlândia.

Simões, A. L. A., Schulz, H. E., and Porto, R. M. (2012). Definições para o comprimento do ressalto hidráulico e bacias de dissipação a jusante de vertedores. $X X V$ Congresso Latino Americano de Hidráulica, San José, 1:1-10.

Toombes, L. and Chanson, H. (2005). Air entrainment and velocity redistribution in a bottom outlet jet flow. XXXI IAHR Congress, September 11 to 16:2716-2726.

Tozzi, M. J. (1992). Caracterização/Comportamento de escoamentos em vertedouros com paramento em degraus. PhD thesis, Universidade de São Paulo, Escola Politécnica.

USA (1965). Hydraulic Design of Spillways. Arm Corporation of Engineers, Engineering Manual EM1110-2-1603.

Versteeg, H. K. e Malalasekera, W. (1995). An introduction to computational fluid dynamics. The finite volume method. Longman Scientific \& Technical.

Wang-ru, W., Jun, D., and Bin, L. (2013). Influence of aeration and initial water thickness on axial velocity attenuation of jet flows. Journal of Zhejiang University- Applied Physics and Engineering, Springer, In press.

Zienkiewicz, O.C. e Taylor, R. (1991). The finite element method, volume II. McGraw Hill. 


\section{Anexos}

\section{Anexo I}

As ferramentas numéricas e a sua utilização são aqui apresentadas como forma de auxílio aos usuários que tenham algum interessa no uso das ferramentas computacionais dos quais este trabalho de pesquisa fez uso ou na reprodução dos resultados aqui apresentados. Conforme comentado anteriormente os software Salome e OpenFoam são de uso e domínio público e podem ser baixados na internet nos seus respectivos websites conforme descritos na Tabela (5). As versões prévias dos softwares apresentavam maiores dificuldades de instalação, entretanto as constantes atualizações e lançamentos de manutenção anuais das ferramentas tem agregado facilidades gerais no que diz respeito a instalação e compatibilidade com o sistema operacional. Em algumas versões do Linux é possível baixar o OpenFoam diretamente do repositório de software. As primeiras análises desse projeto de pesquisa foram realizadas com a versão 1.5 do OpenFoam. Para geometricas simplificas aconselha-se o uso do gerador de malhas no próprio OpenFoam o que dispensa a necessidade de uso do software Salome. No OpenFoam, apesar da malha ser criada através de um sistema de coordenadas, o processo de alteração do refinamento se torna bastante simplificado, ou seja, uma vez definida a geometria através da indicação de coordenada à coordenada, o processo de remalhagem para alteração do refinamento se torna bastante simples. O software Salome também possibilita a ge- 
racao de malhas através de um script em Python o que pode ser uma ferramenta de grande utilidade. Entretanto, para o caso de geometrias mais complexas o processo tradicional ainda é o que apresenta maior facilidade e foi devido a isso que o software Salome foi utilizado nesse projeto de pesquisa. Ele permite importar a geometria em um formato ".step". Pode se dizer que o Salome esta dividido em duas partes, uma para manipulação da geometria e uma para manipulação da malha. Lembrando que embora esta funcionalidade não tenha sido utilizada, o software possui a capacidade de realizar análises estruturais. Na etapa de preparação da geometria, é preciso que as faces estejam bem definidas para que após a geração da malha elas sejam identificadas em grupos. É através do nome dado a esse grupo de faces que as condições de contorno serão aplicadas no OpenFoam. Existe, disponível no software Salome, vários algoritmos para a geração de malha entretanto, a maioria deles não dispõe de muitas opções de refinamento, é preciso que manipulações na geomtria sejam usadas como artifícios de ajuste da malha. Vale lembrar que o OpenFoam é destinado a simulações em três dimensões e nao é permitido que existam elementos 1D ou 2D na malha. Como artifício de refinamento da malha no domínio computacional, fezse uso da ferramenta de partionamento do domínio computacional. O particionar do domínio permite que o gerador da malha identifique pequenas regiões e conduz o algoritmo de geração no processo de criação da malha sobre a região da crista do vertedouro. Apesar da tentativa de utilização de outros geradores de malhas, o que apresentou caracteríscas mais adequadas ao tratamento do problema proposto foi o gerador de malha hexaédrica. O interFoam é um dos solvers do OpenFoam com a capacidade de simular escoamento multifásico. Cada um dos solvers possui suas características específicas, entretanto os diretórios dos solvers do OpenFoam são composto basicamente de três diretórios:

- O diretório "0" onde os parâmetros das condições iniciais devem ser definidas;

- O diretório "constant" para definição dos parâmetros;

- O diretório "system" onde os parâmetros de controle da simulação são especi- 
ficados;

Os arquivos dentro dos diretórios variam de acordo com a versão do OpenFoam e com o solver que esta sendo utilizado. Ele é destinado a fluidos incompressíveis e utiliza o método VOF para o tratamento entre os fluidos. O solver é capaz de fazer simulações em regime laminar ou turbulento e existe no openfoam uma grande variedade de modelos de turbulência disponíveis.

O OpenFoam possui a funcionalidade de conversão de diferentes formatos de malhas, neste trabalho de pesquisa a malha foi exportada do Salome para o OpenFoam em um formato ".unv“. Para as etapas de pós processamento foi utilizado o software ParaFoam que é uma versão do software Paraview adaptada ao OpenFoam. O paraview serve como visualizador de ambos os softwares aqui mencionados.

O endereço eletrônico para download dos softwares pode ser visualizado na Tabela (5).

Tabela 5: Endereço eletrônico para download das ferramentas computacionais.

\begin{tabular}{||cc||}
\hline Ferramenta & Endereço para download \\
\hline OpenSuSe 11.2 & http://www.opensuse.org \\
OpenFoam 1.7 & http://www.openfoam.com \\
ParaFoam 1.7 & http://www.openfoam.com \\
Salome 5.4 & http://www.salome-platform.org \\
GnuPlot 4.2 & http://www.gnuplot.info \\
Liggghts & http://cfdem.dcs-computing.com \\
cfdem & http://cfdem.dcs-computing.com \\
SPH & https://wiki.manchester.ac.uk/sphysics/index.php/Downloads \\
\hline
\end{tabular}

Como todas as informações são abertas ao público, fornece-se aqui também a Tabela (6), que mostra os diferentes endereços eletrônicos nos quais as informações mais relevantes e os foruns de discussões podem ser acessados. 
Tabela 6: Endereço eletrônico de sites de discussões sobre as ferramentas computacionais.

\begin{tabular}{||ccc||}
\hline Ferramenta & Forma de informação & Endereço eletrônico \\
\hline OpenFoam e & Documentação & http://www.openfoam.com/docs \\
ParaFoam & Forum de discussão & http://www.cfd-online.com/Forums \\
& Extend version & http://www.extend-project.de \\
& Vikipedia & http://openfoamwiki.net/index.php/ \\
& Doxgen & http://foam.sourceforge.net/doc/Doxygen \\
\hline Salome & Documentação & http://test.opencascade.com/user-section \\
& Forum de discussão & http://www.salome-platform.org/forum \\
& Doxgen & http://test.opencascade.com/user-section \\
\hline
\end{tabular}




\section{Anexo II}

Esta seção demonstra os arquivos do OpenFoam para definição dos parâmetros da simulação. Através deles os modelos de turbulência, os parâmetros físicos e computacionais são definidos.
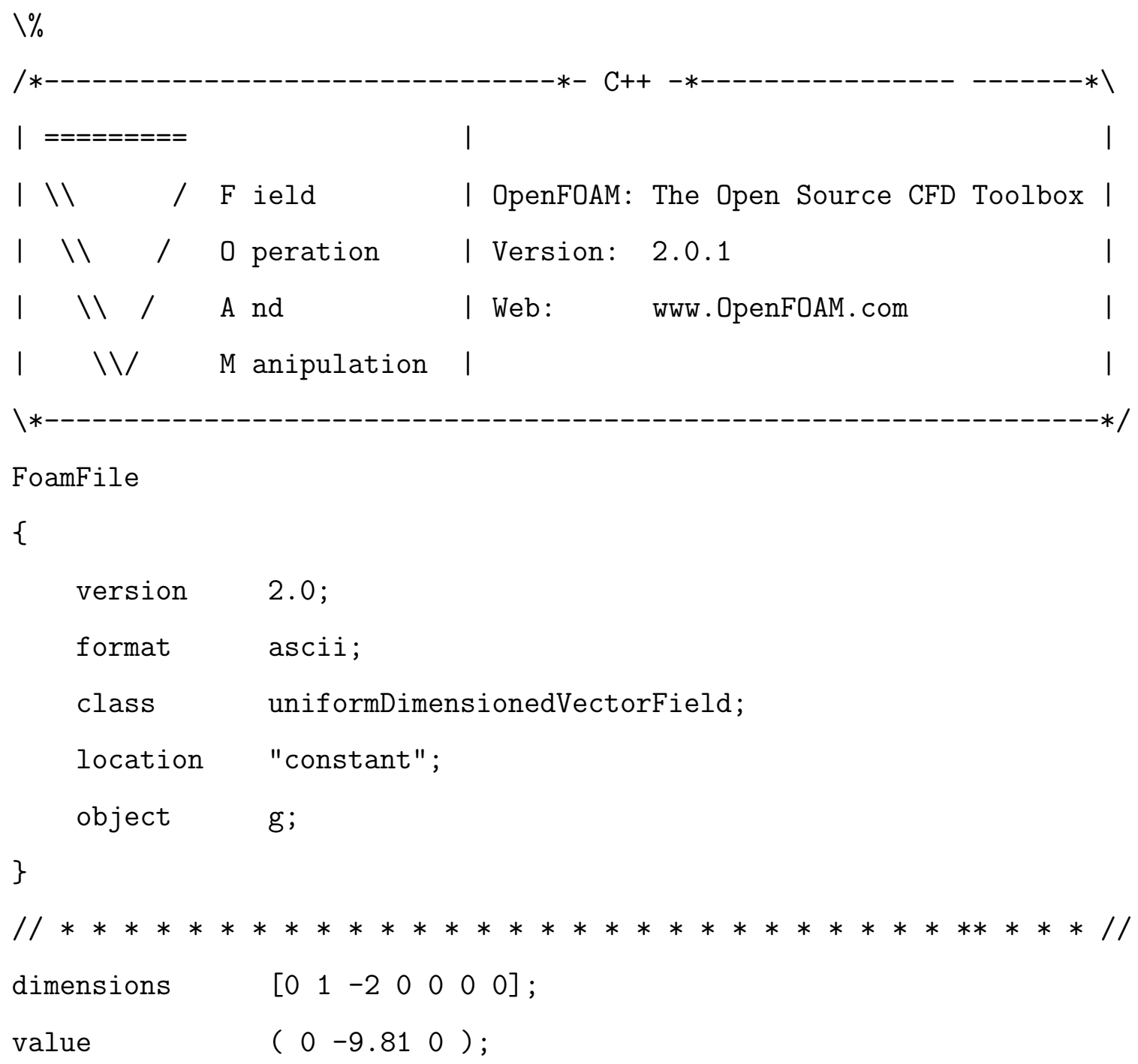


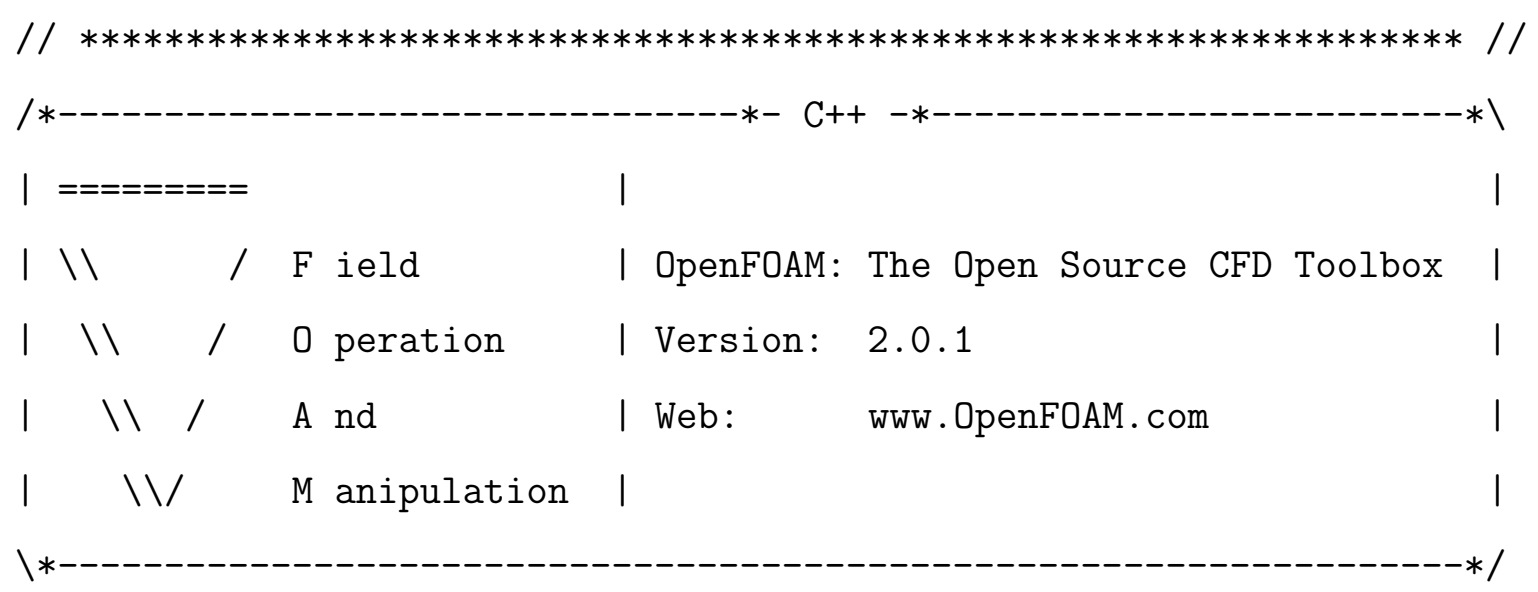

FoamFile

\{

$\begin{array}{ll}\text { version } & 2.0 ; \\ \text { format } & \text { ascii; } \\ \text { class } & \text { dictionary; } \\ \text { location } & \text { "constant"; } \\ \text { object } & \text { RASProperties; }\end{array}$

\}

$/ / * * * * * * * * * * * * * * * * * * * * * * * * * * * * * * * * * / /$

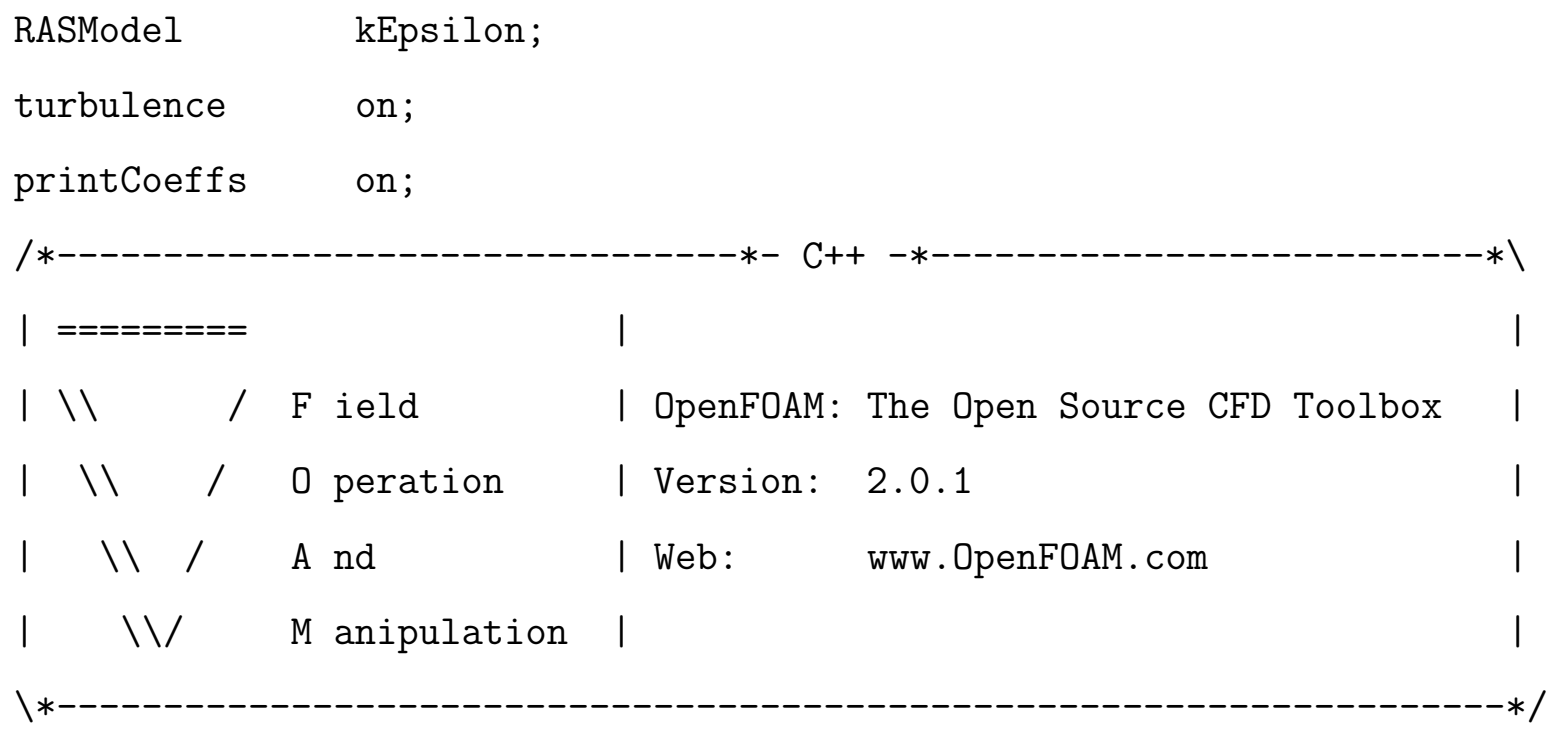

FoamFile

\{ 


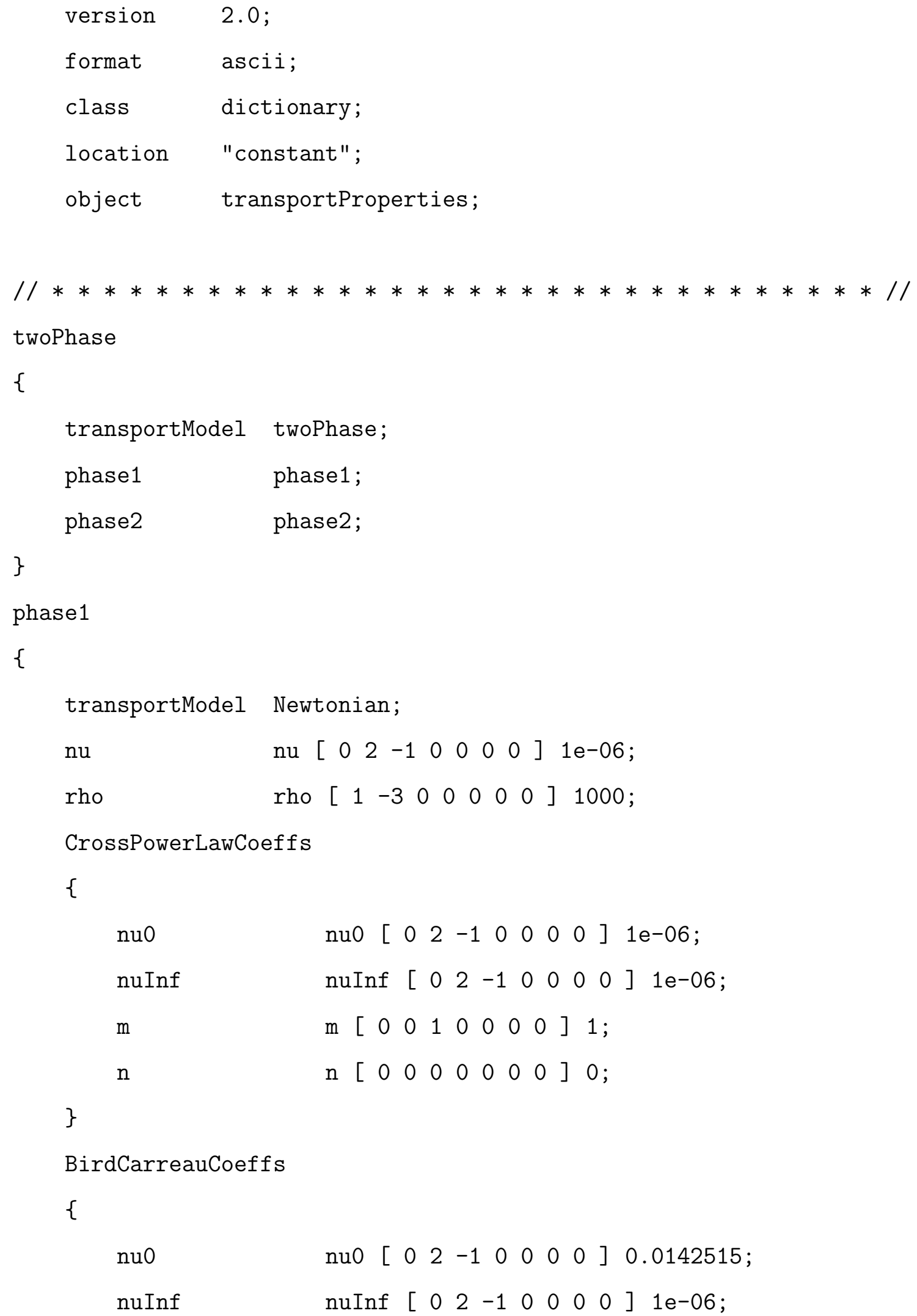

nuo nuInf

m

$\mathrm{n}$

\}

BirdCarreauCoeffs

\{

nuO nuo [ $\left[\begin{array}{llllllllll}0 & 2 & -1 & 0 & 0 & 0 & 0\end{array}\right] 0.0142515$;

nuInf 


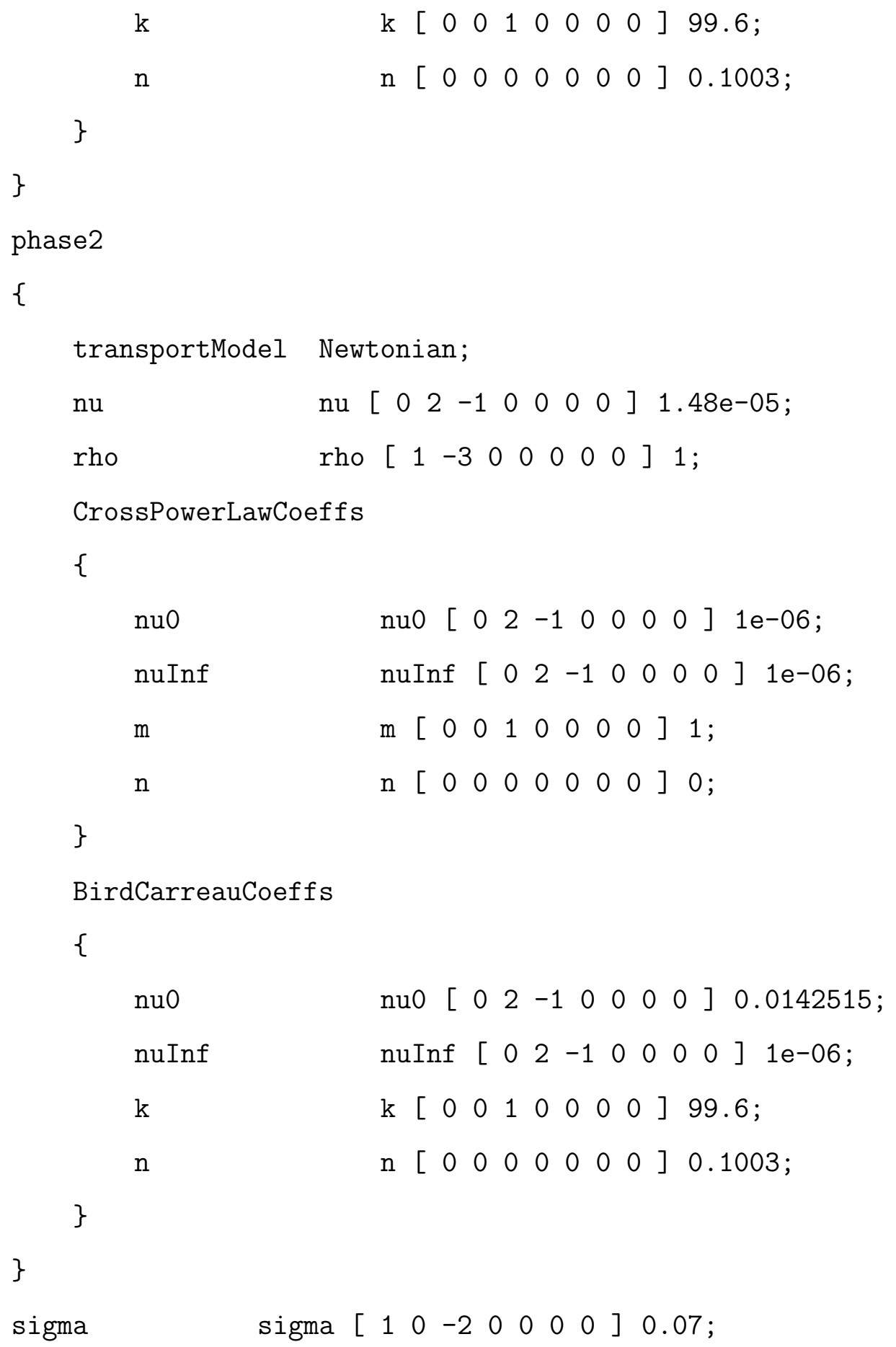




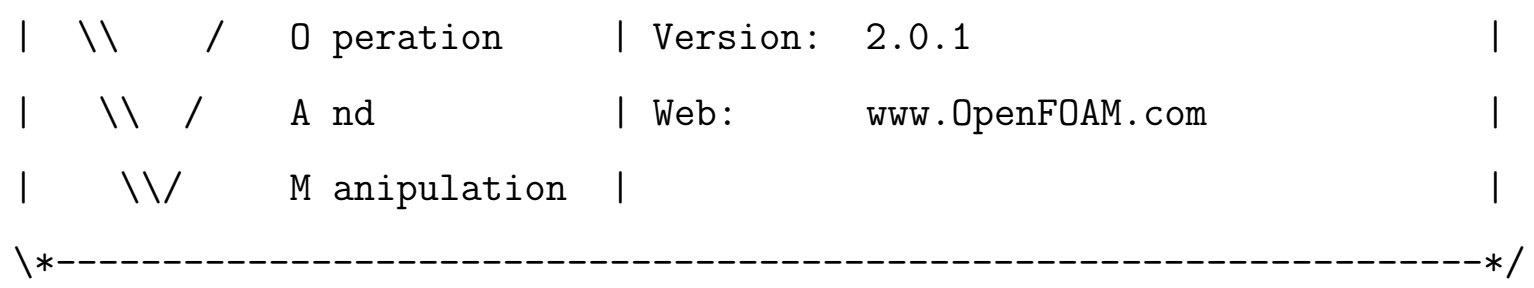

FoamFile

\{

version 2.0;

format ascii;

class dictionary;

location "constant";

object turbulenceProperties;

\}

$/ / * * * * * * * * * * * * * * * * * * * * * * * * * * * * * * * * * / /$ simulationType RASModel;

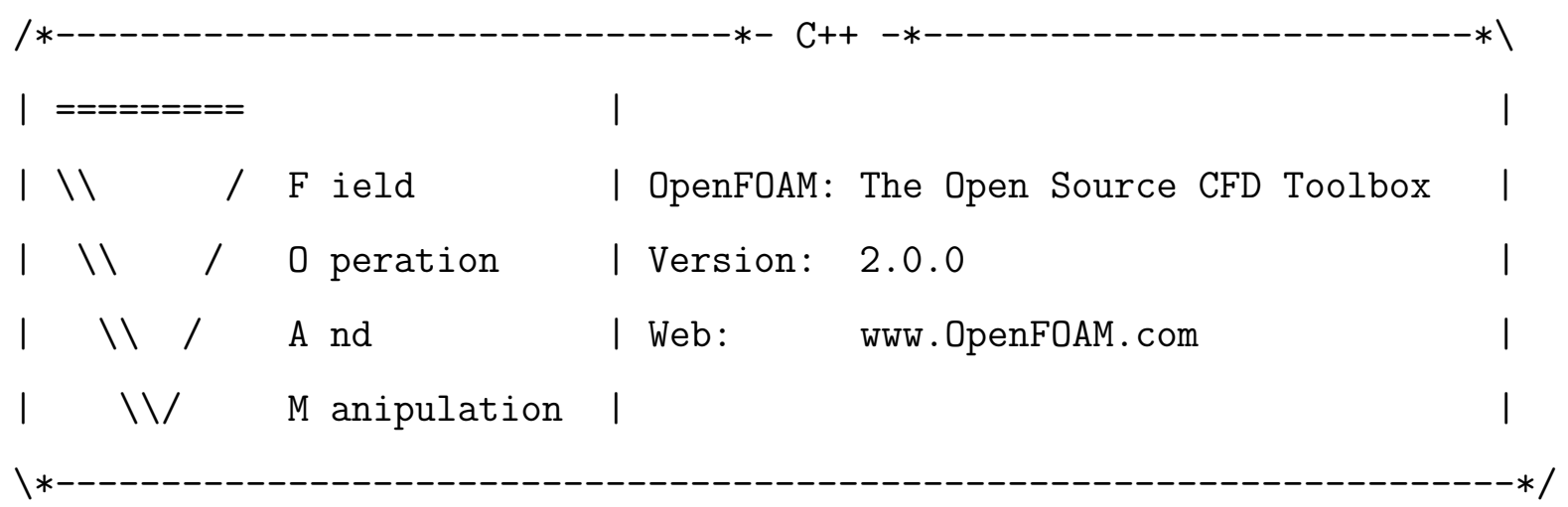

FoamFile

\{

version 2.0;

format ascii;

class polyBoundaryMesh;

location "constant/polyMesh";

object boundary;

\} 


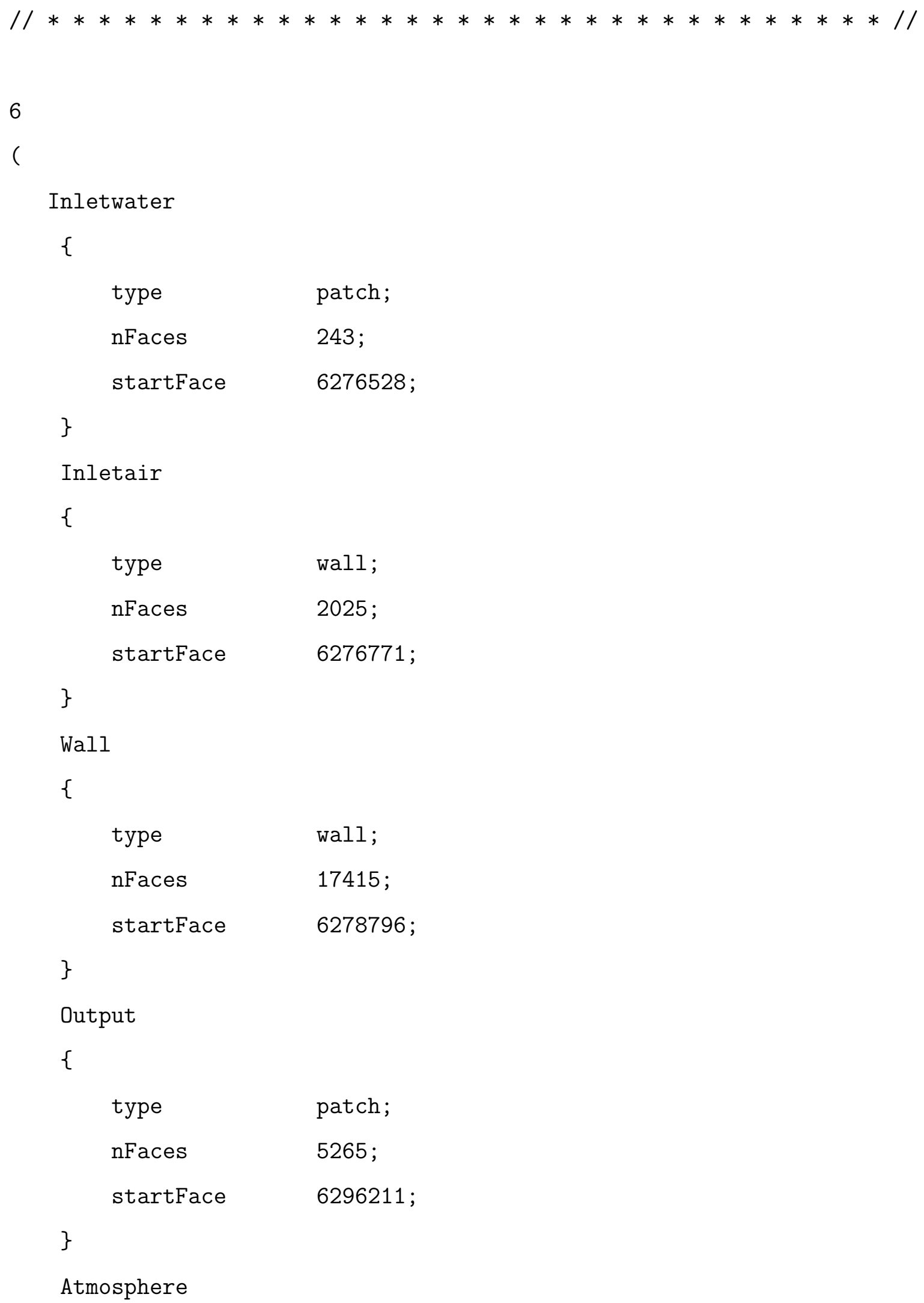




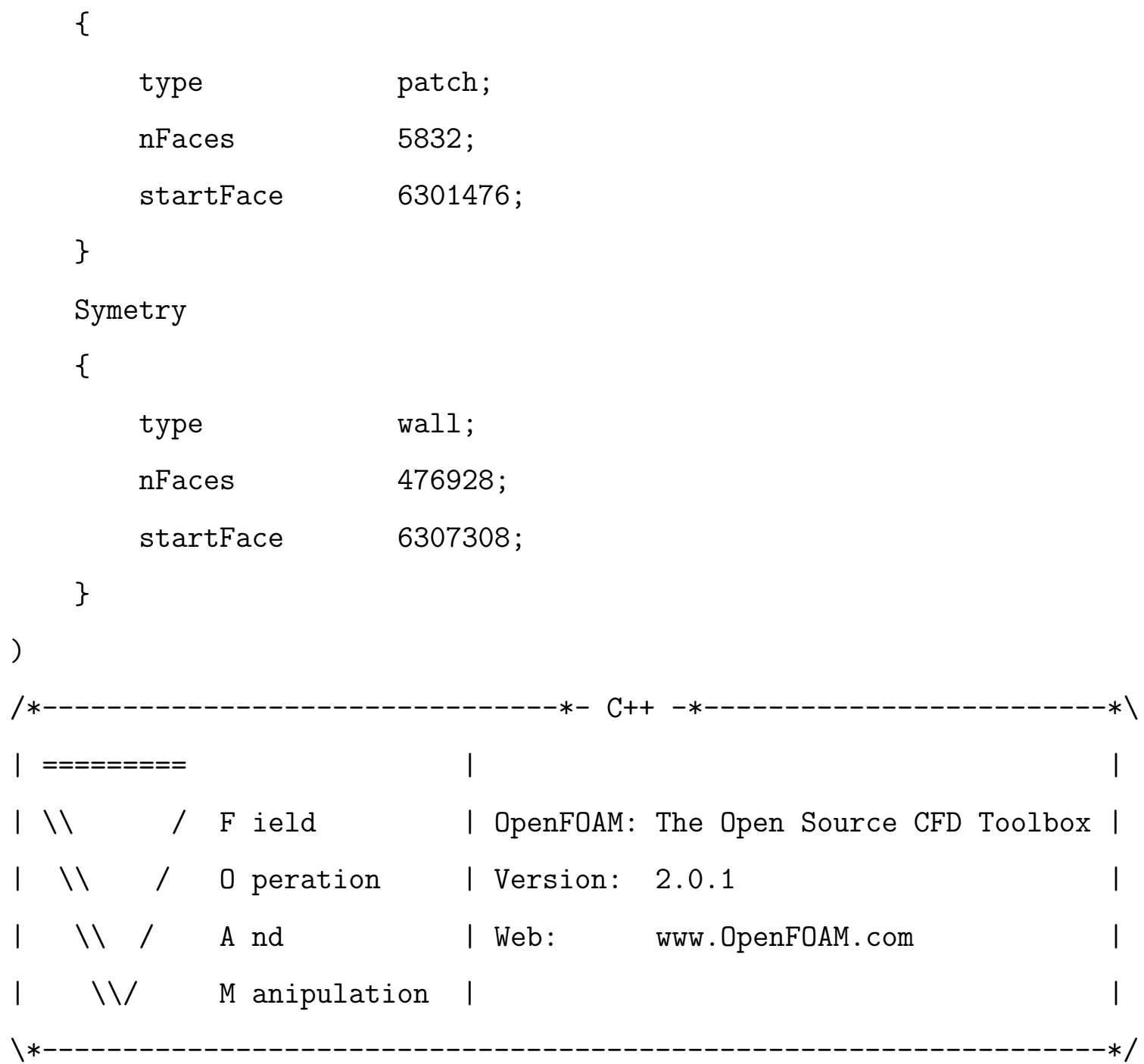

FoamFile

\{

version 2.0 ;

format ascii;

class dictionary;

location "system";

object decomposeParDict;

\}

$/ / * * * * * * * * * * * * * * * * * * * * * * * * * * * * * * * * / /$ numberOfSubdomains 22; 


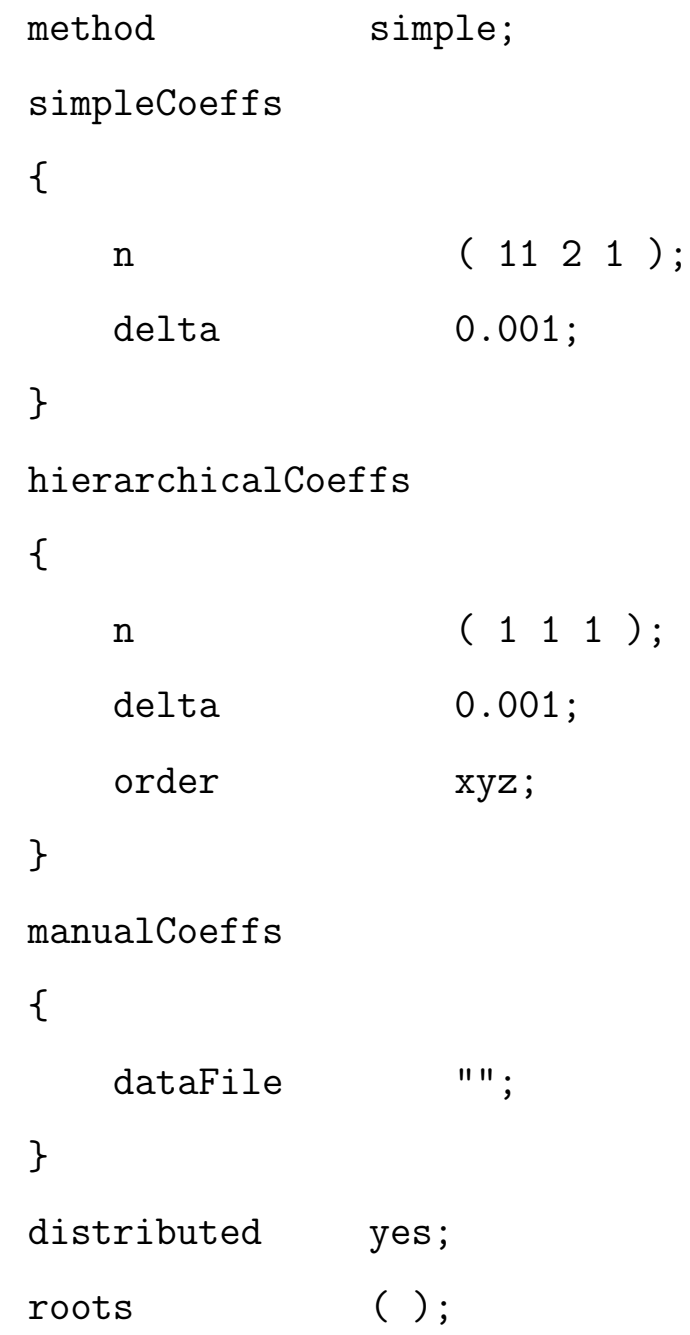

FoamFile

\{

$\begin{array}{ll}\text { version } & 2.0 ; \\ \text { format } & \text { ascii; }\end{array}$




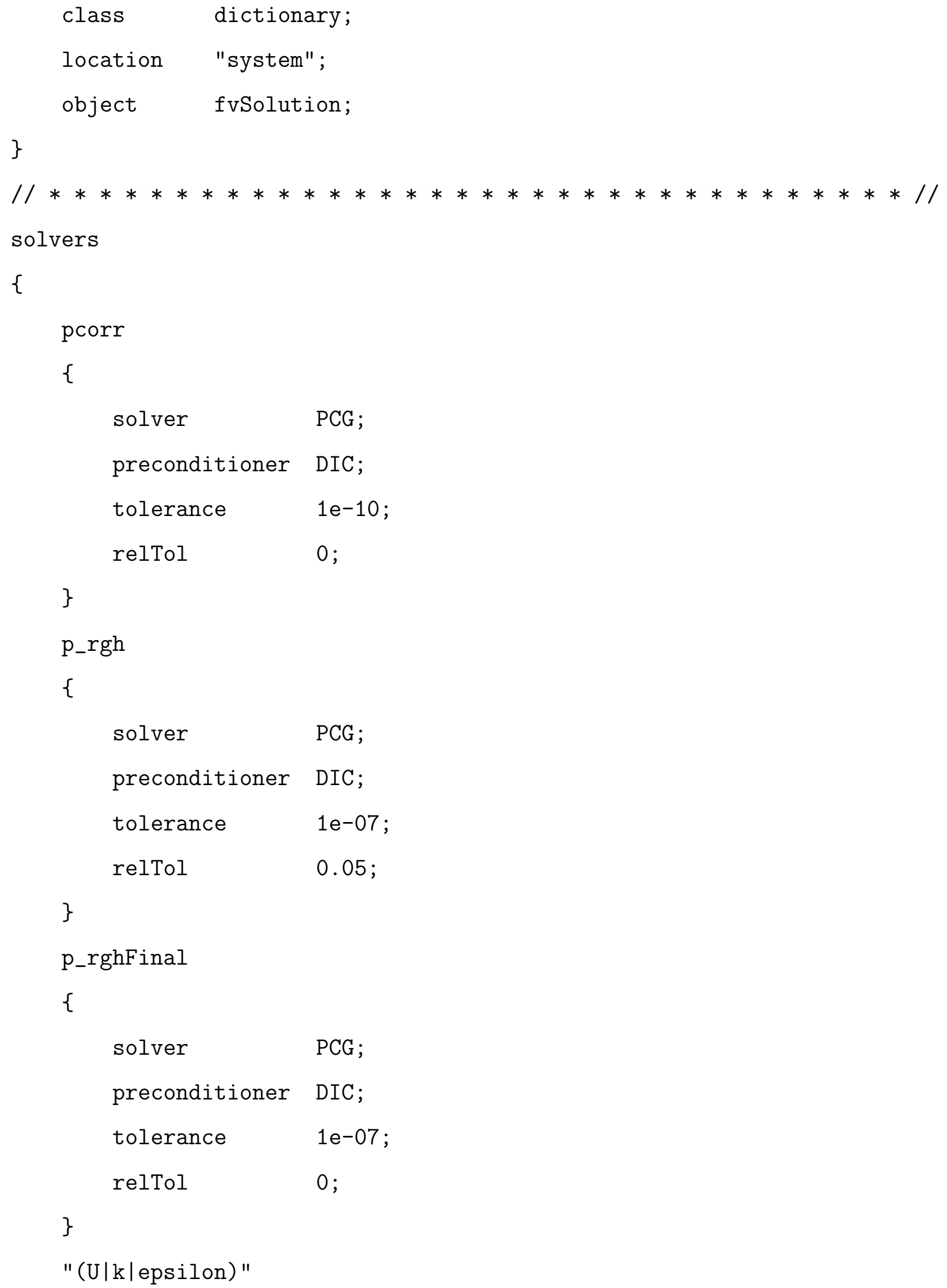




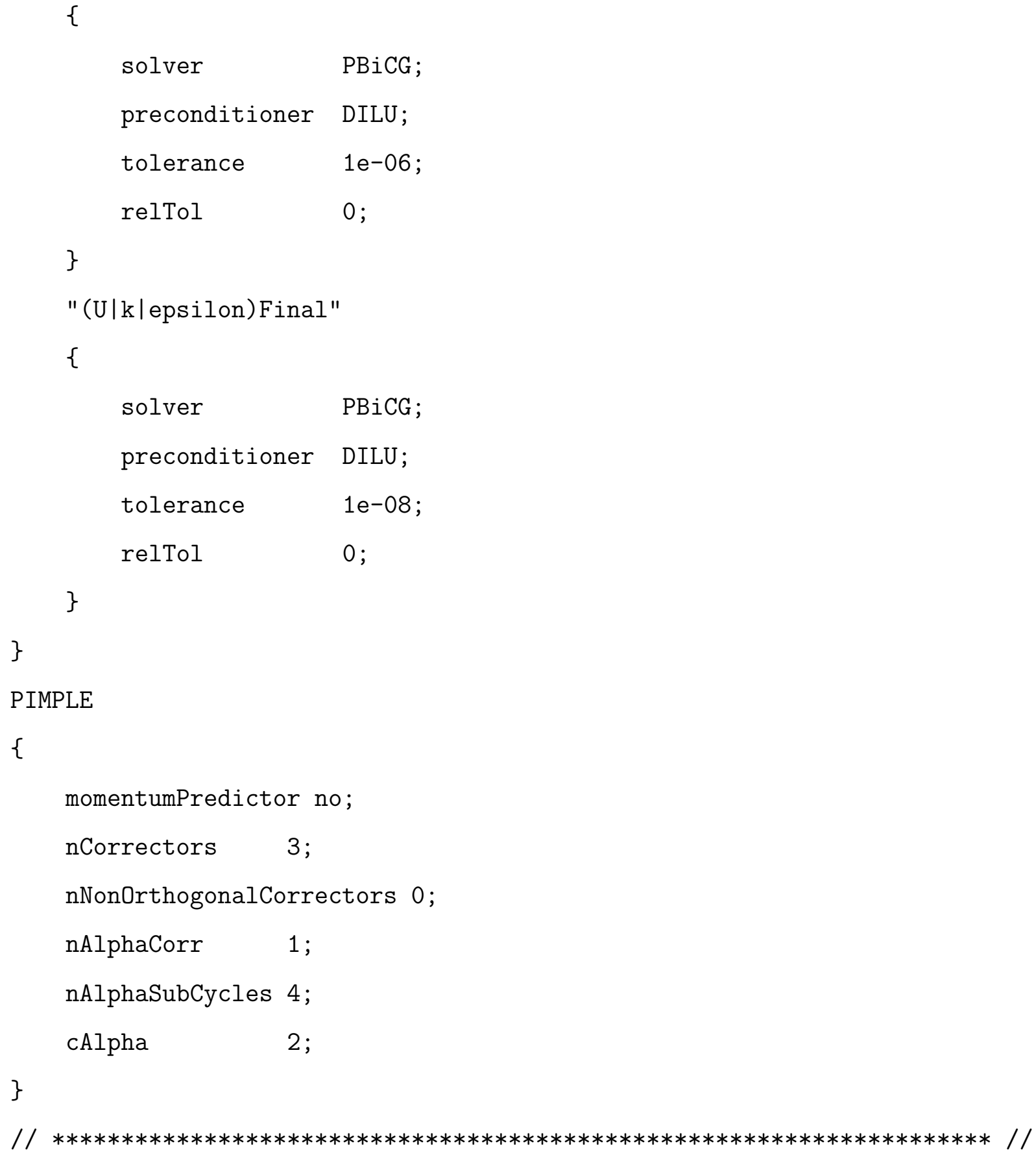

